\title{
Nitrate radicals and biogenic volatile organic compounds: oxidation, mechanisms, and organic aerosol
}

Nga Lee Ng1,2, Steven S. Brown ${ }^{3,4}$, Alexander T. Archibald ${ }^{5}$, Elliot Atlas ${ }^{6}$, Ronald C. Cohen ${ }^{7}$, John N. Crowley ${ }^{8}$, Douglas A. Day ${ }^{9,4}$, Neil M. Donahue ${ }^{10}$, Juliane L. Fry ${ }^{11}$, Hendrik Fuchs ${ }^{12}$, Robert J. Griffin ${ }^{13}$, Marcelo I. Guzman ${ }^{14}$, Hartmut Herrmann $^{15}$, Alma Hodzic ${ }^{16}$, Yoshiteru Iinuma ${ }^{15}$, José L. Jimenez ${ }^{9,4}$, Astrid Kiendler-Scharr ${ }^{12}$, Ben H. Lee ${ }^{17}$, Deborah J. Luecken ${ }^{18}$, Jingqiu Mao ${ }^{19,20, a}$, Robert McLaren ${ }^{21}$, Anke Mutzel ${ }^{15}$, Hans D. Osthoff ${ }^{22}$, Bin Ouyang ${ }^{23}$, Benedicte Picquet-Varrault ${ }^{24}$, Ulrich Platt ${ }^{25}$, Havala O. T. Pye ${ }^{18}$, Yinon Rudich ${ }^{26}$, Rebecca H. Schwantes ${ }^{27}$, Manabu Shiraiwa ${ }^{28}$, Jochen Stutz ${ }^{29}$, Joel A. Thornton ${ }^{17}$, Andreas Tilgner ${ }^{15}$, Brent J. Williams ${ }^{30}$, and Rahul A. Zaveri ${ }^{31}$

${ }^{1}$ School of Chemical and Biomolecular Engineering, Georgia Institute of Technology, Atlanta, GA, USA

${ }^{2}$ School of Earth and Atmospheric Sciences, Georgia Institute of Technology, Atlanta, GA, USA

${ }^{3}$ NOAA Earth System Research Laboratory, Chemical Sciences Division, Boulder, CO, USA

${ }^{4}$ Department of Chemistry and Biochemistry, University of Colorado, Boulder, CO, USA

${ }^{5}$ National Centre for Atmospheric Science, University of Cambridge, Cambridge, UK

${ }^{6}$ Department of Atmospheric Sciences, RSMAS, University of Miami, Miami, FL, USA

${ }^{7}$ Department of Chemistry, University of California at Berkeley, Berkeley, CA, USA

${ }^{8}$ Max-Planck-Institut für Chemie, Division of Atmospheric Chemistry, Mainz, Germany

${ }^{9}$ Cooperative Institute for Research in Environmental Sciences, University of Colorado, Boulder, CO, USA

${ }^{10}$ Center for Atmospheric Particle Studies, Carnegie Mellon University, Pittsburgh, PA, USA

${ }^{11}$ Department of Chemistry, Reed College, Portland, OR, USA

${ }^{12}$ Institut für Energie und Klimaforschung: Troposphäre (IEK-8), Forschungszentrum Jülich, Jülich, Germany

${ }^{13}$ Department of Civil and Environmental Engineering, Rice University, Houston, TX, USA

${ }^{14}$ Department of Chemistry, University of Kentucky, Lexington, KY, USA

${ }^{15}$ Atmospheric Chemistry Department, Leibniz Institute for Tropospheric Research, Leipzig, Germany

${ }^{16}$ Atmospheric Chemistry Observations and Modeling, National Center for Atmospheric Research, Boulder, CO, USA

${ }^{17}$ Department of Atmospheric Sciences, University of Washington, Seattle, WA, USA

${ }^{18}$ National Exposure Research Laboratory, US Environmental Protection Agency, Research Triangle Park, NC, USA

${ }^{19}$ Program in Atmospheric and Oceanic Sciences, Princeton University, Princeton, NJ, USA

${ }^{20}$ Geophysical Fluid Dynamics Laboratory/National Oceanic and Atmospheric Administration, Princeton, NJ, USA

${ }^{21}$ Centre for Atmospheric Chemistry, York University, Toronto, Ontario, Canada

${ }^{22}$ Department of Chemistry, University of Calgary, Calgary, Alberta, Canada

${ }^{23}$ Department of Chemistry, University of Cambridge, Cambridge, UK

${ }^{24}$ Laboratoire Interuniversitaire des Systemes Atmospheriques (LISA), CNRS, Universities of Paris-Est Créteil and ì Paris

Diderot, Institut Pierre Simon Laplace (IPSL), Créteil, France

${ }^{25}$ Institute of Environmental Physics, University of Heidelberg, Heidelberg, Germany

${ }^{26}$ Department of Earth and Planetary Sciences, Weizmann Institute, Rehovot, Israel

${ }^{27}$ Division of Geological and Planetary Sciences, California Institute of Technology, Pasadena, CA, USA

${ }^{28}$ Department of Chemistry, University of California Irvine, Irvine, CA, USA

${ }^{29}$ Department of Atmospheric and Oceanic Sciences, University of California, Los Angeles, CA, USA

${ }^{30}$ Department of Energy, Environmental and Chemical Engineering, Washington University in St. Louis, St. Louis, MO, USA

${ }^{31}$ Atmospheric Sciences and Global Change Division, Pacific Northwest National Laboratory, Richland, WA, USA

${ }^{a}$ now at: Geophysical Institute and Department of Chemistry and Biochemistry, University of Alaska Fairbanks,

Fairbanks, AK, USA 
Correspondence to: Nga Lee Ng (ng@chbe.gatech.edu) and Steven S. Brown (steven.s.brown@ noaa.gov)

Received: 12 August 2016 - Discussion started: 18 August 2016

Revised: 29 December 2016 - Accepted: 2 January 2017 - Published: 13 February 2017

\begin{abstract}
Oxidation of biogenic volatile organic compounds (BVOC) by the nitrate radical $\left(\mathrm{NO}_{3}\right)$ represents one of the important interactions between anthropogenic emissions related to combustion and natural emissions from the biosphere. This interaction has been recognized for more than 3 decades, during which time a large body of research has emerged from laboratory, field, and modeling studies. $\mathrm{NO}_{3}$ BVOC reactions influence air quality, climate and visibility through regional and global budgets for reactive nitrogen (particularly organic nitrates), ozone, and organic aerosol. Despite its long history of research and the significance of this topic in atmospheric chemistry, a number of important uncertainties remain. These include an incomplete understanding of the rates, mechanisms, and organic aerosol yields for $\mathrm{NO}_{3}$-BVOC reactions, lack of constraints on the role of heterogeneous oxidative processes associated with the $\mathrm{NO}_{3}$ radical, the difficulty of characterizing the spatial distributions of BVOC and $\mathrm{NO}_{3}$ within the poorly mixed nocturnal atmosphere, and the challenge of constructing appropriate boundary layer schemes and non-photochemical mechanisms for use in state-of-the-art chemical transport and chemistry-climate models.

This review is the result of a workshop of the same title held at the Georgia Institute of Technology in June 2015. The first half of the review summarizes the current literature on $\mathrm{NO}_{3}$-BVOC chemistry, with a particular focus on recent advances in instrumentation and models, and in organic nitrate and secondary organic aerosol (SOA) formation chemistry. Building on this current understanding, the second half of the review outlines impacts of $\mathrm{NO}_{3}$-BVOC chemistry on air quality and climate, and suggests critical research needs to better constrain this interaction to improve the predictive capabilities of atmospheric models.
\end{abstract}

\section{Introduction}

The emission of hydrocarbons from the terrestrial biosphere represents a large natural input of chemically reactive compounds to Earth's atmosphere (Guenther et al., 1995; Goldstein and Galbally, 2007). Understanding the atmospheric degradation of these species is a critical area of current research that influences models of oxidants and aerosols on regional and global scales. Nitrogen oxides $\left(\mathrm{NO}_{x}=\mathrm{NO}+\mathrm{NO}_{2}\right)$ arising from combustion and microbial action on fertilizer are one of the major anthropogenic inputs that perturb the chemistry of the atmosphere (Crutzen, 1973). Nitrogen oxides have long been understood to in- fluence oxidation cycles of biogenic volatile organic compounds (BVOC), especially through photochemical reactions of organic and hydroperoxy radical intermediates $\left(\mathrm{RO}_{2}\right.$ and $\mathrm{HO}_{2}$ ) with nitric oxide (NO) (Chameides, 1978).

The nitrate radical $\left(\mathrm{NO}_{3}\right)$ arises from the oxidation of nitrogen dioxide $\left(\mathrm{NO}_{2}\right)$ by ozone $\left(\mathrm{O}_{3}\right)$ and occurs principally in the nighttime atmosphere due to its rapid photolysis in sunlight and its reaction with NO (Wayne et al., 1991; Brown and Stutz, 2012). The nitrate radical is a strong oxidant, reacting with a wide variety of volatile organic compounds, including alkenes, aromatics, and oxygenates as well as with reduced sulfur compounds. Reactions of $\mathrm{NO}_{3}$ are particularly rapid with unsaturated compounds (alkenes) (Atkinson and Arey, 2003). BVOC such as isoprene, monoterpenes, and sesquiterpenes typically have one or more unsaturated functionalities such that they are particularly susceptible to oxidation by $\mathrm{O}_{3}$ and $\mathrm{NO}_{3}$.

The potential for $\mathrm{NO}_{3}$ to serve as a large sink for BVOC was recognized more than 3 decades ago (Winer et al., 1984). Field studies since that time have shown that in any environment with moderate to large BVOC concentrations, a majority of the $\mathrm{NO}_{3}$ radical oxidative reactions are with BVOC rather than VOC of anthropogenic origin (Brown and Stutz, 2012). This interaction gives rise to a mechanism that couples anthropogenic $\mathrm{NO}_{x}$ emissions with natural BVOC emissions (Fry et al., 2009; Xu et al., 2015a). Although it is one of several such anthropogenic-biogenic interactions (Hoyle et al., 2011), reactions of $\mathrm{NO}_{3}$ with $\mathrm{BVOC}$ are an area of intense current interest and one whose study has proven challenging. These challenges arise from the more limited current database of laboratory data for $\mathrm{NO}_{3}$ oxidation reactions relative to those of other common atmospheric oxidants such as hydroxyl radical $(\mathrm{OH})$ and $\mathrm{O}_{3}$. The mixing state of the nighttime atmosphere and the limitations it imposes for characterization of nocturnal oxidation chemistry during field measurements and within atmospheric models present a second challenge to this field of research. Figure 1 illustrates these features of nighttime $\mathrm{NO}_{3}$-BVOC chemistry.

Reactions of $\mathrm{NO}_{3}$ with $\mathrm{BVOC}$ have received increased attention in the recent literature as a potential source of secondary organic aerosol (SOA) (Pye et al., 2010; Fry et al., 2014; Boyd et al., 2015). This SOA source is intriguing for several reasons. First, although organics are now understood to comprise a large fraction of total aerosol mass, and although much of these organics are secondary, sources of SOA remain difficult to characterize, in part due to a large number of emission sources and potential chemical mechanisms (Zhang et al., 2007; Hallquist et al., 2009; Jimenez et 


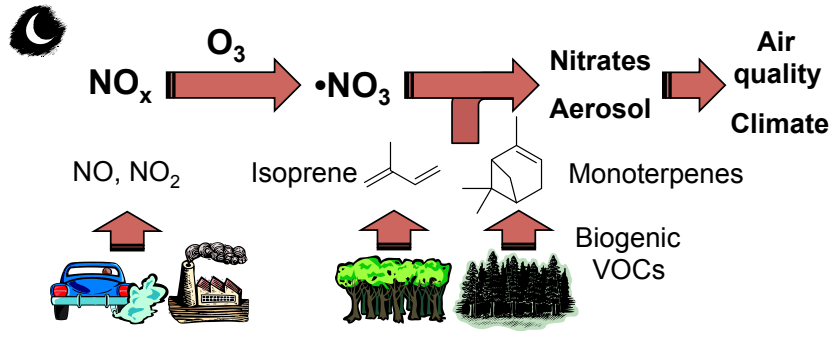

Figure 1. Schematic of nighttime $\mathrm{NO}_{3}-\mathrm{BVOC}$ chemistry.

al., 2009; Ng et al., 2010). Analysis of aerosol organic carbon shows that a large fraction is modern, arising either from biogenic hydrocarbon emissions or biomass burning sources (e.g., Schichtel et al., 2008; Hodzic et al., 2010). Conversely, field data in regionally polluted areas indicate strong correlations between tracers of anthropogenic emissions and SOA, which suggests that anthropogenic influences can lead to production of SOA from modern (i.e., non-fossil) carbon (e.g., Weber et al., 2007). Model studies confirm that global observations are best simulated with a biogenic carbon source in the presence of anthropogenic pollutants (Spracklen et al., 2011). Reactions of $\mathrm{NO}_{3}$ with $\mathrm{BVOC}$ are one such mechanism that may lead to anthropogenically influenced biogenic SOA (Hoyle et al., 2007), and it is important to quantify the extent to which such reactions can explain sources of SOA.

Second, some laboratory and chamber studies suggest that SOA yields from $\mathrm{NO}_{3}$ oxidation of common BVOC, such as isoprene and selected monoterpenes, are greater than that for $\mathrm{OH}$ or $\mathrm{O}_{3}$ oxidation (Hallquist et al., 1997b; Griffin et al., 1999; Spittler et al., 2006; Ng et al., 2008; Fry et al., 2009, 2011, 2014;; Rollins et al., 2009; Boyd et al., 2015). However, among the monoterpenes, the SOA yields may be much more variable for $\mathrm{NO}_{3}$ oxidation than for other oxidants, with anomalously low SOA yields in some cases and high SOA yields in others (Draper et al., 2015; Nah et al., 2016b).

Third, not only is $\mathrm{NO}_{3}$-BVOC chemistry a potentially efficient SOA formation mechanism, it is also a major pathway for the production of organic nitrates (von Kuhlmann et al., 2004; Horowitz et al., 2007), a large component of oxidized reactive nitrogen that may serve as either a $\mathrm{NO}_{x}$ reservoir or $\mathrm{NO}_{x}$ sink. Results from recent field measurements have shown that organic nitrates are important components of ambient OA (Day et al., 2010; Rollins et al., 2012; Fry et al., 2013; Ayres et al., 2015; Xu et al., 2015a, b; Kiendler-Scharr et al., 2016; Lee et al., 2016). Furthermore, within the last several years, the capability to measure both total and speciated gas-phase and particle-phase organic nitrates has been demonstrated (Fry et al., 2009, 2013, 2014; Rollins et al., 2010, 2013; Lee et al., 2016; Nah et al., 2016b). The lifetimes of organic nitrates derived from $\mathrm{BVOC}-\mathrm{NO}_{3}$ reaction with respect to hydrolysis, photooxidation, and deposition play an important role in the $\mathrm{NO}_{x}$ budget and formation of $\mathrm{O}_{3}$ and SOA. These processes appear to depend strongly on the parent VOC and oxidation conditions and must be better constrained for understanding organic nitrate lifetimes in the atmosphere (Darer et al., 2011; Hu et al., 2011; Liu et al., 2012b; Boyd et al., 2015; Pye et al., 2015; Rindelaub et al., 2015; Lee et al., 2016; Nah et al., 2016b).

Fourth, incorporation of SOA yields for $\mathrm{NO}_{3}$-BVOC reactions into regional and global models indicates that these reactions could be a significant, or in some regions even dominant, SOA contributor (Hoyle et al., 2007; Pye et al., 2010, 2015; Chung et al., 2012; Fry and Sackinger, 2012; KiendlerScharr et al., 2016). Model predictions of organic aerosol formation from $\mathrm{NO}_{3}$-BVOC until recently have been difficult to verify directly from field measurements. Recent progress in laboratory and field studies have provided some of the first opportunities to develop coupled gas and particle systems to describe mechanistically and predict SOA and organic nitrate formation from $\mathrm{NO}_{3}$-BVOC reactions (Pye et al., 2015).

Finally, analyses from several recent field studies examining diurnal variation in the organic and/or nitrate content of aerosols conclude that nighttime BVOC oxidation through $\mathrm{NO}_{3}$ radicals constitutes a large organic aerosol source (Rollins et al., 2012; Fry et al., 2013; Xu et al., 2015a, b; Kiendler-Scharr et al., 2016). Although such analyses may correct their estimates of aerosol production for the variation in boundary layer depth, field measurements at surface level are necessarily limited in their ability to accurately assess the atmospheric chemistry in the overlying residual layer or even the gradients that may exist within the relatively shallow nocturnal boundary layer (Stutz et al., 2004; Brown et al., 2007b). Thus, although there is apparent consistency between recent results from both modeling and field studies, the vertically stratified structure of the nighttime atmosphere makes such comparisons difficult to evaluate critically. There is a limited database of nighttime aircraft measurements that has probed this vertical structure with sufficient chemical detail to assess $\mathrm{NO}_{3}$-BVOC reactions (Brown et al., 2007a; Brown et al., 2009), and some of these data show evidence for an OA source related to this chemistry, especially at low altitude (Brown et al., 2013). A larger database of aircraft and/or vertically resolved measurements is required, however, for comprehensive comparisons to model predictions.

The purpose of this article is to review the current literature on the chemistry of $\mathrm{NO}_{3}$ and BVOC to critically assess the current state of the science. The review focuses on BVOC emitted from terrestrial vegetation. The importance of $\mathrm{NO}_{3}$ reactions with reduced sulfur compounds, such as dimethyl sulfide in marine ecosystems, is well known (Platt et al., 1990; Yvon et al., 1996; Allan et al., 1999, 2000; Vrekoussis et al., 2004; Stark et al., 2007; Osthoff et al., 2009) but is outside of the scope of this review. Key uncertainties include chemical mechanisms, yields of major reaction products such as SOA and organic nitrogen, the potential for $\mathrm{NO}_{3}$ and $\mathrm{BVOC}$ to interact in the ambient atmosphere, and the implications of that interaction for current understanding of air quality and climate. The review stems from an In- 
ternational Global Atmospheric Chemistry (IGAC) and US National Science Foundation (NSF) sponsored workshop of the same name held in June 2015 at the Georgia Institute of Technology (Atlanta, GA, USA). Following this introduction, Sect. 2 of this article reviews the current literature in several areas relevant to the understanding of $\mathrm{NO}_{3}$-BVOC atmospheric chemistry. Section 3 outlines perspectives on the implications of this chemistry for understanding climate and air quality, its response to current emission trends, and its relevance to implementation of control strategies. Finally, the review concludes with an assessment of the impacts of $\mathrm{NO}_{3}$ $\mathrm{BVOC}$ reactions on air quality, visibility, and climate.

\section{Review of current literature}

This section contains a literature review of the current state of knowledge of $\mathrm{NO}_{3}$-BVOC chemistry with respect to (1) reaction rate constants and mechanisms from laboratory and chamber studies; (2) secondary organic aerosol yields, speciation, and particle-phase chemistry; (3) heterogeneous reactions of $\mathrm{NO}_{3}$ and their implications for $\mathrm{NO}_{3}-\mathrm{BVOC}$ chemistry; (4) instrumental methods for analysis of reactive nitrogen compounds, including $\mathrm{NO}_{3}$, organic nitrates, and nitrogen-containing particulate matter; (5) field observations relevant to the understanding of $\mathrm{NO}_{3}$ and BVOC chemistry; and (6) models of $\mathrm{NO}_{3}$-BVOC chemistry.

\section{1 $\mathrm{NO}_{3}-\mathrm{BVOC}$ reaction rates and chemical mechanisms}

\subsubsection{Reaction rates}

Among the numerous BVOC emitted into the troposphere, kinetic data for $\mathrm{NO}_{3}$ oxidation have been provided for more than 40 compounds. The most emitted/important BVOC have been subject to several kinetic studies, using both absolute and relative methods, which are evaluated to determine rate constants by IUPAC (Table 1 ). This is the case for isoprene, $\alpha$-pinene, $\beta$-pinene, and 2-methyl-3-buten-2ol (MBO). However, for isoprene, $\beta$-pinene, and MBO, rate constants obtained by different studies range over a factor of 2. For some other terpenes, only few kinetic studies have been carried out, with at least one absolute rate determination. This is the case for sabinene, 2-carene, camphene, d-limonene, $\alpha$-phellandrene, myrcene, $\gamma$-terpinene, and terpinolene. For these compounds, experimental data agree within 30-40\%, except $\alpha$-phellandrene and terpinolene for which discrepancies are larger. For other BVOC, including other terpenes, sesquiterpenes, and oxygenated species, rate constants are mostly based on a single determination and highly uncertain. For these compounds, further rate constant determinations and end-product measurements are essential to better evaluate the role of $\mathrm{NO}_{3}$ in their degradation. The ability to predict the $\mathrm{NO}_{3}$-BVOC rate constants using structure-activity relationships (SARs) has been improved.
A recent study (Kerdouci et al., 2010; Kerdouci, 2014) presented a new SAR parameterization based on $180 \mathrm{NO}_{3}$-VOC reactions. The method is capable of predicting $90 \%$ of the rate constants within a factor of 2 .

\subsubsection{Mechanisms}

In general, $\mathrm{NO}_{3}$ reacts with unsaturated $\mathrm{VOC}$ by addition to a double bond (Wayne et al., 1991), though hydrogen abstraction may occur, most favorably for aldehydic species (Zhang and Morris, 2015). The location and likelihood of the $\mathrm{NO}_{3}$ addition to a double bond depends on the substitution on each end of the double bond, with the favored $\mathrm{NO}_{3}$ addition position being the one resulting in the most substituted carbon radical. In both cases, molecular oxygen adds to the resulting radical to form a peroxy radical $\left(\mathrm{RO}_{2}\right)$. For example, the major $\mathrm{RO}_{2}$ isomers produced from isoprene and $\beta$-pinene oxidation via $\mathrm{NO}_{3}$ are shown in Fig. 2. The $\mathrm{RO}_{2}$ distribution for isoprene oxidation by $\mathrm{OH}$ has been shown to be dependent on the $\mathrm{RO}_{2}$ lifetime (Peeters et al., 2009, 2014), but no similar theoretical studies have been conducted on the $\mathrm{NO}_{3}$ system. Schwantes et al. (2015) determined the $\mathrm{RO}_{2}$ isomer distribution at an $\mathrm{RO}_{2}$ lifetime of $\sim 30 \mathrm{~s}$ for isoprene oxidation via $\mathrm{NO}_{3}$. More theoretical and experimental studies are needed to understand the influence of $\mathrm{RO}_{2}$ lifetime, which is long at night $(\sim 50-200 \mathrm{~s}$ for isoprene; Schwantes et al., 2015), on the $\mathrm{RO}_{2}$ isomer distribution, as this distribution influences the formation of all subsequent products (Fig. 2).

The fate of $\mathrm{RO}_{2}$ determines the subsequent chemistry. During the nighttime in the ambient atmosphere, $\mathrm{RO}_{2}$ will isomerize or react with another $\mathrm{RO}_{2}, \mathrm{NO}_{3}$, or $\mathrm{HO}_{2}$. In order to monitor $\mathrm{RO}_{2}$ isomerization reaction products, $\mathrm{RO}_{2}$ lifetimes must be long in laboratory studies similar to the ambient atmosphere (e.g., Peeters et al., 2009; Crounse et al., 2011). The $\mathrm{NO}_{3}$ plus BVOC $\left(\mathrm{NO}_{3}+\mathrm{BVOC}\right)$ reaction can be a source of nighttime $\mathrm{HO}_{2}$ and $\mathrm{OH}$ radicals (Platt et al., 1990). Reaction with NO is a minor peroxy radical fate at night (Pye et al., 2015; Xiong et al., 2015). Few laboratory studies have contrasted the fates of $\mathrm{RO}_{2}$ and their impacts on gas-phase oxidation and aerosol formation ( $\mathrm{Ng}$ et al., 2008; Boyd et al., 2015; Schwantes et al., 2015). Boyd et al. (2015) examined how $\mathrm{RO}_{2}$ fate influences SOA formation and yields, and studied the competition between the $\mathrm{RO}_{2}$ $\mathrm{NO}_{3}$ and $\mathrm{RO}_{2}-\mathrm{HO}_{2}$ channels for $\beta$-pinene. Boyd et al. (2015) determined that the SOA yields for both channels are comparable, indicating that the volatility distribution of products may not be very different for the different $\mathrm{RO}_{2}$ fates. In contrast, the results from $\mathrm{NO}_{3}$ oxidation of smaller BVOC, such as isoprene, show large differences in SOA yields depending on the $\mathrm{RO}_{2}$ fate (Ng et al., 2008), with larger SOA yields for second-generation $\mathrm{NO}_{3}$ oxidation (Rollins et al., 2009).

The well-established gas-phase first-generation products from the major $\beta$ - and $\delta-\mathrm{RO}_{2}$ isomers formed from isoprene oxidation are shown in Fig. 2 (adapted from Schwantes et al., 2015). Some of the products are common between all 
Table 1. Reaction rate constants of $\mathrm{NO}_{3}+\mathrm{BVOC}$.

\begin{tabular}{|c|c|c|c|}
\hline Compound & $k\left(\mathrm{NO}_{3}+\mathrm{BVOC}\right)\left(\mathrm{cm}^{3} \text { molecule }{ }^{-1} \mathrm{~s}^{-1}\right)^{\mathrm{a}}$ & $\begin{array}{l}\text { Temperature } \\
\text { (K) }\end{array}$ & Technique/reference \\
\hline Isoprene & $\begin{array}{c}(5.94 \pm 0.16) \times 10^{-13} \\
(1.30 \pm 0.14) \times 10^{-12} \\
(3.03 \pm 0.45) \times 10^{-12} \exp [-(450 \pm 70) / \mathrm{T}] \\
(6.52 \pm 0.78) \times 10^{-13} \\
(1.21 \pm 0.20) \times 10^{-12} \\
(7.30 \pm 0.44) \times 10^{-13} \\
(8.26 \pm 0.60) \times 10^{-13} \\
(1.07 \pm 0.20) \times 10^{-12} \\
(6.86 \pm 0.55) \times 10^{-13} \\
(7.3 \pm 0.2) \times 10^{-13} \\
(6.24 \pm 0.11) \times 10^{-13} \\
\mathbf{6 . 5} \times \mathbf{1 0}^{-13}(\Delta \log \boldsymbol{k}: \pm \mathbf{0 . 1 5})\end{array}$ & $\begin{array}{c}295 \\
298 \\
251-281 \\
297 \\
298 \\
298 \\
298 \\
295 \\
298 \\
298 \\
295 \\
\mathbf{2 9 8} \\
\end{array}$ & $\begin{array}{c}\text { RR/(Atkinson et al., 1984) } \\
\text { DF-MS/(Benter and Schindler, 1988) } \\
\text { F-LIF/(Dlugokencky and Howard, 1989) } \\
\text { F-LIF/(Dlugokencky and Howard, 1989) } \\
\text { RR/(Barnes et al., 1990) } \\
\text { DF-MS/(Wille et al., 1991) } \\
\text { DF-MS/(Wille et al., 1991) } \\
\text { PR-A/(Ellermann et al., 1992) } \\
\text { RR/(Berndt and Boge, 1997b) } \\
\text { F-CIMS/(Suh et al., 2001) } \\
\text { RR/(Zhao et al., 2011b) } \\
\text { IUPAC }\end{array}$ \\
\hline pinene & $\begin{array}{c}(5.82 \pm 0.16) \times 10^{-12} \\
(1.19 \pm 0.31) \times 10^{-12} \exp [(490 \pm 70) / \mathrm{T}] \\
(6.18 \pm 0.94) \times 10^{-12} \\
(6.56 \pm 0.94) \times 10^{-12} \\
(3.5 \pm 1.4) \times 10^{-13} \exp [(841 \pm 144) / \mathrm{T}] \\
(5.9 \pm 0.8) \times 10^{-12} \\
(5.82 \pm 0.56) \times 10^{-12} \\
(4.88 \pm 0.46) \times 10^{-12} \\
\mathbf{6 . 2 \times 1 0 ^ { - 1 2 }}(\Delta \log k: \pm \mathbf{0 . 1})\end{array}$ & $\begin{array}{c}295 \\
261-383 \\
298 \\
298 \\
298-423 \\
298 \\
298 \\
298 \\
298\end{array}$ & $\begin{array}{c}\text { RR/(Atkinson et al., 1984) } \\
\text { F-LIF/(Dlugokencky and Howard, 1989) } \\
\text { F-LIF/(Dlugokencky and Howard, 1989) } \\
\text { RR/(Barnes et al., 1990) } \\
\text { DF-LIF/(Martinez et al., 1998) } \\
\text { DF-LIF/(Martinez et al., 1998) } \\
\text { RR/(Kind et al., 1998) } \\
\text { RR/(Stewart et al., 2013) } \\
\text { IUPAC }\end{array}$ \\
\hline & $\begin{array}{c}(2.36 \pm 0.10) \times 10^{-12} \\
(2.38 \pm 0.05) \times 10^{-12} \\
(1.1 \pm 0.4) \times 10^{-12} \\
(2.81 \pm 0.47) \times 10^{-12} \\
(1.6 \pm 1.5) \times 10^{-10} \exp [(-1248 \pm 36) / \mathrm{T}] \\
(2.1 \pm 0.4) \times 10^{-12} \\
(2.81 \pm 0.56) \times 10^{-12} \\
\mathbf{2 . 5} \times \mathbf{1 0}^{-12}(\Delta \log k: \pm \mathbf{0 . 1 2})\end{array}$ & $\begin{array}{c}295 \\
296 \\
298 \\
298 \\
298-293 \\
298 \\
298 \\
\mathbf{2 9 8} \\
\end{array}$ & $\begin{array}{c}\text { RR/(Atkinson et al., 1984) } \\
\text { RR/(Atkinson et al., 1988) } \\
\text { RR/(Kotzias et al., 1989) } \\
\text { RR/(Barnes et al., 1990) } \\
\text { DF-LIF/(Martinez et al., 1998) } \\
\text { DF-LIF/(Martinez et al., 1998) } \\
\text { RR/(Kind et al., 1998) } \\
\text { IUPAC } \\
\end{array}$ \\
\hline $\mathrm{Sa}$ & $\begin{array}{c}(1.01 \pm 0.03) \times 10^{-11} \\
(1.07 \pm 0.16) \times 10^{-11} \\
(2.3 \pm 1.3) \times 10^{-10} \exp [(-940 \pm 200) / \mathrm{T}] \\
\mathbf{1 . 0 \times 1 0 ^ { - 1 1 }}(\Delta \log \boldsymbol{k}: \pm \mathbf{0 . 1 5})\end{array}$ & $\begin{array}{c}296 \\
298 \\
298-393 \\
\mathbf{2 9 8}\end{array}$ & $\begin{array}{c}\text { RR/(Atkinson et al., 1990) } \\
\text { DF-LIF/(Martínez et al., 1999) } \\
\text { DF-LIF/(Martínez et al., 1999) } \\
\text { IUPAC }\end{array}$ \\
\hline Camphene & $\begin{array}{c}(6.54 \pm 0.16) \times 10^{-13} \\
(3.1 \pm 0.5) \times 10^{-12} \exp [(-481 \pm 55) / \mathrm{T}] \\
(6.2 \pm 2.1) \times 10^{-13}\end{array}$ & $\begin{array}{c}296 \\
298-433 \\
298\end{array}$ & $\begin{array}{l}\text { RR/(Atkinson et al., 1990) } \\
\text { DF-LIF/(Martinez et al., 1998) } \\
\text { DF-LIF/(Martinez et al., 1998) }\end{array}$ \\
\hline
\end{tabular}

the pathways, such as methyl vinyl ketone for the dominant $\beta-\mathrm{RO}_{2}$ isomer. However, some products are unique to only one channel (e.g., hydroxy nitrates form from $\mathrm{RO}_{2}-\mathrm{RO}_{2}$ reactions and nitrooxy hydroperoxides form from $\mathrm{RO}_{2}-\mathrm{HO}_{2}$ reactions). In this case, the overall nitrate yield and the specific nitrates formed from isoprene depend on the initial $\mathrm{RO}_{2}$ isomer distribution and the fate of the $\mathrm{RO}_{2}$. Furthermore, the distribution of gas-phase products will then influence the formation of SOA. For isoprene, the SOA yields from $\mathrm{RO}_{2}-\mathrm{RO}_{2}$ reactions are $\sim 2$ times greater than the yield from $\mathrm{RO}_{2}$ $\mathrm{NO}_{3}$ reactions ( $\mathrm{Ng}$ et al., 2008). The less well-established first-generation products from $\beta$-pinene oxidation are also shown in Fig. 2 (adapted from Boyd et al., 2015). There are still lingering uncertainties (shown in red) in the firstgeneration products formed from $\beta$-pinene oxidation. The product yields from the $\mathrm{RO}_{2}+\mathrm{HO}_{2}$ channel are not well constrained, largely due to the unavailability of authentic stan- dards. In Fig. 2, a carbonyl product is assumed to form directly from the $\mathrm{RO}_{2}+\mathrm{HO}_{2}$ reaction instead of proceeding through an alkoxy intermediate consistent with theoretical calculations from different compounds (Hou et al., 2005a, b; Praske et al., 2015). This is also uncertain, as few theoretical studies have been conducted on large molecules like $\beta$ pinene. The identification of the carbonyl compound(s) produced from $\mathrm{RO}_{2}$ reaction with $\mathrm{NO}_{3}, \mathrm{RO}_{2}$, or $\mathrm{HO}_{2}$ is unknown. Hallquist et al. (1999) detected a low molar yield (0-2\%; Table 2 ) of nopinone from $\beta$-pinene $\mathrm{NO}_{3}$ oxidation. Further laboratory studies identifying other carbonyl products are recommended.

Given the limited number of studies that have considered the fate of the peroxy radical, generalizations cannot yet be made for all VOC. Indeed, more studies are needed to determine systematically how gas-phase products and SOA yields are influenced by reactions of $\mathrm{RO}_{2}$. More specifically, for 
Table 1. Continued.

\begin{tabular}{c|c|c|c|}
$(1.87 \pm 0.11) \times 10^{-11}$ & 295 & RR/(Corchnoy and Atkinson, 1990) \\
& $(2.16 \pm 0.36) \times 10^{-11}$ & 295 & RR/(Corchnoy and Atkinson, 1990) \\
DF-LIF/(Martinez et al., 1999) \\
DF-LIF/(Martínez et al., 1999) \\
IUPAC
\end{tabular}

all chamber experiments, constraining the fate and lifetime of $\mathrm{RO}_{2}$ is required to attribute product and SOA yields to a specific pathway. As shown in Table 2 in Sect. 2.2, the nitrate yields and $\mathrm{SOA}$ yields for $\mathrm{NO}_{3}$-induced degradation of many VOC vary significantly between different studies. This is likely, in part, a result of each experiment having a different distribution of $\mathrm{RO}_{2}$ fates, but may also arise from vapor wall losses.

In general, there are very few mechanistic studies for $\mathrm{NO}_{3}$ relative to other oxidants. Furthermore, the elucidation of mechanisms is limited by the fact that most studies provide overall yields of organic nitrates (without individual identification of the species) and/or identification (without quantification) due to the lack of standards.

\subsection{Organic aerosol yields, speciation, and particle-phase chemistry}

Several papers have reported chamber studies to measure the organic aerosol yield and/or gaseous and aerosol-phase oxidation product distribution from $\mathrm{NO}_{3}$-BVOC reactions. These are summarized in Table 2. In general, these experimental results show that monoterpenes are efficient sources of SOA, with reported yields variable but consistently above $20 \%$, with the notable exception of $\alpha$-pinene (yields 0 $15 \%)$. This anomalous monoterpene also has a much larger product yield of carbonyls instead of organic nitrates compared to the others. This difference among monoterpenes was investigated in the context of the competition between $\mathrm{O}_{3}$ and $\mathrm{NO}_{3}$ oxidation (Draper et al., 2015), in which shifting from $\mathrm{O}_{3}$-dominated to $\mathrm{NO}_{3}$-dominated oxidation was observed to suppress SOA formation from $\alpha$-pinene, but not from $\beta$-pinene, $\Delta$-carene, or limonene. The smaller isoprene has substantially lower SOA yields (2-24\%), and the only sesquiterpene studied, $\beta$-caryophyllene, has a much larger yield $(86-150 \%)$ than the monoterpenes.

In general, these chamber experiments are conducted under conditions that focus on first-generation oxidation only, but further oxidation can continue to change SOA loadings 
Table 1. Continued.

\begin{tabular}{|c|c|c|c|}
\hline Myrcene & $\begin{array}{c}(1.06 \pm 0.02) \times 10^{-11} \\
(1.28 \pm 0.11) \times 10^{-11} \\
(2.2 \pm 0.2) \times 10^{-12} \exp [(523 \pm 35) / \mathrm{T}] \\
\mathbf{1 . 1} \times \mathbf{1 0}^{-11}(\Delta \log \boldsymbol{k}: \pm \mathbf{0 . 1 2})\end{array}$ & $\begin{array}{c}294 \\
298 \\
298-433 \\
\mathbf{2 9 8}\end{array}$ & $\begin{array}{c}\text { RR/(Atkinson et al., 1985) } \\
\text { DF-LIF/(Martínez et al., 1999) } \\
\text { DF-LIF/(Martínez et al., 1999) } \\
\text { IUPAC }\end{array}$ \\
\hline$\alpha$-cedrene & $(0.82 \pm 0.30) \times 10^{-11}$ & 296 & RR/(Shu and Atkinson, 1995) \\
\hline$\alpha$-copae & $(1.6 \pm 0.6) \times 10^{-11}$ & 296 & RR/(Shu and Atkinson, 1995) \\
\hline$\beta$-ca & $(1.9 \pm 0.8) \times 10^{-11}$ & 296 & RR/(Shu and Atkinson, 1995) \\
\hline$\alpha-h$ & $(3.5 \pm 1.3) \times 10^{-11}$ & 296 & RR/(Shu and Atkinson, 1995) \\
\hline Longifoler & $(6.8 \pm 2.1) \times 10^{-13}$ & 296 & RR/(Shu and Atkinson, 1995) \\
\hline Isolongifole & $(3.9 \pm 1.6) \times 10^{-12}$ & 298 & RR/(Canosa-Mas et al., 1999b) \\
\hline Alloisolongif & $(1.4 \pm 0.7) \times 10^{-12}$ & 298 & RR/(Canosa-Mas et al., 1999b) \\
\hline
\end{tabular}

in the real atmosphere (e.g., Rollins et al., 2009; ChaconMadrid et al., 2013). Recent experiments showed that particulate organic nitrates formed from $\beta$-pinene- $\mathrm{NO}_{3}$ are resilient to photochemical aging, while those formed from $\alpha$ pinene- $\mathrm{NO}_{3}$ evaporate more readily (Nah et al., 2016b).

Other chamber studies have not reported SOA mass yields or gas-phase product measurements but have otherwise demonstrated the importance of $\mathrm{NO}_{3}-\mathrm{BVOC}$ reactions to SOA production. These studies have identified $\beta$-pinene and $\Delta$-carene as particularly efficient sources of SOA upon $\mathrm{NO}_{3}$ oxidation (Hoffmann et al., 1997), confirmed the greater aerosol-forming potential from $\beta$-pinene versus $\alpha$-pinene (Bonn and Moortgat, 2002), and reported Fourier transform infrared spectroscopy (FTIR) and aerosol mass spectrometry (AMS) measurements of the composition of organic nitrates detected in aerosol formed from $\mathrm{NO}_{3}$-isoprene, $\alpha$-pinene, $\beta$-pinene, $\Delta$-carene, and limonene reactions (Bruns et al., 2010)

Relative humidity ( $\mathrm{RH}$ ) can be an important parameter, as it affects the competition between $\mathrm{NO}_{3}-\mathrm{BVOC}$ reactions and heterogeneous uptake of $\mathrm{N}_{2} \mathrm{O}_{5}$. Among existing laboratory studies, only a few have focused on the effect of RH on SOA formation from $\mathrm{NO}_{3}$-initiated oxidation (Bonn and Moortgat, 2002; Spittler et al., 2006; Fry et al., 2009; Boyd et al., 2015). The impact of RH might be important, especially at night and during the early morning when RH near the surface is high and $\mathrm{NO}_{3}$ radical chemistry is competitive with $\mathrm{O}_{3}$ and $\mathrm{OH}$ reactions. However, observations of the effect of water on $\mathrm{SOA}$ formation originating from $\mathrm{NO}_{3}$ oxidation hint at a varied role. Spittler et al. (2006) reported lower SOA yields under humid conditions, but other studies did not observe a significant effect (Bonn and Moortgat, 2002; Fry et 
Table 1. Continued.

\begin{tabular}{|c|c|c|c|}
\hline$\alpha$-neoclovene & $(8.2 \pm 4.6) \times 10^{-12}$ & 298 & RR/(Canosa-Mas et al., 1999b) \\
\hline $\begin{array}{l}\text { 2-methyl-3-buten- } \\
\text { 2-ol }\end{array}$ & $\begin{array}{c}4.6 \times 10^{-14} \exp [-(400 \pm 35) / \mathrm{T}] \\
(1.21 \pm 0.09) \times 10^{-14} \\
(2.1 \pm 0.3) \times 10^{-14} \\
(1.55 \pm 0.55) \times 10^{-14} \\
(8.7 \pm 3.0) \times 10^{-15} \\
(1.0 \pm 0.2) \times 10^{-14} \\
(1.1 \pm 0.1) \times 10^{-14} \\
\mathbf{1 . 2 \times 1 0 ^ { - 1 4 }}(\Delta \log \boldsymbol{k}: \pm \mathbf{0 . 2})\end{array}$ & $\begin{array}{c}267-400 \\
298 \\
294 \\
294 \\
298 \\
297 \\
297 \\
\mathbf{2 9 8}\end{array}$ & $\begin{array}{c}\text { F-A/(Rudich et al., 1996) } \\
\text { F-A/(Rudich et al., 1996) } \\
\text { DF-A/(Hallquist et al., 1996) } \\
\text { RR/(Hallquist et al., 1996) } \\
\text { RR/(Fantechi et al., 1998b) } \\
\text { RR/(Noda et al., 2002) } \\
\text { RR/(Noda et al., 2002) } \\
\text { IUPAC }\end{array}$ \\
\hline $\begin{array}{l}\text { 3-methyl-2-buten- } \\
\text { 1-ol }\end{array}$ & $(1.0 \pm 0.1) \times 10^{-12}$ & 297 & RR/(Noda et al., 2002) \\
\hline $\begin{array}{c}\text { 3-methyl-3-buten- } \\
\text { 1-ol }\end{array}$ & $(2.7 \pm 0.2) \times 10^{-13}$ & 297 & RR/(Noda et al., 2002) \\
\hline $\mathrm{-Ol}$ & $\begin{array}{l}(2.72 \pm 0.83) \times 10^{-13} \\
(2.67 \pm 0.42) \times 10^{-13}\end{array}$ & $\begin{array}{l}296 \\
298\end{array}$ & $\begin{array}{c}\text { RR/(Atkinson et al., 1995) } \\
\text { DF-CEAS/(Pfrang et al., 2006) }\end{array}$ \\
\hline $\operatorname{trans}$ & $(4.43 \pm 0.91) \times 10^{-13}$ & 298 & DF-CEAS/(Pfrang et al., 2006) \\
\hline cis & $(2.93 \pm 0.48) \times 10^{-13}$ & 298 & DF-CEAS/(Pfrang et al., 2006) \\
\hline & $(1.30 \pm 0.24) \times 10^{-13}$ & 298 & DF-CEAS/(Pfrang et al., 2006) \\
\hline & $(1.56 \pm 0.24) \times 10^{-13}$ & 298 & DF-CEAS/(Pfrang et al., 2006) \\
\hline trans-2-hexenal & $\begin{array}{c}(1.21 \pm 0.44) \times 10^{-14} \\
(1.36 \pm 0.29) \times 10^{-14} \\
(4.7 \pm 1.5) \times 10^{-15}\end{array}$ & $\begin{array}{l}296 \\
295 \\
294\end{array}$ & $\begin{array}{l}\text { RR/(Atkinson et al., 1995) } \\
\text { RR/(Zhao et al., 2011b) } \\
\text { AR/(Kerdouci et al., 2012) }\end{array}$ \\
\hline $\begin{array}{l}\text { 4-methylenehex-5- } \\
\text { enal }\end{array}$ & $(4.75 \pm 0.35) \times 10^{-13}$ & 296 & RR/(Baker et al., 2004) \\
\hline
\end{tabular}

al., 2009; Boyd et al., 2015). Among the important effects of water is its role as a medium for hydrolysis. In laboratory studies, primary and secondary organic nitrates were found to be less prone to aqueous hydrolysis than tertiary organic nitrates (Darer et al., 2011; Hu et al., 2011). First-generation organic nitrates retaining double bonds may also hydrolyze relatively quickly, especially in the presence of acidity (Jacobs et al., 2014; Rindelaub et al., 2015). Depending on the relative amount of these different types of organic nitrates, the overall hydrolysis rate could be different for organic nitrates formed from $\mathrm{NO}_{3}$ oxidation and photooxidation in the presence of $\mathrm{NO}_{x}$ (Boyd et al., 2015). Recently, there has been increasing evidence from field measurements that organic nitrates hydrolyze in the particle phase, producing $\mathrm{HNO}_{3}$ (Liu et al., 2012b; Browne et al., 2013). This has been only a limited focus of chamber experiments to date (Boyd et al., 2015). In addition to the effect of RH, particle-phase acidity is known to affect SOA formation from ozonolysis and OH reaction (e.g., Gao et al., 2004; Tolocka et al., 2004). Thus far, only one study has examined the effect of acidity on $\mathrm{NO}_{3}$-initiated SOA formation and found a negligible effect (Boyd et al., 2015). Notably, an effect of acidity was observed for the hydrolysis of organic nitrates produced in photochemical reactions (Szmigielski et al., 2010; Rindelaub et al., 2015). While much organic nitrate aerosol is formed via $\mathrm{NO}_{3}+\mathrm{BVOC}$ reactions, some fraction can also form from $\mathrm{RO}_{2}+\mathrm{NO}$ chemistry. Rollins et al. (2010) observed the organic nitrate moiety in $6-15 \%$ of total SOA mass generated from high- $\mathrm{NO}_{x}$ photooxidation of limonene, $\alpha$-pinene, $\Delta^{3}$ carene, and tridecane. A very recent study of Berkemeier et 
Table 1. Continued.

\begin{tabular}{|c|c|c|c|}
\hline $\begin{array}{l}\text { (3Z)-4- } \\
\text { methylhexa-3,5- } \\
\text { dienal }\end{array}$ & $(2.17 \pm 0.30) \times 10^{-12}$ & 296 & RR/(Baker et al., 2004) \\
\hline $\begin{array}{l}\text { (3E)-4- } \\
\text { methylhexa-3,5- } \\
\text { dienal }\end{array}$ & $(1.75 \pm 0.27) \times 10^{-12}$ & 296 & RR/(Baker et al., 2004) \\
\hline $\begin{array}{l}\text { 4-methylcyclohex- } \\
\text { 3-en-1-one }\end{array}$ & $(1.81 \pm 0.35) \times 10^{-12}$ & 296 & RR/(Baker et al., 2004) \\
\hline cis-3. & $(2.46 \pm 0.75) \times 10^{-13}$ & 296 & RR/(Atkinson et al., 1995) \\
\hline Methyl vinyl & $\begin{array}{c}<1.2 \times 10^{-16} \\
<6 \times 10^{-16} \\
(3.2 \pm 0.6) \times 10^{-16} \\
(5.0 \pm 1.2) \times 10^{-16} \\
<6 \times 10^{-16}\end{array}$ & $\begin{array}{l}298 \\
296 \\
296 \\
296 \\
\mathbf{2 9 8}\end{array}$ & $\begin{array}{c}\text { F-A/(Rudich et al., 1996) } \\
\text { DF- RR/(Kwok et al., 1996) } \\
\text { LIF/(Canosa-Mas et al., 1999a) } \\
\text { RR/(Canosa-Mas et al., 1999a) } \\
\text { IUPAC }\end{array}$ \\
\hline Met & 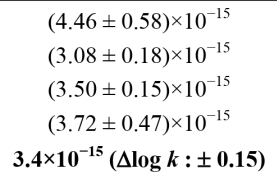 & $\begin{array}{l}296 \\
298 \\
298 \\
296 \\
\mathbf{2 9 8}\end{array}$ & $\begin{array}{c}\text { RR/(Kwok et al., 1996) } \\
\text { RR/(Chew et al., 1998) } \\
\text { RR/(Chew et al., 1998) } \\
\text { RR/(Canosa-Mas et al., 1999a) } \\
\text { IUPAC }\end{array}$ \\
\hline Pinonaldehyde & $\begin{array}{c}(2.40 \pm 0.38) \times 10^{-14} \\
(6.0 \pm 2.0) \times 10^{-14} \\
(2.0 \pm 0.9) \times 10^{-14} \\
\mathbf{2 . 0} \times \mathbf{1 0}^{-14}(\Delta \log k: \pm \mathbf{0 . 2 5})\end{array}$ & $\begin{array}{l}299 \\
300 \\
296 \\
\mathbf{2 9 8}\end{array}$ & $\begin{array}{l}\text { RR/ (Hallquist et al., 1997a) } \\
\text { RR/(Glasius et al., 1997) } \\
\text { RR/(Alvarado et al., 1998) } \\
\text { IUPAC }\end{array}$ \\
\hline $\mathrm{Li}$ & $(1.12 \pm 0.40) \times 10^{-11}$ & 296 & RR/(Atkinson et al., 1995) \\
\hline & $(1.6 \pm 0.4) \times 10^{-11}$ & 297 & RR/(Jones and Ham, 2008) \\
\hline Sabinaketone & $(3.6 \pm 2.3) \times 10^{-16}$ & 296 & RR/(Alvarado et al., 1998) \\
\hline Caronaldehyde & $(2.5 \pm 1.1) \times 10^{-14}$ & 296 & RR/(Alvarado et al., 1998) \\
\hline
\end{tabular}

Given uncertainties are those provided by the authors of the kinetic studies. The procedures used to calculate them are not detailed here, as they often differ from one study to another. Readers are referred to the original papers for more information on the uncertainties' determination.

RR: relative rate; DF-MS: discharge flow-mass spectrometry; DF-LIF: discharge flow-laser-induced fluorescence; DF-A: discharge flow-absorption; DF-CEAS: discharge flow-cavity-enhanced absorption spectroscopy; F-LIF: flow system-laser-induced fluorescence; F-CIMS: flow system-chemical ionization mass spectrometry; F-A: flow system-absorption; PR-A: pulse radiolysis-absorption; AR: absolute rate in simulation chamber.

al. (2016) showed that organic nitrates accounted for $\sim 40 \%$ of SOA mass during initial particle formation in $\alpha$-pinene oxidation by $\mathrm{O}_{3}$ in the presence of $\mathrm{NO}$, decreasing to $\sim 15 \%$ upon particle growth to the accumulation-mode size range. They also observed a tight correlation $\left(R^{2}=0.98\right)$ between organic nitrate content and SOA particle number concentrations. This implies that organic nitrates may be among the extremely low volatility organic compounds (ELVOC) (Ehn et al., 2014; Tröstl et al., 2016) that play a critical role in nucleation and nanoparticle growth. 


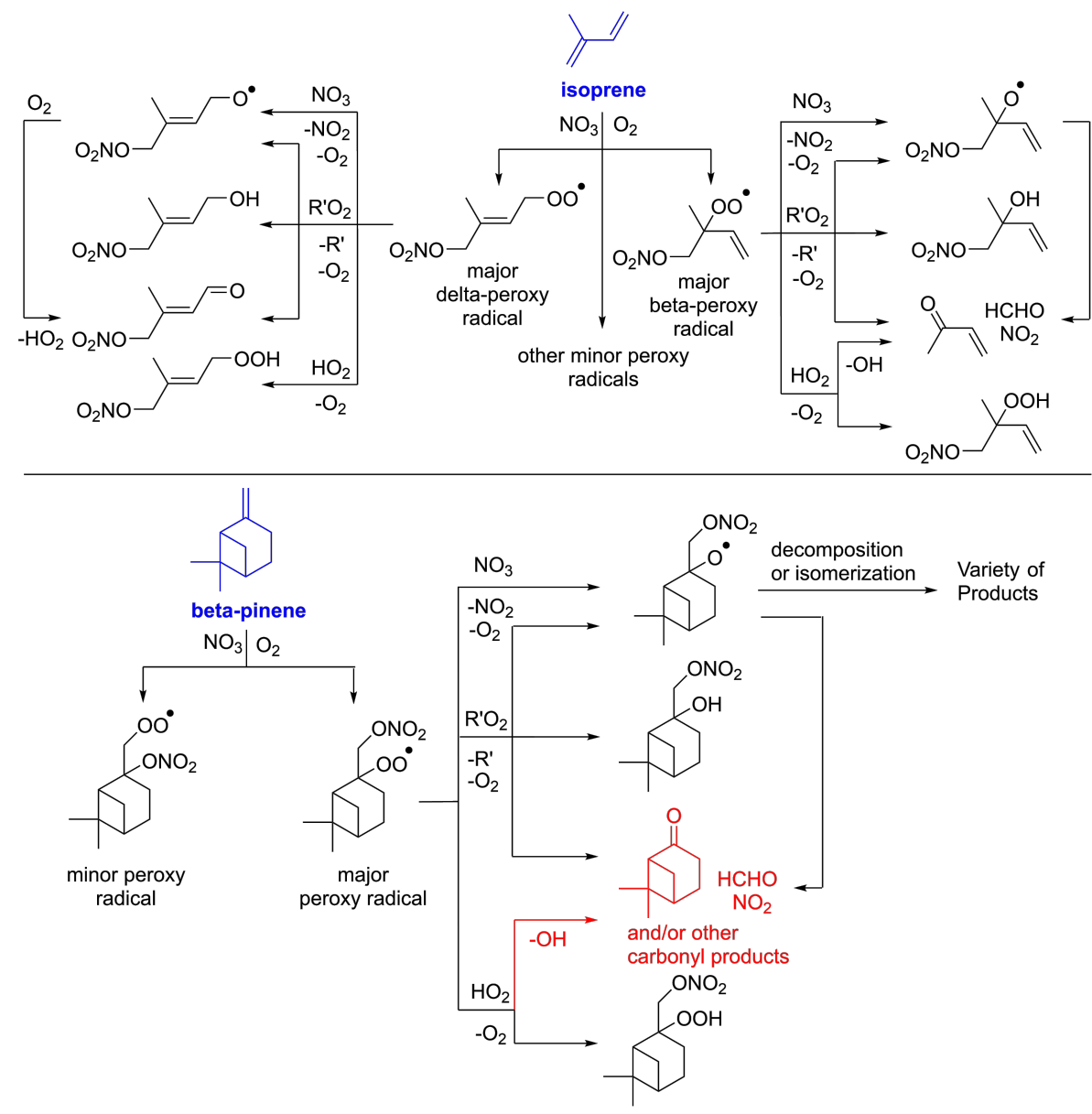

Figure 2. Condensed reaction mechanism for isoprene and $\beta$-pinene oxidation via $\mathrm{NO}_{3}$ (adapted from Schwantes et al., 2015 and Boyd et al., 2015). For brevity, only products generated from the dominant peroxy radicals $\left(\mathrm{RO}_{2}\right)$ are shown. $R^{\prime}$ represents an alkoxy radical, carbonyl compound, or hydroxy compound. Two of the largest uncertainties in $\beta$-pinene oxidation are shown in red: (1) quantification of product yields from the $\mathrm{RO}_{2}+\mathrm{HO}_{2}$ channel and (2) identification of carbonyl products formed from $\mathrm{RO}_{2}$ reaction with $\mathrm{NO}_{3}, \mathrm{RO}_{2}$, or $\mathrm{HO}_{2}$ (see text for more details).

\subsection{Heterogeneous and aqueous-phase $\mathrm{NO}_{3}$ processes}

The $\mathrm{NO}_{3}$ radical is not only a key nighttime oxidant of organic (and especially biogenic) trace gases but it can also play an important role in the aqueous phase of tropospheric clouds and deliquesced particles (Chameides, 1978; Wayne et al., 1991; Herrmann and Zellner, 1998; Rudich et al., 1998). Whilst the reaction of $\mathrm{NO}_{3}$ with organic particles and aqueous droplets in the atmosphere is believed to represent only an insignificant fraction of the overall loss rate for $\mathrm{NO}_{3}$, it can have a substantial impact on the chemical and physical properties of the particle by modifying its lifetime, oxidation state, viscosity, and hygroscopic properties and thus its propensity to act as a cloud condensation nucleus (Rudich, 2003).

Biogenic VOC include, but are not limited to the isoprenoids (isoprene, mono-, and sesquiterpenes) as well as alkanes, alkenes, carbonyls, alcohols, esters, ethers, and acids (Kesselmeier and Staudt, 1999). Recent measurements indicate that biogenic emissions of aromatic trace gases are also significant (Misztal et al., 2015). The gas-phase degradation of BVOC leads to the formation of a complex mixture of organic trace gases including hydroxyl- and nitratesubstituted oxygenates which can transfer to the particle phase by condensation or dissolution. Our present understanding is that non-anthropogenic SOA has a large contribution from isoprenoid degradation.

As is generally the case for laboratory studies of heterogeneous processes, most of the experimental investigations on heterogeneous uptake of $\mathrm{NO}_{3}$ to organic surfaces have dealt with single-component systems that act as surrogates for the considerably more complex mixtures found in atmospheric SOA. A further level of complexity arises when we consider that initially reactive systems, e.g., containing condensed or dissolved unsaturated hydrocarbons, can become 
Table 2. Oxidation products and SOA yields observed in previous studies of $\mathrm{NO}_{3}$-BVOC reactions. Except where noted, carbonyl and organic nitrate molar yields represent initial gas-phase yields measured by FTIR spectroscopy (carbonyl and organic nitrate) or thermal desorption laser-induced fluorescence (TD-LIF) (organic nitrate only; Rollins et al., 2010; Fry et al., 2013). In some cases, the ranges reported correspond to wide ranges of organic aerosol loading, listed in the rightmost column. Where possible, the mass yield at $10 \mu \mathrm{g} \mathrm{m}{ }^{-3}$ is reported for ease of comparison.

\begin{tabular}{|c|c|c|c|c|}
\hline BVOC & Carbonyl molar yield & Organic nitrate molar yield & SOA mass yield & $\begin{array}{l}\text { Corresponding OA loading or other relevant in- } \\
\text { formation }\end{array}$ \\
\hline Isoprene & & $62-78 \%$ (Rollins et al., 2009) & $\begin{array}{l}2 \%(14 \% \text { after further oxidation) } \\
\text { (Rollins et al., 2009) } \\
4-24 \% \text { (Ng et al., 2008) }\end{array}$ & $\begin{array}{l}\text { Nucleation }\left(1 \mu \mathrm{g} \mathrm{m}^{-3}\right) \\
3-70 \mu \mathrm{g} \mathrm{m}^{-3} ; 12 \% \text { at } 10 \mu \mathrm{g} \mathrm{m}^{-3}\end{array}$ \\
\hline \multirow[t]{5}{*}{$\alpha$-pinene } & $\begin{array}{l}58-66 \% \text { (Wangberg et al., } \\
\text { 1997); 69-81\% (Berndt and } \\
\text { Boge, 1997a); 65-72\% } \\
\text { (Hallquist et al., 1999); 39- } \\
58 \% \text { (Spittler et al., 2006) }\end{array}$ & $\begin{array}{l}14 \% \text { (Wangberg et al., 1997); } \\
12-18 \% \text { (Berndt and Boge, } \\
\text { 1997b); 18-25\% (Hallquist et } \\
\text { al., 1999); 11-29\% (Spittler et } \\
\text { al., 2006); 10\% (Fry et al., } \\
2014 \text { ) }\end{array}$ & $0.2-16 \%$ (Hallquist et al., 1999) & $\begin{array}{l}\text { Nucleation; } 0.5 \% \text { at } 10 \text { ppt } \mathrm{N}_{2} \mathrm{O}_{5} \text { reacted, } 7 \% \\
\text { at } 100 \text { ppt } \mathrm{N}_{2} \mathrm{O}_{5} \text { reacted }^{\mathrm{a}}\end{array}$ \\
\hline & & & 4 or $16 \%$ (Spittler et al., 2006) & $\begin{array}{l}\text { Values for } 20 \% \text { RH and dry conditions, respec- } \\
\text { tively, at } M_{\infty} \text { b }\end{array}$ \\
\hline & & & $1.7-3.6 \%$ (Nah et al., 2016a) & $1.2-2.5 \mu \mathrm{g} \mathrm{m}^{-3}$ \\
\hline & & & $0 \%$ (Fry et al., 2014) & Both nucleation and ammonium sulfate seeded \\
\hline & & & 9\% (Perraud et al., 2010) & $\begin{array}{l}\text { Nucleation at } 1 \mathrm{ppm} \mathrm{N}_{2} \mathrm{O}_{5} \text { and } 1 \mathrm{ppm} \alpha- \\
\text { pinene; } \mathrm{OA} \text { is } 480 \mu \mathrm{g} \mathrm{m}^{-3} \text { assuming density is } \\
1.235 \mathrm{~g} \mathrm{~cm}^{-3}\end{array}$ \\
\hline \multirow[t]{5}{*}{$\beta$-pinene } & 0-2\% (Hallquist et al., 1999) & $\begin{array}{l}51-74 \% \text { (Hallquist et al., } \\
1999) ; 40 \% \text { (Fry et al., 2009); } \\
22 \% \text { (Fry et al., 2014); 45- } \\
74 \% \text { of OA mass (Boyd et al., } \\
2015 \text { ) }\end{array}$ & $32-89 \%$ (Griffin et al., 1999) & $32-470 \mu \mathrm{g} \mathrm{m}^{-3} ;$ low end closest to $10 \mu \mathrm{g} \mathrm{m}^{-3}$ \\
\hline & & & $\begin{array}{l}7-40 \% \text { (Moldanova and Ljungstrom, } \\
2000) \text { using new model to reinterpret } \\
\text { data from Hallquist et al. (1999) } \\
(10-52 \%)\end{array}$ & $\begin{array}{l}7-10 \% \text { at } 7 \text { ppt } \mathrm{N}_{2} \mathrm{O}_{5} \text { reacted; } 40-52 \% \text { at } \\
39 \text { ppt } \mathrm{N}_{2} \mathrm{O}_{5} \text { reacted }\end{array}$ \\
\hline & & & $50 \%$ (Fry et al., 2009) & $40 \mu \mathrm{g} \mathrm{m}^{-3} ;$ same yield at both 0 and $60 \% \mathrm{RH}$ \\
\hline & & & 33-44 \% (Fry et al., 2014) & $10 \mu \mathrm{g} \mathrm{m}^{-3 \mathrm{c}}$ \\
\hline & & & 27-104 \% (Boyd et al., 2015) & $\begin{array}{l}5-135 \mu \mathrm{g} \mathrm{m}^{-3} \text {, various seeds and } \mathrm{RO}_{2} \text { fate } \\
\text { regimes; } 50 \% \text { for experiments near } 10 \mu \mathrm{g} \mathrm{m}^{-3}\end{array}$ \\
\hline \multirow[t]{3}{*}{$\Delta$-carene } & 0-3\% (Hallquist et al., 1999) & $\begin{array}{l}68-74 \% \text { (Hallquist et al., } \\
1999) ; 77 \% \text { (Fry et al., 2014) }\end{array}$ & $13-72 \%$ (Griffin et al., 1999) & $24-310 \mu \mathrm{g} \mathrm{m}^{-3} ;$ low end closest to $10 \mu \mathrm{g} \mathrm{m}^{-3}$ \\
\hline & & & $\begin{array}{l}12-49 \% \text { (Moldanova and Ljungstrom, } \\
2000) \text { using new model to reinterpret } \\
\text { data from Hallquist et al. (1999) (15- } \\
62 \% \text { ) }\end{array}$ & $\begin{array}{l}7-395 \text { ppt } \mathrm{N}_{2} \mathrm{O}_{5} \text { reacted; } 12-15 \% \text { at } 6.8 \mathrm{ppt} \\
\mathrm{N}_{2} \mathrm{O}_{5} \text { reacted }\end{array}$ \\
\hline & & & $38-65 \%$ (Fry et al., 2014) & $10 \mu \mathrm{g} \mathrm{m}^{-3 \mathrm{c}}$ \\
\hline \multirow[t]{4}{*}{ Limonene } & $\begin{array}{l}69 \% \text { (Hallquist et al., 1999); } \\
25-33 \% \text { (Spittler et al., 2006) }\end{array}$ & $\begin{array}{l}48 \% \text { (Hallquist et al., 1999); } \\
63-72 \% \text { (Spittler et al., 2006); } \\
30 \% \text { (Fry et al., 2011); } \\
54 \% \text { (Fry et al., 2014) }\end{array}$ & $\begin{array}{l}\text { 14-24\% (Moldanova and Ljungstrom, } \\
2000) \text { using new model to reinterpret } \\
\text { data from Hallquist et al. (1999) (17\%) }\end{array}$ & $\begin{array}{l}10 \mathrm{ppt} \mathrm{N}_{2} \mathrm{O}_{5} \text { reacted; higher number in } \\
\text { Moldanova and Ljungstrom }(2000) \text { from an ad- } \\
\text { ditional injection of } 7 \mathrm{ppt} \mathrm{N}_{2} \mathrm{O}_{5} \text { and accounting } \\
\text { for secondary reactions }\end{array}$ \\
\hline & & & 21 or $40 \%$ (Spittler et al., 2006) & $\begin{array}{l}\text { Ammonium sulfate or organic seed, } \\
\text { respectively, at } M_{\infty} \text { b }\end{array}$ \\
\hline & & & 25-40\% (Fry et al., 2011) & $\begin{array}{l}\text { Nucleation to } 10 \mu \mathrm{g} \mathrm{m}^{-3} \text { (second injection of } \\
\text { oxidant) }\end{array}$ \\
\hline & & & 44-57\% (Fry et al., 2014) & $10 \mu \mathrm{g} \mathrm{m}^{-3 \mathrm{c}}$ \\
\hline \multirow[t]{2}{*}{ Sabinene } & & & $14-76 \%$ (Griffin et al., 1999) & $24-277 \mu \mathrm{g} \mathrm{m}^{-3} ;$ low end closest to $10 \mu \mathrm{g} \mathrm{m}^{-3}$ \\
\hline & & & $25-45 \%$ (Fry et al., 2014) & $10 \mu \mathrm{g} \mathrm{m}^{-3 \mathrm{c}}$ \\
\hline$\beta$-caryophyllene & & & $\begin{array}{l}91-146 \% \text { (Jaoui et al., 2013) } \\
86 \% \text { (Fry et al., 2014) }\end{array}$ & $\begin{array}{l}60-130 \mu \mathrm{g} \mathrm{m}^{-3} ; \text { low end closest to } 10 \mu \mathrm{g} \mathrm{m}^{-3} \\
10 \mu \mathrm{g} \mathrm{m}^{-3}\end{array}$ \\
\hline
\end{tabular}

${ }^{\text {a }}$ The authors assume that $\mathrm{N}_{2} \mathrm{O}_{5}$ reacted is equal to BVOC reacted. The anomalously low $0.2 \%$ yield observed at $390 \mathrm{ppt}_{2} \mathrm{O}_{5}$ reacted is a lower limit; Hallquist et al. note that the number-size distribution for that experiment fell partly outside the measured range. ${ }^{\mathrm{b}} M_{\infty}$ corresponds to extrapolated value at highest mass loading. Organic seed aerosol in these experiments was generated from $\mathrm{O}_{3}+\mathrm{BVOC}$. Full dataset was shown only for limonene, where asymptote is $400 \mathrm{\mu g} \mathrm{m}^{-3}$. ${ }^{\mathrm{c}}$ Yield range corresponds to two different methods of calculating $\triangle \mathrm{BVOC}$.

deactivated as SOA ages, single bonds replace double bonds, and the oxygen-to-carbon ratio increases.

We summarize the results of the laboratory studies to provide a rough guide to $\mathrm{NO}_{3}$ reactivity on different classes of organics which may be present in SOA and note that further studies of $\mathrm{NO}_{3}$ uptake to biogenic SOA which was either generated and aged under well-defined conditions (Fry et al., 2011) or sampled from the atmosphere are required to confirm predictions of uptake efficiency based on the presently available database. 


\subsubsection{Heterogeneous processes}

For some particle-phase organics, the reaction with $\mathrm{NO}_{3}$ is at least as important as other atmospheric oxidants such as $\mathrm{O}_{3}$ and OH (Shiraiwa et al., 2009; Kaiser et al., 2011). The lifetime $(\tau)$ of a single component, liquid organic particle with respect to loss by reaction with $\mathrm{NO}_{3}$ at concentration $\left[\mathrm{NO}_{3}\right]$ is partially governed by the uptake coefficient $(\gamma)$ (Robinson et al., 2006; Gross et al., 2009):

$\tau_{\text {liquid }}=\frac{2 \rho_{\mathrm{org}} N_{\mathrm{A}} D_{\mathrm{p}}}{3 M_{\mathrm{org}} \bar{c} \gamma\left[\mathrm{NO}_{3}\right]}$,

where $D_{\mathrm{p}}$ is the particle diameter, $\rho_{\mathrm{org}}$ and $M_{\text {org }}$ are the density and molecular weight of the organic component, respectively, $\bar{c}$ is the mean molecular velocity of gas-phase $\mathrm{NO}_{3}$, and $\mathrm{N}_{\mathrm{A}}$ is Avogadro number. Thus, defined, $\tau$ is the time required for all the organic molecules in a spherical (i.e., liquid) particle to undergo a single reaction with $\mathrm{NO}_{3}$.

Recent studies have shown that organic aerosols can adopt semi-solid (highly viscous) or amorphous solid (crystalline or glass) phase states, depending on the composition and ambient conditions (Virtanen et al., 2010; Koop et al., 2011; Renbaum-Wolff et al., 2013). Typically, the bulk phase diffusion coefficients of $\mathrm{NO}_{3}$ are $\sim 10^{-7}-10^{-9} \mathrm{~cm}^{2} \mathrm{~s}^{-1}$ in semisolid and $\sim 10^{-10} \mathrm{~cm}^{2} \mathrm{~s}^{-1}$ in solids (Shiraiwa et al., 2011). Slow bulk diffusion of $\mathrm{NO}_{3}$ in a viscous organic matrix can effectively limit the rate of uptake (Xiao and Bertram, 2011; Shiraiwa et al., 2012). Similarly, the solubility may be different in a concentrated, organic medium. If bulk diffusion is slow, the reaction may be confined to the near-surface layers of the particle or bulk substrate. The presence of organic coatings on aqueous aerosols was found to suppress heterogeneous $\mathrm{N}_{2} \mathrm{O}_{5}$ hydrolysis by providing a barrier through which $\mathrm{N}_{2} \mathrm{O}_{5}$ needs to diffuse to undergo hydrolysis (Alvarado et al., 1998; Cosman et al., 2008; Grifiths et al., 2009). Reactive uptake by organic aerosols is expected to exhibit a pronounced decrease at low RH and temperature, owing to a phase transition from viscous liquid to semi-solid or amorphous solid (Arangio et al., 2015). Therefore, the presence of a semi-solid matrix may effectively shield reactive organic compounds from chemical degradation in long-range transport in the free troposphere.

To get an estimate of the processing rate of BVOC-derived SOA, we have summarized the results of several laboratory studies to provide a rough guide to $\mathrm{NO}_{3}$ reactivity on different classes of organics that may be present in SOA (Fig. 3). A rough estimate of the reactivity of $\mathrm{NO}_{3}$ to freshly generated, isoprenoid-derived SOA, which still contains organics with double bonds (e.g., from diolefinic monoterpenes such as limonene), may be obtained by considering the data on alkenes and unsaturated acids, where the uptake coefficient is generally close to 0.1 .

The classes of organics for which heterogeneous reactions with $\mathrm{NO}_{3}$ have been examined are alkanoic/alkenoic acids, alkanes and alkenes, alcohols, aldehydes, polyaromatic hy-

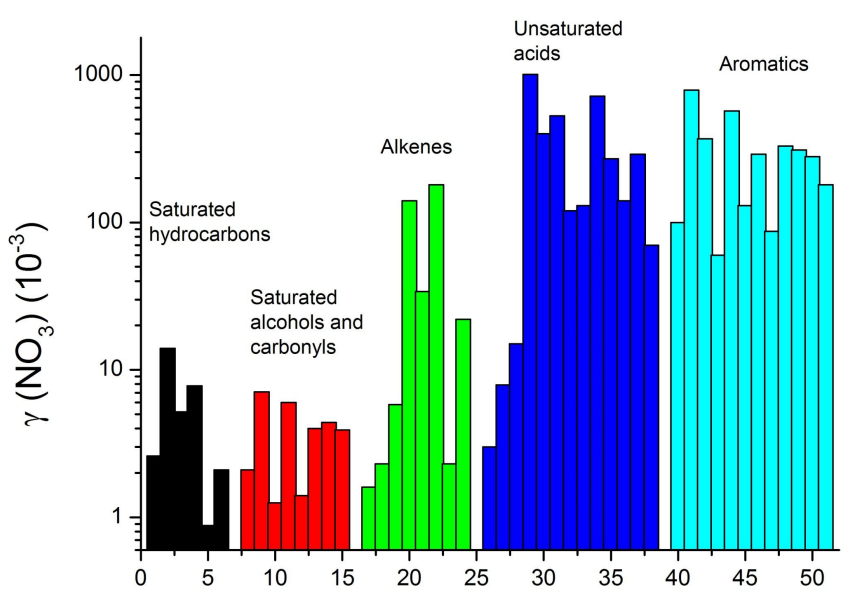

Figure 3. Uptake coefficients, $\gamma\left(\mathrm{NO}_{3}\right)$, for the interaction of $\mathrm{NO}_{3}$ with single-component organic surfaces. Details of the experiments and the references (corresponding to the $x$-axis numbers) are given in Table S1 in the Supplement.

drocarbons (PAHs), and secondary organic aerosols. Laboratory studies have used either pure organic substrates, with the organic of interest internally mixed in an aqueous particle; as a surface coating, with the reactive organic mixed in a nonreactive organic matrix; or in the form of self-assembling monolayers. The surrogate surface may be available as a macroscopic bulk liquid (or frozen liquid) or in particulate form and both gas-phase and particle-phase analyses have been used to derive kinetic parameters and investigate products formed.

In the gas phase, the $\mathrm{NO}_{3}$ radical reacts slowly (by $\mathrm{H}-$ abstraction) with alkanes, more rapidly with aldehydes due to the weaker $\mathrm{C}-\mathrm{H}$ bond of the carbonyl group, and most readily with alkenes and aromatics via electrophilic addition. This trend in reactivity is also observed in the condensedphase reactions of $\mathrm{NO}_{3}$ with organics so that long-chain organics, for which non-sterically hindered addition to a double bond is possible, and aromatics are the most reactive. In very general terms, uptake coefficients are in the range of $1-10 \times 10^{-3}$ for alkanes, alcohols, and acids without double bonds, $2-200 \times 10^{-3}$ for alkenes with varying numbers of double bonds, $3-1000 \times 10^{-3}$ for acids with double bonds again depending on the number of double bonds, and 100$500 \times 10^{-3}$ for aromatics. These trends are illustrated in Fig. 3 which plots the experimental data for the uptake of $\mathrm{NO}_{3}$ to single-component organic surfaces belonging to different classes of condensable organics. Condensed-phase organic nitrates have been frequently observed following interaction of $\mathrm{NO}_{3}$ with organic surfaces (see below).

\section{Saturated hydrocarbons}

Uptake of $\mathrm{NO}_{3}$ to saturated hydrocarbons is relatively slow, with uptake coefficients close to $10^{-3}$. Moise et al. (2002) 
found that (for a solid sample) uptake to a branched-chain alkane was more efficient than for a straight-chain alkane, which is consistent with known trends in gas-phase reactivity of $\mathrm{NO}_{3}$. The slow surface reaction with alkanes enables both surface and bulk components of the reaction to operate in parallel. The observation of $\mathrm{RONO}_{2}$ as product is explained (Knopf et al., 2006; Gross and Bertram, 2009) by processes similar to those proceeding in the gas phase, i.e., abstraction followed by formation of peroxy and alkoxy intermediates which react with $\mathrm{NO}_{2}$ and $\mathrm{NO}_{3}$ to form the organic nitrate.

\section{Unsaturated hydrocarbons}

With exception of the data of Moise et al. (2002), the uptake of $\mathrm{NO}_{3}$ to an unsaturated organic surface is found to be much more efficient than to the saturated analogue. The $\mathrm{NO}_{3}$ uptake coefficient for, e.g., squalene, is at least an order of magnitude more efficient than for squalane (Xiao and Bertram, 2011; Lee et al., 2013). The location of the double bond is also important and the larger value for $\gamma$ found for a self-assembling monolayer of $\mathrm{NO}_{3}+$ undec-10-ene-1-thiol compared to liquid, long-chain alkenes is due to the fact that the terminal double bond is located at the interface and is thus more accessible for a gas-phase reactant (Gross and Bertram, 2009). $\mathrm{NO}_{3}$ uptake to mixtures of unsaturated methyl oleate in a matrix of saturated organic was found to be consistent with either a surface or bulk reaction (Xiao and Bertram, 2011). The formation of condensed-phase organic nitrates and simultaneous loss of the vinyl group indicates that the reaction proceeds, as in the gas phase, by addition of $\mathrm{NO}_{3}$ to the double bond followed by reaction of $\mathrm{NO}_{3}\left(\right.$ or $\left.\mathrm{NO}_{2}\right)$ with the resulting alkyl and peroxy radicals formed (Zhang et al., 2014b).

\section{Saturated alcohols and carbonyls}

Consistent with reactivity trends for $\mathrm{NO}_{3}$ in the gas phase, the weakening of some $\mathrm{C}-\mathrm{H}$ bonds in oxidized, saturated organics results in a more efficient interaction of $\mathrm{NO}_{3}$ than for the non-oxidized counterparts although, as far as the limited dataset allows trends to be deduced, the gas-phase reactivity trend of polyalcohol being greater than alkanoate appears to be reversed in the liquid phase (Gross et al., 2009). For multicomponent liquid particles, the uptake coefficient will also depend on the particle viscosity (Iannone et al., 2011) though it has not been clearly established if the reaction proceeds predominantly at the surface or throughout the particle (Iannone et al., 2011). The reaction products are expected to be formed via similar pathways as seen in the gas phase, i.e., abstraction of the aldehydic- $\mathrm{H}$ atom for aldehydes and abstraction of an $\mathrm{H}$ atom from either the $\mathrm{O}-\mathrm{H}$ or adjacent $\alpha$ $\mathrm{CH}_{2}$ group for alcohols prior to reaction of $\mathrm{NO}_{2}$ and $\mathrm{NO}_{3}$ with the ensuing alkyl and peroxy radicals (Zhang and Morris, 2015).

\section{Organic acids}

The efficiency of uptake of $\mathrm{NO}_{3}$ to unsaturated acids is comparable to that found with other oxidized, saturated organics (Moise et al., 2002) suggesting that the reaction proceeds, as in the gas phase, via abstraction rather than addition. Significantly larger uptake coefficients have been observed for a range of unsaturated, long-chain acids, with $\gamma$ often between 0.1 and 1 (Gross et al., 2009; Knopf et al., 2011; Zhao et al., 2011a). $\gamma$ depends on the number and position (steric factors) of the double bond. For example, the uptake coefficient for abietic acid is a factor of 100 lower than for linoleic acid (Knopf et al., 2011). The condensed-phase products formed in the interaction of $\mathrm{NO}_{3}$ with unsaturated acids are substituted carboxylic acids, including hydroxy nitrates, carbonyl nitrates, dinitrates, and hydroxy dinitrates (Hung et al., 2005; Docherty and Ziemann, 2006; McNeill et al., 2007; Zhao et al., 2011a).

\section{Aromatics}

The interaction of $\mathrm{NO}_{3}$ with condensed-phase aromatics and PAHs results in the formation of a large number of nitrated aromatics and nitro PAHs. Similar to the gas-phase mechanism, the reaction is initiated by addition of $\mathrm{NO}_{3}$ to the aromatic ring, followed by breaking of an $\mathrm{N}-\mathrm{O}$ bond to release $\mathrm{NO}_{2}$ to the gas phase and forming a nitrooxycyclohexadienyl-type radical which can further react with $\mathrm{O}_{2}, \mathrm{NO}_{2}$, or undergo internal rearrangement to form hydroxyl species (Gross and Bertram, 2008; Lu et al., 2011). The uptake coefficients are large and comparable to those derived for the unsaturated fatty acids.

The literature results on the interaction of $\mathrm{NO}_{3}$ with organic substrates are tabulated in Table S1 in the Supplement, in which the uptake coefficient is listed (if available) along with the observed condensed- and gas-phase products.

\subsubsection{Aqueous-phase reactions}

The in situ formation of $\mathrm{NO}_{3}$ (e.g., electron transfer reactions between nitrate anions and other aqueous radical anions such as $\mathrm{SO}_{x}^{-}$, sulfur-containing radical anions, or $\mathrm{Cl}_{2}^{-}$) is generally of minor importance and the presence of $\mathrm{NO}_{3}$ in aqueous particles is largely a result of transfer from the gas phase (Herrmann et al., 2005; Tilgner et al., 2013). Concentrations of $\mathrm{NO}_{3}$ in tropospheric aqueous solutions cannot be measured in situ, and literature values are based on multiphase model predictions (Herrmann et al., 2010). Model studies with the chemical aqueous-phase radical mechanism (CAPRAM; Herrmann et al., 2005; Tilgner et al., 2013) pre$\operatorname{dict}\left[\mathrm{NO}_{3}\right]$ between $1 \times 6 \times 10^{-16}$ and $2.7 \times 10^{-13} \mathrm{~mol} \mathrm{~L}^{-1}$. High $\mathrm{NO}_{3}$ concentration levels are associated with urban clouds, while in rural and marine clouds these levels are an order of magnitude lower. Since the $\mathrm{NO}_{3}$ concentrations are related to the $\mathrm{NO}_{x}$ budget, typically higher $\mathrm{NO}_{3}$ concentra- 

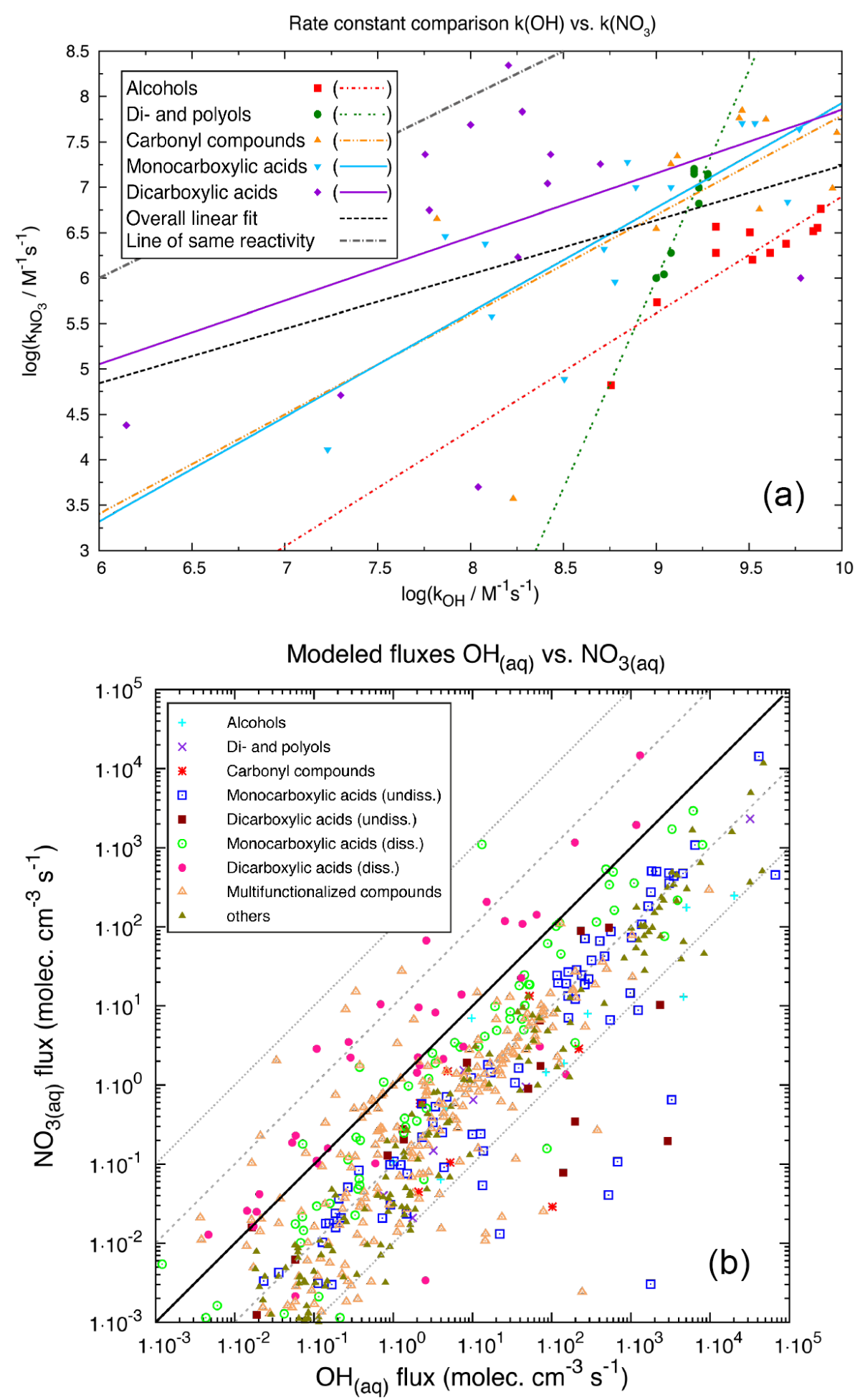

Figure 4. (a) Correlation of $\mathrm{OH}$ versus $\mathrm{NO}_{3}$ radical rate constants in the aqueous phase for the respective compound classes. The linear regression fits for the different compound classes are presented in the same color as the respective data points. The black line represents the correlation of the overall data. (b) Comparison of modeled, aqueous-phase reaction fluxes (mean chemical fluxes in mol $\mathrm{cm}^{-3} \mathrm{~s}^{-1} \mathrm{over} \mathrm{a}$ simulation period of 4-5 days) of organic compounds with hydroxyl $(\mathrm{OH})$ versus nitrate $\left(\mathrm{NO}_{3}\right)$ radicals distinguished by different compound classes (urban CAPRAM summer scenario). 
tions are present under urban cloud conditions compared to rural and marine cloud regimes.

$\mathrm{NO}_{3}$ radicals react with dissolved organic species via three different pathways: (i) by $\mathrm{H}$-atom abstraction from saturated organic compounds, (ii) by electrophilic addition to double bonds within unsaturated organic compounds, and (iii) by electron transfer from dissociated organic acids (Huie, 1994; Herrmann and Zellner, 1998). For a detailed overview on aqueous-phase $\mathrm{NO}_{3}$ radical kinetics, the reader is referred to several recent summaries (Neta et al., 1988; Herrmann and Zellner, 1998; Ross et al., 1998; Herrmann, 2003; Herrmann et al., 2010, 2015). Compared to the highly reactive and non-selective $\mathrm{OH}$ radical, the $\mathrm{NO}_{3}$ radical is characterized by a lower reactivity and represents a more selective aqueous-phase oxidant. The available kinetic data indicate that the reactivity of $\mathrm{NO}_{3}$ radicals with organic compounds in comparison to the two other key radicals $\left(\mathrm{OH}, \mathrm{SO}_{4}^{-}\right)$is as follows: $\mathrm{OH}>\mathrm{SO}_{4}^{-} \gg \mathrm{NO}_{3}$ (Herrmann et al., 2015).

In Table S2, we list kinetic parameters for reaction of $\mathrm{NO}_{3}$ with aliphatic organic compounds as presently incorporated in the CAPRAM database (Bräuer et al., 2017). Typical ranges of rate constants (in $\mathrm{M}^{-1} \mathrm{~s}^{-1}$ ) for reactions of $\mathrm{NO}_{3}$ in the aqueous phase are $10^{6}-10^{7}$ for saturated alcohols, carbonyls, and sugars; $10^{4}-10^{6}$ for protonated aliphatic mono- and dicarboxylic acids, with higher values for oxygenated acids; $10^{6}-10^{8}$ for deprotonated aliphatic mono- and dicarboxylic acids (higher values typically for oxygenated acids); $10^{7}-10^{9}$ for unsaturated aliphatic compounds; and $10^{8}-2 \times 10^{9}$ for aromatic compounds (without nitro/acid functionality). The somewhat larger rate constants for deprotonated aliphatic mono- and dicarboxylic acids, unsaturated aliphatic compounds and aromatic compounds is related to the occurrence of electron transfer reactions and addition reaction pathways, which are often faster than $\mathrm{H}$-abstraction reactions.

Many aqueous-phase $\mathrm{NO}_{3}$ reaction rate constants, even for small oxygenated organic compounds, are not available in the literature and have to be estimated. In the absence of SARs for $\mathrm{NO}_{3}$ radical reactions with organic compounds, Evans-Polanyi-type reactivity correlations are used to predict kinetic data for $\mathrm{H}$-abstraction $\mathrm{NO}_{3}$ radical reactions. The latest correlation for $\mathrm{NO}_{3}$ reactions in aqueous solution based on $38 \mathrm{H}$-abstraction reactions of aliphatic alcohols, carbonyl compounds and carboxylic acids was published by Hoffmann et al. (2009):

$\log \left(k_{\mathrm{H}}\right)=(39.9 \pm 5.4)-(0.087 \pm 0.014) \times \mathrm{BDE}$,

where BDE is the bond dissociation energy (in $\mathrm{kJ} \mathrm{mol}^{-1}$ ). The correlation is quite tight, with a correlation coefficient of $R=0.9$.

A direct comparison of the aqueous-phase $\mathrm{OH}$ and $\mathrm{NO}_{3}$ radical rate constants $\left(k_{298} \mathrm{~K}\right)$ of organic compounds from different compound classes is presented in Fig. 4, which shows that the $\mathrm{NO}_{3}$ radical reaction rate constants for many organic compounds are about 2 orders of magnitude smaller than respective $\mathrm{OH}$ rate constants. In contrast, deprotonated dicarboxylic acids can react with $\mathrm{NO}_{3}$ via electron transfer and have similar rate constants for $\mathrm{OH}$ reaction. Rate constants for $\mathrm{OH}$ and $\mathrm{NO}_{3}$ with alcohols and diols/polyols are well correlated ( $R^{2}$ values are given in Table S3), whereas those rate constants for carbonyl compounds and diacids have a lower degree of correlation.

Figure $4 \mathrm{~b}$ shows a comparison of the modeled chemical turnovers of reactions of organic compounds with $\mathrm{OH}$ versus $\mathrm{NO}_{3}$ radicals distinguished for different compound classes. The simulations were performed with the SPACCIM model (Wolke et al., 2005) for the urban summer CAPRAM scenario (see Tilgner et al., 2013 for details) using the master chemical mechanism (MCM) 3.2/CAPRAM 4.0 mechanism (Rickard, 2015; Bräuer et al., 2017) which has in total 862 $\mathrm{NO}_{3}$ radical reactions with organic compounds.

Most of the data lie under the 1:1 line, indicating that, for most of the organic compounds considered, chemical degradation by $\mathrm{OH}$ is more important than by $\mathrm{NO}_{3}$, with a significant fraction of the data lying close to a $10: 1$ line, though $\mathrm{OH}$ fluxes sometimes exceed $\mathrm{NO}_{3}$ fluxes by a factor of $10^{3}-10^{4}$. Approximate relative flux ratios $\left(\mathrm{NO}_{3} / \mathrm{OH}\right)$ for different classes of organic are $10^{-1}-10^{-2}$ for alcohols (including diols and polyols) and carbonyl compounds, $10^{-1}-10^{-4}$ for undissociated monoacids and diacids, $\sim 1$ (or larger) for dissociated monoacids, $10^{-2}->10$ for dissociated diacids, and $10^{-2}-1$ for organic nitrates. For carboxylate ions, $\mathrm{NO}_{3}$-initiated electron transfer is thus the dominant oxidation pathway. As $\mathrm{OH}$-initiated oxidation proceeds via an $\mathrm{H}$-abstraction, high $\mathrm{NO}_{3}-\mathrm{OH}$ flux ratios can be observed for carboxylate ions but not for protonated carboxylic acids.

Overall, Fig. 4b shows that, over a 4-day summer cycle, $\mathrm{NO}_{3}$ radical reactions can compete with $\mathrm{OH}$ radical reactions in particular for protonated carboxylic acids and multifunctional compounds. Nevertheless, aqueous $\mathrm{NO}_{3}$ radical reactions with organics will become more important during winter or at higher latitudes, where photochemistry as the main source of $\mathrm{OH}$ is less important. Finally, it should be noted that $\mathrm{NO}_{3}$ aqueous-phase nighttime chemistry will influence the concentration levels of many aqueous-phase reactants available for reaction during the next day.

\subsection{Instrumental methods}

Atmospheric models of the interaction of $\mathrm{NO}_{3}$ with BVOC rely on experimental data gathered in both the laboratory and the field. These experimental data are used to define model parameters and to evaluate model performance by comparison to observed quantities. Instrumentation for measurements of nitrogen-containing species, oxidants, and organic compounds, including $\mathrm{NO}_{x}, \mathrm{O}_{3}, \mathrm{NO}_{3}, \mathrm{BVOC}$, and oxidized reactive nitrogen compounds, are all important to understand the processes at work. Of particular importance to the subject of this review is the characterization of organic nitrates, 
which are now known to exist in both the gas and particle phases and whose atmospheric chemistry is complex. This section reviews historical and current experimental methods used for elucidating $\mathrm{NO}_{3}$-BVOC atmospheric chemistry.

\subsubsection{Nitrate radical measurements}

Optical absorption spectroscopy has been the primary measurement technique for $\mathrm{NO}_{3}$. It usually makes use of two prominent absorption features of $\mathrm{NO}_{3}$ near 623 and $662 \mathrm{~nm}$. Note that the dissociation limit of the $\mathrm{NO}_{3}$ molecule lies between the two absorption lines (Johnston et al., 1996); thus, illumination by measurement radiation at the longer wavelength band does not lead to photolysis of $\mathrm{NO}_{3}$. The room temperature absorption cross section of $\mathrm{NO}_{3}$ at $662 \mathrm{~nm}$ is $\sim 2 \times 10^{-17} \mathrm{~cm}^{2} \mathrm{molec}^{-1}$ and increases at lower temperature (Yokelson et al., 1994; Osthoff et al., 2007). Thus, at a typical minimum detectable optical density (reduction of the intensity compared to no absorption) and a light-path length of $5 \mathrm{~km}$, a detection limit of $10^{7}$ molec $\mathrm{cm}^{-3}$ or $\sim 0.4 \mathrm{ppt}$ (under standard conditions) is achieved.

Initial measurements of $\mathrm{NO}_{3}$ in the atmosphere were longpath averages using light paths between either the sun or the moon (e.g., Noxon et al., 1978) and the receiving spectrometer (also called passive techniques because natural light sources were used) or between an artificial light source and spectrometer over a distance of several kilometers (active techniques; e.g., Platt et al., 1980). Passive techniques were later extended to yield $\mathrm{NO}_{3}$ vertical profiles (e.g., Weaver et al., 1996). In recent years, resonator cavity techniques allowed construction of very compact instruments capable of performing in situ measurements of $\mathrm{NO}_{3}$ with absorption spectroscopy (see in situ measurement techniques below).

An important distinction between the techniques is whether $\mathrm{NO}_{3}$ can be deliberately or inadvertently removed from the absorption path as part of the observing strategy. Long-path absorption spectroscopy does not allow control over the sample for obtaining a zero background by removing $\mathrm{NO}_{3}$ (Category 1). Resonator techniques (at least as long as the resonator is encased) allow deliberate removal of $\mathrm{NO}_{3}$ from the absorption path as part of the measurement sequence and may also result in inadvertent removal during sampling (Category 2).

For instruments of Category 1, the intensity without absorber $\left(\mathrm{I}_{0}\right)$ cannot be easily detected. Therefore, the information about the absorption due to $\mathrm{NO}_{3}$ (and any other trace gas) has to be determined from the structure of the absorption, which is usually done by using differential optical absorption spectroscopy (DOAS) (Platt and Stutz, 2008), which relies on the characteristic fingerprint of the $\mathrm{NO}_{3}$ absorption structure in a finite wavelength range (about several $10 \mathrm{~nm}$ wide). Thus, a spectrometer of sufficient spectral range and resolution (around $0.5 \mathrm{~nm}$ ) is required.

Instruments of Category 2 can determine the $\mathrm{NO}_{3}$ concentration from the difference (or rather log of the ratio) of the intensity with and without $\mathrm{NO}_{3}$ in the measurement volume. In this case, only an intensity measurement at a single wavelength (typically of a laser) is necessary, and specificity can be achieved through chemical titration with NO (Brown et al., 2001). However, enhanced specificity without chemical titration can be gained by combining resonator techniques with DOAS detection. It should be noted that the advantage of a closed cavity to be able to remove (or manipulate) $\mathrm{NO}_{3}$ comes at the expense of potential wall losses, which have to be characterized. Such instruments have the advantage of being able to also detect $\mathrm{N}_{2} \mathrm{O}_{5}$, which is in thermal equilibrium with $\mathrm{NO}_{3}$ and can be quantitatively converted to $\mathrm{NO}_{3}$ by thermal dissociation (Brown et al., 2001, 2002).

Another complication arises from the presence of water vapor and oxygen lines in the wavelength range of strong $\mathrm{NO}_{3}$ absorptions. To compensate for these potential interferences in open-path measurements (where $\mathrm{NO}_{3}$ cannot easily be removed), daytime measurements are frequently used as reference because $\mathrm{NO}_{3}$ levels are typically very low (but not necessarily negligibly low) (Geyer et al., 2003). Thus, a good fraction of the reported $\mathrm{NO}_{3}$ data (in particular, older data) represents day-night differences.

\section{Passive long-path remote sensing techniques}

Measurements of the $\mathrm{NO}_{3}$ absorption structure using sunlight take advantage of the fact that $\mathrm{NO}_{3}$ is very quickly photolyzed by sunlight (around $5 \mathrm{~s}$ lifetime during the day) allowing for vertically resolved measurements during twilight (e.g., Aliwell and Jones, 1998; Allan et al., 2002; Coe et al., 2002; von Friedeburg et al., 2002). The fact that the $\mathrm{NO}_{3}$ concentration is nearly zero due to rapid photolysis in the directly sunlit atmosphere, while it is largely undisturbed in a shadowed area, can be used to determine $\mathrm{NO}_{3}$ vertical concentration profiles during sunrise using the moon as a light source (Smith and Solomon, 1990; Smith et al., 1993; Weaver et al., 1996). Alternatively, the time series of the $\mathrm{NO}_{3}$ column density derived from scattered sunlight originating from the zenith (or from a viewing direction away from the sun) during sunrise can be evaluated to yield $\mathrm{NO}_{3}$ vertical profiles (Allan et al., 2002; Coe et al., 2002; von Friedeburg et al., 2002).

Nighttime $\mathrm{NO}_{3}$ total column data have been derived by spectroscopy of moonlight and starlight (Naudet et al., 1981), the intensity of which is about 4-5 orders of magnitude lower than that of sunlight. Thus, photolysis of $\mathrm{NO}_{3}$ by moonlight is negligible. A series of moonlight $\mathrm{NO}_{3}$ measurements have been reported (Noxon et al., 1980; Noxon, 1983; Sanders et al., 1987; Solomon et al., 1989, 1993; Aliwell and Jones, 1996a, b; Wagner et al., 2000). These measurements yield total column data of $\mathrm{NO}_{3}$, the sum of tropospheric and stratospheric partial columns. Separation between stratospheric and tropospheric $\mathrm{NO}_{3}$ can be accomplished (to some extent) by the Langley plot method (Noxon et al., 1980), which takes advantage of the different dependence of tropospheric and 
stratospheric $\mathrm{NO}_{3}$ slant column density on the lunar zenith angle.

\section{Active long-path techniques}

A large number of $\mathrm{NO}_{3}$ measurements have been made using the active long-path DOAS technique (Platt et al., 1980, 1981, 1984; Pitts et al., 1984; Heintz et al., 1996; Allan et al., 2000; Martinez et al., 2000; Geyer et al., 2001a, b, 2003; Gölz et al., 2001; Stutz et al., 2002, 2004, 2010; Asaf et al., 2009; McLaren et al., 2010; Crowley et al., 2011; Sobanski et al., 2016). Here, a searchlight-type light source is used to transmit a beam of light across a kilometer-long light path in the open atmosphere to a receiving telescope-spectrometer combination. The light source typically is a broadband thermal radiator (incandescent lamp, Xe arc lamp, laser-driven light source). More recently, LED light sources were also used (Kern et al., 2006). The telescope (around $0.2 \mathrm{~m}$ diameter) collects the radiation and transmits it, usually through an optical fiber, into the spectrometer, which produces the absorption spectrum. Modern instruments now almost exclusively use transmitter/receiver combinations at one end of the light path and retro-reflector arrays (e.g., cat-eye-like optical devices) at the other end. The great advantage of this approach is that power and optical adjustment is only required at one end of the light path while the other end (with the retro-reflector array) is fixed. In this way, several retroreflector arrays, for instance, mounted at different altitudes, can be used sequentially with the same transmitter/receiver unit allowing determination of vertical profiles of $\mathrm{NO}_{3}$ (and other species measurable by DOAS) (Stutz et al., 2002, 2004, 2010).

\section{In situ measurement techniques}

Cavity ring-down spectroscopy (CRDS) and cavityenhanced absorption spectroscopy (CEAS) are related techniques for in situ quantification of atmospheric trace gases such as $\mathrm{NO}_{3}$. These methods are characterized by high sensitivity, specificity, and acquisition speed (Table 3a), and they allow for spatially resolved measurements on mobile platforms.

In CRDS, laser light is "trapped" in a high-finesse stable optical cavity, which usually consists of a pair of highly reflective spherical mirrors in a near-confocal arrangement. The concentrations of the optical absorbers present within the resonator are derived from the Beer-Lambert law and the rate of light leaking from the cavity after the input beam has been switched off (O'Keefe and Deacon, 1988). CRDS instruments are inherently sensitive as they achieve long effective optical absorption paths (up to, or in some cases exceeding, $100 \mathrm{~km}$ ) as the light decay is monitored for several $100 \mu \mathrm{s}$, and the absorption measurement is not affected by laser intensity fluctuations. For detection of $\mathrm{NO}_{3}$ at $662 \mathrm{~nm}$, pulsed laser sources such as Nd:YAG pumped dye lasers have been used because of the relative ease of coupling the laser beam to the optical cavity (Brown et al., 2002, 2003; Dubé et al., 2006). Relatively lower cost continuous-wave (cw) diode laser modules that are easily modulated also have been popular choices (e.g., King et al., 2000; Simpson, 2003; Ayers et al., 2005; Odame-Ankrah and Osthoff, 2011; Wagner et al., 2011).

In a CEAS instrument (also referred to as integrated cavity output spectroscopy, ICOS, or cavity-enhanced DOAS, CEDOAS), the spectrum transmitted through a high-finesse optical cavity is recorded. Mixing ratios of the absorbing gases are derived using spectral retrieval routines similar to those used for open-path DOAS (e.g., O'Keefe, 1998, 1999; Ball et al., 2001; Fiedler et al., 2003; Platt et al., 2009; Schuster et al., 2009).

CRDS and CEAS are, in principle, absolute measurement techniques and do not need to rely on external calibration. In practice, however, chemical losses can occur on the inner walls of the inlet (even when constructed from inert materials such as Teflon) or at the aerosol filters necessary for CRDS instruments. Hence, the inlet transmission efficiencies have to be monitored for measurements to be accurate (Fuchs et al., 2008, 2012; Odame-Ankrah and Osthoff, 2011). On the other hand, a key advantage of in situ instruments over openpath instruments is that the sampled air can be manipulated. Deliberate addition of excess NO to the instrument's inlet titrates $\mathrm{NO}_{3}$ and allows measurement of the instrument's zero level and separation of contributions to optical extinction from other species, such as $\mathrm{NO}_{2}, \mathrm{O}_{3}$, and $\mathrm{H}_{2} \mathrm{O}$. Adding a heated section to the inlet (usually in a second detection channel) enables (parallel) detection of $\mathrm{N}_{2} \mathrm{O}_{5}$ via the increase in the $\mathrm{NO}_{3}$ signal (Brown et al., 2001; Simpson, 2003).

In addition, non-optical techniques have been used to detect and quantify $\mathrm{NO}_{3}$. Chemical ionization mass spectrometry (CIMS) is a powerful method for sensitive, selective, and fast quantification of a variety of atmospheric trace gases (Huey, 2007). $\mathrm{NO}_{3}$ is readily detected after reaction with iodide reagent ion as the nitrate anion at $\mathrm{m} / \mathrm{z} 62$; at this mass, however, there are several known interferences, including dissociative generation from $\mathrm{N}_{2} \mathrm{O}_{5}, \mathrm{HNO}_{3}$, and $\mathrm{HO}_{2} \mathrm{NO}_{2}$ (Slusher et al., 2004; Abida et al., 2011; Wang et al., 2014). There has been more success with the quantification of $\mathrm{N}_{2} \mathrm{O}_{5}$, usually as the iodide cluster ion at $\mathrm{m} / z 235$ (Kercher et al., 2009), though accurate $\mathrm{N}_{2} \mathrm{O}_{5}$ measurement at $m / z 62$ has been reported from recent aircraft measurements with a large $\mathrm{N}_{2} \mathrm{O}_{5}$ signal (Le Breton et al., 2014).

Two groups have used laser-induced fluorescence (LIF) to quantify $\mathrm{NO}_{3}$ (and $\mathrm{N}_{2} \mathrm{O}_{5}$ through thermal dissociation) in ambient air (Wood et al., 2003; Matsumoto et al., 2005a, b). The major drawback of this method is the relatively low fluorescence quantum yield of $\mathrm{NO}_{3}$, and hence the method has not gained wide use.

Another technique that was demonstrated to be capable of measuring $\mathrm{NO}_{3}$ radicals at atmospheric concentration is matrix isolation electron spin resonance (MIESR) (Geyer et al., 
1999). Although the technique allows simultaneous detection of other radicals (including $\mathrm{HO}_{2}$ and $\mathrm{NO}_{2}$ ), it has not been used extensively, probably because of its complexity.

Recently, a variety of in situ $\mathrm{NO}_{3}$ (Dorn et al., 2013) and $\mathrm{N}_{2} \mathrm{O}_{5}$ (Fuchs et al., 2012) measurement techniques were compared at the SAPHIR chamber in Jülich, Germany. All instruments measuring $\mathrm{NO}_{3}$ were optically based (absorption or fluorescence). $\mathrm{N}_{2} \mathrm{O}_{5}$ was detected as $\mathrm{NO}_{3}$ after thermal decomposition in a heated inlet by either CRDS or LIF. Generally, agreement within the accuracy of instruments was found for all techniques detecting $\mathrm{NO}_{3}$ and/or $\mathrm{N}_{2} \mathrm{O}_{5}$ in this comparison exercise. This study showed excellent agreement between the instruments on the single-digit ppt $\mathrm{NO}_{3}$ and $\mathrm{N}_{2} \mathrm{O}_{5}$ levels with no noticeable interference due to $\mathrm{NO}_{2}$ and water vapor for instruments based on cavity ring-down or cavity-enhanced spectroscopy. Because of the low sensitivity of LIF instruments, $\mathrm{N}_{2} \mathrm{O}_{5}$ measurements by these instruments were significantly noisier compared to the measurements by cavity-enhanced methods. The agreement between instruments was less good in experiments with high aerosol mass loadings, specifically for $\mathrm{N}_{2} \mathrm{O}_{5}$, presumably due to enhanced, unaccounted loss of $\mathrm{NO}_{3}$ and $\mathrm{N}_{2} \mathrm{O}_{5}$ demonstrating the need for regular filter changes in closed-cavity instruments. Whereas differences between $\mathrm{N}_{2} \mathrm{O}_{5}$ measurements were less than $20 \%$ in the absence of aerosol, measurements differed up to a factor of 2.5 for the highest aerosol surface concentrations of $5 \times 10^{8} \mathrm{~nm}^{2} \mathrm{~cm}^{-3}$. Also, differences between $\mathrm{NO}_{3}$ measurements showed an increasing trend (up to $50 \%$ ) with increasing aerosol surface concentration for some instruments.

\subsubsection{Gas-phase organic nitrate measurements}

Analytical techniques to detect gaseous organic nitrates have been documented in a recent review by Perring et al. (2013). Sample collection techniques for organic nitrates include preconcentration on solid adsorbents (Atlas and Schauffler, 1991; Schneider and Ballschmiter, 1999; Grossenbacher et al., 2001), cryogenic trapping (Flocke et al., 1991) or collection in stainless steel canisters (Flocke et al., 1998; Blake et al., 1999), or direct sampling (Day et al., 2002; Beaver et al., 2012).

The approaches to the analysis of the organic nitrates fall into three broad categories. First, one or more chemically speciated organic nitrates are measured by a variety of techniques including liquid chromatography (LC) (Kastler et al., 2000) or gas chromatography (GC) with electron capture detection (Fischer et al., 2000), GC with electron impact or negative-ion chemical ionization mass spectrometry (GC-MS) (Atlas, 1988; Luxenhofer et al., 1996; Blake et al., 1999, 2003a, b; Worton et al., 2008), GC followed by conversion to $\mathrm{NO}$ and chemiluminescent detection (Flocke et al., 1991, 1998), GC followed by photoionization mass spectrometry (Takagi et al., 1981), GC followed by conversion of organic nitrates to $\mathrm{NO}_{2}$ and luminol chemilumines- cent detection (Hao et al., 1994), CIMS (Beaver et al., 2012; Paulot et al., 2012), and proton transfer reaction MS (PTRMS) (Perring et al., 2009). Second, the sum of all organic nitrates can be measured directly by thermal dissociation to $\mathrm{NO}_{2}$, which is subsequently measured by LIF (TD-LIF) (Day et al., 2002), CRDS (TD-CRDS) (Paul et al., 2009; Thieser et al., 2016), or cavity-attenuated phase shift spectroscopy (TD-CAPS) (Sadanaga et al., 2016). Finally, the sum of all organic nitrates can be measured indirectly as the difference between all reactive $\mathrm{NO}_{x}$ except for organic nitrates and total oxidized nitrogen $\left(\mathrm{NO}_{y}\right)$ (Parrish et al., 1993).

Recent advances in adduct ionization utilize detection of the charged cluster of the parent reagent ion with the compound of interest. This scheme is then coupled to highresolution time-of-flight (HR-ToF) mass spectrometry. The combination of these methods allows the identification of molecular composition due to the soft ionization approach that minimizes fragmentation. Multifunctional organic nitrates resulting from the oxidation of BVOC have been detected using $\mathrm{CF}_{3} \mathrm{O}^{-}$(Bates et al., 2014; Nguyen et al., 2015; Schwantes et al., 2015; Teng et al., 2015) and iodide as reagent ions (Lee et al., 2014a, 2016; Xiong et al., 2015, 2016; Nah et al., 2016b).

\subsubsection{Online analysis of particulate matter}

Total (organic plus inorganic) mass of particulate nitrates is routinely quantified using online AMS (Jayne et al., 2000; Allan et al., 2004), from which the mass of organic nitrates can be obtained by three techniques. First, the $\mathrm{NO}^{+} / \mathrm{NO}_{2}^{+}$ ratio (or $\mathrm{NO}_{2}^{+} / \mathrm{NO}^{+}$ratio) in the mass spectra is used to distinguish organic from inorganic nitrates (Fry et al., 2009, 2013; Farmer et al., 2010; Xu et al., 2015b; Kiendler-Scharr et al., 2016). It is noted that the $\mathrm{NO}_{2}^{+} / \mathrm{NO}^{+}$approaches zero in the case of low or nonexistent $\mathrm{NO}_{2}^{+}$signal, while $\mathrm{NO}^{+} / \mathrm{NO}_{2}^{+}$gives large numbers. Second, positive matrix factorization (PMF) of data matrices including the $\mathrm{NO}^{+}$and $\mathrm{NO}_{2}^{+}$ions in addition to organic ions (Sun et al., 2012; Hao et al., 2014; Xu et al., 2015b) is used. Third, the particulate inorganic nitrate concentration, as measured by an independent method such as ion chromatography, is subtracted from the total particulate nitrate concentration (Schlag et al., 2016; Xu et al., 2015a, b). A detailed comparison of these three methods is presented in Xu et al. (2015b). As the $\mathrm{NO}^{+} / \mathrm{NO}_{2}^{+}$ratio in AMS data is dependent on instruments and the types of nitrates (inorganic and organic nitrates from different VOC oxidations), different strategies were developed when using this method to estimate particulate organic nitrates (Fry et al., 2013; Xu et al., 2015b).

A specialized inlet that selectively scrubs gaseous organic nitrates or collects particulate mass on a filter has been coupled to some of the techniques summarized in this section and utilized to observe particulate organic nitrates in the ambient atmosphere and laboratory studies. A TD-LIF equipped with a gas-scrubbing denuder (Rollins et al., 2010, 2012) and 
Table 3. (a) Selected CRDS and CEAS instruments used to quantify $\mathrm{NO}_{3}$ mixing ratios in ambient air. (b) Selected instruments used to quantify $\mathrm{NO}_{3}$ and $\mathrm{N}_{2} \mathrm{O}_{5}$ mixing ratios in ambient air other than by cavity-enhanced absorption spectroscopy.

\begin{tabular}{|c|c|c|}
\hline $\begin{array}{l}\text { Principle of measurement } \\
\text { (laser pulse rate) }\end{array}$ & $\begin{array}{l}\text { LOD or precision } \\
\text { (integration time) }\end{array}$ & Reference \\
\hline BB-CEAS & $2.5 \mathrm{pptv}(8.6 \mathrm{~min})$ & Ball et al. (2004) \\
\hline BB-CRDS & 1 pptv (100s) & Bitter et al. (2005) \\
\hline Off-axis cw CRDS (500 Hz) & $2 \operatorname{pptv}(5 \mathrm{~s})$ & Ayers and Simpson (2006) \\
\hline On-axis pDL-CRDS $(33 \mathrm{~Hz})$ & $<1$ pptv $(1 \mathrm{~s})$ & Dubé et al. (2006) \\
\hline BB-CEAS & 4 pptv $(60 s)$ & Venables et al. (2006) \\
\hline pDL-CRDS $(10 \mathrm{~Hz})$ & $2.2 \mathrm{pptv}(100 \mathrm{~s})$ & Nakayama et al. (2008) \\
\hline Off-axis cw CRDS $(200 \mathrm{~Hz})$ & $2 \operatorname{pptv}(5 \mathrm{~s})$ & Schuster et al. (2009), Crowley et al. (2010) \\
\hline CE-DOAS & 6.3 pptv $(300 \mathrm{~s})$ & Platt et al. (2009), Meinen et al. (2010) \\
\hline BB-CEAS & 2 pptv (15s) & Langridge et al. (2008), Benton et al. (2010) \\
\hline BB-CEAS & $<2$ pptv $(1 \mathrm{~s})$ & Kennedy et al. (2011) \\
\hline On-axis cw-CRDS $(500 \mathrm{~Hz})$ & $<1$ pptv (1 s) & Wagner et al. (2011) \\
\hline On-axis cw-CRDS $(300 \mathrm{~Hz})$ & 8 pptv $(10 \mathrm{~s})$ & Odame-Ankrah and Osthoff (2011) \\
\hline BB-CEAS & 1 pptv $(1 \mathrm{~s})$ & Le Breton et al. (2014) \\
\hline BB-CEAS & $7.9 \operatorname{pptv}(60 \mathrm{~s})$ & Wu et al. (2014) \\
\hline
\end{tabular}

(b)

\begin{tabular}{|c|c|c|c|}
\hline $\begin{array}{l}\text { Principle of } \\
\text { measurement }\end{array}$ & $\begin{array}{l}\text { LOD or precision } \\
\text { (integration time) }\end{array}$ & $\begin{array}{l}\text { Species } \\
\text { detected }\end{array}$ & Reference \\
\hline MIESR & $<2 \operatorname{pptv}(30 \mathrm{~min})$ & $\mathrm{NO}_{3}$ & Geyer et al. (1999) \\
\hline CIMS & 12 pptv (1s) & $\mathrm{NO}_{3}+\mathrm{N}_{2} \mathrm{O}_{5}$ & Slusher et al. (2004) \\
\hline LIF & 11 pptv $(10 \mathrm{~min})$ & $\mathrm{NO}_{3}$ & $\begin{array}{l}\text { Matsumoto et al. (2005a), } \\
\text { Matsumoto et al. (2005b) }\end{array}$ \\
\hline LIF & 28 pptv (10 min) & $\mathrm{NO}_{3}$ & Wood et al. (2005) \\
\hline CIMS & $30 \mathrm{pptv}(30 \mathrm{~s})$ & $\mathrm{N}_{2} \mathrm{O}_{5}$ & Zheng et al. (2008) \\
\hline CIMS & 5 pptv $(1 \mathrm{~min})$ & $\mathrm{N}_{2} \mathrm{O}_{5}$ & Kercher et al. (2009) \\
\hline CIMS & $7.4 \mathrm{pptv}(1 \mathrm{~s})$ & $\mathrm{N}_{2} \mathrm{O}_{5}$ & Le Breton et al. (2014) \\
\hline CIMS & 39 pptv (6s) & $\mathrm{N}_{2} \mathrm{O}_{5}$ & Wang et al. (2014) \\
\hline
\end{tabular}

CEAS = cavity-enhanced absorption spectroscopy; CRDS = cavity ring-down spectroscopy;

$\mathrm{BB}=$ broadband; $\mathrm{pDL}=$ pulsed dye laser; $\mathrm{CE}-\mathrm{DOAS}=$ cavity-enhanced differential optical absorption spectroscopy; $\mathrm{cw}=$ continuous-wave diode laser. MIESR = matrix isolation electron spin resonance; $\mathrm{CIMS}=$ chemical ionization mass spectrometry; $\mathrm{LIF}=$ laser-induced fluorescence; $\mathrm{LOD}=$ limit of detection.

the filter inlet for gases and aerosols (FIGAERO) (LopezHilfiker et al., 2014) at the front end of an iodide adduct HRToF-CIMS are examples (Lee et al., 2016; Nah et al., 2016b).

\subsubsection{Offline analysis of particulate matter}

Owing to its ability to analyze polar organic compounds without a prior derivatization step, liquid chromatography coupled to MS (HPLC/MS) is well suited for the characterization of SOA compounds originating from the reactions of BVOC and $\mathrm{NO}_{3}$. Unlike in GC/MS methods, a soft ionization technique such as electrospray ionization (ESI) is utilized to ionize target analytes in the LC/MS technique. In the ESI/MS, target analytes are detected as a cation adduct of a target analyte (e.g., $[M+\mathrm{H}]^{+}$or $\left.[M+\mathrm{Na}]^{+}\right)$for a positive mode or a deprotonated form of a target analyte $\left([M-\mathrm{H}]^{-}\right)$ for a negative mode. As a biogenic SOA compound typically bears a functional group, such as a carboxylic group or a sulfate group, that easily loses a proton, the negative-mode ESI $((-) \mathrm{ESI})$ is commonly applied to detect SOA compounds. High-resolution MS such as TOF or Fourier transform ion cyclotron (FTICR) MS is commonly used to assign chemical formulas for SOA compounds unambiguously.

The LC/(-)ESI-MS technique played a crucial role in relating the formation of organosulfates (OS) and nitrooxyorganosulfates (NOS) to $\mathrm{NO}_{3}$-initiated oxidation of BVOC in laboratory-generated and ambient SOA. Since these earlier works, a number of studies have reported the presence of OS and/or NOS compounds in ambient samples (Table S4), though most studies do not connect these compounds explicitly to the $\mathrm{NO}_{3}$ oxidation of BVOC. It should be noted that the direct infusion (-)ESI-MS technique rather than LC/(-)ESI-MS is often used for the analysis of fog, rainwater, and cloud water samples as diluted liquid water samples 
can be injected into the ion source directly without a sample pretreatment procedure. However, caution is warranted for the direct infusion technique because it cannot separate isobaric isomers and it is susceptible to ion suppression, especially from the presence of inorganic ions in the samples.

Whilst the LC or direct infusion (-)ESI-MS techniques have been successfully applied for the detection of the oxidation products from $\mathrm{NO}_{3}-\mathrm{BVOC}$ reactions, the techniques have been less successful in quantifying these compounds, mainly due to the lack of authentic standard compounds. The synthesis of these compounds should be a priority for future studies.

Finally, total organic nitrate functional groups within the particle phase have been quantified in ambient air using FTIR of particles collected on $\mathrm{ZnSe}$ impaction disks (low-pressure cascade impactor, size segregated) or Teflon filters $\left(\mathrm{PM}_{1}\right)$ (Mylonas et al., 1991; Garnes and Allen, 2002; Day et al., 2010). The organic nitrate content of particles can be quantified offline as well by collection on quartz fiber filters, extraction into solution (e.g., with water-acetonitrile mixtures), and analysis using standard wet chemistry techniques such as high-pressure liquid chromatography coupled to electrospray ionization mass spectrometry (HPLC-ESI-MS) (Angove et al., 2006; Perraud et al., 2010; Draper et al., 2015).

\subsection{Field observations}

This section surveys the current literature on field observations of nitrate radicals and BVOC (Sect. 2.5.1), and organic nitrate aerosol attributable to $\mathrm{NO}_{3}$-BVOC chemistry (Sect. 2.5.2).

\subsubsection{Nitrate radicals and BVOC}

A few years after the first measurement of tropospheric $\mathrm{NO}_{3}$ (Noxon et al., 1980; Platt et al., 1980), it was recognized that the nitrate radical is a significant sink for BVOC, especially monoterpenes in terrestrial ecosystems and dimethyl sulfide (DMS) in maritime air influenced by continental $\mathrm{NO}_{x}$ sources (Winer et al., 1984). The conclusion was based upon computer simulations using $\mathrm{NO}_{3}$ concentrations measured in field studies in the western US and Europe, and measured rate constants of $\mathrm{NO}_{3}$ with olefins. The scenarios in these simulations showed very low monoterpene concentrations in the early morning that were directly attributable to BVOC reactions with $\mathrm{NO}_{3}$. An analysis of $\mathrm{NO}_{3}$ formation rates at several urban and rural sites in Scandinavia (Ljungström and Hallquist, 1996) resulted in the conclusion that while nighttime urban loss of $\mathrm{NO}_{3}$ is dominated by reaction with $\mathrm{NO}$, the loss in rural regions is likely dominated by reactive hydrocarbons, especially monoterpenes.

Due to the fast reactions of $\mathrm{NO}_{3}$ with $\mathrm{BVOC}$, lifetimes of $\mathrm{NO}_{3}$ in biogenically influenced environments can be very short, making simultaneous detection of $\mathrm{VOC}$ and $\mathrm{NO}_{3}$ in biogenic regions very difficult. For this reason, several stud- ies have inferred levels of $\mathrm{NO}_{3}$ and its role in processing BVOC using observational analysis and supporting modeling. In particular, the rapid decay of isoprene after sunset has received considerable attention. Measurements of BVOC $\sim 1-2 \mathrm{~m}$ above canopy level in a loblolly pine plantation in Alabama during the 1990 ROSE program (Goldan et al., 1995) were used to infer a nighttime $\mathrm{NO}_{3}$ mixing ratio of only $0.2 \mathrm{ppt}$ and $\mathrm{NO}_{3}$ lifetime of only $7 \mathrm{~s}$ due to high levels of monoterpenes. The $4 \mathrm{~h}$ decay time of isoprene after sunset could not be accounted for by gas reactions with $\mathrm{NO}_{3}$ and $\mathrm{O}_{3}$ although the decrease in the $\alpha-/ \beta$-pinene ratio at night was consistent with known $\mathrm{NO}_{3}$ and $\mathrm{O}_{3}$ chemistry. As part of the North American Research Strategy for Tropospheric Ozone - Canada East (NARSTO-CE) campaign, measurements of BVOC were made in Nova Scotia in a heavily forested region (Biesenthal et al., 1998). A box-model simulation based on the observational analysis found that the short lifetime of isoprene at night $(\tau=1-3 \mathrm{~h})$ could not be explained by the $\mathrm{NO}_{3}$ radical, which was estimated to be 0.1 ppt maximum at night due to low $\mathrm{NO}_{x}$ and $\mathrm{O}_{3}$ levels and high monoterpene emissions. When $\mathrm{OH}$ yields from ozonolysis of BVOC were included in the model, this nighttime $\mathrm{OH}$ oxidant could partially account for the isoprene decay. During the Southern Oxidants Study (SOS) campaign in Nashville, TN (Starn et al., 1998), a chemical box model was used to show that rapid nighttime decays of isoprene were consistent with simulated $\mathrm{NO}_{3}$ but only when the site was impacted by urban $\mathrm{NO}_{x}$ emissions. During the PROPHET study, measurements of VOC were made in a mixed forest approximately $10 \mathrm{~m}$ above the canopy surface (Hurst et al., 2001). Isoprene decays at night had an average lifetime of $\sim 2.7 \mathrm{~h}$. Box modeling showed that $\mathrm{O}_{3}$ reactions as well as dry deposition were insufficient to account for the decay, and that the $\mathrm{NO}_{3}$ radical was a significant sink only after the majority of isoprene had already decayed. On some nights, oxidation by $\mathrm{OH}$ could account for all the decay but the decay rates were overpredicted. The authors concluded that vertical transport of isoprene-depleted air aloft contributes to the fast initial decay of isoprene, followed by nighttime $\mathrm{OH}$, $\mathrm{NO}_{3}$, and $\mathrm{O}_{3}$ chemistry decay. Steinbacher et al. (2005) reported on surface measurements in the Po Valley at a site 200-300 $\mathrm{m}$ from the closest edge of a deciduous forest. Bimodal diurnal cycles of isoprene were observed with morning and evening maxima that were reproduced by a Eulerian model. Isoprene decay lifetimes of $1-3 \mathrm{~h}$ were partially explained by $\mathrm{NO}_{3}$ decay, although a dynamic influence on isoprene decrease seemed to be likely including horizontal and vertical dispersion. During the HOHenpeissenberg Photochemistry Experiment (HOHPEX) field campaign, BVOC were analyzed via 2-D GC at a site located on a hilltop above adjacent rural agricultural/forested area that is frequently in the residual layer at night (Bartenbach et al., 2007). For the reactive monoterpenes, a significant non-zero dependency of the concentration variability on lifetime was found, indicating that chemistry (as well as transport) was playing a role 
in determining the ambient VOC concentrations. The nighttime analysis gave an estimate of the $\mathrm{NO}_{3}$ mixing ratio of $6.2 \pm 4.2 \mathrm{ppt}$, indicating it was a significant chemical factor in depletion of monoterpenes.

While the studies above made indirect conclusions about the role of $\mathrm{NO}_{3}$ in BVOC processing, field studies including direct measurements of $\mathrm{NO}_{3}$ are key to confirming the above findings. Golz et al. (2001) reported measurements of $\mathrm{NO}_{3}$ by long-path DOAS at an eucalyptus forest site in Portugal during the FIELDVOC94 campaign in 1994. The DOAS beam passed directly over the canopy at heights of 15 and $25 \mathrm{~m}$, and as a result, they were unable to measure $\mathrm{NO}_{3}$ above the $6 \mathrm{ppt}$ instrumental detection limit despite $\mathrm{NO}_{3}$ production rates of $0.4 \mathrm{ppt} \mathrm{s}^{-1}$. Rapid reaction with BVOC limited the $\mathrm{NO}_{3}$ lifetime to approximately $20 \mathrm{~s}$ such that $\mathrm{NO}_{3}$ reactions dominated other indirect losses, such as heterogeneous $\mathrm{N}_{2} \mathrm{O}_{5}$ uptake. Simultaneous measurements of $\mathrm{NO}_{3}$ and VOC during the Berliner Ozonexperiment (BERLIOZ) campaign in 1998 allowed one of the first assessments of the $\mathrm{NO}_{3}$ budget in comparison to $\mathrm{OH}$ and $\mathrm{O}_{3}$ oxidants (Geyer et al., 2001b). Surface measurements at this semi-rural location close to forests found the $\mathrm{NO}_{3}$ radical above detection limit (2.4 ppt) on 15 of 19 nights with a maximum of $70 \mathrm{ppt}$, a steady-state lifetime ranging from 20 to $540 \mathrm{~s}$ and $\mathrm{N}_{2} \mathrm{O}_{5}$ ranging from 2 to 900 ppt. The two most significant losses of $\mathrm{NO}_{3}$ were found to be its direct reaction with olefins (monoterpenes dominating) and indirect loss due to heterogeneous hydrolysis of $\mathrm{N}_{2} \mathrm{O}_{5}$. Over the study, it was possible for the first time to quantify the relative contribution of the $\mathrm{NO}_{3}$ radical to oxidation of $\mathrm{VOC}$ as $28(24 \mathrm{~h})$ and $31 \%$ for olefinic VOC $(24 \mathrm{~h})$ compared to the total oxidation via $\mathrm{NO}_{3}, \mathrm{OH}$, and $\mathrm{O}_{3}$. As part of the 1999 SOS study, $\mathrm{NO}_{3}$, isoprene, and its oxidation products were measured at a suburban forested site in Nashville, TN (Stroud et al., 2002). The nitrate radical measured at multiple beam heights by DOAS had maximum mixing ratios of $100 \mathrm{ppt}$ that were generally found to anticorrelate with isoprene levels with significant vertical gradients on some nights. Early evening losses of isoprene were attributable to reaction with the $\mathrm{NO}_{3}$ radical. During the Pacific 2001 Air Quality Study (PACIFIC 2001) field campaign, $\mathrm{NO}_{3}$ was measured by long-path DOAS at an elevated forested site in the lower Fraser Valley of British Columbia with beam-path nighttime $\mathrm{NO}_{3}$ levels up to a maximum of $50 \mathrm{ppt}$ (average of nighttime boundary layer and residual layer) (McLaren et al., 2004). Simultaneous analysis of carbonyl compounds in aerosol samples (Liggio and Mclaren, 2003) during the study found that only monoterpene oxidation products pinonaldehyde and nopinone (not reported) were enhanced in aerosol filters collected at night, evidence of the role of $\mathrm{NO}_{3}$ in nighttime oxidation of BVOC in the valley. In 2004 measurements of $\mathrm{NO}_{3}$ and $\mathrm{N}_{2} \mathrm{O}_{5}$ by CRDS, isoprene and its oxidation products were made on board the NOAA P-3 aircraft as part of the New England Air Quality Study (NEAQS) and International Consortium for Atmospheric Research on Transport and Transforma- tion (ICARTT) campaigns in the northeast US (Brown et al., 2009). These studies found a very clear anticorrelation between isoprene levels after dark and $\mathrm{NO}_{3}$ mixing ratios, which varied as high as 350 ppt when isoprene was absent from the air mass. The loss frequencies (i.e., first-order loss rate constants) of $\mathrm{NO}_{3}$ were strongly correlated with the loss rate constant of $\mathrm{NO}_{3}$ with isoprene for lifetimes less than $20 \mathrm{~min}$, clearly showing that isoprene was the most important factor determining the lifetime of $\mathrm{NO}_{3}$. It was also shown that more than $20 \%$ of emitted isoprene was oxidized at night and that $1-17 \%$ of SOA was contributed by $\mathrm{NO}_{3}$-isoprene oxidation. A number of recent studies have also investigated the role of $\mathrm{NO}_{3}+\mathrm{BVOC}$ chemistry in more polluted areas. In many urban areas, the $\mathrm{NO}_{3}+\mathrm{BVOC}$ chemistry occurs in parallel to heterogeneous $\mathrm{NO}_{3} / \mathrm{N}_{2} \mathrm{O}_{5}$ chemistry and reactions of $\mathrm{NO}_{3}$ with anthropogenic VOC. Examples of such environments have been discussed in Brown et al. (2011, 2013) and Stutz et al. (2010) who presented observations in Houston, TX. Brown et al. (2011) and Stutz et al. (2010) found that up to $50 \%$ of the $\mathrm{NO}_{3}+\mathrm{VOC}$ reactions in Houston are driven by isoprene, with the other VOC emitted by industrial sources. Surprisingly, heterogeneous $\mathrm{NO}_{3} / \mathrm{N}_{2} \mathrm{O}_{5}$ chemistry plays a minor role in Houston. Brown et al. (2011) also point out that the nocturnal VOC oxidation by $\mathrm{NO}_{3}$ dominates over that by ozone. Nocturnal $\mathrm{NO}_{3}$ formation rates were rapid and comparable to those of $\mathrm{OH}$ during the day. Crowley et al. (2011) compared $\mathrm{NO}_{3}$ chemistry in air masses of marine, continental, and urban origin at a field site in southern Spain. Under all conditions, $\mathrm{NO}_{3}+\mathrm{BVOC}$ reactions (predominately $\alpha$-pinene and limonene) contributed to the overall $\mathrm{NO}_{3}$ reactivity, confirming other observations that concluded that this chemistry is important in all environments where BVOC sources are present. In the southeastern US summer, this importance extends even through the daytime, when photolysis and NO reactions compete (Ayres et al., 2015). The $\mathrm{NO}_{3}+\mathrm{BVOC}$ reaction rates observed in these studies imply a high production rate of SOA and organic peroxy radicals.

\subsubsection{Organic nitrate aerosols}

There are many factors that motivate understanding organic nitrate in the particulate phase through field deployment of a variety of instrumentation, much of which is described in other sections of this review. Nitrogen-containing organic fragments (not necessarily organic nitrates) have been identified in atmospheric particles using mass spectrometric techniques (Reemtsma et al., 2006; Farmer et al., 2010; O'Brien et al., 2014). Total atmospheric organic nitrates, as well as organic nitrates segregated by phase, also have been measured in the atmosphere using techniques such as TD-LIF, CIMS, etc. (Day et al., 2003; Beaver et al., 2012). Given these observations and the propensity of organic nitrate compounds to partition to the condensed phase to create SOA (Rollins et al., 2013), it is critical to determine the level of organic nitrates that reside specifically in the atmospheric aerosol phase 
under typical ambient conditions and to identify the chemical and physical processes that determine their concentrations. It is also important to note that formation of SOA that contains organic nitrate groups has the potential to sequester $\mathrm{NO}_{x}$, thereby influencing the cycling of atmospheric oxidants.

Organic nitrates in urban PM that were identified using functional group analyses such as FTIR spectroscopy have been attributed to emission of nitrogen-containing primary organic aerosol or to involvement of reactive nitrogen compounds in SOA formation chemistry (Mylonas et al., 1991; Garnes and Allen, 2002; Day et al., 2010). Other more advanced techniques, such as TD-LIF enhanced with the ability to separate phases or techniques to obtain high-resolution mass spectra (HR-ToF-AMS), have been utilized to quantify the amount of organic nitrate in particles in areas less likely to be influenced strongly by BVOC emissions, such as urban areas or areas influenced by oil and gas operations (Lee et al., 2015). Of specific interest here, however, are observations of organic nitrate PM in areas with a significant influence of BVOC, especially if co-located measurements allow for insight into the role that $\mathrm{NO}_{3}$ plays in the initial BVOC oxidation step. As such, we focus here on online measurements and on measurements that allow specific attribution to BVOC- $\mathrm{NO}_{3}$ reactions. Such measurements broadly can be categorized by region of sampling: the eastern United States (US), the western US, and Europe. Figure 5a summarizes average mass concentrations of submicrometer particulate organic nitrates $\left(\mathrm{NO}_{3}\right.$, org $)$ and particulate inorganic nitrates $\left(\mathrm{NO}_{3}\right.$, inorg $)$ in different months at multiple sites around the world. Figure $5 \mathrm{~b}$ summarizes the corresponding percentage (by mass) of submicrometer particulate organic nitrate aerosols in ambient organic aerosols. Detailed information and measurements for each site are provided in Table S5.

\section{Eastern United States}

The first reports of aerosol organic nitrates in the southeastern (SE) US resulted from composition analysis of four daily PM filter samples from four Southeastern Aerosol Research and Characterization (SEARCH) network sites during summer 2004. Filters were analyzed for polar compounds, with particular focus on organosulfates, using offline chromatographic-MS methods (Gao et al., 2006; Surratt et al., 2007, 2008). Several nitrooxy organosulfates were identified, but the only one quantified (1-2\% of organic mass) was associated with $\alpha$-pinene photooxidation or reaction with $\mathrm{NO}_{3}$. Several of the nitrooxy organosulfates were likely the same as products from BVOC-oxidant- $\mathrm{NO}_{x}$-seed systems based on comparison to spectra collected from chamber studies.

Brown et al. (2013) examined several nighttime aircraft vertical profiles in Houston (October 2006 during the Texas Air Quality Study 2006) that showed increases of total nitrate aerosol (and increases in AMS $m / z, 30$ to $m / z 46$ ratio, the unit mass resolution approximation for $\mathrm{NO}^{+} / \mathrm{NO}_{2}^{+}$, indicative of organic nitrates; Farmer et al., 2010) and oxygenated organic aerosol (OOA). The OA versus carbon monoxide (CO) slopes at lower altitudes were consistent with SOA sources from $\mathrm{NO}_{3}$-BVOC reactions, with a combination of observations and zero-dimensional modeling showing 1 to $2 \mu \mathrm{g} \mathrm{m}^{-3} \mathrm{SOA}$ formation from $\mathrm{NO}_{3}$-BVOC oxidation overnight with formation rates of 0.05 to $1 \mu \mathrm{g} \mathrm{m}^{-3} \mathrm{~h}^{-1}$.

More recently, during the summer Southern Oxidant and Aerosol Study (SOAS; mixed, semi-polluted forest) in Alabama (2013), an unprecedented suite of instruments quantified particle-phase organic nitrates using five different online methods: HR-ToF-AMS $\left(\mathrm{NO}^{+} / \mathrm{NO}_{2}^{+}\right)$, HR-ToF-AMS - PiLS (particle-into-liquid sampler) ion chromatography (PiLS-IC), HR-ToF-AMS (PMF), TD-LIF (denuded), and iodide CIMS. Total particle-phase nitrates increased throughout the night and peaked in early/mid-morning. $\mathrm{Xu}$ et al. (2015b) systematically evaluated the three AMS-related methods in estimating ambient particulate organic nitrate concentrations. Analysis presented in Xu et al. (2015a, b) using the HR-ToF-AMS - PiLS-IC method showed that organic nitrate functional groups comprised $\sim 5-12 \%$ of OA mass and correlated with PMF-derived less-oxidized oxygenated OA (LO-OOA). Two-thirds of the LO-OOA was estimated to be formed via $\mathrm{NO}_{3}$-BVOC chemistry (dominantly monoterpenes, $\sim 80 \%$ ), with the balance due to ozone $\left(\mathrm{O}_{3}\right)$ BVOC chemistry. Organic nitrates were calculated to comprise $20-30 \%$ of the LO-OOA factor. Ayres et al. (2015) used a measurement-constrained model for nighttime that compared $\mathrm{NO}_{3}$ production/loss to total organic nitrate (HRToF-AMS $\mathrm{NO}^{+} / \mathrm{NO}_{2}^{+}$, TD-LIF) formation to calculate a molar yield of aerosol-phase organic nitrates of 23-44\% (organic nitrate formed per $\mathrm{NO}_{3}-\mathrm{BVOC}$ reaction) that was dominated by monoterpene oxidation. They noted that the estimated yield was low compared to aggregated aerosolphase organic nitrate yields, possibly due to rapid nitrate losses not considered in the model. Organic nitrate hydrolysis in the particle phase is one potential loss pathway, although recent laboratory studies suggest this process is slow for $\mathrm{NO}_{3}+\beta$-pinene SOA (Boyd et al., 2015). Also, particlephase organic nitrates were observed to contribute $30-45 \%$ to the total $\mathrm{NO}_{y}$ budget. Lee et al. (2016) quantified speciated particle-phase organic nitrates using iodide CIMS (88 individual $\mathrm{C}_{4}-\mathrm{C}_{17}$ mono/dinitrates). A large fraction was highly functionalized, with six to eight oxygen atoms per molecule. Diurnal cycles of isoprene-derived organic nitrates generally peaked during daytime, and monoterpene-derived organic nitrates peaked at night or during early/mid-morning. Using an observationally constrained diurnal zero-dimensional model, they showed that the observations were consistent with fast gas-particle equilibrium and a short particle-phase lifetime ( $2-4 \mathrm{~h}$ ), again possibly due to hydrolysis if the field-derived lifetimes for particle-phase organic nitrates can be reconciled with recent laboratory studies (Boyd et al., 2015). The sum of the CIMS particle-phase organic nitrates (mass of nitrate functional groups only) was correlated with the two to- 
(a)

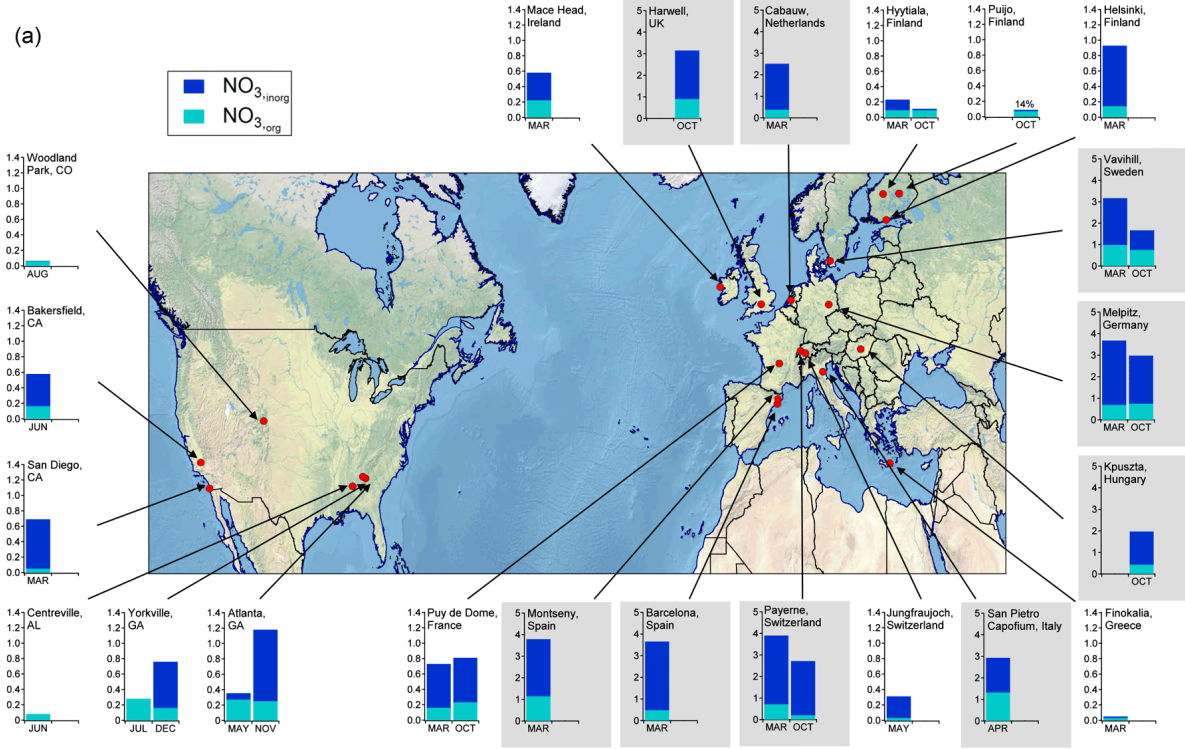

(b)

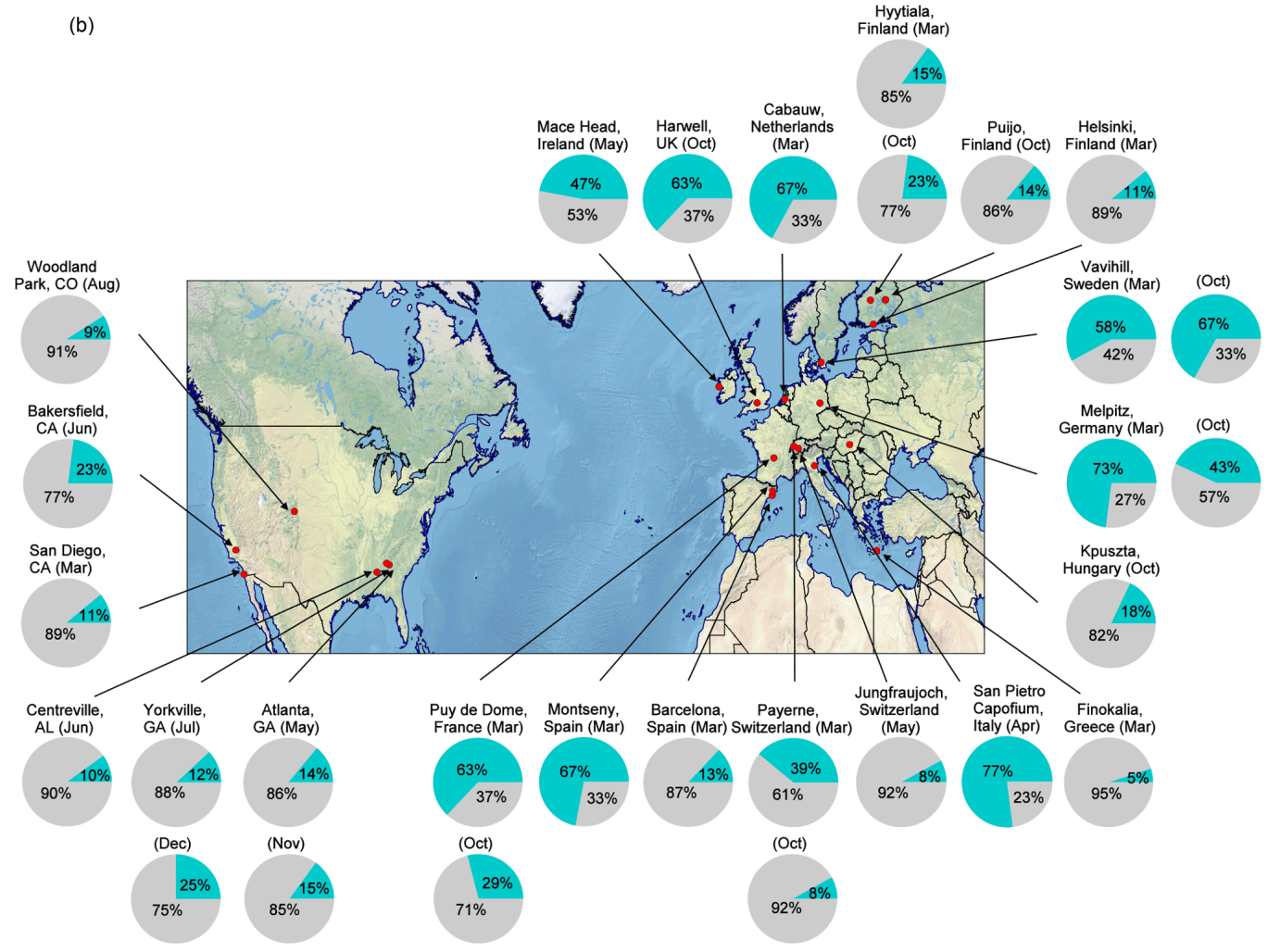

Figure 5. (a) Average mass concentrations (in $\mu \mathrm{g} \mathrm{m}^{-3}$, ambient temperature and pressure) of submicrometer particulate organic nitrates $\left(\mathrm{NO}_{3}\right.$, org $)$ and particulate inorganic nitrates $\left(\mathrm{NO}_{3}\right.$, inorg $)$ in different months at multiple sites. The concentrations correspond to mass concentrations of $-\mathrm{ONO}_{2}$ functionality. Note that the $y$ axis is different for sites with total nitrates greater than $1 \mu \mathrm{g} \mathrm{m}{ }^{-3}$ (shaded). Detailed information and measurements for each site are provided in Table S5. (b) Percentage (by mass; cyan) of submicrometer particulate organic nitrate aerosols in ambient organic aerosols in different months at multiple sites. Detailed information and measurements for each site are provided in Table S5. 
tal aerosol organic nitrate AMS-based methods $\left(R^{2}=0.52\right.$, 0.67 ) with slopes of 0.63 and 0.90 (Lee et al., 2016). The CIMS sum was also correlated with the total measured with the TD-LIF method $\left(R^{2}=0.55\right)$; however, since the TD-LIF measurements were $\sim 2-4$ times higher (depending on period) than the AMS-based methods, the CIMS versus TDLIF slope was substantially lower (0.19). Reasons for the differences between the total organic nitrate measured by different methods have been investigated but remain unclear.

A seasonal and regional survey of particle-phase organic nitrates is reported by Xu et al. (2015b) using a HR-ToFAMS and an aerosol chemical speciation monitor (ACSM) (Ng et al., 2011) at four rural and urban sites in the greater Atlanta area (2012-2013) and in Centreville, AL (summer 2013 only, SOAS). They show strong diurnal cycles during summer, peaking early/mid-morning, and cycles with similar timing but smaller magnitude during winter. The concentrations were slightly higher in summer, which was attributed to compensating effects of source strength and gas-particle partitioning. Shallower boundary layers during winter also may have played a role in making the summer and winter concentrations more similar (Kim et al., 2015).

Fisher et al. (2016) report a broad regional survey of particle-phase (and gas-phase) organic nitrates (HR-ToFAMS $\mathrm{NO}^{+} / \mathrm{NO}_{2}^{+}$) during summertime for the Studies of Emissions and Atmospheric Composition, Clouds and Climate Coupling by Regional Surveys (SEAC4RS) aircraft campaign (August-September, 2013, SE US only) as well as the ground-based SOAS measurements. A substantial vertical gradient was observed in particle-phase organic nitrates, with concentrations decreasing by several-fold from the boundary/residual layer into the free troposphere. Consistent with SOAS ground observations, $10-20 \%$ of observed boundary layer total (gas plus particle) organic nitrates were in the particle phase for the aircraft measurements.

In addition to the measurements made in the SE US, characterization of aerosol organic nitrates has been performed in New England. As part of the New England Air Quality Study (NEAQS) in summer 2002, Zaveri et al. (2010) observed evolution of aerosols in the nocturnal residual layer with an airborne quadrupole (Q)-AMS in the Salem Harbor power plant plume. The aerosols were acidic and internally mixed, suggesting that the observed nitrate was in the form of organic nitrate and that the enhanced particulate organics in the plume were possibly formed from $\mathrm{NO}_{3}$-initiated oxidation of isoprene present in the residual layer.

\section{Western United States}

Significant work on understanding ambient organic nitrate formation from BVOC-NO $\mathrm{NO}_{3}$ has been performed in California. During the California Research at the Nexus of Air Quality and Climate Change (CalNex) field campaign from midMay through June 2010, Rollins et al. (2012, 2013) measured particulate total alkyl and multifunctional nitrates ( $p \Sigma$ ANs) with TD-LIF at a ground site in Bakersfield, California. They attributed the increase in $p \Sigma \mathrm{AN}$ concentrations at night to oxidation of BVOC by $\mathrm{NO}_{3}$ forming $\mathrm{SOA}$, with an estimated 27 to $40 \%$ of the OA growth due to molecules with nitrate functionalities. On average, $21 \%$ of $\Sigma$ ANs were in the particle phase and increased with OA, which was fit to a volatility basis set in which $p \Sigma$ ANs / $\Sigma$ ANs increased from $\sim 10 \%$ at $<1 \mu \mathrm{g} \mathrm{m}^{-3}$ and plateaued at $\sim 30 \%$ by $\sim 5 \mu \mathrm{g} \mathrm{m}^{-3}$. At the same site, using PMF analysis of FTIR and HR-ToFAMS measurements, Liu et al. (2012a) showed that the organic nitrate-containing biogenic SOA condensed onto 400 to $700 \mathrm{~nm}$ sized primary particles at night. As part of the Carbonaceous Aerosol and Radiative Effects Study (CARES) in June 2010, Setyan et al. (2012) observed enhanced SOA formation due to interactions between anthropogenic and biogenic emissions at a forest site in the foothills of the Sierra Nevada mountains, approximately $40 \mathrm{~km}$ downwind of Sacramento. While nitrate accounted for only $\sim 4 \%$ of the particle mass measured by a HR-ToF-AMS, it was attributed potentially to organic nitrates based on the much higher $\mathrm{NO}^{+} / \mathrm{NO}_{2}^{+}$ion ratio than observed in pure ammonium nitrate.

During the Rocky Mountain Biogenic Aerosol Study field campaign in Colorado's Front Range (rural coniferous montane forest) (BEACHON-RoMBAS) from July to August 2011, Fry et al. (2013) observed aerosol-phase organic nitrates by optical spectroscopic (denuded TD-LIF) and mass spectrometric (HR-ToF-AMS, $\mathrm{NO}^{+} / \mathrm{NO}_{2}^{+}$) instruments. The two methods agreed well on average (AMS/TDLIF slope of 0.94-1.16, depending on averaging method) with a fair correlation $\left(R^{2}=0.53\right)$. Similar to studies in other forested environments, the organic nitrate concentration was found to peak at night. The organic nitrate concentration was positively correlated with the product of the nitrogen dioxide and $\mathrm{O}_{3}$ mixing ratios but not with that of $\mathrm{O}_{3}$ alone; this suggested nighttime $\mathrm{NO}_{3}$-initiated oxidation of monoterpenes as a significant source of nighttime aerosol organic nitrates. The gas-particle partitioning also showed a strong diurnal cycle, with the fraction in the particle phase peaking at $\sim 30 \%$ at night and decreasing to a broad minimum of $\sim 5 \%$ during daytime, which suggests a change in composition in addition to thermodynamic partitioning effects.

\section{Europe}

Iinuma et al. (2007) analyzed ambient aerosol samples collected on filters in a Norway spruce forest in northeastern Germany during the BEWA campaign (Regional biogenic emissions of reactive volatile organic compounds from forests: process studies, modeling, and validation experiments) and compared the results to those from chamber studies. The filter extracts were analyzed using LC-ESI-ToF-MS in parallel to ion trap MS. Several nitrooxy organosulfates with significant mass in the BEWA ambient samples were enhanced in the nighttime samples relative to the daytime 
samples. Their abundance in the nighttime samples strongly suggests that $\mathrm{NO}_{3}$-monoterpene chemistry in the presence of sulfate aerosols has an important role in the formation of these nitrooxy organosulfate aerosols.

A similar study by Gómez-González et al. (2008) focused on isoprene through LC-multidimensional MS (MS ${ }^{n}$ ) analysis of filter samples from both chamber studies and ambient summer day/night $\mathrm{PM}_{2.5}$ samples from K-Puszta, Hungary, a mixed deciduous/coniferous forest site. Although not the focus of the study, they confirmed the presence of significant quantities of nitrooxy organosulfates that were enhanced in the nighttime samples over the daytime samples.

Initial online evidence of the production of organic nitrate aerosols in Europe was provided by Allan et al. (2006) when studying nucleation events driven by BVOC oxidation in Hyytiälä, a (boreal) forested region in Finland. The QAMS $m / z 30$ to $m / z 46$ ratio (the unit mass resolution approximation for $\mathrm{NO}^{+} / \mathrm{NO}_{2}^{+}$ratio) was frequently found to be very high, $\sim 10$, for a distinct organic Aitken mode that became apparent late in the afternoon and increased at night. They hypothesized that the excess $m / z 30\left(\mathrm{NO}^{+}\right)$signal was associated with organic nitrates, although could not rule out amine contributions. During the same field study, Vaattovaara et al. (2009) applied two tandem differential mobility analyzer methods to study the evolution of the nucleationand Aitken-mode particle compositions at this boreal forest site. The results showed a clear anthropogenic influence on the nucleation- and Aitken-mode-particle compositions during the events and suggested organic nitrate and organosulfate aerosol was generated from monoterpene oxidation. Also, it was shown that organic nitrate was enhanced in aerosol exposed to elevated temperatures, implying low volatility of organic nitrates (Häkkinen et al., 2012).

More recently, Hao et al. (2014) used a HR-ToF-AMS on a tower in Kuopio, Finland, $224 \mathrm{~m}$ above a lake surrounded by a mixed forest of mostly coniferous (pine and spruce) mixed with deciduous trees (mostly birch) to measure submicron aerosol composition. The site also was influenced by urban emissions. A particular focus of the study was to separate organic and inorganic nitrate using PMF. They found that $\sim 37 \%$ of the nitrate mass at this location and time could be allocated to organic nitrate factors, the rest being inorganic nitrate. The organic nitrate aerosol was segregated into two organic factors, less-oxidized OOA (LO-OOA), and moreoxidized OOA (MO-OOA) (previously called SV- and LVOOA, respectively); the majority ( $74 \%$ ) of the organic nitrate was found to be in the more volatile LO-OOA factor. Based on meteorology, the air mass source of the organic nitrate aerosol was from a sector with residential and forested areas. Again, the organic nitrate aerosol showed a diurnal trend that was highest at night.

An analysis of AMS data taken across Europe within EUCAARI and EMEP intensive measurement campaigns (Kulmala et al., 2011; Crippa et al., 2014) has recently shown high organic nitrate contributions to total measured $\mathrm{PM}_{1}$ ni- trate (Kiendler-Scharr et al., 2016). The spatial distribution and diurnal pattern of particulate organic nitrate indicate a gradient of concentration. High concentrations are found in source regions with $\mathrm{NO}_{x}$ emissions and during the night. Low concentrations are found in remote regions and during the day. EURAD-IM simulations for Europe show an increase of SOA by 50 to $70 \%$ when considering SOA formation by $\mathrm{NO}_{3}$ oxidation with maximum ground-level concentrations of $\mathrm{SOA}$ from $\mathrm{NO}_{3}$ oxidation in the range of 2 to $4 \mu \mathrm{g} \mathrm{m}^{-3}$ (Li et al., 2013; Kiendler-Scharr et al., 2016).

\section{Summary of organic nitrate aerosol observations}

Taken together, the observations of particle-phase organic nitrates in the US and Europe suggest that particle-phase organic nitrates (formed substantially via $\mathrm{NO}_{3}$-BVOC chemistry) are ubiquitous, especially in, but not limited to, summer. Their formation appears to play an important role in SOA formation, which can potentially be underestimated due to short particle-phase lifetimes. Regions with widespread $\mathrm{NO}_{x}$ and $\mathrm{BVOC}$ emissions and a humid climate may create optimal conditions for a rapid life cycle of particle-phase organic nitrates.

\subsection{Models of $\mathrm{NO}_{3}-\mathrm{BVOC}$ chemistry}

To understand the implications of $\mathrm{NO}_{3}$-BVOC chemistry on atmospheric chemistry as a whole, under both current and future scenarios, the physical and chemical processes, such as those reported in Sect. 2.1 through Sect. 2.3, must be parameterized in numerical models. In this section, we summarize how these reactions are represented in current air quality models (AQMs).

\subsubsection{Chemical mechanisms}

Organic nitrates are produced from the reactions of VOC with $\mathrm{OH}$ followed by $\mathrm{NO}$ as well as with $\mathrm{NO}_{3}$, and both of these pathways are represented in chemical mechanisms albeit at varying levels of detail. The use of the term "model" below refers to the treatment of BVOC $+\mathrm{NO}_{3}$ chemistry in lumped chemical mechanisms. The products formed from the $\mathrm{OH}$-initiated (typically daytime) versus $\mathrm{NO}_{3}$-initiated (typically nighttime) chemistry may or may not be treated separately.

The $\mathrm{NO}_{3}-\mathrm{BVOC}$ reactions result in an $\mathrm{RO}_{2}$ that reacts with $\mathrm{NO}_{3}$, other $\mathrm{RO}_{2}, \mathrm{HO}_{2}$, or NO. $\mathrm{RO}_{2}-\mathrm{NO}$ reactions for $\mathrm{NO}_{3}-$ initiated chemistry are relatively unimportant due to rapid reaction of $\mathrm{NO}$ with $\mathrm{NO}_{3}$ at night (Perring et al., 2009), but they are included in models. Unimolecular rearrangements of the $\mathrm{NO}_{3}$-initiated $\mathrm{RO}_{2}$ radical are not currently considered in models (Crounse et al., 2011). The products of the initial $\mathrm{NO}_{3}$-BVOC reaction may retain the nitrate group, thus forming an organic nitrate or releasing nitrogen as $\mathrm{NO}_{2}$. The branching between organic nitrate formation and $\mathrm{N}$ recycling is parameterized in models. Table 4 summarizes the gas- 
phase organic nitrate yields for isoprene and monoterpene oxidation by $\mathrm{NO}_{3}$ in a number of currently available chemical mechanisms. The yields represent the first-generation yields since products may react to form further organic nitrates or release $\mathrm{NO}_{2}$. The organic nitrate yield values span from 0 (e.g., SAPRC07 isoprene) to $100 \%$ (e.g., MCM isoprene). Although GEOS-Chem v10-01 does not consider gas-phase monoterpene chemistry, the model has recently been updated to consider a $10-50 \%$ yield of organic nitrates from the monoterpene- $\mathrm{NO}_{3}$ reaction independent of the nitrate- $\mathrm{RO}_{2}$ fate but dependent on monoterpene identity (Fisher et al., 2016). Differences in the organic nitrate yield from $\mathrm{NO}_{3}$ oxidation result from a number of causes including treatment of $\mathrm{RO}_{2}$ fate, assumptions about decomposition versus retention, and prioritization of functional group identity.

Some models parameterize the yield of organic nitrates as a function of $\mathrm{RO}_{2}$ fate while others, such as the carbon bondbased (CB) mechanisms, treat all $\mathrm{RO}_{2}$ fates the same. The MCM v3.3.1 also considers the yield of isoprene organic nitrates to be independent of $\mathrm{RO}_{2}$ fate, but monoterpene organic nitrate yields are variable between 0 and $100 \%$ depending on $\mathrm{RO}_{2}$ fate. Differences in organic nitrate formation, due to treating the organic nitrate yield as a function of $\mathrm{RO}_{2}$ fate, may vary with atmospheric conditions. Reactions with both $\mathrm{HO}_{2}$ and $\mathrm{RO}_{2}$ are significant at night (Xie et al., 2013; Pye et al., 2015). $\mathrm{RO}_{2}-\mathrm{NO}_{3}$ may be important in urban areas or locations where BVOC concentrations are not so high as to deplete $\mathrm{NO}_{3}$ (Rollins et al., 2012).

Mechanisms differ in their assumptions about whether or not the organic nitrates from $\mathrm{NO}_{3}$-initiated chemistry release $\mathrm{NO}_{2}$ or retain the nitrate group. An example of this difference in treatment of organic nitrates can been seen in the reactions of nitrated peroxy radicals with different radicals (NO, $\mathrm{HO}_{2}, \mathrm{RO}_{2}$ ) predicted by SAPRC07 and MCM. MCM predicts greater loss of the nitrate group, while SAPRC tends to retain it, leading to either $<5 \%$ (MCM) or $>50 \%$ (SAPRC) organic nitrate yields.

In order to predict accurately the fates of $\mathrm{RO}_{2}$ and yield of organic nitrates, models must also include information on $\mathrm{RO}_{2}$ reaction rate constants. Some mechanisms use the same set of $\mathrm{RO}_{2}$ rate constants for all hydrocarbons. However, the MCM (Jenkin et al., 1997; Saunders et al., 2003) indicates that the $\mathrm{RO}_{2}-\mathrm{HO}_{2}$ rate constant should vary with carbon number $(n)$ and predict $k=2.91 \times 10^{-13} \exp (1300 / \mathrm{T})$ $[1-\exp (-0.245 n)]$ molec $^{-1} \mathrm{~cm}^{3} \mathrm{~s}^{-1}$. The $\mathrm{MCM} \mathrm{RO}_{2}-\mathrm{RO}_{2}$ rate constant varies between $2 \times 10^{-12} \mathrm{~cm}^{3} \mathrm{molec}^{-1} \mathrm{~s}^{-1}$ (based on $\mathrm{C}_{1}-\mathrm{C}_{3}$ primary $\mathrm{RO}_{2}$ with adjacent $\mathrm{O}$ or $\mathrm{Cl}$ ) and $6.7 \times 10^{-15} \mathrm{~cm}^{3} \mathrm{molec}^{-1} \mathrm{~s}^{-1}$ for tertiary alkyl $\mathrm{RO}_{2}$ (based on $\left.t-\mathrm{C}_{4} \mathrm{H}_{9} \mathrm{O}_{2}\right) . \mathrm{RO}_{2}-\mathrm{NO}_{3}$ and $\mathrm{RO}_{2}-\mathrm{NO}$ rate constants are estimated as $2.3 \times 10^{-13}$ and $9.0 \times 10^{-12} \mathrm{~cm}^{3} \mathrm{molec}^{-1} \mathrm{~s}^{-1}$ at $298 \mathrm{~K}$.

AQMs and chemistry-climate models typically cannot handle the complexity associated with tracking each individual VOC and all its possible reaction products. As a result, surrogate species are often used to represent classes of compounds (e.g., CB05, which uses the designation NTR to indicate organic nitrates). This mapping can cause yields of organic nitrates to be falsely low in a mechanism if other functional groups are prioritized over nitrate in the mapping of predicted products to mechanism species. Compared to the other mechanisms in Table 4, SAPRC07 monoterpenes tend to have very low organic nitrate yields as a result of prioritization of peroxide and non-nitrate functional groups. If nitrate groups were prioritized, SAPRC07 would more closely resemble the "other monoterpene" yields from SAPRC07tic. In addition, the diversity across mechanisms in the $\mathrm{RO}_{2}-\mathrm{HO}_{2}$ monoterpene organic nitrate yields would be reduced such that they would all indicate $>50 \%$ organic nitrate yields and all but the CB mechanisms would predict a $100 \%$ yield of organic nitrates from $\mathrm{RO}_{2}-\mathrm{HO}_{2}$. The $\mathrm{RO}_{2}-\mathrm{HO}_{2}$ pathway is relatively unstudied in laboratory conditions due to difficulties in maintaining sufficient concentrations of both $\mathrm{NO}_{3}$ and $\mathrm{HO}_{2}$ radicals (Boyd et al., 2015; Schwantes et al., 2015).

\subsubsection{Influence on organic aerosol}

Nitrate radical oxidation can lead to significant amounts of SOA on global and regional scales. Due to a lack of information on the identity and volatility of later-generation $\mathrm{BVOC}+\mathrm{NO}_{3}$ products, most models parameterize $\mathrm{SOA}$ formation separately from gas-phase chemistry using either the Odum two-product (Odum et al., 1996) fit, volatility basis set (VBS) (Donahue et al., 2006) fit, or fixed yield (Table 5). Based on the understanding of SOA pathways at the time, Hoyle et al. (2007) found that up to $21 \%$ of the global average SOA burden may be due to $\mathrm{NO}_{3}$ oxidation, and Pye et al. (2010) predicted $\sim 10 \%$ of global SOA production was due to $\mathrm{NO}_{3}$. Regional contributions to SOA concentrations can be much higher (Hoyle et al., 2007; Pye et al., 2010). Nitrate radical reactions themselves are estimated to account for less than $3 \%$ of isoprene oxidation and less than $2 \%$ of sesquiterpene oxidation globally; however, they account for $26 \%$ of bicyclic monoterpene oxidation (Pye et al., 2010). Representations of monoterpene- $\mathrm{NO}_{3}$ SOA are more widespread in chemistry-climate models than other BVOC- $-\mathrm{NO}_{3}$ SOA parameterizations due to the relatively early recognition of its high yields (e.g., Griffin et al., 1999) and relative importance for SOA. Inclusion of SOA from isoprene- $\mathrm{NO}_{3}$ is more variable as reflected in Table 5.

SOA from BVOC- $\mathrm{NO}_{3}$ reactions traditionally has been parameterized on the initial hydrocarbon reaction assuming semivolatile products and an Odum two-product approach (e.g., Chung and Seinfeld, 2002). This treatment is often implemented in parallel to the gas-phase chemistry, meaning that later-generation products leading to SOA are not identified. Information is still emerging on the fate of organic nitrates, and that information is just beginning to be included in models. Hydrolysis of particle-phase organic nitrates is one such process more recently considered with impacts for both 
Table 4. Gas-phase organic nitrate yields (in percent) from $\mathrm{BVOC}+\mathrm{NO}_{3}$ systems in current chemical mechanisms. Gas-phase organic nitrate yields depend on $\mathrm{RO}_{2}$ fate as indicated in the ternary diagrams; clockwise from the top: $\mathrm{RO}_{2}$ reacts with $\mathrm{NO}_{3}, \mathrm{RO}_{2}$, and $\mathrm{HO}_{2}$.

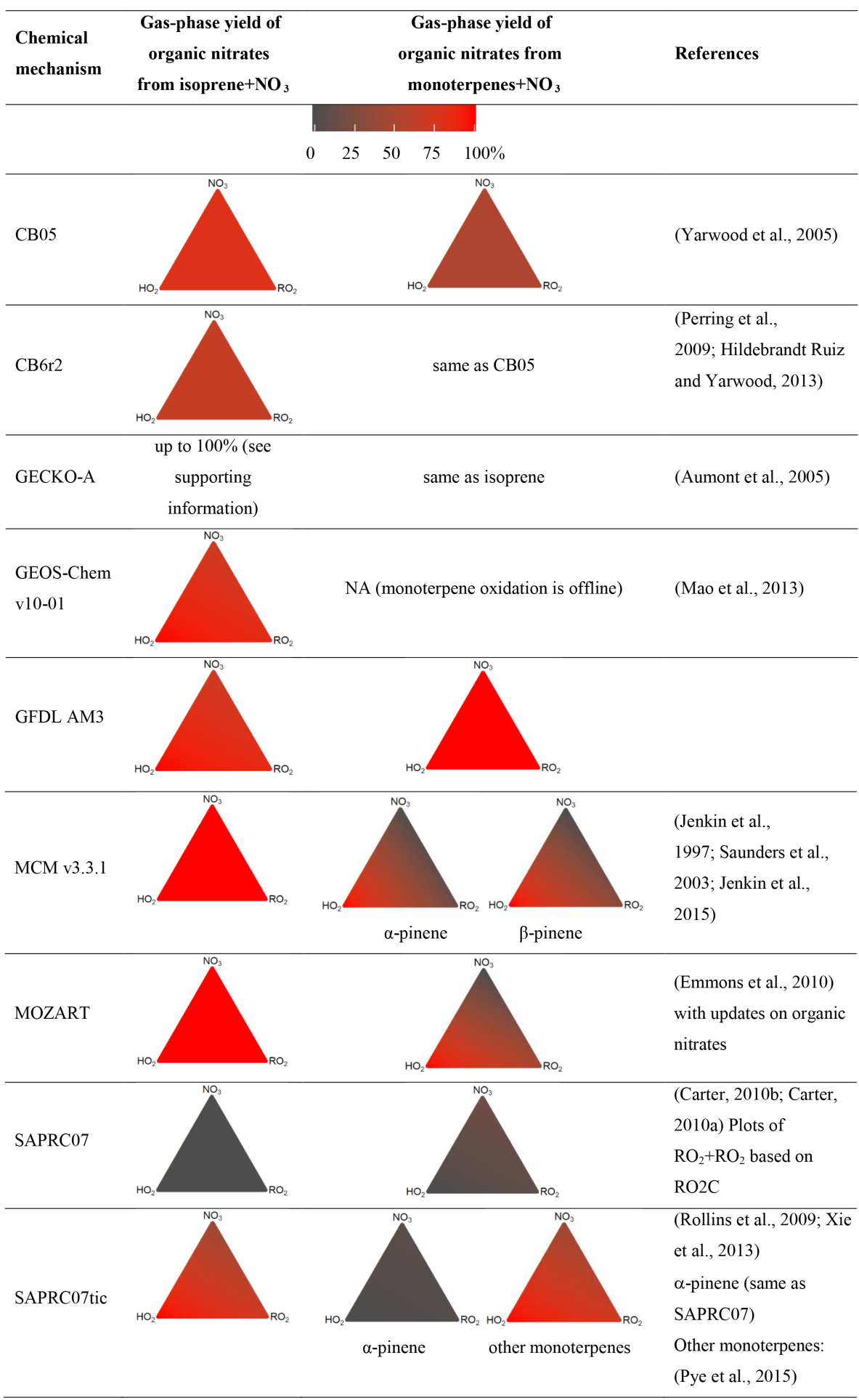


$\mathrm{O}_{3}$ and PM in models (Hildebrandt Ruiz and Yarwood, 2013; Browne et al., 2014; Pye et al., 2015; Fisher et al., 2016).

\subsubsection{Influence on reactive nitrogen and ozone}

The influence of BVOC nighttime oxidation on the nitrogen budget remains unclear. Current modeling efforts have mainly focused on the nighttime oxidation of isoprene, which is dominated by isoprene- $\mathrm{NO}_{3}$ reaction. This pathway is initialized via addition of $\mathrm{NO}_{3}$ to one of the double bonds, as discussed in Sect. 2.1.2. Due to the additional stabilization from alkoxy radical and nitrate functional groups (Paulson and Seinfeld, 1992), the yield of first-generation organic nitrates is relatively high (62-78\%; Table 2$)$; they may react with $\mathrm{NO}_{3}$ again to produce secondary dinitrates (Perring et al., 2009; Rollins et al., 2009, 2012). Assuming little $\mathrm{NO}_{x}$ is recycled from these organic nitrates, most models suggest that nighttime oxidation of isoprene by $\mathrm{NO}_{3}$ contributes significantly to the budget of organic nitrates (von Kuhlmann et al., 2004; Horowitz et al., 2007; Mao et al., 2013; Xie et al., 2013). Two recent studies (Suarez-Bertoa et al., 2012; Müller et al., 2014), however, suggest fast photolysis of carbonyl nitrates with high efficiency of $\mathrm{NO}_{x}$ recycling, which could lead to release of $\mathrm{NO}_{x}$ in the next day. Further modeling is required to investigate the importance of nighttime isoprene oxidation on the nitrogen budget.

Very little modeling effort has been dedicated to the influence of nighttime terpene oxidation on the nitrogen budget, mainly due to the lack of laboratory data on oxidation products and their fate. In contrast to isoprene, terpene emissions are temperature sensitive but not light sensitive (Guenther et al., 1995), leading to a significant portion of terpene emissions being released at night. The high yield of organic nitrates and SOA from the terpene- $\mathrm{NO}_{3}$ reaction (Fry et al., 2009, 2011, 2014; Boyd et al., 2015) provides an important sink for $\mathrm{NO}_{x}$ at night, likely larger than for isoprene- $\mathrm{NO}_{3}$ over the eastern US (Warneke et al., 2004). Recent laboratory experiments suggest that aerosol organic nitrates can be either a permanent or temporary $\mathrm{NO}_{x}$ sink depending on their monoterpene precursors (and hence nature of the resulting $\mathrm{RO}_{2}$ ) as well as ambient $\mathrm{RH}$ (Boyd et al., 2015; Nah et al., 2016b). In order to understand the impact of terpenes on nighttime chemistry, a fully coupled model of terpene- $\mathrm{NO}_{x}$ chemistry will be required, as monoterpenes can be the dominant loss process for $\mathrm{NO}_{3}$ and $\mathrm{N}_{2} \mathrm{O}_{5}$ at night (Ayres et al., 2015).

While a significant portion of nitrogen is emitted at night (Boersma et al., 2008), the impact of nighttime chemistry on the initiation of the following daytime chemistry has received little attention in regional and global models. Different treatments of $\mathrm{NO}_{3}$ chemistry can result in $20 \%$ change in the following daytime $\mathrm{O}_{3}$ concentration, as shown by a 1-D model study (Wong and Stutz, 2010) and box model simulations (Millet et al., 2016). This impact can be further complicated by uncertainty in emissions of BVOC and model resolutions.
For example, a recent study by Millet et al. (2016) shows that in a city downwind of an isoprene-rich forest, daytime $\mathrm{O}_{3}$ can be largely modulated by the chemical removal of isoprene throughout the night. Such local-scale events may only be captured by a very high-resolution model with detailed characterization of emission sources. It is important to assess this impact on a global scale using 3-D chemistry models, owing to the profound coupling of boundary layer dynamics and chemistry. Quantifying the impact of BVOC- $\mathrm{NO}_{3}$ chemistry on $\mathrm{NO}_{x}$ fate is important given the long-standing problem in current global and regional AQMs of a large overestimate of $\mathrm{O}_{3}$ over the eastern US in summer (Fiore et al., 2009).

\subsubsection{Comparison of field data with air quality models}

Recent field campaigns (SOAS, SEAC4RS, EUCAARI, EMEP) have allowed for the attribution of SOA to $\mathrm{NO}_{3}$ oxidation to provide model constraints not previously available. Pye et al. (2015) and Fisher et al. (2016) implemented updated $\mathrm{BVOC}+\mathrm{NO}_{3}$ chemistry in CMAQ and GEOS-Chem, respectively, to interpret data in the SE US during the summer of 2013 (SOAS and SEAC4RS). Model predictions of gas-phase monoterpene nitrates (primarily $\mathrm{NO}_{3}$ derived) were higher than the sum of $\mathrm{C}_{10} \mathrm{H}_{17} \mathrm{NO}_{4}$ and $\mathrm{C}_{10} \mathrm{H}_{17} \mathrm{NO}_{5}$ (Nguyen et al., 2015) by a factor of 2-3 (Fisher et al., 2016) and 7 (Pye et al., 2015), consistent with a significant fraction of the monoterpene nitrates being highly functionalized (Lee et al., 2016). The studies identified particle-phase hydrolysis as an important modulator of particulate organic-nitrate concentrations and organic nitrate lifetime. The GEOS-Chem simulation reproduced the particle-phase organic nitrate diurnal cycles (SOAS), boundary layer concentrations, and gasparticle partitioning reasonably well; however, it underestimated concentrations in the free troposphere, possibly due to measurement limitations and/or the implementation of rapid uptake followed by hydrolysis of all gas-phase organic nitrates in the model, which may not be valid for non-tertiary organic nitrates (Fisher et al., 2016).

\section{Perspectives and outlook}

Section 3 outlines perspectives on the implications of $\mathrm{NO}_{3}$ BVOC atmospheric chemistry with respect to (1) aerosol optical and physical properties; (2) health effects; (3) trends in $\mathrm{NO}_{x}$ emissions and organic aerosols and their implications for control strategies related to particulate matter; (4) critical needs for analytical methods; (5) critical needs for models; (6) field studies in the developing world and under-studied areas; and (7) critical issues to address in future field and laboratory measurements in light of current understanding of this chemistry and trends in emissions. 
Table 5. Treatment of SOA formation from BVOC-NO 3 systems in current 3-D models.

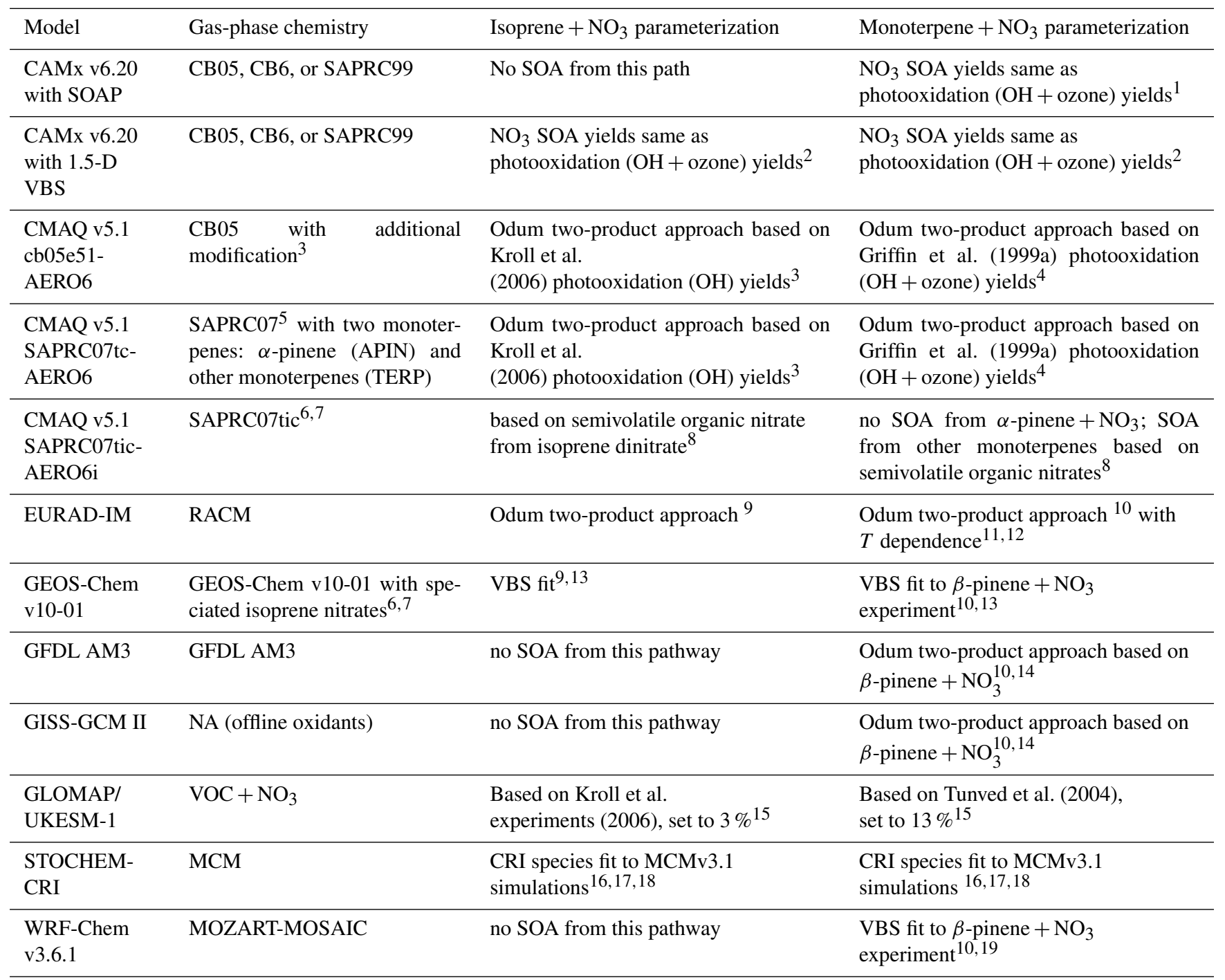

${ }^{1}$ Strader et al. (1999). ${ }^{2}$ Koo et al. (2014). ${ }^{3}$ Appel et al. (2016). ${ }^{4}$ Carlton et al. (2010a). ${ }^{5}$ Hutzell et al. (2012). ${ }^{6}$ Rollins et al. (2009). ${ }^{7}$ Xie et al. (2013). ${ }^{8}$ Pye et al. (2015). ${ }^{9}$ Ng et al. (2008). ${ }^{10}$ Griffin et al. (1999). ${ }^{11}$ Li et al. (2013). ${ }^{12}$ Kiendler-Scharr et al. (2016). ${ }^{13}$ Pye et al. (2010). ${ }^{14}$ Chung and Seinfeld (2002). ${ }^{15}$ Scott et al. (2014). ${ }^{16}$ Utembe et al. (2009). ${ }^{17}$ Johnson et al. (2006). ${ }^{18}$ Khan et al. (2015). ${ }^{19}$ Knote et al. (2014).

\subsection{Aerosol optical and physical properties}

The climatic effects of atmospheric aerosols depend on their various physical and chemical properties. Hygroscopicity, cloud condensation nuclei $(\mathrm{CCN})$ activity, optical properties (namely light absorption and scattering), and ability to act as $\mathrm{CCN}$ and ice nuclei (IN) are the key aerosol properties that would determine their ability to affect climate. Additional properties such as aerosol number size distribution, chemical composition, mixing state, and morphology will determine whether the aerosols will be optically important or whether they would affect cloud properties. These aerosol properties depend on the sources, aging processes, and removal pathways that aerosols experience in the atmosphere (Boucher, 2013).
Absorption by aerosol may affect the cloud lifetime and altitude due to heating of the atmosphere (Mishra et al., 2014). They can also change the atmospheric lapse rate, which in turn can result in modification in aerosol microphysics in mixed-phase, ice, and convective clouds (Boucher, 2013). In addition to direct emissions of known absorbing particles (black carbon, mineral dust, biomass burning aerosols), SOA may also have absorption properties. The absorbing component of organic carbon $(\mathrm{OC})$, namely "brown carbon" $(\mathrm{BrC})$, is associated with OC found in both primary and secondary $\mathrm{OC}$ and has a spectral-dependent absorption that smoothly increases from short visible to UV wavelengths (Bond and Bergstrom, 2006). It has been suggested that $\mathrm{BrC}$ is a component of SOA that is composed of high molecular weight 
and multifunctional species such as humic-like substances, organic nitrates, and organosulfate species (Andreae and $\mathrm{Ge}$ lencser, 2006; Bond and Bergstrom, 2006; Ramanathan et al., 2007b; Laskin et al., 2015; Moise et al., 2015). Many modeling studies often assume that BC and mineral dust are the only two significant types of light-absorbing aerosols on the global scale. Therefore, they treat SOA as a purely scattering component that leads to climate cooling (Stier et al., 2007; Bond et al., 2011; Ma et al., 2012). However, observations suggest that $\mathrm{BrC}$ is widespread mostly around and downwind urban centers (Jacobson, 1999). In such places, $\mathrm{BrC}$ may have significant contribution, and in some cases it may dominate the total aerosol absorption at specific (short) wavelengths (Ramanathan et al., 2007a; Bahadur et al., 2012; Chung et al., 2012; Feng et al., 2013).

Based on observations, Chung et al. (2012) recently suggested that the direct radiative forcing of carbonaceous aerosols is +0.65 ( 0.5 to about 0.8$) \mathrm{Wm}^{-2}$, comparable to that of methane, the second most important greenhouse gas. This study emphasizes the important role of $\mathrm{BrC}$ and calls for better measurements of the absorption properties of $\mathrm{BrC}$, specifically at short wavelengths where the absorption is most significant. Many previous studies have concentrated on primary particulate matter, mostly from biomass burning. However, these studies often neglected contributions to absorption due to BrC in SOA. There is ample laboratory and field evidence for the formation of such absorbing material in SOA (Chung et al., 2012; Lack et al., 2012). This absorbing component is the least characterized component of the atmospheric absorbing aerosols and constitutes a major knowledge gap, calling for an urgent need to identify the optical properties of the organic $(\mathrm{BrC})$ component in SOA, and the chemical pathways leading to its formation and losses (Laskin et al., 2015; Lin et al., 2015; Moise et al., 2015).

Recently, Washenfelder et al. (2015) measured aerosol optical extinction and absorption in rural Alabama during the SOAS campaign. While they found that the majority of $\mathrm{BrC}$ aerosol mass was associated with biomass burning, a smaller (but not negligible) contribution was attributed to biogenically derived SOA. This fraction reached a daily maximum at night and correlated with particle-phase organic nitrates and is associated with nighttime reactions between monoterpenes and the $\mathrm{NO}_{3}$ radical (Xu et al., 2015a). Based on the above, it is concluded that SOA produced from reactions of $\mathrm{NO}_{3}$ with BVOC can be a major source of SOA during the night that may affect daytime aerosol loading. This important fraction of $\mathrm{NO}_{3}$-derived $\mathrm{SOA}$ can contribute to the direct radiative effect of SOA through scattering and absorption of incoming solar radiation.

Nitration of aromatic compounds (oxidation via $\mathrm{NO}_{2}$, $\mathrm{NO}_{3}, \mathrm{~N}_{2} \mathrm{O}_{5}$ ) has a potential to form chromophores that can absorb solar radiation. Theoretical and experimental studies have shown that nitration of PAHs leads to nitro PAHs and their derivatives such as nitrophenols (Jacobson, 1999; Harrison et al., 2005; Lu et al., 2011). The nitro substituents on the aromatic ring in compounds enhance and shift the absorption to longer wavelengths $(>350 \mathrm{~nm})$. Field studies report that nitrogen-containing mono- and polyaromatic SOA constituents absorb light at short (near-UV and visible) wavelengths. The reaction products between $\mathrm{NO}_{3}$ and $\mathrm{BVOC}$ have the potential to form effective chromophores. Multifunctional organic nitrates and organosulfate compounds formed during the nighttime suggest that the SOA produced from $\mathrm{NO}_{3}$ reactions leads to formation of $\mathrm{BrC}$ that can absorb solar radiation (Iinuma et al., 2007).

Only a few studies have investigated optical properties of SOA partially composed of organic nitrates (Moise et al., 2015). Most existing literature on optical properties of organic nitrates in SOA has been focused on oxidation of anthropogenic precursor compounds (Jacobson, 1999; Nakayama et al., 2010; Lu et al., 2011; Liu et al., 2012b), while a few partially contradictory studies have examined SOA formed from $\mathrm{NO}_{3}$ reaction with biogenic precursors (Song et al., 2013; Varma et al., 2013). The typically high mass absorption coefficient (MAC) that was observed for anthropogenic high- $\mathrm{NO}_{x}$ SOA can be partially attributed to the presence of nitroaromatic groups, for example, via the nitration of PAHs (Jacobson, 1999; Lu et al., 2011). Song et al. (2013) examined optical properties of SOA formed by $\mathrm{NO}_{3}+\mathrm{O}_{3}+\alpha$-pinene. With neutral seed aerosol, organic nitrates were present but observed to be non-absorbing; however, with acidic seed aerosol, SOA were strongly light absorbing, which the authors attributed to nitrooxy organosulfates formed via aldol condensation. Varma et al. (2013) measured absorption of $\mathrm{NO}_{3}+\beta$-pinene SOA and found a higher refractive index than when oxidation was via $\mathrm{OH}$ or $\mathrm{O}_{3}$, and attributed to the difference to the low $\mathrm{HC} / \mathrm{NO}_{x}$ ratio and presence of organic nitrates in the particle phase.

Laboratory and field studies suggest that SOA formed by nighttime chemistry can have profound regional and possible global climatic effects via their absorbing properties. However, the optical properties of $\mathrm{NO}_{3}$-containing SOA are not well known. Varma et al. (2013) measured a high value for the refractive index real part value of $1.61( \pm 0.03)$ at $\lambda=655-687 \mathrm{~nm}$ following reactions of $\mathrm{NO}_{3}$ with $\beta$-pinene. This value is significantly higher than values observed following OH- and ozone-initiated terpene oxidation (Fig. 6) (Moise et al., 2015). This has been attributed to the high content (up to $45 \%$ ) of organic nitrates in the particle phase (Varma et al., 2013).

Key physical parameters of aerosols include particle size and number, volatility, viscosity, hygroscopicity, and CCN activity. While it is clear that atmospheric particle size increases through condensation of $\mathrm{BVOC}+\mathrm{NO}_{3}$ oxidation products, the effect of $\mathrm{NO}_{3}$ oxidation on particle number is not usually studied in laboratory experiments. Very little is known about the volatility of SOA from $\mathrm{NO}_{3}$, with field studies from Hyytiälä indicating that organic nitrates may have low volatility (Häkkinen et al., 2012). Viscosity is not known. Few studies report the hygroscopicity and CCN 

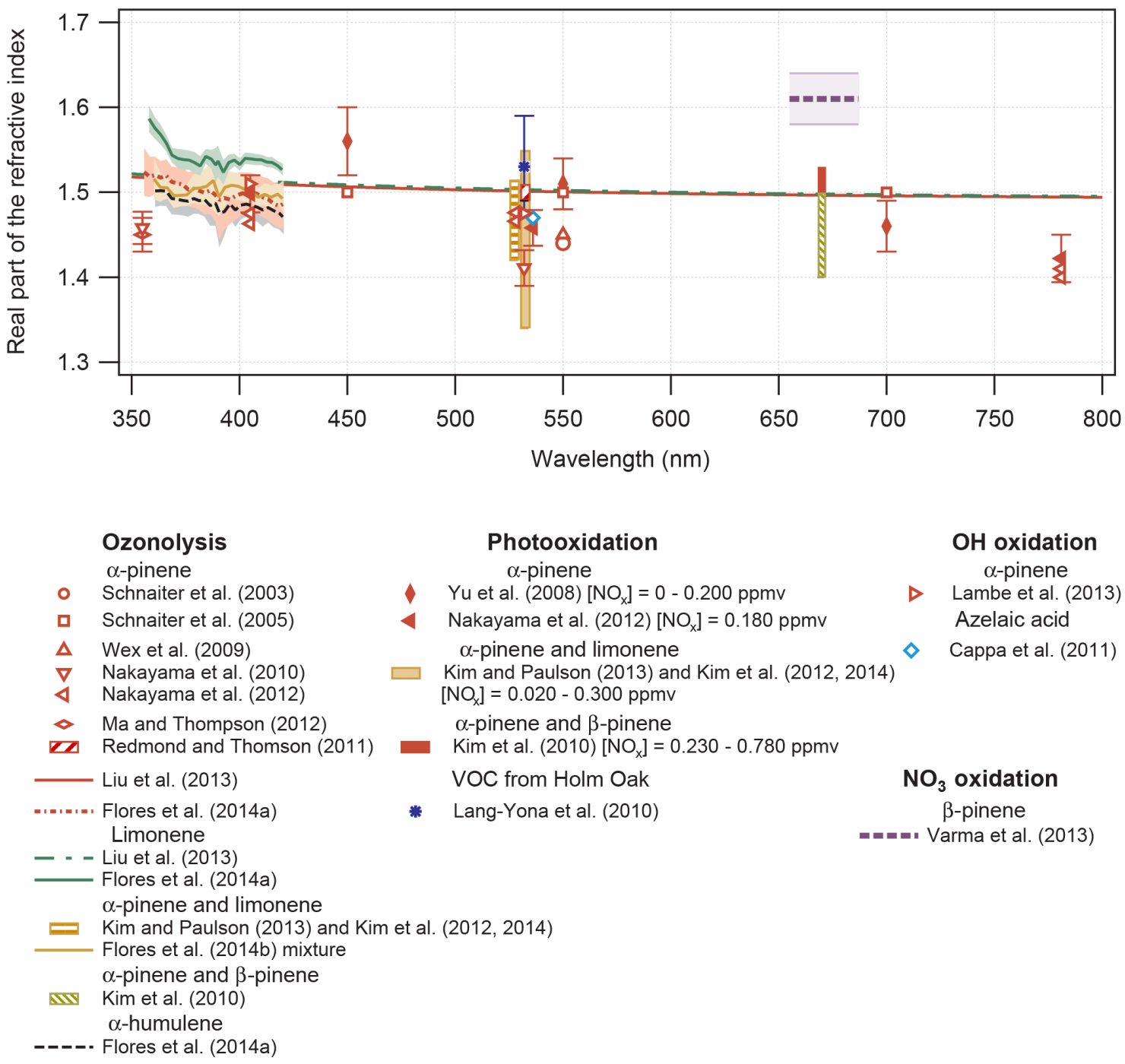

Figure 6. The real part of refractive index (RI) (mr) for biogenic SOA compiled from several chamber studies. The legend specifies the precursor type and oxidation pathway as well as the reference. The figure is reprinted with permission from Moise et al. (2015).

activity of SOA from $\mathrm{NO}_{3}$ oxidation of BVOC. A study by Suda et al. (2014) showed that organic compounds with nitrate functionality (compared to other functional groups such as hydroxyl, carbonyl, hydroperoxide) have the lowest hygroscopicity and CCN efficiency. Recently, Cerully et al. (2015) reported that the hygroscopicity of less-oxidized OOA (LO-OOA, mostly from BVOC $+\mathrm{NO}_{3}$ ) is lower than other OA subtypes (MO-OOA and isoprene-OA) resolved by PMF analysis of AMS data from the SOAS campaign. As monoterpenes $+\mathrm{NO}_{3}$ reactions can contribute $\sim 50 \%$ of nighttime OA production ( $\mathrm{Xu}$ et al., 2015a), results from Cerully et al. (2015) suggested that it is possible that SOA formed from $\mathrm{NO}_{3}$ oxidation of $\mathrm{BVOC}$ is less hygroscopic than OA formed from other oxidation pathways.

\subsection{Health effects}

Nitrated organic compounds also pose adverse health effects (Franze et al., 2003, 2005; Pöschl, 2005; Gruijthuijsen et al., 2006; Pöschl and Shiraiwa, 2015). In particular, several studies have reported that biological particles such as birch pollen protein can be nitrated by $\mathrm{O}_{3}$ and $\mathrm{NO}_{2}$ in polluted urban air (Franze et al., 2005; Reinmuth-Selzle et al., 2014). The mechanism of protein nitration involves the formation of long-lived reactive oxygen intermediates, which are most likely tyrosyl radicals (phenoxy radical derivatives of tyrosine) (Shiraiwa et al., 2011). The resulting organic nitrates were found to enhance the immune response and the allergenicity of proteins and biomedical data suggest strong links between protein nitration and various diseases (Gruijthuijsen et al., 2006). Inhalation and deposition of organic nitrates 
into lung lining fluid in the human respiratory tract may lead to hydrolysis of organic nitrates forming $\mathrm{HNO}_{3}$, which may reduce pulmonary functions (Koenig et al., 1989). Consequently, inhalation of aerosols partially composed of nitrated proteins or nitrating reagents might promote (i) immune reactions, (ii) the genesis of allergies, (iii) the intensity of allergic diseases, and (iv) airway inflammation. Toxicity of nitrated SOA compounds is still unclear. In the light of these observations and remaining uncertainties, the effect of organic nitrates present in biogenic SOA on human health should be a focus of future studies.

Formaldehyde is an important source of atmospheric radicals as well as a major hazardous air pollutant (HAP). It is a degradation product of almost every VOC in the atmosphere, and BVOC are known to contribute substantially to ambient concentrations of formaldehyde (Luecken et al., 2012). The overall yield of formaldehyde from $\mathrm{BVOC}-\mathrm{NO}_{3}$ reactions is lower than from corresponding $\mathrm{OH}$ reactions, indicating that any changes in the relative distribution of oxidation routes will have a corresponding change in formaldehyde (and thus oxidant regeneration and HAP exposure).

\subsection{Trends in $\mathrm{NO}_{x}$ emissions and organic aerosols - implications for air quality control strategies}

Nitrogen oxide emissions are converted to $\mathrm{NO}_{3}$ and thus affect nitrate-derived SOA. In the United States, where $\mathrm{NO}_{x}$ emissions are dominated by fuel combustion, regulatory actions have resulted in decreasing $\mathrm{NO}_{x}$ levels after increases from 1940 to 1970 (Nizich et al., 2000) and relatively stable levels between $\sim 1970$ and $\sim 2000$ (Richter et al., 2005). $\mathrm{NO}_{x}$ emissions in the US are estimated to have decreased by roughly $30-40 \%$ in the recent past (between 2005 and 2011/2012), as reflected in satellite-observed $\mathrm{NO}_{2}$, ground-based measurements, and the Environmental Protection Agency (EPA) National Emission Inventory (NEI) (Russell et al., 2012; Xing et al., 2013, 2015; Hidy et al., 2014; Tong et al., 2015). Recent decreases in $\mathrm{NO}_{x}$ have been attributed to the mobile sector, and power plant controls including the EPA $\mathrm{NO}_{x}$ State Implementation Plan Call implemented between 2003 and 2004 (Kim et al., 2006; Russell et al., 2012; Hidy et al., 2014; Foley et al., 2015; Lu et al., 2015). In the United States, $\mathrm{NO}_{x}$ emissions are expected to continue to decrease and reach 72 and $61 \%$ of their 2011 levels in 2018 and 2025, respectively (Eyth et al., 2014). Furthermore, recent work indicates that $\mathrm{NO}_{x}$ emissions may be overestimated in models for the United States (Travis et al., 2016) particularly for on-road gasoline vehicles (McDonald et al., 2012).

Globally, the Representative Concentration Pathway trajectories indicate that $\mathrm{NO}_{x}$ emissions will decrease below year 2000 levels by the middle of the 21 st century (Lamarque et al., 2011). Europe has experienced declines in $\mathrm{NO}_{x}$ with $\mathrm{NO}_{2}$ concentrations decreasing by $20 \%$ over western Europe between 1996 and 2002 (Richter et al., 2005) and decreasing by an additional $\sim 20 \%$ in the more recent past (2004-2010) (Castellanos and Boersma, 2012). In contrast, $\mathrm{NO}_{x}$ emissions in China have increased by large amounts since 1996 (Richter et al., 2005; Stavrakou et al., 2008; Verstraeten et al., 2015) with a more recent leveling out or decrease of $\mathrm{NO}_{2}$ concentrations (Krotkov et al., 2016). $\mathrm{NO}_{2}$ concentrations in India have continued to increase (Krotkov et al., 2016; Duncan et al., 2016).

These large past and expected future changes in anthropogenic $\mathrm{NO}_{x}$ emissions indicate that analysis of historical data could reveal how $\mathrm{NO}_{x}$ emissions affect organic aerosol formation and more specifically $\mathrm{SOA}$ from $\mathrm{NO}_{3}$-initiated chemistry. Long-term monitoring networks often measure $\mathrm{NO}_{x}$ and $\mathrm{OC}$, which could allow for correlation analysis. In addition, air quality trends in organic aerosol from traditionally less-sampled locations (e.g., Streets et al., 2008) and emissions for locations such as China have been characterized and could be used for analysis.

In addition to examining measurement data for relationships between $\mathrm{NO}_{3}$-derived $\mathrm{SOA}$ and $\mathrm{NO}_{x}$, chemical transport modeling with emission sensitivity simulations can be used to provide estimates of how various SOA pathways respond to changes in $\mathrm{NO}_{x}$ emissions. For example, Carlton et al. (2010b) used the CMAQ model to determine that controllable $\mathrm{NO}_{x}$ emissions were responsible for just over $20 \%$ of total SOA in the United States based on the $\mathrm{NO}_{3}$-BVOC mechanism available at the time. Pye et al. (2015) predicted nitrate-derived SOA concentrations would decrease by $25 \%$ due to a $25 \%$ reduction in $\mathrm{NO}_{x}$ emissions, but the overall change including all organic aerosol components would be only $9 \%$ as a result of other less sensitive (or increasing) components. Other modeling studies (Lane et al., 2008; Zheng et al., 2015; Fisher et al., 2016) have shown that total organic aerosol or particle-phase organic nitrates may not respond strongly to decreased $\mathrm{NO}_{x}$ emissions, but significant spatial and composition changes can occur.

\subsection{Organic nitrate standards}

The CIMS technique allows for highly time-resolved, chemically speciated measurements of multifunctional organic nitrates (Beaver et al., 2012; Paulot et al., 2012; Lee et al., 2014a; Xiong et al., 2015). Synthesis, purification, and independent quantification of an individual, isomerically specific organic nitrate is, however, required for calibration because standards are not commercially available, except for a few monofunctional alkyl nitrates.

The synthesis of monofunctional alkyl nitrates can be performed via several methods (Boschan et al., 1955), including nitration of alkyl halides with silver nitrate, direct nitration of alcohols or alkanes with nitric acid (Luxenhofer et al., 1996; Woidich et al., 1999), or treatment of alcohols with dinitrogen pentoxide (Kames et al., 1993). Techniques for the synthesis of multifunctional nitrates (in particular, hydroxynitrates) have been described in previous reports (Muthuramu 
et al., 1993; Kastler and Ballschmiter, 1998; Werner et al., 1999; Treves et al., 2000). Carbonyl nitrates have also been synthesized using the same protocol, i.e., nitration of hydroxy ketones with dinitrogen pentoxide (Kames et al., 1993; Suarez-Bertoa et al., 2012).

Most recently, three isomers of isoprene hydroxynitrates were synthesized (Lockwood et al., 2010; Lee et al., 2014b). As the precursor ingredient is an organic epoxide on which hydroxy and nitrate functional groups are attached, the same protocol (Nichols et al., 1953; Cavdar and Saracoglu, 2008) can be applied to synthesize hydroxynitrates of various VOC backbones assuming availability of precursor compounds. Oxidation of a single-parent compound can yield numerous isomerically unique byproducts possessing various functional groups, including one or more nitrates. As such, synthesis of and calibration for each nitrate rapidly become prohibitive. Given that multifunctional organic nitrates possessing more than four oxygen atoms, for which synthesis protocols currently do not exist, dominate the particulate nitrate mass of submicron particles (Lee et al., 2016), a more comprehensive calibration technique is needed. Three broad approaches are currently utilized. One is to cryogenically collect a suite of oxidation byproducts (present in the atmosphere, formed in a simulation chamber or flow tube, etc.) on a GC column. The desorbing eluent, separated in time by volatility/polarity as it is thermally desorbed, is measured simultaneously by CIMS and a quantitative instrument such as the TD-LIF (Day et al., 2002; Lee et al., 2014b). The corresponding eluting peaks detected by both instruments allow for calibration of each surviving, isobarically unique (at least for unit mass resolution spectrometers) organic nitrate (Bates et al., 2014; Schwantes et al., 2015; Teng et al., 2015). The second approach employed for the iodide adduct ionization technique is to deduce the instrument response from a comparison of the binding energies of the numerous iodide organic nitrate clusters to those of compounds with known sensitivities by applying variable voltages in the ion molecule reaction region to break up charged clusters systematically. The rate at which the signal of an organic nitrate cluster decays with voltage is a function of its binding energy, which governs its transmission efficiency through the electric fields and thus its sensitivity (Lopez-Hilfiker et al., 2016). Lastly, quantum chemical calculations of specific compounds allow the determination of the sensitivity of their iodide adduct (Iyer et al., 2016) and $\mathrm{CF}_{3} \mathrm{O}^{-}$(Kwan et al., 2012; Paulot et al., 2012) ionizations.

\subsection{Critical needs for models}

\subsubsection{Robust and efficient representation of gas-phase chemistry}

Previous sections have detailed the reactions of BVOC with $\mathrm{NO}_{3}$ and the need to include this chemistry to represent more accurately processes that control $\mathrm{O}_{3}$ and SOA forma- tion. But applying that information in a way that can be used for air quality studies presents a serious challenge. As highlighted in Sect. 2.6.1, the chemical mechanisms currently being used in AQMs are limited in their representation of $\mathrm{NO}_{3}$-BVOC chemistry, largely lumping all monoterpenes together, and with no agreement on yields. The lack of detail in current mechanisms is reflected in the variety of methods by which SOA formation from BVOC- $\mathrm{NO}_{3}$ chemistry is estimated (Sect. 2.6.2).

Typically, the $\mathrm{NO}_{3}$-BVOC chemistry is implemented in AQMs into the existing system of organic and inorganic chemical reactions that occur in the atmosphere. Because there may be hundreds or thousands of different chemical reactions occurring simultaneously and the computational efforts required to solve those on a 3-D grid are onerous, the chemical mechanisms used in AQMs are typically condensed to a certain extent. The greatest challenges in modeling the reactions initiated by $\mathrm{NO}_{3}$ and $\mathrm{BVOC}$ in AQMs are (1) deciding how much detail must be included to accurately represent the chemistry; (2) estimating intermediate reactions and/or products when direct experimental observations are not available; (3) integrating the new reactions into existing chemical mechanisms; and (4) validating the complete schemes against observational data.

Including all of the attack pathways and isomers that are formed in the reactions of $\mathrm{NO}_{3}$ and $\mathrm{BVOC}$ and their subsequent products rapidly becomes an intractable problem, as the number of species and reactions produced from a VOC grows exponentially with the number of carbons in the compound (Aumont et al., 2005), resulting in an estimate of almost 400 million products from a single $\mathrm{C}_{10}$ hydrocarbon. Even restricting the chemistry solely to the $\mathrm{RO}_{2}$ formed from $\alpha$-pinene, $\beta$-pinene, and limonene via addition of $\mathrm{NO}_{3}$ to the double bond results in 861 unique product species and 2646 reactions as estimated from the MCM (http://mcm.leeds.ac. uk/MCM-devel/home.htt; Saunders et al., 2003). In comparison, the chemical mechanisms used in AQMs typically consider a total of 100-200 species and less than 400 reactions to model the entire gas-phase chemistry occurring in the troposphere. One challenge is to find a balance between complexity and computational efficiency that involves both deriving complete mechanisms as well as condensing them to the extent possible.

The second major challenge is that many of the chemical pathways must be estimated given the limited experimental measurements of intermediate reaction rate constants and products. Structure-activity predictions have been used heavily in the past, but these have been formulated for a limited number of compounds. Their predictions become less accurate as the complexity of the molecule increases (Calvert et al., 2015). When heterogeneous reactions play a significant role in the transport and fate of reaction products, as they do in monoterpene chemistry, the challenge becomes even greater. With recent research, new product structures that contribute to SOA have been identified (Boyd et al., 
2015). However, these are not covered by existing predictive theory, and these new pathways must be characterized, including reaction rate constants, co-reactants, and products. Physical parameters of all of these new species, such as solubility, radiative properties, emission rates, and deposition velocities also are required, but data are often unavailable for these or even comparable species.

The last challenge is integrating the chemistry within the rest of the chemistry occurring in the atmosphere. The major chemical mechanisms used in AQMs today were developed primarily to address episodes of elevated $\mathrm{O}_{3}$ under conditions of high $\mathrm{NO}_{x}$ and have been evaluated for this purpose. Thus, the mechanisms often do not lend themselves well to predicting the chemistry of complex VOC or other air quality endpoints (Kaduwela et al., 2015). Minor pathways with respect to $\mathrm{O}_{3}$ formation have been removed from the mechanisms to reduce the computational burden, but these pathways may be important for formation of SOA. In addition, the detailed chemistry of multistep alkoxy and peroxy radical chemistry is condensed into a single step in some mechanisms, but identifying whether these radicals react with $\mathrm{NO}_{x}$ or $\mathrm{HO}_{x}$ or isomerize is critical for predicting the types of organic molecules that are formed. As described in Sect. 2.6, existing mechanisms include the capability for a limited number of nitrates, and in many cases the links to facilitate expansion to more detailed representations are missing.

Significant work must be done to allow modelers to implement this new information in AQMs and thus use this updated knowledge to develop improved predictions of future air quality. One approach is to focus on key chemicals of interest, derive mechanisms that are suitable for specialized applications, and append these on to existing frameworks (for example, Xie et al., 2013). The longer-term view requires a more comprehensive approach that draws on the development of community archives that can better accommodate rapidly changing information and better represent the interactions of biogenic with anthropogenic chemistry. Here, we put forward our recommendations for future work in the following areas:

1. Development of tools for the semi-automated production of the reaction pathways and products of latergeneration products resulting from alternate pathways of radical reactions with BVOC. These tools should be able to incorporate experimental data when available. In conjunction with the automated development, we require advanced methods for condensing these large mechanisms into computationally feasible reaction schemes.

2. Improvements in estimation techniques for uncertain pathways, including reaction rate constants for multifunctional stable compounds and radicals for which measurements are not available, and the quantification of the errors associated with these estimation methods.
3. Development of theory and techniques for integrating gas-phase products with SOA production, in this case, describing the transformation of gas-phase organic nitrates to their SOA products.

4. Development of more versatile base mechanisms that have the flexibility to accept increased detail in VOC description and the continuing validation of the complete tropospheric chemical mechanisms against observational data.

\subsubsection{Improved techniques and protocols for evaluation of complex and reduced gas-phase mechanisms}

Generally speaking, once detailed mechanisms are developed, they are evaluated through some form of benchmarking. Systematic strategies for mechanism evaluation include validation of highly detailed mechanisms unable to be run in 3-D models against benchmark data from well-characterized simulation chamber experiments (Jenkin et al., 1997; Aumont et al., 2005) and the incorporation of these mechanisms into box or 1-D models to validate radical and short-lived species against field campaign observations. Less-detailed air quality (AQ) mechanisms can then be compared to these reference mechanisms by way of sensitivity experiments in idealized modeling studies - often aimed at assessing the sensitivity in $\mathrm{O}_{3}$ to changing $\mathrm{NO}_{x}$ and VOC emissions (Archibald et al., 2010; Squire et al., 2015). AQ mechanisms are often also then re-evaluated against chamber and/or field experiment data before they are implemented into 3-D models and then undergo evaluation against extensive measurements in the residual layer.

One of the greatest challenges in the BVOC- $\mathrm{NO}_{3}$ system is that current nighttime measurements are mainly collected from surface sites, which are confined to a shallow surface layer at night and not representative of the whole nighttime boundary layer. The impact of nighttime chemistry on daytime ozone and nitrogen/aerosol budget would require careful investigation of nighttime chemistry in the residual layer, which contains $>80 \%$ of air masses at night.

Moreover, the benchmarking activities mentioned above and the development process discussed in Sect. 3.5.1 are not well aligned. A more unified approach that identifies some key mechanistic problems and identifies strategies to evaluate them is required in order to make improved progress on simulating the changing composition of the atmosphere.

\subsubsection{Reduce uncertainties in sub-grid-scale processes}

Uncertainties in AQM predictions also arise from the representation of physical sub-grid-scale processes. The ones particularly relevant for the $\mathrm{NO}_{3}$-BVOC chemistry include, but are not limited to, the following. 


\section{Nighttime boundary layer mixing}

The spatial distribution of $\mathrm{BVOC}$ and $\mathrm{NO}_{x}$ precursors is highly variable, but the current AQMs neglect these heterogeneities and assume perfect mixing within grid cells of typically $3-10 \mathrm{~km}$ in the horizontal. At those resolutions, models are unable to resolve the localized surface emission sources and the microscale structure of boundary layer turbulence, and therefore cannot resolve spatial heterogeneities in chemistry, partitioning, and mixing of chemicals, which are essential for predicting the concentrations of secondary pollutants.

Typically, the freshly emitted monoterpene species have a tendency to accumulate in the shallow nighttime boundary layer (typically $<200 \mathrm{~m}$ ), and can react with $\mathrm{NO}_{3}$ if available. However, often $\mathrm{NO}_{3}$ is located in the residual layer that is decoupled from the nighttime boundary layer (NBL), and the $\mathrm{BVOC}+\mathrm{NO}_{3}$ reactions would depend on the model's ability to mix the two layers. Thus, mixing within and out of the boundary layer provides a key challenge for modeling the impacts of BVOC-NO $\mathrm{NO}_{3}$ chemistry, as the measured gradients of $\mathrm{NO}_{3}$ and $\mathrm{BVOC}$ are very strong in the vertical (e.g., Brown et al., 2007b; Fuentes et al., 2007).

A large focus on model evaluation has been on the impacts of higher horizontal resolution (Jang et al., 1995). It has been shown in several cases that owing to the complex interplay of chemical families, the sensitivity of the chemical system is not captured at lower resolution (e.g., Cohan et al., 2006). However, very little work has focused on the role of improvements in vertical resolution, despite the fact that inter-model differences in properties like the height of the boundary layer vary by over a factor of 2 in some cases (e.g., Hu et al., 2010). Moreover, the NBL is not well mixed, so evaluation of nocturnal physics requires more than just evaluating the NBL height.

\section{Plume parameterizations}

Typically, parameterizations have been applied to anthropogenic emission sources (e.g., aircraft plumes, urban plumes) and not to biogenic sources. Partly, this is a result of the differences in the source terms, anthropogenic emissions often being well represented as point sources in space, whereas biogenic emissions are often large area sources. However, as the emissions of BVOC are often very species specific, and observations highlight large spatial variability over small areas (e.g., Niinemets et al., 2010), the adoption of the anthropogenic plume parameterizations to BVOC emissions could lead to improvements in model performance.

One approach is the plume-in-grid (PiG) parameterization (Karamchandani et al., 2002). This aims to solve the problem of sub-grid-scale chemical processes by implementing ensembles of Gaussian puffs within the AQM (e.g., Vijayaraghavan et al., 2006). Other approaches include hybrid Eulerian-Lagrangian models (Alessandrini and Ferrero, 2009). These differ from the PiG models by simulating large numbers of stochastic trajectories that can make use of variable reactive volumes to simulate their diffusion into background air masses simulated on Eulerian grids.

Global models have generally used a different approach to the problem of plumes. Broadly, following one of the two paradigms (Paoli et al., 2011) to (i) modify the emissions of the reaction mix (using so-called effective emissions or applying emission conversion factors) and (ii) modify the rates of reaction (effective reaction rates).

\subsection{Field studies in the developing world and under-studied areas}

In light of the questions raised earlier in this review, assessing the role of $\mathrm{NO}_{3}$-BVOC chemistry will require field experiments over a wide range of ratios of isoprene to monoterpene emissions and of $\mathrm{NO}_{3}$ to BVOC. Future studies of $\mathrm{NO}_{3}-$ BVOC chemistry are in the planning stages for North America. These studies will provide access to environments with different $\mathrm{NO}_{x}$ levels and over a modest range of isoprene and monoterpene emission rates. A wider range of these parameters can be accessed in countries where $\mathrm{NO}_{x}$ emission controls are not as completely implemented and where BVOC emissions are abundant. Bringing the state-of-the-art capabilities developed for study of $\mathrm{NO}_{3}$-BVOC chemistry to locations in China and India would allow insight not only into the role of that chemistry in those countries now but also into the role this chemistry played in Europe and the US prior to implementation of current emission standards. Experiments in the tropics potentially would allow observations of the confluence of BVOC and very low $\mathrm{NO}_{x}$ to be explored, thus providing insight into $\mathrm{BVOC}-\mathrm{NO}_{3}$ as a sink of $\mathrm{NO}_{x}$.

\subsection{Future needs for chamber studies}

Field studies, by definition, include the entire complexity of the real atmosphere, so that the identification of single processes and quantification of their impact is challenging. Specific experiments in chambers allow investigating processes without effects from meteorology, which largely impacts observations in the real atmosphere specifically during nighttime, when the lower troposphere is not as well mixed as it is during daytime. In chamber experiments, specific compounds of interest can be isolated and studied under well-controlled oxidation environments, allowing a more detailed and direct characterization of the composition, chemical, and physical properties of aerosols. Because such laboratory chamber data provide the basic understanding for predicting SOA formation, it is important that the design of such experiments mimics the oxidation environments in the atmosphere to the greatest extent possible. Several important needs for understanding $\mathrm{NO}_{3}$-BVOC chemistry in chambers include (1) elucidation of kinetic and mechanistic information for $\mathrm{NO}_{3}$-BVOC reactions; (2) characterization of wall losses for low-volatility products in the $\mathrm{NO}_{3}$-BVOC system; 
(3) understanding the fate of peroxy radicals in the nighttime atmosphere and its influence on this chemistry; (4) hydrolysis and photooxidation of BVOC-derived organic nitrates from specific BVOC plus specific oxidant pairs over a range of appropriate conditions; (5) optical properties of aerosol organic nitrate; and (6) intercomparison of instrumental methods for key species in the $\mathrm{NO}_{3}$-BVOC system.

\section{Kinetic and mechanistic elucidation}

The number of chamber studies investigating $\mathrm{NO}_{3}$ chemistry is small compared to the number of studies for photochemical oxidation and ozonolysis. In most of the studies, gas-phase oxidation products and SOA yields from the oxidation of BVOC have been measured. Studies include the investigation of SOA from monoterpenes (Wangberg et al., 1997; Griffin et al., 1999; Hallquist et al., 1999; Spittler et al., 2006; Fry et al., 2009, 2011; Boyd et al., 2015; Nah et al., 2016b), methyl butenol (Fantechi et al., 1998a, b), and isoprene (Rollins et al., 2009; Ng et al., 2010; Schwantes et al., 2015). A few more studies investigated gas-phase reaction kinetics, including the reactions of $\mathrm{NO}_{3}$ with aldehydes (Clifford et al., 2005; Bossmeyer et al., 2006), amines (Zhou and Wenger, 2013), or cresol (Olariu et al., 2013). As a consequence of the small number of studies, the oxidation mechanisms of organic compounds by $\mathrm{NO}_{3}$ and the yields of oxidation products in the gas phase and particle phase have larger uncertainties. The well-controlled oxidation environments in chamber experiments, coupled with complimentary gas-phase and particle-phase measurements (online and offline), allow for elucidating detailed oxidation mechanisms under varying reaction conditions ( $\mathrm{Ng}$ et al., 2008; Boyd et al., 2015; Schwantes et al., 2015). Identification of gas- and particle-phase reaction products from $\mathrm{NO}_{3}$-BVOC chemistry within controlled chamber environments can also greatly aid in the interpretation of field data in which multiple oxidants and BVOC are present. Future chamber experiments will naturally take advantage of new advanced gas-aerosol instrumentation and aim to constrain the formation yields of gasphase oxidation products and establish a fundamental understanding of aerosol formation mechanisms from $\mathrm{NO}_{3}$-BVOC under a wide range of oxidation conditions.

\section{Wall losses}

Although chamber studies allow separating processes driven by chemistry and physics from transport processes that occur in the real atmosphere, careful characterization of the behavior of $\mathrm{NO}_{3}$ in chambers as well as the organic products of the $\mathrm{NO}_{3}$ oxidation remains a research priority. Yields of gas-phase oxidation products can be influenced by chamberspecific loss processes (surface loss on the chamber wall) and SOA yields can be impacted by both direct loss of particles and loss of species that can condense on particle or chamber wall surfaces (McMurry and Grosjean, 1985; Loza et al., 2010; Matsunaga and Ziemann, 2010; Yeh and Ziemann, 2014; Zhang et al., 2014a, 2015; Krechmer et al., 2016; La et al., 2016; Nah et al., 2016a; Ye et al., 2016). The extent to which vapor wall loss affects SOA yields appears to be dependent on the VOC system, from relatively small effects to as high as a factor of 4 (Zhang et al., 2014a; Nah et al., 2016a). Studies on the effects of vapor loss on $\mathrm{SOA}$ formation from $\mathrm{BVOC}+\mathrm{NO}_{3}$ are limited. With minimal or no competing gas-particle partitioning processes, substantial vapor wall loss of organic nitrates has been observed in experiments not specific to $\mathrm{NO}_{3}$ oxidation (Yeh and Ziemann, 2014; Krechmer et al., 2016). However, the use of excess oxidant concentrations and rapid SOA formation in $\mathrm{BVOC}+\mathrm{NO}_{3}$ experiments (hence, shorter experiments) could potentially mitigate the effects of vapor wall loss on SOA yields in chamber studies (Boyd et al., 2015; Nah et al., 2016a). In light of the developing understanding of this issue, an important consideration for the design of any future systematic chamber studies is the influence of vapor wall loss on SOA formation from nitrate radical oxidation under different reaction conditions, such as peroxy radical fates, relative humidity, seeds, oxidant level, chamber volume, etc.

\section{Peroxy radical fate}

As discussed above, the fate of peroxy radicals directly governs the product distribution in the $\mathrm{NO}_{3}$-BVOC system, including SOA yields and composition. Dark reactions of peroxy radicals differ significantly from their photochemical analogs, and are directly related to the development of mechanistic understanding in the $\mathrm{NO}_{3}$-BVOC system. There is a need to systematically investigate reaction products and SOA formation from $\mathrm{NO}_{3}-\mathrm{BVOC}$ reactions under different peroxy radical reaction regimes, but this aspect has only recently become a focus of chamber studies (Ng et al., 2008; Boyd et al., 2015; Schwantes et al., 2015). Rapid formation of highly oxygenated organic nitrates has been observed in laboratory studies of $\beta$-pinene $+\mathrm{NO}_{3}$ and $\alpha$-pinene $+\mathrm{NO}_{3}$; these products could be formed by unimolecular isomerization of peroxy radicals or autoxidation (Nah et al., 2016b). The importance of this peroxy radical reaction channel in $\mathrm{NO}_{3}$-BVOC chemistry warrants further studies. Future chamber studies will need to be explicit in their specification of the peroxy radical chemistry regime that is investigated in a particular experiment, and will need to relate that regime to the conditions of ambient nighttime atmosphere.

\section{Organic nitrate hydrolysis and photooxidation}

Recent field studies have shown that organic nitrates formed from $\mathrm{NO}_{3}$-BVOC are important components of ambient OA. However, the reactivity in both gaseous and condensed phases of these biogenic nitrates, in particular of polyfunctional nitrates, has been subject to few studies and requires better characterization to evaluate the role of these com- 
pounds as reservoirs/sinks of $\mathrm{NO}_{x}$. Field results suggest that the fate of organic nitrates in both the gas and aerosol phase have variable lifetimes with respect to hydrolysis. The difference in the relative amount of primary/secondary/tertiary organic nitrates (which hydrolyze with different rates) from nitrate radical oxidation versus photochemical oxidation needs to be constrained. Most of the hydrolysis studies thus far are conducted in bulk, except for a few recent studies on monoterpene organic nitrates (e.g., Boyd et al., 2015; Rindelaub et al., 2015). The solubility of multifunctional organic nitrates in water and the extent to which hydrolysis occurs in aerosol water warrant future studies. The effect of particle acidity on hydrolysis might also be important for organic nitrates formed in different BVOC systems.

While there are extensive studies on photochemical aging of ozonolysis SOA, studies on photochemical aging of $\mathrm{NO}_{3}$-initiated SOA and organic nitrates are extremely limited. A recent study shows that the particle-phase organic nitrates from $\mathrm{NO}_{3}+\beta$-pinene and $\mathrm{NO}_{3}+\alpha$-pinene reactions exhibit completely different behavior upon photochemical aging during the night-to-day transition, and act as permanent and temporary $\mathrm{NO}_{x}$ sinks, respectively ( $\mathrm{Nah}$ et al., 2016b). With the $\sim 1$-week lifetime of aerosols in the atmosphere and the majority of $\mathrm{NO}_{3}$-BVOC organic nitrates that are formed at night, the photochemical fates of these organic nitrates could impact next-day $\mathrm{NO}_{x}$ cycling and ozone formation. Therefore, there is a critical need to understand the multigenerational chemistry and characterize the evolution of organic nitrates over its diurnal life cycle, including aging $\mathrm{NO}_{3}$-initiated SOA and organic nitrates by photolysis and/or $\mathrm{OH}$ radicals.

\section{Aerosol optical properties}

The optical properties, especially in the short wavelength region, of $\mathrm{NO}_{3}$-derived $\mathrm{SOA}$ may be most conveniently measured during coordinated chamber studies that also include detailed measurements of gas-phase oxidation chemistry and aerosol composition. Such studies could also serve to isolate the specific optical properties of $\mathrm{NO}_{3}$-BVOC-derived aerosol to obtain better optical closure in the interpretation of field data. Field studies that include aerosol optical properties measurements in conjunction with other instrumentation can help quantify the bulk organic nitrate abundance and identify organic nitrate molecular composition in the SOA.

\section{Instrument intercomparisons}

The discussion above shows that recent advances in analytical instrumentation are key to the developing science of $\mathrm{NO}_{3}$-BVOC chemistry. Chamber studies provide an excellent opportunity for the comparison and validation of such instrumentation. State-of-the-art and developing instruments for measurement of $\mathrm{NO}_{3}$ and $\mathrm{N}_{2} \mathrm{O}_{5}$ were compared approximately a decade ago (Fuchs et al., 2012; Dorn et al., 2013).
These instruments have improved and proliferated since that time, and further validation studies are needed. Measurements of total and speciated gas and aerosol-phase organic nitrates, as well as other oxygenated compounds that result from $\mathrm{NO}_{3}$-BVOC reactions, have not been the subject of a specific intercomparison study. Their comparison and validation will be a priority in future coordinated chamber studies.

\section{Utility of coordinated chamber studies}

Because of the need for a better understanding of $\mathrm{NO}_{3}$ oxidation and because of the challenges of chamber studies, investigating $\mathrm{NO}_{3}$ chemistry, coordination between studies carried out in different chambers, and between chamber and field studies, can augment efforts of single or stand-alone chamber studies. Coordinated studies that would include several chambers could increase the accuracy and reliability of results and quantify realistic errors associated with product yield estimates. This can be achieved by determining the same quantities in similar experiments in different chambers. Studies could benefit from complementary capabilities and properties of chambers. Chambers that typically operate at higher concentration ranges, and therefore increased oxidation rates, are suitable to perform a larger number of experiments that are useful for screening experiments and a series of experiments with systematic variations of chemical conditions. Other chambers are suited to perform experiments at atmospheric reactant concentrations. Experiments in these chambers may take place on a longer timescale, for example, a scale characteristic of the duration of at least one night. Analytical instrumentation and capability also differs considerably among chambers, so that coordinated chamber studies can make use of the determination of complementary quantities such as product yields of different organic compounds and characterization of various properties of particles for the same chemical system. For instance, it would be invaluable to conduct coordinated studies where a variety of instrument techniques are used to measure total and speciated gas- and particle-phase organic nitrates, as well as aerosol physical and chemical properties in the same chamber.

Substantial insights into aerosol sources, formation, and processing can be gained from coordinated laboratory chamber and field studies. Laboratory chamber experiments provide the fundamental data to interpret field measurements. The analysis of field data in turn can provide important insights for constraining chamber experiment parameters so that the oxidation conditions in chambers can be as representative as possible of those in the atmosphere. Two recent sets of experiments serve as examples of this approach. Fundamental chamber studies on $\beta$-pinene $+\mathrm{NO}_{3}$ in the Georgia Tech Environmental Chamber (GTEC) facility under conditions relevant to the SE US provided constraints on the contribution of monoterpenes $+\mathrm{NO}_{3}$ to ambient $\mathrm{OA}$ during the 2013 SOAS campaign (Boyd et al., 2015; Xu et al., 2015a). The Focused Isoprene eXperiment at California Institute of 
Technology (FIXCIT) chamber study following SOAS advanced the understanding of isoprene oxidation chemistry relevant to the SE US (Nguyen et al., 2014). It is important not to consider fundamental laboratory studies as isolated efforts, but they should be an integrated part of field studies. Similarly, having the modeling community involved in early planning stages of laboratory and field studies will greatly aid in the identification of critically needed measurement data.

\section{Impacts of $\mathrm{NO}_{3}-\mathrm{BVOC}$ chemistry on air quality}

The previous sections have demonstrated that understanding how $\mathrm{NO}_{3}$ reacts with BVOC, including the ultimate fate of products, encompasses all aspects of atmospheric physics, chemistry, and transport. These sections have raised numerous complex and fascinating scientific questions and highlighted the critical need for much more basic science to fill in unknown aspects of this system. However, "getting this system right" is not just an interesting scientific problem because it has direct implications for policy decisions that governments across the world are taking to protect citizens and ecosystems from harmful effects of air pollutants. Addressing the uncertainties raised in the previous sections is critical for developing efficient, accurate, and cost-effective strategies to reduce the harmful effects of air pollution.

BVOC have long been predicted to be significant contributors to regional and global $\mathrm{O}_{3}$ (e.g., Pierce et al., 1998; Curci et al., 2009) and $\mathrm{PM}_{2.5}$ (Pandis et al., 1991), with $\mathrm{NO}_{3}$ reactions providing a major pathway for loss of ambient BVOC (Winer et al., 1984; Pye et al., 2010; Xie et al., 2013). If BVOC react with $\mathrm{NO}_{3}$ instead of $\mathrm{OH}$, the $\mathrm{O}_{3}$ production of the BVOC can be reduced relative to reactions through $\mathrm{OH}$, although in some instances they may slightly increase $\mathrm{O}_{3}$ by reducing next-day $\mathrm{NO}_{x}$. For example, measurements in St. Louis (Millet et al., 2016) demonstrate that nights with lower levels of $\mathrm{NO}_{3}$ resulted in higher isoprene concentrations the following morning, producing higher and earlier $\mathrm{O}_{3}$ peaks. Recent insights into the role of biogenic nitrates, which are produced in large quantities through the reactions of $\mathrm{NO}_{3}$ with primary emitted BVOC and subsequent reactions of their stable products, demonstrate that these compounds can substantially alter the availability of $\mathrm{NO}_{x}$ (Perring et al., 2013). This highlights the importance of accurate treatment of fates of organic nitrates that form from nighttime chemistry in models, which will impact the next-day $\mathrm{NO}_{x}$ and ozone levels. Organic nitrates from $\mathrm{BVOC}+\mathrm{NO}_{3}$ also can contribute to nitrogen deposition (Nguyen et al., 2015), which adversely impacts ecosystems. The ways in which the patterns of deposition for biogenic nitrates affect inorganic nitrate deposition remain poorly understood.

\section{Implications for spatial distribution of ozone and $\mathbf{P M}_{\mathbf{2 . 5}}$}

While it is clear that $\mathrm{NO}_{3}$-BVOC reactions affect oxidant availability and SOA, it remains unclear how large that role is in the ambient atmosphere relative to other VOC and other oxidants and where it occurs. The extent of $\mathrm{O}_{3}$ formation downwind of sources is influenced by the transport of $\mathrm{NO}_{y}$ species, including organic nitrates, which can release $\mathrm{NO}_{x}$ downwind, where $\mathrm{O}_{3}$ may be formed more efficiently. Biogenically derived nitrates are the dominant organic nitrates in many places (Pratt et al., 2012). A variety of different organic nitrates are formed from different BVOC, with some being short lived (releasing $\mathrm{NO}_{2}$ locally) and others being long lived (releasing $\mathrm{NO}_{2}$ downwind unless they are removed in the meantime). Errors in our attribution of the lifetime of individual biogenic nitrate compounds can cause errors in predicted $\mathrm{NO}_{x}$ redistributions regionally and globally, and modify the spatial distributions of $\mathrm{O}_{3}$ (Perring et al., 2013). Updates to the chemistry of BVOC- $\mathrm{NO}_{3}$ also could alter calculations of the relative role of biogenic species versus anthropogenic pollutants to $\mathrm{O}_{3}$ and $\mathrm{PM}_{2.5}$ formation.

\section{Implications for control strategy development}

Air quality models are used not only to understand the production of air pollutants in the current atmosphere but also to guide the development of strategies to reduce the future pollution burden. Uncertainties in the chemistry and removal of BVOC can contribute to uncertainties in the sensitivity of $\mathrm{O}_{3}$ and $\mathrm{PM}$ to emission reduction strategies. This increases the risk of implementing expensive control strategies that are found later to be inefficient (more control specified than needed) or ineffective (do not meet the air quality goals for which they were developed). As noted by Millet et al. (2016), in urban areas downwind of high isoprene emissions, the loss of isoprene by $\mathrm{NO}_{3}$ at night can produce the opposite $\mathrm{O}_{3}-\mathrm{NO}_{x}$ behavior that would normally be expected in urban areas, potentially causing a reassessment of optimum control strategies. In addition, the early $\mathrm{O}_{3}$ peaks noted on low $\mathrm{NO}_{3}$ nights expands the high ozone time window, resulting in higher $8 \mathrm{~h} \mathrm{O}_{3}$ averages, on which regulatory compliance in the US is based.

The uncertainties in our understanding of $\mathrm{NO}_{3}$-BVOC chemistry propagate into chemical mechanisms, as described in Sect. 3. Past work has shown that vastly different chemical mechanisms may predict similar $\mathrm{O}_{3}$ in current atmospheres but show huge differences for intermediate species (e.g., Luecken et al., 2008) and different potential responses to precursor reductions, including different indicators of $\mathrm{O}_{3}$ sensitivity to VOC versus $\mathrm{NO}_{x}$ reductions (Knote et al., 2015). The presence of large weekend effects in $\mathrm{NO}_{x}$ makes identifying such errors more likely in current analyses.

Incorporating new information on biogenic chemistry within a chemical mechanism will impact the availability of $\mathrm{NO}_{x}$ (e.g., Archibald et al., 2010; Xie et al., 2013) and mod- 
ify the predicted effectiveness of anthropogenic $\mathrm{NO}_{x}$ controls. Incorporating new chemical information into models can also impact $\mathrm{PM}_{2.5}$ sensitivities to $\mathrm{NO}_{x}$ reductions. In one example, organic $\mathrm{PM}_{2.5}$ was almost twice as responsive to a $\mathrm{NO}_{x}$ reduction than in older mechanisms (Pye et al., 2015). Because much of the $\mathrm{NO}_{x}$ dependence of $\mathrm{O}_{3}$ and aerosols from $\mathrm{NO}_{3}$-BVOC reactions is inadequately accounted for in models, the few examples we have hint that current $\mathrm{NO}_{x}$ control strategies might result in more significant improvements to air quality than currently assumed. Retrospective analyses should focus on elucidating the elements of this hypothesis that are represented in the historical record.

The role of climate change in modifying air quality is also a highly uncertain issue and may be particularly sensitive to the characterization of BVOC. Biogenic emissions may increase or decrease in the future, depending on many factors including increased temperatures, changes in water availability, occurrence of biotic and abiotic stress (e.g., Kleist et al., 2012; $\mathrm{Wu}$ et al., 2015), $\mathrm{CO}_{2}$ fertilization, $\mathrm{CO}_{2}$ inhibition, and land use changes (Chen et al., 2009; Squire et al., 2014). Uncertainties in biogenic reactions may be amplified as they become a larger share of the VOC burden in some places. The predicted response of $\mathrm{O}_{3}$ to future climate has been found to be especially sensitive to assumptions about the chemical pathways of BVOC reactions, in particular the treatment of nitrates. Mao et al. (2013) and several earlier researchers found that predictions of the $\mathrm{O}_{3}$ response to $\mathrm{NO}_{x}$ reductions change from negative to positive depending solely on how the isoprene chemistry was represented. Similarly, a comparison of several widely used chemical mechanisms with varied descriptions of BVOC-derived nitrates (Squire et al., 2015) found that description of BVOC chemistry significantly alters not only the amount of oxidant change predicted under future scenarios but also the direction of the change. Direct measurements of the key steps in isoprene oxidation should eliminate the ambiguity in such model calculations. Nonetheless, the exquisite sensitivity of model predictions of ozone trends to the representation of isoprene and $\mathrm{NO}_{x}$ indicates that ambient observations of those trends are an excellent strategy for evaluating the accuracy of mechanisms.

The relative distribution of emissions among different types of BVOC may also shift as climate and land use changes, emphasizing the need to understand differences among terpenes in their chemistry, transport, and fate (Pratt et al., 2012). While most of the research to date has been done on isoprene, with some on $\alpha$-pinene and $\beta$-pinene, little has been done on products or reaction parameters of other terpenes. The previous sections have demonstrated that different terpenoid structures can have vastly different atmospheric chemistry and physical properties, so it is unclear whether assuming one "representative" species or distribution, as is done in most chemical mechanisms, will adequately account for future impacts of $\mathrm{BVOC}$ on $\mathrm{O}_{3}$ and PM.

\section{Summary of impacts}

This review has illustrated that accurate characterization of $\mathrm{NO}_{3}$-BVOC chemistry is critical to our understanding of both the air quality and climate impacts of $\mathrm{NO}_{x}$ emissions. Our knowledge of the complexity of $\mathrm{NO}_{3}-\mathrm{BVOC}$ reaction pathways and multigenerational products has advanced rapidly, especially in the last decade. Despite the fact that much of that information is not yet in a form that can be included in current air quality models, we anticipate improved predictive capabilities in models in the coming years through sustained laboratory and field studies coupled to model development. While the current levels of uncertainty make it difficult to accurately quantify the impact of $\mathrm{NO}_{3}-\mathrm{BVOC}$ chemistry on air pollutant concentrations, we expect that developments in this field will improve the effectiveness of air pollution control strategies going forward. The limited studies available demonstrate that even small changes to BVOC chemistry modify the production of oxidants $\left(\mathrm{NO}_{3}, \mathrm{OH}\right.$, and $\mathrm{O}_{3}$ ) and change the transport of $\mathrm{NO}_{y}$. Therefore, $\mathrm{NO}_{3}-$ BVOC oxidation modifies the chemical regime in which additional BVOC oxidation occurs. Of most importance will be the studies that indicate changes in the direction of predicted future pollutant concentrations as chemical mechanisms of BVOC are updated. Emission control strategies and attainment of air quality goals rely on the best possible chemical models. Current and future laboratory and field research is critical to the improvement of chemical mechanisms that account for biogenic chemical processes and products which will augment efforts to reduce harmful air pollutants. 


\section{Appendix A}

Glossary of abbreviations and common chemical formulas.

\begin{tabular}{|c|c|}
\hline ACSM & Aerosol chemical speciation monitor \\
\hline AM3 & Atmospheric Model 3 \\
\hline AMS & Aerosol mass spectrometry/spectrometer \\
\hline AQM & Air quality model \\
\hline $\mathrm{AR}$ & Absolute rate in simulation chamber \\
\hline BB-CEAS & Broadband cavity-enhanced absorption spectroscopy \\
\hline BB-CRDS & Broadband cavity ring-down spectroscopy \\
\hline BDE & Bond dissociation energy \\
\hline BEACHON-RoMBAS & Rocky Mountain Biogenic Aerosol Study \\
\hline BERLIOZ & Berliner Ozonexperiment \\
\hline BEWA & Regional Biogenic Emissions of Reactive Volatile Organic Compounds from Forests \\
\hline $\mathrm{BC}$ & Black carbon \\
\hline $\mathrm{BrC}$ & Brown carbon \\
\hline BVOC & Biogenic volatile organic compound(s) \\
\hline CalNex & California Research at the Nexus of Air Quality and Climate Change \\
\hline CAMx & Comprehensive Air Quality Model with extensions \\
\hline CARES & Carbonaceous Aerosol and Radiative Effects Study \\
\hline CAPRAM & Chemical aqueous-phase radical mechanism \\
\hline CAPS & Cavity-attenuated phase shift spectroscopy/spectrometer \\
\hline CB05 & Carbon Bond 2005 chemical mechanism \\
\hline $\mathrm{CCN}$ & Cloud condensation nuclei \\
\hline CEAS & Cavity-enhanced absorption spectroscopy/spectrometer \\
\hline CE-DOAS & Cavity-enhanced differential optical absorption spectroscopy \\
\hline CIMS & Chemical ionization mass spectrometry/spectrometer \\
\hline CMAQ & Community Multiscale Air Quality \\
\hline CRDS & Cavity ring-down spectroscopy/spectrometer \\
\hline DF-A & Discharge flow - absorption \\
\hline DF-CEAS & Discharge flow - cavity-enhanced absorption spectroscopy \\
\hline DF-LIF & Discharge flow - laser-induced fluorescence \\
\hline DF-MS & Discharge flow - mass spectrometry \\
\hline DMS & Dimethyl sulfide \\
\hline DOAS & Differential optical absorption spectroscopy/spectrometer \\
\hline ELVOC & Extremely low volatility organic compounds \\
\hline EMEP & European Monitoring and Evaluation Program \\
\hline EPA & Environmental Protection Agency \\
\hline ESI & Electrospray ionization \\
\hline EUCAARI & European Integrated project on Aerosol, Cloud, Climate, and Air Quality Interactions \\
\hline EURAD-IM & EURopean Air pollution Dispersion - Inverse Model \\
\hline F-A & Flow system - absorption \\
\hline F-CIMS & Flow system - chemical ionization mass spectrometry \\
\hline F-LIF & Flow system - laser-induced fluorescence \\
\hline FIGAERO & Filter inlet for gases and aerosols \\
\hline FIXCIT & Focused Isoprene eXperiment at California Institute of Technology \\
\hline FTICR & Fourier transform ion cyclotron \\
\hline FTIR & Fourier transform infrared spectroscopy \\
\hline GC & Gas chromatography \\
\hline GC-MS & Gas chromatography mass spectrometry \\
\hline GCM & Global climate model \\
\hline GECKO-A & Generator of Explicit Chemistry and Kinetics of Organics in the Atmosphere \\
\hline GEOS-Chem & Goddard Earth Observing System - Chemistry \\
\hline GLOMAP & Global Model of Aerosol Processes \\
\hline GTEC & Georgia Tech Environmental Chamber \\
\hline HAP & Hazardous air pollutant(s) \\
\hline HOHPEX & HOHenpeissenberg Photochemistry Experiment \\
\hline HPLC & High-performance liquid chromatography \\
\hline $\mathrm{HO}_{2}$ & Hydroperoxy radical \\
\hline HR-ToF & High-resolution time-of-flight \\
\hline $\mathrm{IC}$ & Ion chromatography \\
\hline ICARTT & International Consortium for Atmospheric Research on Transport and Transformation \\
\hline IGAC & International Global Atmospheric Chemistry \\
\hline IN & Ice nuclei \\
\hline IUPAC & International Union of Pure and Applied Chemistry \\
\hline $\mathrm{LC}$ & Liquid chromatography \\
\hline LED & Light-emitting diode \\
\hline
\end{tabular}


Glossary of abbreviations and common chemical formulas.

\begin{tabular}{|c|c|}
\hline LIF & Laser-induced fluorescence \\
\hline LO-OOA & Less-oxidized oxygenated organic aerosol \\
\hline LV-OOA & Low-volatility oxygenated organic aerosol \\
\hline MAC & Mass absorption coefficient \\
\hline $\mathrm{MCM}$ & Master chemical mechanism \\
\hline MBO & 2-methyl-3-buten-2-ol \\
\hline MIESR & Matrix isolation electron spin resonance \\
\hline MO-OOA & More-oxidized oxygenated organic aerosol \\
\hline MOSAIC & Model for Simulating Aerosol Interactions and Chemistry \\
\hline MOZART & Model for OZone and Related chemical Tracers \\
\hline NARSTO & North American Research Strategy for Tropospheric Ozone \\
\hline NEAQS & New England Air Quality Study \\
\hline NBL & Nocturnal boundary layer \\
\hline NEI & National Emissions Inventory \\
\hline NO & Nitric oxide \\
\hline $\mathrm{NO}_{2}$ & Nitrogen dioxide \\
\hline $\mathrm{NO}_{3}$ & Nitrate radical \\
\hline $\mathrm{N}_{2} \mathrm{O}_{5}$ & Dinitrogen pentoxide \\
\hline $\mathrm{NO}_{x}$ & Nitrogen oxides, $\mathrm{NO}+\mathrm{NO}_{2}$ \\
\hline $\mathrm{NO}_{y}$ & Total reactive nitrogen \\
\hline NOS & Nitrooxy organosulfate \\
\hline NSF & National Science Foundation \\
\hline $\mathrm{O}_{3}$ & Ozone \\
\hline OA & Organic aerosol \\
\hline $\mathrm{OC}$ & Organic carbon \\
\hline $\mathrm{OH}$ & Hydroxyl radical \\
\hline OS & Organosulfate \\
\hline PACIFIC & Pacific Air Quality Study \\
\hline PAHs & Polyaromatic (or polycyclic aromatic) hydrocarbons \\
\hline PiLS & Particle-into-liquid sampler \\
\hline PiG & Plume-in-grid \\
\hline PM & Particulate matter \\
\hline $\mathrm{PM}_{1 / 2.5}$ & Particulate matter smaller than $1 / 2.5 \mu$ \\
\hline $\mathrm{PMF}$ & Positive matrix factorization \\
\hline PROPHET & Program for Research on Oxidants: Photochemistry, Emissions and Transport \\
\hline PTR-MS & Proton transfer reaction mass spectrometry \\
\hline PR-A & Pulse radiolysis - absorption \\
\hline RH & Relative humidity \\
\hline RI & Refractive index \\
\hline RL & Residual layer \\
\hline $\mathrm{RONO}_{2}$ & Organic nitrate \\
\hline $\mathrm{RO}_{2}$ & Organic peroxy radical \\
\hline RR & Relative rate \\
\hline SAPRC & Statewide Air Pollution Research Center \\
\hline SAR & Structure activity relationship \\
\hline $\mathrm{SEAC}^{4} \mathrm{RS}$ & $\begin{array}{l}\text { Studies of Emissions and Atmospheric Composition, Clouds and } \\
\text { Climate Coupling by Regional Surveys }\end{array}$ \\
\hline SEARCH & Southeastern Aerosol Research and Characterization \\
\hline SOA & Secondary organic aerosol \\
\hline SOAS & Southern Oxidant and Aerosol Study \\
\hline SOS & Southern Oxidant Study \\
\hline STOCHEM-CRI & STOchastic lagrangian CHEMistry model using Common Representative Intermediates \\
\hline SV-OOA & Semi-volatile oxygenated organic aerosol \\
\hline TD-CAPS & Thermal dissociation cavity-attenuated phase shift spectroscopy \\
\hline TD-CRDS & Thermal dissociation cavity ring-down spectroscopy \\
\hline TD-LIF & Thermal dissociation laser-induced fluorescence \\
\hline UKESM-1 & UK Earth System Model 1 \\
\hline VBS & Volatility basis set \\
\hline VOC & Volatile organic compound(s) \\
\hline WRF-Chem & Weather Research and Forecasting Model with Chemistry \\
\hline
\end{tabular}




\section{The Supplement related to this article is available online at doi:10.5194/acp-17-2103-2017-supplement.}

Competing interests. The authors declare that they have no conflict of interest.

Acknowledgements. The authors acknowledge support from the International Global Atmospheric Chemistry project (IGAC), the US National Science Foundation (NSF grants AGS-1541331 and AGS-1644979), and Georgia Tech College of Engineering and College of Sciences for support of the workshop on nitrate radicals and biogenic hydrocarbons that led to this review article. N. L. Ng acknowledges support from NSF CAREER AGS-1555034 and US Environmental Protection Agency STAR (Early Career) RD-83540301. S. S. Brown acknowledges support from the NOAA Atmospheric Chemistry, Carbon Cycle and Climate program. A. T. Archibald and B. Ouyang thank NERC for funding through NE/M00273X/1. E. Atlas acknowledges NSF grant AGS-0753200. R. C. Cohen acknowledges NSF grant AGS-1352972. J. N. Crowley acknowledges the Max Planck Society. J. L. Fry, D. A. Day, and J. L. Jimenez acknowledge support from the NOAA Climate Program Office's AC4 program, award no. NA13OAR4310063 (Colorado)/NA13OAR4310070 (Reed). N. M. Donahue acknowledges NSF AGS-1447056. M. I. Guzman wishes to acknowledge support from NSF CAREER award (CHE-1255290). J. L. Jimenez and D. A. Day acknowledge support from NSF AGS-1360834 and EPA 83587701-0. R. McLaren acknowledges NSERC grant RGPIN/183982-2012. H. Herrmann, A. Tilgner, and A. Mutzel acknowledge the DARK KNIGHT project funded by DFG under HE 3086/25-1. B. Picquet-Varrault acknowledges support from the French National Agency for Research (project ONCEM-ANR-12-BS06-0017-01). R. H. Schwantes acknowledges NSF AGS-1240604. Y. Rudich and S. S. Brown acknowledge support from the USA-Israel Binational Science Foundation (BSF) grant no. 2012013. Y. Rudich acknowledges support from the Henri Gutwirth Foundation. J. Mao acknowledges support from the NOAA Climate Program Office grant no. NA13OAR4310071. J. A. Thornton acknowledges support from NSF AGS 1360745. B. H. Lee was supported by the NOAA Climate and Global Change Postdoctoral Fellowship. R. A. Zaveri acknowledges support from the US Department of Energy (DOE) Atmospheric System Research (ASR) program under contract DE-AC06-76RLO 1830 at Pacific Northwest National Laboratory. The US Environmental Protection Agency (EPA), through its Office of Research and Development (ORD), collaborated in the research described herein. It has been subjected to Agency administrative review and approved for publication, but may not necessarily reflect official Agency policy.

Edited by: E. Harris

Reviewed by: two anonymous referees

\section{References}

Abida, O., Mielke, L. H., and Osthoff, H. D.: Observation of gasphase peroxynitrous and peroxynitric acid during the photolysis of nitrate in acidified frozen solutions, Chem. Phys. Lett., 511, 187-192, doi:10.1016/j.cplett.2011.06.055, 2011.

Alessandrini, S. and Ferrero, E.: A hybrid Lagrangian-Eulerian particle model for reacting pollutant dispersion in nonhomogeneous non-isotropic turbulence, Physica A, 388, 13751387, doi:10.1016/j.physa.2008.12.015, 2009.

Aliwell, S. R. and Jones, R. L.: Measurement of atmospheric $\mathrm{NO}_{3} 2$. Diurnal variation of stratospheric $\mathrm{NO}_{3}$ at midlatitude, Geophys. Res. Lett., 23, 2589-2592, 1996a.

Aliwell, S. R. and Jones, R. L.: Measurement of atmospheric $\mathrm{NO}_{3}$ 1. Improved removal of water vapour absorption features in the analysis for $\mathrm{NO}_{3}$, Geophys. Res. Lett., 23, 2585-2588, $1996 \mathrm{~b}$.

Aliwell, S. R. and Jones, R. L.: Measurements of tropospheric $\mathrm{NO}_{3}$ at midlatitude, J. Geophys. Res., 103, 5719-5727, 1998.

Allan, B. J., Carslaw, N., Coe, H., Burgess, R. A., and Plane, J. M. C.: Observations of the Nitrate Radical in the Marine Boundary Layer, J. Atmos. Chem., 33, 129-154, 1999.

Allan, B. J., McFiggans, G., Plane, J. M. C., Coe, H., and McFadyen, G. G.: The nitrate radical in the remote marine boundary layer, J. Geophys. Res., 105, 24191-124204, 2000.

Allan, B. J., Plane, J. M. C., Coe, H., and Shillito, J.: Observations of $\mathrm{NO}_{3}$ concentration profiles in the troposphere, J. Geophys. Res., 107, 4588, doi:10.1029/2002JD002112, 2002.

Allan, J. D., Delia, A. E., Coe, H., Bower, K. N., Alfarra, M. R., Jimenez, J. L., Middlebrook, A. M., Drewnick, F., Onasch, T. B., Canagaratna, M. R., Jayne, J. T., and Worsnop, D. R.: A generalised method for the extraction of chemically resolved mass spectra from aerodyne aerosol mass spectrometer data, J. Aerosol. Sci., 35, 909-922, 2004.

Allan, J. D., Alfarra, M. R., Bower, K. N., Coe, H., Jayne, J. T., Worsnop, D. R., Aalto, P. P., Kulmala, M., Hyötyläinen, T., Cavalli, F., and Laaksonen, A.: Size and composition measurements of background aerosol and new particle growth in a Finnish forest during QUEST 2 using an Aerodyne Aerosol Mass Spectrometer, Atmos. Chem. Phys., 6, 315-327, doi:10.5194/acp-6-315-2006, 2006.

Alvarado, A., Arey, J., and Atkinson, R.: Kinetics of the GasPhase Reactions of $\mathrm{OH}$ and $\mathrm{NO}_{3}$ Radicals and $\mathrm{O}_{3}$ with the Monoterpene Reaction Products Pinonaldehyde, Caronaldehyde, and Sabinaketone, J. Atmos. Chem., 31, 281-297, 1998.

Andreae, M. O. and Gelencser, A.: Black carbon or brown carbon? The nature of light-absorbing carbonaceous aerosols, Atmos. Chem. Phys., 6, 3131-3148, doi:10.5194/acp-6-3131-2006, 2006.

Angove, D., Fookes, C., Hynes, R., Walters, C., and Azzi, M.: The characterisation of secondary organic aerosol formed during the photodecomposition of 1, 3-butadiene in air containing nitric oxide, Atmos. Environ., 40, 4597-4607, 2006.

Arangio, A. M., Slade, J. H., Berkemeier, T., Pöschl, U., Knopf, D. A., and Shiraiwa, M.: Multiphase Chemical Kinetics of OH Radical Uptake by Molecular Organic Markers of Biomass Burning Aerosols: Humidity and Temperature Dependence, Surface Reaction, and Bulk Diffusion, J. Phys. Chem. A, 119, 4533-4544, doi:10.1021/jp510489z, 2015.

Archibald, A. T., Cooke, M. C., Utembe, S. R., Shallcross, D. E., Derwent, R. G., and Jenkin, M. E.: Impacts of mechanis- 
tic changes on $\mathrm{HO}_{\mathrm{x}}$ formation and recycling in the oxidation of isoprene, Atmos. Chem. Phys., 10, 8097-8118, 10.5194/acp-108097-2010, 2010.

Asaf, D., D., P., Matveev, V., Peleg, M., Kern, C., Zingler, J., Platt, U., and Luria, M.: Long-Term Measurements of $\mathrm{NO}_{3}$ Radical at a Semiarid Urban Site: 1. Extreme Concentration Events and Their Oxidation Capacity, Environ. Sci. Technol., 43, 91179123, 2009.

Atkinson, R. and Arey, J.: Atmospheric Degradation of Volatile Organic Compounds, Chem. Rev., 103, 4605-4638, 2003.

Atkinson, R., Aschmann, S. M., Winer, A. M., and Pitts, J. N.: Kinetics of the Gas-Phase Reactions of $\mathrm{NO}_{3}$ Radicals with a Series of Dialkenes, Cycloalkenes, and Monoterpenes at $295 \pm 1$ K, Environ. Sci. Technol., 18, 370-375, 1984.

Atkinson, R., Aschmann, S. M., Winer, A. M., and Pitts, J. N.: Kinetics and atmospheric implications of the gas-phase reactions of $\mathrm{NO}_{3}$ radicals with a series of monoterpenes and related organics at $294 \pm 2-K$, Environ. Sci. Technol., 19, 159-163, doi:10.1021/es00132a009, 1985.

Atkinson, R., Aschmann, S. M., and Pitts, J. N.: Rate constants for the gas-phase reactions of the nitrate radical with a series of organic compounds at $296 \pm 2 \mathrm{~K}$, J. Phys. Chem. A, 92, 34543457, 1988.

Atkinson, R., Aschmann, S. M., and Arey, J.: Rate constants for the gas-phase reactions of $\mathrm{OH}$ and $\mathrm{NO}_{3}$ radicals and $\mathrm{O}_{3}$ with sabinene and camphene at $296 \pm 2 \mathrm{~K}$, Atmos. Environ., 24, 2647-2654, 1990.

Atkinson, R., Arey, J., Aschmann, S. M., Corchnoy, S. B., and Shu, Y.: Rate constants for the gas-phase reactions of cis-3-Hexen-1ol, cis-3-Hexenylacetate, trans-2-Hexenal, and Linalool with $\mathrm{OH}$ and $\mathrm{NO}_{3}$ radicals and $\mathrm{O}_{3}$ at $296 \pm 2 \mathrm{~K}$, and $\mathrm{OH}$ radical formation yields from the $\mathrm{O}_{3}$ reactions, Int. J. Chem. Kinet., 27, 941-955, 1995.

Atlas, E.: Evidence for Greater-Than-or-Equal-to-C-3 Alkyl Nitrates in Rural and Remote Atmospheres, Nature, 331, 426-428, 1988.

Atlas, E. and Schauffler, S.: Analysis of alkyl nitrates and selected halocarbons in the ambient atmosphere using a charcoal preconcentration technique, Environ. Sci. Technol., 25, 61-67, 1991.

Aumont, B., Szopa, S., and Madronich, S.: Modelling the evolution of organic carbon during its gas-phase tropospheric oxidation: development of an explicit model based on a self generating approach, Atmos. Chem. Phys., 5, 2497-2517, doi:10.5194/acp-52497-2005, 2005.

Ayers, J. D. and Simpson, W. R.: Measurements of $\mathrm{N}_{2} \mathrm{O}_{5}$ near Fairbanks, Alaska, J. Geophys. Res.-Atmos., 111, 13377-13392, doi:10.1029/2006JD007070, 2006.

Ayers, J. D., Apodaca, R. L., Simpson, W. R., and Baer, D. S.: Off-axis cavity ringdown spectroscopy: application to atmospheric nitrate radicaldetection, Appl. Optics, 44, 7239-7242, doi:10.1364/AO.44.007239, 2005.

Ayres, B. R., Allen, H. M., Draper, D. C., Brown, S. S., Wild, R. J., Jimenez, J. L., Day, D. A., Campuzano-Jost, P., Hu, W., de Gouw, J., Koss, A., Cohen, R. C., Duffey, K. C., Romer, P., Baumann, K., Edgerton, E., Takahama, S., Thornton, J. A., Lee, B. H., Lopez-Hilfiker, F. D., Mohr, C., Wennberg, P. O., Nguyen, T. B., Teng, A., Goldstein, A. H., Olson, K., and Fry, J. L.: Organic nitrate aerosol formation via $\mathrm{NO}_{3}^{+}$biogenic volatile organic com- pounds in the southeastern United States, Atmos. Chem. Phys., 15, 13377-13392, doi:10.5194/acp-15-13377-2015, 2015.

Bahadur, R., Praveen, P. S., Xu, Y., and Ramanathan, V.: Solar absorption by elemental and brown carbon determined from spectral observations, P. Natl. Acad. Sci. USA, 109, 17366-17371, 2012.

Baker, J., Arey, J., and Atkinson, R.: Kinetics of the gas-phase reactions of $\mathrm{OH}$ radicals, $\mathrm{NO}_{3}$ radicals and $\mathrm{O}_{3}$ with three $\mathrm{C}_{7}$ carbonyls formed from the atmospheric reactions of myrcene, ocimene and terpinolene, J. Atmos. Chem., 48, 241-260, 2004.

Ball, S. M., Povey, I. M., Norton, E. G., and Jones, R. L.: Broadband cavity ringdown spectroscopy of the $\mathrm{NO}_{3}$ radical, Chem Phys. Lett., 342, 113-120, doi:10.1016/S0009-2614(01)005735, 2001.

Ball, S. M., Langridge, J. M., and Jones, R. L.: Broadband cavity enhanced absorption spectroscopy using light emitting diodes, Chem. Phys. Lett., 398, 68-74, doi:10.1016/j.cplett.2004.08.144, 2004.

Barnes, I., Bastian, V., Becker, K. H., and Tong, Z.: Kinetics and Products of the Reactions of $\mathrm{NO}_{3}$ with Monoalkenes, Dialkenes, and Monoterpenes, J. Phys. Chem.-Us., 94, 2413-2419, 1990.

Bartenbach, S., Williams, J., Plass-Dülmer, C., Berresheim, H., and Lelieveld, J.: In-situ measurement of reactive hydrocarbons at Hohenpeissenberg with comprehensive two-dimensional gas chromatography $(\mathrm{GC} \times \mathrm{GC}-\mathrm{FID})$ : use in estimating $\mathrm{HO}$ and $\mathrm{NO}_{3}$, Atmos. Chem. Phys., 7, 1-14, doi:10.5194/acp-7-1-2007, 2007.

Bates, K. H., Crounse, J. D., St Clair, J. M., Bennett, N. B., Nguyen, T. B., Seinfeld, J. H., Stoltz, B. M., and Wennberg, P. O.: Gas Phase Production and Loss of Isoprene Epoxydiols, J. Phys. Chem. A, 118, 1237-1246, 2014.

Beaver, M. R., Clair, J. M. S., Paulot, F., Spencer, K. M., Crounse, J. D., LaFranchi, B. W., Min, K. E., Pusede, S. E., Woolridge, P. J., Schade, G. W., Park, C., Cohen, R. C., and Wennberg, P. O.: Importance of biogenic precursors to the budget of organic nitrates during BEARPEX 2009: observations of multifunctional organic nitrates by CIMS and TD-LIF, Atmos. Chem. Phys., 12, 5773-5785, doi:10.5194/acpd-12-319-2012, 2012.

Benter, T. and Schindler, R. N.: Absolute rate coefficients for the reaction of $\mathrm{NO}_{3}$ radicals with simple dienes, Chem. Phys. Lett., 145, 67-70, doi:10.1016/0009-2614(88)85134-0, 1988.

Benton, A. K., Langridge, J. M., Ball, S. M., Bloss, W. J., Dall'Osto, M., Nemitz, E., Harrison, R. M., and Jones, R. L.: Night-time chemistry above London: measurements of $\mathrm{NO}_{3}$ and $\mathrm{N}_{2} \mathrm{O}_{5}$ from the BT Tower, Atmos. Chem. Phys., 10, 9781-9795, doi:10.5194/acp-10-9781-2010, 2010.

Berkemeier, T., Ammann, M., Mentel, T. F., Pöschl, U., and Shiraiwa, M.: Organic Nitrate Contribution to New Particle Formation and Growth in Secondary Organic Aerosols from $\alpha$-Pinene Ozonolysis, Environ. Sci. Technol., 50, 6334-6342, doi:10.1021/acs.est.6b00961, 2016.

Berndt, T. and Boge, O.: Gas-phase reaction of $\mathrm{NO}_{3}$ radicals with isoprene: A kinetic and mechanistic study, Int. J. Chem. Kinet., 29, 755-765, 1997a.

Berndt, T. and Boge, O.: Products and mechanism of the gas-phase reaction of $\mathrm{NO}_{3}$ radicals with $\alpha$-pinene, J. Chem. Soc. Faraday Trans., 93, 3021-3027, doi:10.1039/a702364b, 1997b.

Berndt, T., Boge, O., Kind, I., and Rolle, W.: Reaction of $\mathrm{NO}_{3}$ radicals with 1,3-cyclohexadiene alpha-terpinene, and alpha- 
phellandrene: Kinetics and products, Ber. Bunsen-Ges. Phys. Chem. Chem. Phys., 100, 462-469, 1996.

Biesenthal, T., Bottenheim, J., Shepson, P., Li, S. M., and Brickell, P.: The chemistry of biogenic hydrocarbons at a rural site in eastern Canada, J. Geophys. Res.-Atmos., 103, 25487-25498, 1998.

Bitter, M., Ball, S. M., Povey, I. M., and Jones, R. L.: A broadband cavity ringdown spectrometer for in-situ measurements of atmospheric trace gases, Atmos. Chem. Phys., 5, 2547-2560, doi:10.5194/acp-5-2547-2005, 2005.

Blake, N. J., Blake, D. R., Wingenter, O. W., Sive, B. C., Kang, C. H., Thornton, D. C., Bandy, A. R., Atlas, E., Flocke, F., Harris, J. M., and Rowland, F. S.: Aircraft measurements of the latitudinal, vertical, and seasonal variations of NMHCs, methyl nitrate, methyl halides, and DMS during the First Aerosol Characterization Experiment (ACE 1), J. Geophys. Res.-Atmos., 104, 2180321817, 1999.

Blake, N. J., Blake, D. R., Sive, B. C., Katzenstein, A. S., Meinardi, S., Wingenter, O. W., Atlas, E. L., Flocke, F., Ridley, B. A., and Rowland, F. S.: The seasonal evolution of NMHCs and light alkyl nitrates at middle to high northern latitudes during TOPSE, J. Geophys. Res.-Atmos., 108, 8359, doi:10.1029/2001jd001467, 2003a.

Blake, N. J., Blake, D. R., Swanson, A. L., Atlas, E., Flocke, F., and Rowland, F. S.: Latitudinal, vertical, and seasonal variations of C-1-C-4 alkyl nitrates in the troposphere over the Pacific Ocean during PEM-Tropics A and B: Oceanic and continental sources, J. Geophys. Res.-Atmos., 108, 8242, doi:10.1029/2001jd001444, 2003 b.

Boersma, K. F., Jacob, D. J., Eskes, H. J., Pinder, R. W., Wang, J., and van der A, R. J.: Intercomparison of SCIAMACHY and OMI tropospheric $\mathrm{NO}_{2}$ columns: Observing the diurnal evolution of chemistry and emissions from space, J. Geophys. Res.-Atmos., 113, D16S26, doi:10.1029/2007JD008816, 2008.

Bond, T. C. and Bergstrom, R. W.: Light absorption by carbonaceous particles: An investigative review, Aerosol Sci. Tech., 40, 1-41, 2006.

Bond, T. C., Zarzycki, C., Flanner, M. G., and Koch, D. M.: Quantifying immediate radiative forcing by black carbon and organic matter with the Specific Forcing Pulse, Atmos. Chem. Phys., 11, 1505-1525, doi:10.5194/acp-11-1505-2011, 2011.

Bonn, B. and Moorgat, G. K.: New particle formation during $a$ and $b$-pinene oxidation by $\mathrm{O}_{3}, \mathrm{OH}$ and $\mathrm{NO}_{3}$, and the influence of water vapour: particle size distribution studies, Atmos. Chem. Phys., 2, 183-196, doi:10.5194/acp-2-183-2002, 2002.

Boschan, R., Merrow, R. T., and Vandolah, R. W.: The Chemistry of Nitrate Esters, Chem. Rev., 55, 485-510, 1955.

Bossmeyer, J., Brauers, T., Richter, C., Rohrer, F., Wegener, R., and Wahner, A.: Simulation chamber studies of the $\mathrm{NO}_{3}$ chemistry of atmospheric aldehydes, Geophys. Res. Lett., 33, L18810, doi:10.11029/12006GL026778, 2006.

Boucher, O., Randall, D., Artaxo, P., Bretherton, C., Feingold G., Forster, P., Kerminen, V.-M., Kondo, Y., Liao, H., Lohmann, U., Rasch, P., Satheesh, S. K., Sherwood, S., Stevens, B., and Zhang, X. Y.: Clouds and Aerosols. In: Climate Change 2013: The Physical Science Basis. Contribution of Working Group I to the Fifth Assessment Report of the Intergovernmental Panel on Climate Change, Cambridge, United Kingdom and New York, NY, USA, 2013.
Boyd, C. M., Sanchez, J., Xu, L., Eugene, A. J., Nah, T., Tuet, W. Y., Guzman, M. I., and Ng, N. L.: Secondary organic aerosol formation from the $\beta$-pinene $+\mathrm{NO}_{3}$ system: effect of humidity and peroxy radical fate, Atmos. Chem. Phys., 15, 7497-7522, doi:10.5194/acp-15-7497-2015, 2015.

Bräuer, P., Mouchel-Vallon, C., Tilgner, A., Mutzel, A., Böge, O., Rodigast, M., Poulain, L., van Pinxteren, D., Aumont, B., and Herrmann, H.: Development of a protocol designed for the selfgeneration of explicit aqueous phase oxidation schemes of organic compounds, Atmos. Chem. Phys. Discuss., in preparation, 2017.

Brown, S. S. and Stutz, J.: Nighttime Radical Observations and Chemistry, Chem. Soc. Rev., 41, 6405-6447, doi:10.1039/c2cs35181a, 2012.

Brown, S. S., Stark, H., Ciciora, S. J., and Ravishankara, A. R.: Insitu measurement of atmospheric $\mathrm{NO}_{3}$ and $\mathrm{N}_{2} \mathrm{O}_{5}$ via cavity ringdown spectroscopy, Geophys. Res. Lett., 28, 3227-3230, 2001.

Brown, S. S., Stark, H., Ciciora, S. J., McLaughlin, R. J., and Ravishankara, A. R.: Simultaneous in-situ detection of atmospheric $\mathrm{NO}_{3}$ and $\mathrm{N}_{2} \mathrm{O}_{5}$ via cavity ring-down spectroscopy, Rev. Sci. Instr., 73, 3291-3301, 2002.

Brown, S. S., Stark, H., Ryerson, T. B., Williams, E. J., Nicks, D. K. J., Trainer, M., Fehsenfeld, F. C., and Ravishankara, A. R.: Nitrogen oxides in the nocturnal boundary layer: Simultaneous, in-situ detection of $\mathrm{NO}_{3}, \mathrm{~N}_{2} \mathrm{O}_{5}, \mathrm{NO}, \mathrm{NO}_{2}$ and $\mathrm{O}_{3}$, J. Geophys. Res., 108, D94299, doi:10.1029/2002JD002917, 2003.

Brown, S. S., Dubé, W. P., Osthoff, H. D., Stutz, J., Ryerson, T. B., Wollny, A. G., Brock, C. A., Warneke, C., de Gouw, J. A., Atlas, E., Neuman, J. A., Holloway, J. S., Lerner, B. M., Williams, E. J., Kuster, W. C., Goldan, P. D., Angevine, W. M., Trainer, M., Fehsenfeld, F. C., and Ravishankara, A. R.: Vertical profiles in $\mathrm{NO}_{3}$ and $\mathrm{N}_{2} \mathrm{O}_{5}$ measured from an aircraft: Results from the NOAA P-3 and surface platforms during NEAQS 2004, J. Geophys. Res., 112, D22304, doi:10.1029/2007JD008883, 2007a.

Brown, S. S., Dubé, W. P., Osthoff, H. D., Wolfe, D. E., Angevine, W. M., and Ravishankara, A. R.: High resolution vertical distributions of $\mathrm{NO}_{3}$ and $\mathrm{N}_{2} \mathrm{O}_{5}$ through the nocturnal boundary layer, Atmos. Chem. Phys., 7, 139-149, doi:10.5194/acp-7-139-2007, 2007b.

Brown, S. S., deGouw, J. A., Warneke, C., Ryerson, T. B., Dubé, W. P., Atlas, E., Weber, R. J., Peltier, R. E., Neuman, J. A., Roberts, J. M., Swanson, A., Flocke, F., McKeen, S. A., Brioude, J., Sommariva, R., Trainer, M., Fehsenfeld, F. C., and Ravishankara, A. R.: Nocturnal isoprene oxidation over the Northeast United States in summer and its impact on reactive nitrogen partitioning and secondary organic aerosol, Atmos. Chem. Phys., 9, 30273042, doi:10.5194/acp-9-3027-2009, 2009.

Brown, S. S., Dubé, W. P., Peischl, J., Ryerson, T. B., Atlas, E., Warneke, C., de Gouw, J., Te Lintel Hekkert, S., Brock, C. A., Flocke, F., Trainer, M., Parrish, D. D., Fehsenfeld, F. C., and Ravishankara, A. R.: Budgets for nocturnal VOC oxidation by nitrate radicals aloft during the 2006 Texas Air Quality Study, J. Geophys. Res., 116, D24305, doi:10.1029/2011JD016544, 2011.

Brown, S. S., Dubé, W. P., Bahreini, R., Middlebrook, A. M., Brock, C. A., Warneke, C., de Gouw, J. A., Washenfelder, R. A., Atlas, E., Peischl, J., Ryerson, T. B., Holloway, J. S., Schwarz, J. P., Spackman, R., Trainer, M., Parrish, D. D., Fehsenfeld, F. C., and Ravishankara, A. R.: Biogenic VOC oxidation and organic aerosol formation in an urban noctural boundary layer: Air- 
craft vertical profiles in Houston, TX, Atmos. Chem. Phys., 13, 11317-11337, doi:10.5194/acp-13-11317-2013, 2013.

Browne, E. C., Min, K. E., Wooldridge, P. J., Apel, E., Blake, D. R., Brune, W. H., Cantrell, C. A., Cubison, M. J., Diskin, G. S., Jimenez, J. L., Weinheimer, A. J., Wennberg, P. O., Wisthaler, A., and Cohen, R. C.: Observations of total $\mathrm{RONO}_{2}$ over the boreal forest: $\mathrm{NO}_{x}$ sinks and $\mathrm{HNO}_{3}$ sources, Atmos. Chem. Phys., 13, 4543-4562, doi:10.5194/acp-13-4543-2013, 2013.

Browne, E. C., Wooldridge, P. J., Min, K. E., and Cohen, R. C.: On the role of monoterpene chemistry in the remote continental boundary layer, Atmos. Chem. Phys., 14, 1225-1238, doi:10.5194/acp-14-1225-2014, 2014.

Bruns, E. A., Perraud, V., Zelenyuk, A., Ezell, M. J., Johnson, S. N., Yu, Y., Imre, D., Finlayson-Pitts, B. J., and Alexander, M. L.: Comparison of FTIR and Particle Mass Spectrometry for the Measurement of Particulate Organic Nitrates, Environ. Sci. Technol., 44, 1056-1061, 2010.

Calvert, J. G., Orlando, J., Stockwell, W. R., and Wallington, T. J.: The Mechanisms of Reactions Influencing Atmospheric Ozone, Oxford University Press, New York, New York, 2015.

Canosa-Mas, C. E., Carr, S., King, M. D., Shallcross, D. E., Thompson, K. C., and Wayne, R. P.: A kinetic study of the reactions of $\mathrm{NO}_{3}$ with methyl vinyl ketone, methacrolein, acrolein, methyl acrylate and methyl methacrylate, Phys. Chem. Chem. Phys., 1, 4195-4202, 1999a.

Canosa-Mas, C. E., King, M. D., Scarr, P. J., Thompson, K. C., and Wayne, R. P.: An experimental study of the gas-phase reactions of the $\mathrm{NO}_{3}$ radical with three sesquiterpenes: isolongifolene, alloisolongifolene, and neoclovene, Phys. Chem. Chem. Phys., 1, 2929-2933, 1999b.

Carlton, A. G., Bhave, P. V., Napelenok, S. L., Edney, E. O., Sarwar, G., Pinder, R. W., Pouliot, G. A., and Houyoux, M.: Model Representation of Secondary Organic Aerosol in CMAQv4.7, Environ. Sci. Technol., 44, 8553-8560, doi:10.1021/es100636q, 2010a.

Carlton, A. G., Pinder, R. W., Bhave, P. V., and Pouliot, G. A.: To What Extent Can Biogenic SOA be Controlled?, Environ. Sci. Technol., 44, 3376-3380, doi:10.1021/es903506b, 2010b.

Carter, W. P. L.: Development of the SAPRC-07 Chemical Mechanism and Updated Ozone Reactivity Scales, Final report to the California Air Resources Board Contract No. 03-318, 27 January, 2010a.

Carter, W. P. L.: Development of the SAPRC-07 chemical mechanism, Atmos. Environ., 44, 5324-5335, doi:10.1016/j.atmosenv.2010.01.026, 2010b.

Castellanos, P. and Boersma, K. F.: Reductions in nitrogen oxides over Europe driven by environmental policy and economic recession, Sci. Rep., 2, 265, 2012.

Cavdar, H. and Saracoglu, N.: Synthesis of new beta-hydroxy nitrate esters as potential glycomimetics or vasodilators, Eur. J. Org. Chem., 4615-4621, 2008.

Cerully, K. M., Bougiatioti, A., Hite Jr, J. R., Guo, H., Xu, L., Ng, N. L., Weber, R., and Nenes, A.: On the link between hygroscopicity, volatility, and oxidation state of ambient and water-soluble aerosols in the southeastern United States, Atmos. Chem. Phys., 15, 8679-8694, doi:10.5194/acp-15-8679-2015, 2015.

Chacon-Madrid, H. J., Henry, K. M., and Donahue, N. M.: Photooxidation of pinonaldehyde at low $\mathrm{NO}_{x}$ : from chemistry to or- ganic aerosol formation, Atmos. Chem. Phys., 13, 3227-3236, doi:10.5194/acp-13-3227-2013, 2013.

Chameides, W. L.: Photo-chemical role of tropospheric nitrogen oxides, Geophys. Res. Lett., 5, 17-20, 1978.

Chen, J., Avise, J., Guenther, A., Wiedinmyer, C., Salathe, E., Jackson, R. B., and Lamb, B.: Future land use and land cover influences on regional biogenic emissions and air quality in the United States, Atmos. Environ., 43, 5771-5780, doi:10.1016/j.atmosenv.2009.08.015, 2009.

Chew, A. A., Atkinson, R., and Aschmann, S. M.: Kinetics of the gas-phase reactions of $\mathrm{NO}_{3}$ radicals with a series of alcohols, glycol ethers, ethers and chloroalkenes, J. Chem. Soc. Faraday Trans., 94, 1083-1089, 1998.

Chung, C. E., Ramanathan, V., and Decremer, D.: Observationally constrained estimates of carbonaceous aerosol radiative forcing, P. Natl. Acad. Sci. USA, 109, 11624-11629, doi:10.1073/pnas.1203707109, 2012.

Chung, S. H. and Seinfeld, J. H.: Global distribution and climate forcing of carbonaceous aerosols, J. Geophys. Res., 107, 4407, doi:10.1029/2001JD001397, 2002.

Clifford, G. M., Thüner, L. P., Wenger, J. C., and Shallcross, D. E.: Kinetics of the gas-phase reactions of $\mathrm{OH}$ and $\mathrm{NO}_{3}$ radicals with aromatic aldehydes, J. Photoch. Photobio. A, 176, 172-182, doi:10.1016/j.jphotochem.2005.09.022, 2005.

Coe, H., Allan, B. J., and Plane, J. M. C.: Retrieval of vertical profiles of $\mathrm{NO}_{3}$ from zenith sky measurements using an optimal estimation method, J. Geophys. Res., 107, 4587, doi:10.1029/2002JD002111, 2002.

Cohan, D. S., Hu, Y., and Russell, A. G.: Dependence of ozone sensitivity analysis on grid resolution, Atmos. Environ., 40, 126135, doi:10.1016/j.atmosenv.2005.09.031, 2006.

Corchnoy, S. B. and Atkinson, R.: Kinetics of the gas-phase reactions of hydroxyl and nitrogen oxide $\left(\mathrm{NO}_{3}\right)$ radicals with 2 carene, 1,8-cineole, p-cymene, and terpinolene, Environ. Sci. Technol., 24, 1497-1502, 1990.

Cosman, L. M., Knopf, D. A., and Bertram, A. K.: $\mathrm{N}_{2} \mathrm{O}_{5}$ Reactive Uptake on Aqueous Sulfuric Acid Solutions Coated with Branched and Straight-Chain Insoluble Organic Surfactants, J. Phys. Chem. A, 112, 2386-2396, 2008.

Crippa, M., Canonaco, F., Lanz, V. A., Äijälä, M., Allan, J. D., Carbone, S., Capes, G., Ceburnis, D., Dall'Osto, M., Day, D. A., DeCarlo, P. F., Ehn, M., Eriksson, A., Freney, E., Hildebrandt Ruiz, L., Hillamo, R., Jimenez, J. L., Junninen, H., Kiendler-Scharr, A., Kortelainen, A.-M., Kulmala, M., Laaksonen, A., Mensah, A. A., Mohr, C., Nemitz, E., O’Dowd, C., Ovadnevaite, J., Pandis, S. N., Petäjä, T., Poulain, L., Saarikoski, S., Sellegri, K., Swietlicki, E., Tiitta, P., Worsnop, D. R., Baltensperger, U., and Prévôt, A. S. H.: Organic aerosol components derived from 25 AMS data sets across Europe using a consistent ME-2 based source apportionment approach, Atmos. Chem. Phys., 14, 61596176, doi:10.5194/acp-14-6159-2014, 2014.

Crounse, J. D., Paulot, F., Kjaergaard, H. G., and Wennberg, P. O.: Peroxy radical isomerization in the oxidation of isoprene, Phys. Chem. Chem. Phys., 13, 13607-13613, doi:10.1039/C1CP21330J, 2011.

Crowley, J. N., Schuster, G., Pouvesle, N., Parchatka, U., Fischer, H., Bonn, B., Bingemer, H., and Lelieveld, J.: Nocturnal nitrogen oxides at a rural mountain-site in south-western Germany, 
Atmos. Chem. Phys., 10, 2795-2812, doi:10.5194/acp-10-27952010, 2010.

Crowley, J. N., Thieser, J., Tang, M. J., Schuster, G., Bozem, H., Beygi, Z. H., Fischer, H., Diesch, J. M., Drewnick, F., Borrmann, S., Song, W., Yassaa, N., Williams, J., Pöhler, D., Platt, U., and Lelieveld, J.: Variable lifetimes and loss mechanisms for $\mathrm{NO}_{3}$ and $\mathrm{N}_{2} \mathrm{O}_{5}$ during the DOMINO campaign: contrasts between marine, urban and continental air, Atmos. Chem. Phys., 11, 10853-10870, doi:10.5194/acp-11-10853-2011, 2011.

Crutzen, P. J.: A Discussion of the Chemistry of Some Minor Constituents in the Stratosphere and Troposphere, Pure Appl. Geophys., 106, 1385-1399, 1973.

Curci, G., Beekmann, M., Vautard, R., Smiatek, G., Steinbrecher, R., Theloke, J., and Friedrich, R.: Modelling study of the impact of isoprene and terpene biogenic emissions on European ozone levels, Atmos. Environ., 43, 1444-1455, doi:10.1016/j.atmosenv.2008.02.070, 2009.

Darer, A. I., Cole-Filipiak, N. C., O'Connor, A. E., and Elrod, M. J.: Formation and Stability of Atmospherically Relevant IsopreneDerived Organosulfates and Organonitrates, Environ. Sci. Technol., 45, 1895-1902, doi:10.1021/es103797z, 2011.

Day, D., Wooldridge, P., Dillon, M., Thornton, J., and Cohen, R.: A thermal dissociation laser-induced fluorescence instrument for in situ detection of $\mathrm{NO}_{2}$, peroxy nitrates, alkyl nitrates, and $\mathrm{HNO}_{3}$, J. Geophys. Res.-Atmos., 107, 4046, doi:10.1029/2001JD000779, 2002.

Day, D. A., Dillon, M. B., Wooldridge, P. J., Thornton, J. A., Rosen, R. S., Wood, E. C., and Cohen, R. C.: On alkyl nitrates, $\mathrm{O}_{3}$, and the "missing $\mathrm{NO}_{y}$ ", J. Geophys. Res., 108, 4501, doi:10.129/2003JD003685, 2003.

Day, D. A., Liu, S., Russell, L. M., and Ziemann, P. J.: Organonitrate group concentrations in submicron particles with high nitrate and organic fractions in coastal southern California, Atmos. Environ., 44, 1970-1979, 2010.

Dlugokencky, E. J. and Howard, C. J.: Studies of $\mathrm{NO}_{3}$ radical reactions with some atmospheric organic compounds at low pressures, J. Phys. Chem.-Us., 93, 1091-1096, doi:10.1021/j100340a015, 1989.

Docherty, K. S. and Ziemann, P. J.: Reaction of Oleic Acid Particles with $\mathrm{NO}_{3}$ Radicals: Products, Mechanism, and Implications for Radical-Initiated Organic Aerosol Oxidation, J. Phys. Chem. A, 110, 3567-3577, 2006.

Donahue, N. M., Robinson, A. L., Stanier, C. O., and Pandis, S. N.: Coupled Partitioning, Dilution, and Chemical Aging of Semivolatile Organics, Environ. Sci. Technol., 40, 2635-2643, doi:10.1021/es052297c, 2006.

Dorn, H. P., Apodaca, R. L., Ball, S. M., Brauers, T., Brown, S. S., Crowley, J. N., Dubé, W. P., Fuchs, H., Häseler, R., Heitmann, U., Jones, R. L., Kiendler-Scharr, A., Labazan, I., Langridge, J. M., Meinen, J., Mentel, T. F., Platt, U., Pöhler, D., Rohrer, F., Ruth, A. A., Schlosser, E., Schuster, G., Shillings, A. J. L., Simpson, W. R., Thieser, J., Tillmann, R., Varma, R., Venables, D. S., and Wahner, A.: Intercomparison of $\mathrm{NO}_{3}$ radical detection instruments in the atmosphere simulation chamber SAPHIR, Atmos. Meas. Tech., 6, 1111-1140, doi:10.5194/amt-6-1111-2013, 2013.

Draper, D. C., Farmer, D. K., Desyaterik, Y., and Fry, J. L.: A qualitative comparison of secondary organic aerosol yields and composition from ozonolysis of monoterpenes at varying con- centrations of $\mathrm{NO}_{2}$, Atmos. Chem. Phys., 15, 12267-12281, doi:10.5194/acp-15-12267-2015, 2015.

Dubé, W. P., Brown, S. S., Osthoff, H. D., Nunley, M. R., Ciciora, S. J., Paris, M. W., McLaughlin, R. J., and Ravishankara, A. R.: Aircraft instrument for simultaneous, in situ measurement of $\mathrm{NO}_{3}$ and $\mathrm{N}_{2} \mathrm{O}_{5}$ via pulsed cavity ring-down spectroscopy, Rev. Sci. Instrum., 77, 034101, doi:10.1063/1.2176058, 2006.

Duncan, B. N., Lamsal, L. N., Thompson, A. M., Yoshida, Y., Lu, Z., Streets, D. G., Hurwitz, M. M., and Pickering, K. E.: A space-based, high-resolution view of notable changes in urban $\mathrm{NO}_{x}$ pollution around the world (2005-2014), J. Geophys. Res. Atmos., 121, 976-996, doi:10.1002/2015JD024121, 2016.

Ehn, M., Thornton, J. A., Kleist, E., Sipila, M., Junninen, H., Pullinen, I., Springer, M., Rubach, F., Tillmann, R., Lee, B., LopezHilfiker, F., Andres, S., Acir, I.-H., Rissanen, M., Jokinen, T., Schobesberger, S., Kangasluoma, J., Kontkanen, J., Nieminen, T., Kurten, T., Nielsen, L. B., Jorgensen, S., Kjaergaard, H. G., Canagaratna, M., Maso, M. D., Berndt, T., Petaja, T., Wahner, A., Kerminen, V.-M., Kulmala, M., Worsnop, D. R., Wildt, J., and Mentel, T. F.: A large source of low-volatility secondary organic aerosol, Nature, 506, 476-479, doi:10.1038/nature13032, 2014.

Ellermann, T., Nielsen, O. J., and Skov, H.: Absolute rate constants for the reaction of $\mathrm{NO}_{3}$ radicals with a series of dienes at 295-K, Chem. Phys. Lett., 200, 224-229, doi:10.1016/00092614(92)80002-s, 1992.

Emmons, L. K., Walters, S., Hess, P. G., Lamarque, J. F., Pfister, G. G., Fillmore, D., Granier, C., Guenther, A., Kinnison, D., Laepple, T., Orlando, J., Tie, X., Tyndall, G., Wiedinmyer, C., Baughcum, S. L., and Kloster, S.: Description and evaluation of the Model for Ozone and Related chemical Tracers, version 4 (MOZART-4), Geosci. Model Dev., 3, 43-67, doi:10.5194/gmd3-43-2010, 2010.

Eyth, A., Zubrow, A., and Mason, R.: Preparation of Emissions Inventories for the Version 6.1, 2011 Emissions Modeling Platform Report, Technical Support Document (TSD), 2014.

Fantechi, G., Jensen, N. R., Hjorth, J., and Peeters, J.: Determination of the rate constants for the gas-phase reactions of methyl butenol with $\mathrm{OH}$ radicals, ozone, $\mathrm{NO}_{3}$ radicals, and $\mathrm{Cl}$ atoms, Int. J. Chem. Kinet., 30, 589-594, 1998a.

Fantechi, G., Jensen, N. R., Hjorth, J., and Peeters, J.: Mechanistic studies of the atmospheric oxidation of methyl butenol by $\mathrm{OH}$ radicals, ozone and $\mathrm{NO}_{3}$ radicals, Atmos. Environ., 32, 35473556, doi:10.1016/S1352-2310(98)00061-2, 1998 b.

Farmer, D. K., Matsunaga, A., Docherty, K. S., Surratt, J. D., Seinfeld, J. H., Ziemann, P. J., and Jimenez, J. L.: Response of the Aerosol Mass Spectrometer to organonitrates and organosulfates and implications for field studies., PNAS, 107, 6670-6675, doi:10.1073/pnas.0912340107, 2010.

Feng, Y., Ramanathan, V., and Kotamarthi, V.: Brown carbon: a significant atmospheric absorber of solar radiation?, Atmos. Chem. Phys., 13, 8607-8621, doi:10.5194/acp-13-8607-2013, 2013.

Fiedler, S. E., Hoheisel, G., Ruth, A. A., and Hese, A.: Incoherent broad-band cavity-enhanced absorption spectroscopy of azulene in a supersonic jet, Chem. Phys. Lett., 382, 447-453, doi:10.1016/j.cplett.2003.10.075, 2003.

Fiore, A. M., Dentener, F. J., Wild, O., Cuvelier, C., Schultz, M. G., Hess, P., Textor, C., Schulz, M., Doherty, R. M., Horowitz, L. W., MacKenzie, I. A., Sanderson, M. G., Shindell, D. T., 
Stevenson, D. S., Szopa, S., Van Dingenen, R., Zeng, G., Atherton, C., Bergmann, D., Bey, I., Carmichael, G., Collins, W. J., Duncan, B. N., Faluvegi, G., Folberth, G., Gauss, M., Gong, S., Hauglustaine, D., Holloway, T., Isaksen, I. S. A., Jacob, D. J., Jonson, J. E., Kaminski, J. W., Keating, T. J., Lupu, A., Marmer, E., Montanaro, V., Park, R. J., Pitari, G., Pringle, K. J., Pyle, J. A., Schroeder, S., Vivanco, M. G., Wind, P., Wojcik, G., Wu, S., and Zuber, A.: Multimodel estimates of intercontinental sourcereceptor relationships for ozone pollution, J. Geophys. Res., 114, D04301, doi:10.1029/2008JD010816, 2009.

Fischer, R. G., Kastler, J., and Ballschmiter, K.: Levels and pattern of alkyl nitrates, multifunctional alkyl nitrates, and halocarbons in the air over the Atlantic Ocean, J. Geophys. Res.-Atmos., 105, 14473-14494, doi:10.1029/1999jd900780, 2000.

Fisher, J. A., Jacob, D. J., Travis, K. R., Kim, P. S., Marais, E. A., Chan Miller, C., Yu, K., Zhu, L., Yantosca, R. M., Sulprizio, M. P., Mao, J., Wennberg, P. O., Crounse, J. D., Teng, A. P., Nguyen, T. B., St. Clair, J. M., Cohen, R. C., Romer, P., Nault, B. A., Wooldridge, P. J., Jimenez, J. L., CampuzanoJost, P., Day, D. A., Hu, W., Shepson, P. B., Xiong, F., Blake, D. R., Goldstein, A. H., Misztal, P. K., Hanisco, T. F., Wolfe, G. M., Ryerson, T. B., Wisthaler, A., and Mikoviny, T.: Organic nitrate chemistry and its implications for nitrogen budgets in an isoprene- and monoterpene-rich atmosphere: constraints from aircraft (SEAC4RS) and ground-based (SOAS) observations in the Southeast US, Atmos. Chem. Phys., 16, 5969-5991, doi:10.5194/acp-16-5969-2016, 2016.

Flocke, F., Volzthomas, A., and Kley, D.: Measurements of Alkyl Nitrates in Rural and Polluted Air Masses, Atmos. Environ. A, 25, 1951-1960, 1991.

Flocke, F., Atlas, E., Madronich, S., Schauffler, S. M., Aikin, K., Margitan, J. J., and Bui, T. P.: Observations of methyl nitrate in the lower stratosphere during STRAT: Implications for its gas phase production mechanisms, Geophys. Res. Lett., 25, 18911894, 1998.

Foley, K. M., Hogrefe, C., Pouliot, G., Possiel, N., Roselle, S. J., Simon, H., and Timin, B.: Dynamic evaluation of CMAQ part I: Separating the effects of changing emissions and changing meteorology on ozone levels between 2002 and 2005 in the eastern US, Atmos. Environ., 103, 247-255, doi:10.1016/j.atmosenv.2014.12.038, 2015.

Franze, T., Weller, M. G., Niessner, R., and Pöschl, U.: Enzyme immunoassays for the investigation of protein nitration by air pollutants, Analyst, 128, 824-831, doi:10.1039/b303132b, 2003.

Franze, T., Weller, M. G., Niessner, R., and Pöschl, U.: Protein Nitration by Polluted Air, Environ. Sci. Technol., 39, 1673-1678, doi:10.1021/es0488737, 2005.

Fry, J. L. and Sackinger, K.: Model evaluation of $\mathrm{NO}_{3}$ secondary organic aerosol (SOA) source and heterogeneous organic aerosol (OA) sink in the Western United States, Atmos. Chem. Phys., 12, 8797-8811, doi:10.5194/acpd-12-5189-2012, 2012.

Fry, J. L., Kiendler-Scharr, A., Rollins, A. W., Wooldridge, P. J., Brown, S. S., Fuchs, H., Dubé, W., Mensah, A., dal Maso, M., Tillmann, R., Dorn, H.-P., Brauers, T., and Cohen, R. C.: Organic nitrate and secondary organic aerosol yield from $\mathrm{NO}_{3}$ oxidation of $\beta$-pinene evaluated using a gas-phase kinetics/aerosol partitioning model, Atmos. Chem. Phys., 9, 14311449, doi:10.5194/acp-9-1431-2009, 2009.
Fry, J. L., Kiendler-Scharr, A., Rollins, A. W., Brauers, T., Brown, S. S., Dorn, H.-P., Dubé, W. P., Fuchs, H., Mensah, A., Rohrer, F., Tillmann, R., Wahner, A., Wooldridge, P. J., and Cohen, R. C.: SOA from limonene: role of $\mathrm{NO}_{3}$ in its generation and degradation, Atmos. Chem. Phys., 11, 3879-3894, doi:10.5194/acp-113879-2011, 2011.

Fry, J. L., Draper, D. C., Zarzana, K. J., Campuzano-Jost, P., Day, D. A., Jimenez, J. L., Brown, S. S., Cohen, R. C., Kaser, L., Hansel, A., Cappellin, L., Karl, T., Hodzic Roux, A., Turnipseed, A., Cantrell, C., Lefer, B., and Grossberg, N.: Observations of gas- and aerosol-phase organic nitrates at BEACHON-RoMBAS 2011, Atmos. Chem. Phys., 13, 8585-8605, doi:10.5194/acp-138585-2013, 2013.

Fry, J. L., Draper, D. C., Barsanti, K. C., Smith, J. N., Ortega, J., Winkler, P. M., Lawler, M. J., Brown, S. S., Edwards, P. M., Cohen, R. C., and Lee, L.: Secondary Organic Aerosol Formation and Organic Nitrate Yield from $\mathrm{NO}_{3}$ Oxidation of Biogenic Hydrocarbons, Environ. Sci. Technol., 48, 11944-11953, doi:10.1021/es502204x, 2014.

Fuchs, H., Dubé, W. P., Ciciora, S. J., and Brown, S. S.: Determination of Inlet Transmission and Conversion Efficiencies for in Situ Measurements of the Nocturnal Nitrogen Oxides, $\mathrm{NO}_{3}$, $\mathrm{N}_{2} \mathrm{O}_{5}$ and $\mathrm{NO}_{2}$, via Pulsed Cavity Ring-Down Spectroscopy, Anal. Chem., 80, 6010-6017, 2008.

Fuchs, H., Simpson, W. R., Apodaca, R. L., Brauers, T., Cohen, R. C., Crowley, J. N., Dorn, H. P., Dubé, W. P., Fry, J. L., Häseler, R., Kajii, Y., Kiendler-Scharr, A., Labazan, I., Matsumoto, J., Mentel, T. F., Nakashima, Y., Rohrer, F., Rollins, A. W., Schuster, G., Tillmann, R., Wahner, A., Wooldridge, P. J., and Brown, S. S.: Comparison of $\mathrm{N}_{2} \mathrm{O}_{5}$ mixing ratios during NO3Comp 2007 in SAPHIR, Atmos. Meas. Tech., 5, 2763-2777, doi:10.5194/amtd5-4927-2012, 2012.

Fuentes, J. D., Wang, D., Bowling, D. R., Potosnak, M., Monson, R. K., Goliff, W. S., and Stockwell, W. R.: Biogenic Hydrocarbon Chemistry within and Above a Mixed Deciduous Forest, J. Atmos. Chem., 56, 165-185, 2007.

Gao, S., Ng, N. L., Keywood, M., Varutbangkul, V., Bahreini, R., Nenes, A., He, J., Yoo, K. Y., Beauchamp, J. L., Hodyss, R. P., Flagan, R. C., and Seinfeld, J. H.: Particle Phase Acidity and Oligomer Formation in Secondary Organic Aerosol, Environ. Sci. Technol., 38, 6582-6589, doi:10.1021/es049125k, 2004.

Gao, S., Surratt, J. D., Knipping, E. M., Edgerton, E. S., Shahgholi, M., and Seinfeld, J. H.: Characterization of polar organic components in fine aerosols in the southeastern United States: Identity, origin, and evolution, J. Geophys. Res.-Atmos., 111, D14314, doi:10.1029/2005JD006601, 2006.

Garnes, L. A. and Allen, D. T.: Size Distributions of Organonitrates in Ambient Aerosol Collected in Houston, Texas, Aerosol Sci Tech., 36, 983-992, doi:10.1080/02786820290092186, 2002.

Geyer, A., Alicke, B., Mihelcic, D., Stutz, J., and Platt, U.: Comparison of tropospheric $\mathrm{NO}_{3}$ radical measurements by differential optical absorption spectroscopy and matrix isolation electron spin resonance, J. Geophys. Res., 104, 26097-26105, 1999.

Geyer, A., Ackermann, R., Dubois, R., Lohrmann, B., Müller, T., and Platt, U.: Long-term observation of nitrate radicals in the continental boundary layer near Berlin, Atmos. Environ., 35, 3619-3631, doi:10.1016/S1352-2310(00)00549-5, 2001a.

Geyer, A., Alicke, B., Konrad, S., Schmitz, T., Stutz, J., and Platt, U.: Chemistry and oxidation capacity of the nitrate radical in the 
continental boundary layer near Berlin, J. Geophys. Res.-Atmos., 106, 8013-8025, doi:10.1029/2000JD900681, 2001b.

Geyer, A., Alicke, B., Ackermann, R., Martinez, M., Harder, H., Brune, W., di Carlo, P., Williams, E., Jobson, T., Hall, S., Shetter, R., and Stutz, J.: Direct observations of daytime $\mathrm{NO}_{3}$ : Implications for urban boundary layer chemistry, J. Geophys. Res., 108, 4368, doi:10.1029/2002JD002967, 2003.

Glasius, M., Calogirou, A., Jensen, N. R., Hjorth, J., and Nielsen, C. J.: Kinetic study of gas-phase reactions of pinonaldehyde and structurally related compounds, Int. J. Chem. Kinet., 29, 527533, 1997.

Goldan, P. D., Kuster, W. C., Fehsenfeld, F. C., and Montzka, S. A.: Hydrocarbon measurements in the southeastern United States: The rural oxidants in the southern environment (ROSE) program 1990, J. Geophys. Res.-Atmos., 100, 25945-25963, 1995.

Goldstein, A. and Galbally, I.: Known and Unexplored Organic Constituents in the Earth's Atmosphere, Environ. Sci. Technol., 41, 1514-1521, 2007.

Gölz, C., Senzig, J., and Platt, U.: $\mathrm{NO}_{3}$-initiated oxidation of biogenic hydrocarbons, Chemosphere, 3, 339-352, doi:10.1016/S1465-9972(01)00015-0, 2001.

Gómez-González, Y., Surratt, J. D., Cuyckens, F., Szmigielski, R., Vermeylen, R., Jaoui, M., Lewandowski, M., Offenberg, J. H., Kleindienst, T. E., Edney, E. O., Blockhuys, F., Van Alsenoy, C., Maenhaut, W., and Claeys, M.: Characterization of organosulfates from the photooxidation of isoprene and unsaturated fatty acids in ambient aerosol using liquid chromatography/(-) electrospray ionization mass spectrometry, J. Mass Spectrom., 43, 371-382, doi:10.1002/jms.1329, 2008.

Griffin, R. J., Cocker, D. R., III, Flagan, R. C., and Seinfeld, J. H.: Organic aerosol formation from the oxidation of biogenic hydrocarbons, J. Geophys. Res., 104, 3555-3567, 1999.

Grifiths, P. T., Badger, C. L., Cox, R. A., Folkers, M., Henk, H. H., and Mentel, T. F.: Reactive Uptake of $\mathrm{N}_{2} \mathrm{O}_{5}$ by Aerosols Containing Dicarboxylic Acids. Effect of Particle Phase, Composition, and Nitrate Content, J. Phys. Chem., 113, 5082-5090, 2009.

Gross, S. and Bertram, A. K.: Reactive Uptake of $\mathrm{NO}_{3}, \mathrm{~N}_{2} \mathrm{O}_{5}, \mathrm{NO}_{2}$, $\mathrm{HNO}_{3}$, and $\mathrm{O}_{3}$ on Three Types of Polycyclic Aromatic Hydrocarbon Surfaces, J. Phys. Chem. A, 112, 3104-3113, 2008.

Gross, S. and Bertram, A. K.: Products and kinetics of the reaction of an alkane monolayer and a terminal alkene monolayer with $\mathrm{NO}_{3}$ radicals, J. Geophys. Res., 114, D02307, doi:10.1029/2008JD010987, 2009.

Gross, S., Iannone, R. Q., Xiao, S., and Bertram, A. K.: Reactive uptake studies of $\mathrm{NO}_{3}$ and $\mathrm{N}_{2} \mathrm{O}_{5}$ on alkenoic acid, alkanoate and polyalcohol substrates to probe nighttime aerosol chemistry, Phys. Chem. Chem. Phys., 11, 7792-7803, 2009.

Grossenbacher, J. W., Couch, T., Shepson, P. B., Thornberry, T., Witmer-Rich, M., Carroll, M. A., Faloona, I., Tan, D., Brune, W., Ostling, K., and Bertman, S.: Measurements of isoprene nitrates above a forest canopy, J. Geophys. Res.-Atmos., 106, 2442924438, 2001.

Gruijthuijsen, Y. K., Grieshuber, I., Stöcklinger, A., Tischler, U., Fehrenbach, T., Weller, M. G., Vogel, L., Vieths, S., Pöschl, U., and Duschl, A.: Nitration Enhances the Allergenic Potential of Proteins, Int. Arch. Allerg. Imm., 141, 265-275, 2006.

Guenther, A., Hewitt, C. N., Erickson, D., Fall, R., Geron, C., Graedel, T. E., Harley, P., Klinger, L., Lerdau, M., McKay, W.
A., Pierce, T. E., Scholes, B., Steinbrecher, R., Tallamraju, R., Taylor, J., and Zimmerman, P.: A global model of natural volatile organic compound emissions, J. Geophys. Res., 100, 8873-8892, 1995.

Häkkinen, S. A. K., Äijälä, M., Lehtipalo, K., Junninen, H., Backman, J., Virkkula, A., Nieminen, T., Vestenius, M., Hakola, H., Ehn, M., Worsnop, D. R., Kulmala, M., Petäjä, T., and Riipinen, I.: Long-term volatility measurements of submicron atmospheric aerosol in Hyytiälä, Finland, Atmos. Chem. Phys., 12, 1077110786, doi:10.5194/acp-12-10771-2012, 2012.

Hallquist, M., Langer, S., Ljungstrom, E., and Wangberg, I.: Rates of reaction between the nitrate radical and some unsaturated alcohols, Int. J. Chem. Kinet., 28, 467-474, 1996.

Hallquist, M., Wangberg, I., and Ljungstrom, E.: Atmospheric Fate of Carbonyl Oxidation Products Originating from -Pinene and 3Carene: Determination of Rate of Reaction with $\mathrm{OH}$ and $\mathrm{NO}_{3}$ Radicals, UV Absorption Cross Sections, and Vapor Pressures, Environ. Sci. Technol., 31, 3166-3172, 1997a.

Hallquist, M., Wängberg, I., and Ljungström, E.: Atmospheric Fate of Carbonyl Oxidation Products Originating from alphaPinene and delta ${ }^{3}$-Carene: Determination of Rate of Reaction with $\mathrm{OH}$ and $\mathrm{NO}_{3}$ Radicals, UV Absorption Cross Sections, and Vapor Pressures, Environ. Sci. Technol., 31, 3166-3172, doi:10.1021/es970151a, 1997b.

Hallquist, M., Wängberg, I., Ljungstrom, E., Barnes, I., and Becker, K. H.: Aerosol and Product Yields from $\mathrm{NO}_{3}$ Radical-Initiated Oxidation of Selected Monoterpenes, Environ. Sci. Technol., 33, 553-559, 1999.

Hallquist, M., Wenger, J. C., Baltensperger, U., Rudich, Y., Simpson, D., Claeys, M., Dommen, J., Donahue, N. M., George, C., Goldstein, A. H., Hamilton, J. F., Herrmann, H., Hoffmann, T., Iinuma, Y., Jang, M., Jenkin, M. E., Jimenez, J. L., KiendlerScharr, A., Maenhaut, W., McFiggans, G., Mentel, T. F., Monod, A., Prévot, A. S. H., Seinfeld, J. H., Surratt, J. D., Szmigielski, R., and Wildt, J.: The formation, properties and impact of secondary organic aerosol: current and emerging issues, Atmos. Chem. Phys., 9, 5155-5236, doi:10.5194/acp-9-5155-2009, 2009.

Hao, C., Shepson, P. B., Drummond, J. W., and Muthuramu, K.: Gas chromatographic detector for selective and sensitive detection of atmospheric organic nitrates, Anal. Chem., 66, 3737-3743, 1994.

Hao, L. Q., Kortelainen, A., Romakkaniemi, S., Portin, H., Jaatinen, A., Leskinen, A., Komppula, M., Miettinen, P., Sueper, D., Pajunoja, A., Smith, J. N., Lehtinen, K. E. J., Worsnop, D. R., Laaksonen, A., and Virtanen, A.: Atmospheric submicron aerosol composition and particulate organic nitrate formation in a boreal forestland-urban mixed region, Atmos. Chem. Phys., 14, 1348313495, doi:10.5194/acp-14-13483-2014, 2014.

Harrison, M. A., Barra, S., Borghesi, D., Vione, D., Arsene, C., and Olariu, R. I.: Nitrated phenols in the atmosphere: a review, Atmos. Environ., 39, 231-248, 2005.

Heintz, F., Platt, U., Flentje, J., and Dubois, R.: Long-term observation of nitrate radicals at the Tor Station, Kap Arkona (Rügen), J. Geophys. Res., 101, 22891-22910, 1996.

Herrmann, H.: Kinetics of aqueous phase reactions relevant for atmospheric chemistry, Chem. Rev., 103, 4691-4716, doi:10.1021/cr020658q, 2003.

Herrmann, $\mathrm{H}$. and Zellner, R.: Reactions of $\mathrm{NO}_{3}$-Radicals in Aqueous Solution, in: N-Centered Radicals, edited by: Alfassi, Z. B., Wiley, Chichester, 291-343, 1998. 
Herrmann, H., Tilgner, A., Barzaghi, P., Majdik, Z., Gligorovski, S., Poulain, L., and Monod, A.: Towards a more detailed description of tropospheric aqueous phase organic chemistry: CAPRAM 3.0, Atmos. Environ., 39, 4351-4363, 2005.

Herrmann, H., Hoffmann, D., Schaefer, T., Brauer, P., and Tilgner, A.: Tropospheric Aqueous-Phase Free-Radical Chemistry: Radical Sources, Spectra, Reaction Kinetics and Prediction Tools, Chem. Phys. Chem., 11, 3796-3822, doi:10.1002/cphc.201000533, 2010.

Herrmann, H., Schaefer, T., Tilgner, A., Styler, S. A., Weller, C., Teich, M., and Otto, T.: Tropospheric Aqueous-Phase Chemistry: Kinetics, Mechanisms, and Its Coupling to a Changing Gas Phase, Chem. Rev., 115, 4259-4334, doi:10.1021/cr500447k, 2015.

Hidy, G. M., Blanchard, C. L., Baumann, K., Edgerton, E., Tanenbaum, S., Shaw, S., Knipping, E., Tombach, I., Jansen, J., and Walters, J.: Chemical climatology of the southeastern United States, 1999-2013, Atmos. Chem. Phys., 14, 11893-11914, doi:10.5194/acp-14-11893-2014, 2014.

Hildebrandt Ruiz, L. H., and Yarwood, G.: Interactions between organic aerosol and NOy: Influence on oxidant production., Prepared for the Texas AQRP (Project 12-012), by the University of Texas at Austin, and ENVIRON International Corporation, Novato, CA, 2013

Hodzic, A., Jimenez, J. L., Prévôt, A. S. H., Szidat, S., Fast, J. D., and Madronich, S.: Can 3-D models explain the observed fractions of fossil and non-fossil carbon in and near Mexico City?, Atmos. Chem. Phys., 10, 10997-11016, doi:10.5194/acp10-10997-2010, 2010.

Hoffmann, D., Weigert, B., Barzaghi, P., and Herrmann, H.: Reactivity of poly-alcohols towards $\mathrm{OH}, \mathrm{NO}_{3}$ and $\mathrm{SO}_{4}^{-}$in aqueous solution, Phys. Chem. Chem. Phys., 11, 9351-9363, 2009.

Hoffmann, T., Odum, J. R., Bowman, F., Collins, D., Klockow, D., Flagan, R. C., and Seinfeld, J. H.: Formation of organic aerosols from the oxidation of biogenic hydrocarbons, J. Atmos. Chem., 26, 189-222, 1997.

Horowitz, L. W., Fiore, A. M., Milly, G. P., Cohen, R. C., Perrin, A., Wooldridge, P. J., Hess, P. G., Emmons, L. K., and Lamarque, J. F.: Observational constraints on the chemistry of isoprene nitrates over the eastern United States, J. Geophys. Res., 112, D12S08, doi:10.1029/2006JD007747, 2007.

Hou, H. and Wang, B.: A Systematic Computational Study on the Reactions of $\mathrm{HO}_{2}$ with $\mathrm{RO}_{2}$ : The $\mathrm{HO}_{2}+\mathrm{CH}_{3} \mathrm{O}_{2}\left(\mathrm{CD}_{3} \mathrm{O}_{2}\right)$ and $\mathrm{HO}_{2}+\mathrm{CH}_{2} \mathrm{FO}_{2}$ Reactions, J. Phys. Chem. A, 109, 451-460, doi:10.1021/jp046329e, 2005.

Hou, H., Deng, L., Li, J., and Wang, B.: A Systematic Computational Study of the Reactions of $\mathrm{HO}_{2}$ with $\mathrm{RO}_{2}$ : The $\mathrm{HO}_{2}+\mathrm{CH}_{2} \mathrm{ClO}_{2}, \mathrm{CHCl}_{2} \mathrm{O}_{2}$, and $\mathrm{CCl}_{3} \mathrm{O}_{2}$ Reactions, J. Phys. Chem. A, 109, 9299-9309, doi:10.1021/jp052718c, 2005.

Hoyle, C. R., Berntsen, T., Myhre, G., and Isaksen, I. S. A.: Secondary organic aerosol in the global aerosol - chemical transport model Oslo CTM2, Atmos. Chem. Phys., 7, 5675-5694, doi:10.5194/acp-7-5675-2007, 2007.

Hoyle, C. R., Boy, M., Donahue, N. M., Fry, J. L., Glasius, M., Guenther, A., Hallar, A. G., Huff Hartz, K., Petters, M. D., Petaja, T., Rosenoern, T., and Sullivan, A. P.: A review of the anthropogenic influence on biogenic secondary organic aerosol, Atmos. Chem. Phys., 11, 321-343, doi:10.5194/acpd-10-195152010, 2011.
Hu, K. S., Darer, A. I., and Elrod, M. J.: Thermodynamics and kinetics of the hydrolysis of atmospherically relevant organonitrates and organosulfates, Atmos. Chem. Phys., 11, 8307-8320, doi:10.5194/acp-11-8307-2011, 2011.

Hu, X.-M., Nielsen-Gammon, J. W., and Zhang, F.: Evaluation of Three Planetary Boundary Layer Schemes in the WRF Model, J. Appl. Meteorol. Climatol., 49, 1831-1844, doi:10.1175/2010JAMC2432.1, 2010.

Huey, L. G.: Measurement of trace atmospheric species by chemical ionization mass spectrometry: Speciation of reactive nitrogen and future directions, Mass Spectrom. Rev., 26, 166-184, doi:10.1002/mas.20118, 2007.

Huie, R. E.: Laboratory Studies of Atmospheric Heterogeneous Chemistry; Current Problems in Atmospheric Chemistry, in: Advances in Physical Chemistry Series, edited by: Barker, J. R., World Scientific, Singapore, 374-419, 1994.

Hung, H., -M, Katrib, Y., and Martin, S., T.: Products and Mechanisms of the Reaction of Oleic Acid with Ozone and Nitrate Radical, J. Phys. Chem. A, 109, 4517-4530, doi:10.1021/jp0500900, 2005.

Hurst, J. M., Barket, D. J., Herrera-Gomez, O., Couch, T. L., Shepson, P. B., Faloona, I., Tan, D., Brune, W., Westberg, H., and Lamb, B.: Investigation of the nighttime decay of isoprene, J. Geophys. Res.-Atmos., 106, 24335-24346, 2001.

Hutzell, W. T., Luecken, D. J., Appel, K. W., and Carter, W. P. L.: Interpreting predictions from the SAPRC07 mechanism based on regional and continental simulations, Atmos. Environ., 46, 417429, doi:10.1016/j.atmosenv.2011.09.030, 2012.

Iannone, R., Xiao, S., and Bertram, A. K.: Potentially important nighttime heterogeneous chemistry: $\mathrm{NO}_{3}$ with aldehydes and $\mathrm{N}_{2} \mathrm{O}_{5}$ with alcohols, Phys. Chem. Chem. Phys., 13, 10214 10223, doi:10.1039/C1CP20294D, 2011.

Iinuma, Y., Müller, C., Berndt, T., Böge, O., Claeys, M., and Herrmann, H.: Evidence for the Existence of Organosulfates from b-Pinene Ozonolysis in Ambient Secondary Organic Aerosol, Environ. Sci. Technol., 41, 6678-6683, doi:10.1021/es070938t, 2007.

Iyer, S., Lopez-Hilfiker, F., Lee, B. H., Thornton, J. A., and Kurten, T.: Modeling the Detection of Organic and Inorganic Compounds Using Iodide-Based Chemical Ionization, J. Phys. Chem. A, 120, 576-587, 2016.

Jacobs, M. I., Burke, W. J., and Elrod, M. J.: Kinetics of the reactions of isoprene-derived hydroxynitrates: gas phase epoxide formation and solution phase hydrolysis, Atmos. Chem. Phys., 14, 8933-8946, doi:10.5194/acp-14-8933-2014, 2014.

Jacobson, M. Z.: Isolating nitrated and aromatic aerosols and nitrated aromatic gases as sources of ultraviolet light absorption, J. Geophys. Res.-Atmos., 104, 3527-3542, doi:10.1029/1998jd100054, 1999.

Jang, J.-C. C., Jeffries, H. E., and Tonnesen, S.: Sensitivity of ozone to model grid resolution - II. Detailed process analysis for ozone chemistry, Atmos. Environ., 29, 3101-3114, doi:10.1016/13522310(95)00119-J, 1995.

Jaoui, M., Kleindienst, T. E., Docherty, K. S., Lewandowski, M., and Offenberg, J. H.: Secondary organic aerosol formation from the oxidation of a series of sesquiterpenes: $\alpha$-cedrene, $\beta$ caryophyllene, $\alpha$-humulene and $\alpha$-farnesene with $\mathrm{O}_{3}, \mathrm{OH}$ and $\mathrm{NO}_{3}$ radicals, Environ. Chem., 10, 178-193, 2013. 
Jayne, J. T., Leard, D. C., Zhang, X. F., Davidovits, P., Smith, K. A., Kolb, C. E., and Worsnop, D. R.: Development of an aerosol mass spectrometer for size and composition analysis of submicron particles, Aerosol Sci. Tech., 33, 49-70, 2000.

Jenkin, M. E., Saunders, S. M., and Pilling, M. J.: The tropospheric degradation of volatile organic compounds: a protocol for mechanism development, Atmos. Environ., 31, 81-104, doi:10.1016/S1352-2310(96)00105-7, 1997.

Jenkin, M. E., Young, J. C., and Rickard, A. R.: The MCM v3.3.1 degradation scheme for isoprene, Atmos. Chem. Phys., 15, 11433-11459, doi:10.5194/acp-15-11433-2015, 2015.

Jimenez, J. L., Canagaratna, M. R., Donahue, N. M., Prevot, A. S. H., Zhang, Q., Kroll, J. H., DeCarlo, P. F., Allan, J. D., Coe, H., Ng, N. L., Aiken, A. C., Docherty, K. S., Ulbrich, I. M., Grieshop, A. P., Robinson, A. L., Duplissy, J., Smith, J. D., Wilson, K. R., Lanz, V. A., Hueglin, C., Sun, Y. L., Tian, J., Laaksonen, A., Raatikainen, T., Rautiainen, J., Vaattovaara, P., Ehn, M., Kulmala, M., Tomlinson, J. M., Collins, D. R., Cubison, M. J., Dunlea, E. J., Huffman, J. A., Onasch, T. B., Alfarra, M. R., Williams, P. I., Bower, K., Kondo, Y., Schneider, J., Drewnick, F., Borrmann, S., Weimer, S., Demerjian, K., Salcedo, D., Cottrell, L., Griffin, R., Takami, A., Miyoshi, T., Hatakeyama, S., Shimono, A., Sun, J. Y., Zhang, Y. M., Dzepina, K., Kimmel, J. R., Sueper, D., Jayne, J. T., Herndon, S. C., Trimborn, A. M., Williams, L. R., Wood, E. C., Middlebrook, A. M., Kolb, C. E., Baltensperger, U., and Worsnop, D. R.: Evolution of Organic Aerosols in the Atmosphere, Science, 326, 1525-1529, 2009.

Johnston, H. S., Davis, H. F., and Lee, Y. T.: $\mathrm{NO}_{3}$ Photolysis Product Channels: Quantum Yields from Observed Energy Thresholds, J. Phys. Chem., 100, 4713-4723, 1996.

Jones, B. T. and Ham, J. E.: alpha-Terpineol reactions with the nitrate radical: Rate constant and gas-phase products, Atmos. Environ., 42, 6689-6698, doi:10.1016/j.atmosenv.2008.04.017, 2008.

Kaduwela, A., Luecken, D., Carter, W., and Derwent, R.: New directions: Atmospheric chemical mechanisms for the future, Atmos. Environ., 122, 609-610, doi:10.1016/j.atmosenv.2015.10.031, 2015.

Kaiser, J. C., Riemer, N., and Knopf, D. A.: Detailed heterogeneous oxidation of soot surfaces in a particle-resolved aerosol model, Atmos. Chem. Phys., 11, 4505-4520, doi:10.5194/acp-11-45052011, 2011.

Kames, J., Schurath, U., Flocke, F., and Volzthomas, A.: Preparation of Organic Nitrates from Alcohols and $\mathrm{N}_{2} \mathrm{O}_{5}$ for Species Identification in Atmospheric Samples, J. Atmos. Chem., 16, 349-359, 1993.

Karamchandani, P., Seigneur, C., Vijayaraghavan, K., and Wu, S.-Y.: Development and application of a state-of-the-science plume-in-grid model, J. Geophys. Res.-Atmos., 107, 11-13, doi:10.1029/2002JD002123, 2002.

Kastler, J. and Ballschmiter, K.: Bifunctional alkyl nitrates - trace constituents of the atmosphere, Fresen. J. Anal. Chem., 360, 812-816, 1998.

Kastler, J., Jarman, W., and Ballschmiter, K.: Multifunctional organic nitrates as constituents in European and US urban photo-smog, Fresen. J. Anal. Chem., 368, 244-249, doi:10.1007/s002160000550, 2000.

Kennedy, O., Ouyang, B., Langridge, J., Daniels, M., Bauguitte, S., Freshwater, R., McLeod, M., Ironmonger, C., Sendall, J., and Norris, O.: An aircraft based three channel broadband cavity en- hanced absorption spectrometer for simultaneous measurements of $\mathrm{NO}_{3}, \mathrm{~N}_{2} \mathrm{O}_{5}$ and $\mathrm{NO}_{2}$, Atmos. Meas. Tech., 4, 1759-1776, doi:10.5194/amtd-4-3499-2011, 2011.

Kercher, J. P., Riedel, T. P., and Thornton, J. A.: Chlorine activation by $\mathrm{N}_{2} \mathrm{O}_{5}$ : simultaneous, in situ detection of $\mathrm{ClNO}_{2}$ and $\mathrm{N}_{2} \mathrm{O}_{5}$ by chemical ionization mass spectrometry, Atmos. Meas. Tech., 2, 193-204, doi:10.5194/amt-2-193-2009, 2009.

Kerdouci, J., Picquet-Varrault, B., and Doussin, J.-F.: Prediction of Rate Constants for Gas-Phase Reactions of Nitrate Radical with Organic Compounds: A New Structure-Activity Relationship, Chem. Phys. Chem., 11, 3909-3920, 2010.

Kerdouci, J., Picquet-Varrault, B., Durand-Jolibois, R., Gaimoz, C., and Doussin, J.-F.: An Experimental Study of the Gas-Phase Reactions of $\mathrm{NO}_{3}$ Radicals with a Series of Unsaturated Aldehydes: trans-2-Hexenal, trans-2-Heptenal, and trans-2-Octenal, J. Phys. Chem. A, 116, 10135-10142, doi:10.1021/jp3071234, 2012.

Kerdouci, J., Picquet-Varrault, B., and Doussin, J.-F.: Structure-activity relationship for the gas-phase reactions of $\mathrm{NO}_{3}$ radical with organic compounds: Update and extension to aldehydes, Atmos. Environ., 84, 363-372, doi:10.1016/j.atmosenv.2013.11.024, 2014.

Kern, C., Trick, S., Rippel, B., and Platt, U.: Applicability of lightemitting diodes as light sources for active differential optical absorption spectroscopy measurements, Appl. Opt., 45, 20772088, 2006.

Kesselmeier, J. and Staudt, M.: Biogenic Volatile Organic Compounds (VOC): An Overview on Emission, Physiology and Ecology, J. Atmos. Chem., 33, 23-88, doi:10.1023/A:1006127516791, 1999.

Khan, M. A. H., Cooke, M. C., Utembe, S. R., Archibald, A. T., Derwent, R. G., Xiao, P., Percival, C. J., Jenkin, M. E., Morris, W. C., and Shallcross, D. E.: Global modeling of the nitrate radical $\left(\mathrm{NO}_{3}\right)$ for present and pre-industrial scenarios, Atmos. Res., 164/165, 347-357, doi:10.1016/j.atmosres.2015.06.006, 2015.

Kiendler-Scharr, A., Mensah, A. A., Friese, E., Topping, D., Nemitz, E., Prevot, A. S. H., Äijälä, M., Allan, J., Canonaco, F., Canagaratna, M., Carbone, S., Crippa, M., Dall Osto, M., Day, D. A., De Carlo, P., Di Marco, C. F., Elbern, H., Eriksson, A., Freney, E., Hao, L., Herrmann, H., Hildebrandt, L., Hillamo, R., Jimenez, J. L., Laaksonen, A., McFiggans, G., Mohr, C., O’Dowd, C., Otjes, R., Ovadnevaite, J., Pandis, S. N., Poulain, L., Schlag, P., Sellegri, K., Swietlicki, E., Tiitta, P., Vermeulen, A., Wahner, A., Worsnop, D., and Wu, H. C.: Organic nitrates from night-time chemistry are ubiquitous in the European submicron aerosol, Geophys. Res. Lett., 43, 7735-7744, doi:10.1002/2016GL069239, 2016.

Kim, P. S., Jacob, D. J., Fisher, J. A., Travis, K., Yu, K., Zhu, L., Yantosca, R. M., Sulprizio, M. P., Jimenez, J. L., CampuzanoJost, P., Froyd, K. D., Liao, J., Hair, J. W., Fenn, M. A., Butler, C. F., Wagner, N. L., Gordon, T. D., Welti, A., Wennberg, P. O., Crounse, J. D., St. Clair, J. M., Teng, A. P., Millet, D. B., Schwarz, J. P., Markovic, M. Z., and Perring, A. E.: Sources, seasonality, and trends of southeast US aerosol: an integrated analysis of surface, aircraft, and satellite observations with the GEOS-Chem chemical transport model, Atmos. Chem. Phys., 15, 10411-10433, doi:10.5194/acp-15-10411-2015, 2015.

Kim, S.-W., Heckel, A., McKeen, S. A., Frost, G. J., Hsie, E. Y., Trainer, M. K., Richter, A., Burrows, J. P., Peckham, S. E., and Grell, G. A.: Satellite-observed US power plant $\mathrm{NO}_{x}$ emission 
reductions and their impact on air quality, Geophys. Res. Lett., 33, L22812, doi:10.1029/2006GL027749, 2006.

Kind, I., Berndt, T., and Böge, O.: Gas-phase rate constants for the reaction of $\mathrm{NO}_{3}$ radicals with a series of cyclic alkenes, 2-ethyl-1-butene and 2,3-dimethyl-1,3-butadiene, Chem. Phys. Lett., 288, 111-118, 1998.

King, M. D., Dick, E. M., and Simpson, W. R.: A new method for the atmospheric detection of the nitrate radical $\left(\mathrm{NO}_{3}\right)$, Atmos. Environ., 34, 685-688, doi:10.1016/S1352-2310(99)00418-5, 2000.

Kleist, E., Mentel, T. F., Andres, S., Bohne, A., Folkers, A., Kiendler-Scharr, A., Rudich, Y., Springer, M., Tillmann, R., and Wildt, J.: Irreversible impacts of heat on the emissions of monoterpenes, sesquiterpenes, phenolic BVOC and green leaf volatiles from several tree species, Biogeosciences, 9, 51115123, doi:10.5194/bg-9-5111-2012, 2012.

Knopf, D. A., Mak, J., Gross, S., and Bertram, A. K.: Does atmospheric processing of saturated hydrocarbon surfaces by $\mathrm{NO}_{3}$ lead to volatilization, Geophys. Res. Lett., 33, L17816, doi:10.1029/2006GL026884, 2006.

Knopf, D. A., Forrester, S. M., and Slade, J. H.: Heterogeneous oxidation kinetics of organic biomass burning aerosol surrogates by $\mathrm{O}_{3}, \mathrm{NO}_{2}, \mathrm{~N}_{2} \mathrm{O}_{5}$, and $\mathrm{NO}_{3}$, Phys. Chem. Chem. Phys., 13, 21050-21062, 2011.

Knote, C., Hodzic, A., Jimenez, J. L., Volkamer, R., Orlando, J. J., Baidar, S., Brioude, J., Fast, J., Gentner, D. R., Goldstein, A. H., Hayes, P. L., Knighton, W. B., Oetjen, H., Setyan, A., Stark, H., Thalman, R., Tyndall, G., Washenfelder, R., Waxman, E., and Zhang, Q.: Simulation of semi-explicit mechanisms of SOA formation from glyoxal in aerosol in a 3-D model, Atmos. Chem. Phys., 14, 6213-6239, doi:10.5194/acp-14-6213-2014, 2014.

Knote, C., Tuccella, P., Curci, G., Emmons, L., Orlando, J. J., Madronich, S., Baró, R., Jiménez-Guerrero, P., Luecken, D., Hogrefe, C., Forkel, R., Werhahn, J., Hirtl, M., Pérez, J. L., San José, R., Giordano, L., Brunner, D., Yahya, K., and Zhang, Y.: Influence of the choice of gas-phase mechanism on predictions of key gaseous pollutants during the AQMEII phase-2 intercomparison, Atmos. Environ., 115, 553568, doi:10.1016/j.atmosenv.2014.11.066, 2015.

Koenig, J. Q., Covert, D. S., and Pierson, W. E.: Effects of Inhalation of Acidic Compounds on Pulmonary Function in Allergic Adolescent Subjects, Environ. Health Persp., 79, 173-178, 1989.

Koo, B., Knipping, E., and Yarwood, G.: 1.5-Dimensional volatility basis set approach for modeling organic aerosol in CAMx and CMAQ, Atmos. Environ., 95, 158-164, doi:10.1016/j.atmosenv.2014.06.031, 2014.

Koop, T., Bookhold, J., Shiraiwa, M., and Pöschl, U.: Glass transition and phase state of organic compounds: dependency on molecular properties and implications for secondary organic aerosols in the atmosphere, Phys. Chem. Chem. Phys., 13, 19238-19255, doi:10.1039/C1CP22617G, 2011.

Kotzias, D., Hjorth, J. L., and Skov, H.: A chemical mechanism for dry deposition - The role of biogenic hydrocarbon (terpene) emissions in the dry deposition of $\mathrm{O}_{3}, \mathrm{SO}_{2}$ and $\mathrm{NO}_{x}$ in forest areas, Toxicol. Environ. Chem., 20, 95-99, doi:10.1080/02772248909357364, 1989.

Krechmer, J. E., Pagonis, D., Ziemann, P. J., and Jimenez, J. L.: Quantification of Gas-Wall Partitioning in Teflon Environmental Chambers Using Rapid Bursts of Low-Volatility Oxidized
Species Generated in Situ, Environ. Sci. Technol., 50, 57575765, doi:10.1021/acs.est.6b00606, 2016.

Krotkov, N. A., McLinden, C. A., Li, C., Lamsal, L. N., Celarier, E. A., Marchenko, S. V., Swartz, W. H., Bucsela, E. J., Joiner, J., Duncan, B. N., Boersma, K. F., Veefkind, J. P., Levelt, P. F., Fioletov, V. E., Dickerson, R. R., He, H., Lu, Z., and Streets, D. G.: Aura OMI observations of regional $\mathrm{SO}_{2}$ and $\mathrm{NO}_{2}$ pollution changes from 2005 to 2015, Atmos. Chem. Phys., 16, 46054629, doi:10.5194/acp-16-4605-2016,

Kulmala, M., Asmi, A., Lappalainen, H. K., Baltensperger, U., Brenguier, J.-L., Facchini, M. C., Hansson, H.-C., Hov, Ø., O’Dowd, C. D., Pöschl, U., Wiedensohler, A., Boers, R., Boucher, O., de Leeuw, G., Denier van der Gon, H. A. C., Feichter, J., Krejci, R., Laj, P., Lihavainen, H., Lohmann, U., McFiggans, G., Mentel, T., Pilinis, C., Riipinen, I., Schulz, M., Stohl, A., Swietlicki, E., Vignati, E., Alves, C., Amann, M., Ammann, M., Arabas, S., Artaxo, P., Baars, H., Beddows, D. C. S., Bergström, R., Beukes, J. P., Bilde, M., Burkhart, J. F., Canonaco, F., Clegg, S. L., Coe, H., Crumeyrolle, S., D’Anna, B., Decesari, S., Gilardoni, S., Fischer, M., Fjaeraa, A. M., Fountoukis, C., George, C., Gomes, L., Halloran, P., Hamburger, T., Harrison, R. M., Herrmann, H., Hoffmann, T., Hoose, C., Hu, M., Hyvärinen, A., Hõrrak, U., Iinuma, Y., Iversen, T., Josipovic, M., Kanakidou, M., Kiendler-Scharr, A., Kirkevåg, A., Kiss, G., Klimont, Z., Kolmonen, P., Komppula, M., Kristjánsson, J.-E., Laakso, L., Laaksonen, A., Labonnote, L., Lanz, V. A., Lehtinen, K. E. J., Rizzo, L. V., Makkonen, R., Manninen, H. E., McMeeking, G., Merikanto, J., Minikin, A., Mirme, S., Morgan, W. T., Nemitz, E., O’Donnell, D., Panwar, T. S., Pawlowska, H., Petzold, A., Pienaar, J. J., Pio, C., Plass-Duelmer, C., Prévôt, A. S. H., Pryor, S., Reddington, C. L., Roberts, G., Rosenfeld, D., Schwarz, J., Seland, Ø., Sellegri, K., Shen, X. J., Shiraiwa, M., Siebert, H., Sierau, B., Simpson, D., Sun, J. Y., Topping, D., Tunved, P., Vaattovaara, P., Vakkari, V., Veefkind, J. P., Visschedijk, A., Vuollekoski, H., Vuolo, R., Wehner, B., Wildt, J., Woodward, S., Worsnop, D. R., van Zadelhoff, G.-J., Zardini, A. A., Zhang, K., van Zyl, P. G., Kerminen, V.-M., S Carslaw, K., and Pandis, S. N.: General overview: European Integrated project on Aerosol Cloud Climate and Air Quality interactions (EUCAARI) - integrating aerosol research from nano to global scales, Atmos. Chem. Phys., 11, 13061-13143, doi:10.5194/acp11-13061-2011, 2011.

Kwan, A. J., Chan, A. W. H., Ng, N. L., Kjaergaard, H. G., Seinfeld, J. H., and Wennberg, P. O.: Peroxy radical chemistry and OH radical production during the $\mathrm{NO}_{3}$-initiated oxidation of isoprene, Atmos. Chem. Phys., 12, 7499-7515, doi:10.5194/acp-12-74992012, 2012.

Kwok, E. S. C., Aschmann, S. M., Arey, J., and Atkinson, R.: Product formation from the reaction of the $\mathrm{NO}_{3}$ radical with isoprene and rate constants for the reactions of methacrolein and methyl vinyl ketone with the $\mathrm{NO}_{3}$ radical, Int. J. Chem. Kinet., 28, 925 934, 1996.

La, Y. S., Camredon, M., Ziemann, P. J., Valorso, R., Matsunaga, A., Lannuque, V., Lee-Taylor, J., Hodzic, A., Madronich, S., and Aumont, B.: Impact of chamber wall loss of gaseous organic compounds on secondary organic aerosol formation: explicit modeling of SOA formation from alkane and alkene oxidation, Atmos. Chem. Phys., 16, 1417-1431, doi:10.5194/acp-161417-2016, 2016. 
Lack, D., NLangridg, J. M., Bahreni, R., Cappa, C. D., Middlebrook, A. M., and Schwarz, J. P.: Brown carbon and internal mixing in biomass burning particles, P. Natl. Acad. Sci. USA, 109, 14802-14807, 2012.

Lamarque, J.-F., Kyle, G. P., Meinshausen, M., Riahi, K., Smith, S. J., Vuuren, D. P., Conley, A. J., and Vitt, F.: Global and regional evolution of short-lived radiatively-active gases and aerosols in the Representative Concentration Pathways, Climatic Change, 109, 191-212, doi:10.1007/s10584-011-0155-0, 2011.

Lane, T. E., Donahue, N. M., and Pandis, S. N.: Effect of NOx on Secondary Organic Aerosol Concentrations, Environ. Sci. Technol., 42, 6022-6027, doi:10.1021/es703225a, 2008.

Langridge, J. M., Ball, S. M., Shillings, A. J. L., and Jones, R. L.: A broadband absorption spectrometer using light emitting diodes for ultrasensitive, in situ trace gas detection, Rev. Sci. Instrum., 79, 123110, doi:10.1063/1.3046282, 2008.

Laskin, A., Laskin, J., and Nizkorodov, S. A.: Chemistry of Atmospheric Brown Carbon, Chem. Rev., 115, 4335-4382, 2015.

Le Breton, M., Bacak, A., Muller, J. B. A., Bannan, T. J., Kennedy, O., Ouyang, B., Xiao, P., Bauguitte, S. J. B., Shallcross, D. E., Jones, R. L., Daniels, M. J. S., Ball, S. M., and Percival, C. J.: The first airborne comparison of $\mathrm{N}_{2} \mathrm{O}_{5}$ measurements over the UK using a CIMS and BBCEAS during the RONOCO campaign, Analtyical Methods, 6, 9731-9743, doi:10.1039/C4AY02273D, 2014.

Lee, B. H., Lopez-Hilfiker, F. D., Mohr, C., Kurten, T., Worsnop, D. R., and Thornton, J. A.: An Iodide-Adduct High-Resolution Time-of-Flight Chemical-Ionization Mass Spectrometer: Application to Atmospheric Inorganic and Organic Compounds, Environ. Sci. Technol., 48, 6309-6317, 2014a.

Lee, B. H., Mohr, C., Lopez-Hilfiker, F. D., Lutz, A., Hallquist, M., Lee, L., Romer, P., Cohen, R. C., Iyer, S., Kurten, T., Hu, W., Day, D. A., Campuzano-Jost, P., Jimenez, J. L., Xu, L., Ng, N. L., Guo, H., Weber, R. J., Wild, R. J., Brown, S. S., Koss, A., de Gouw, J., Olson, K., Goldstein, A. H., Seco, R., Kim, S., McAvery, K., Shepson, P. B., Baumann, K., Edgerton, E., Liu, J., Shilling, J. E., Miller, D. O., Brune, W. H., D'Ambro, E. L., and Thornton, J. A.: Highly functionalized organic nitrates in the southeast United States: Contribution to secondary organic aerosol and reactive nitrogen budgets, P. Natl. Acad. Sci., 113, 1516-1521, 2016.

Lee, L., Wooldridge, P., Nah, T., Wilson, K., and Cohen, R.: Observation of rates and products in the reaction of $\mathrm{NO}_{3}$ with submicron squalane and squalene aerosol, Phys. Chem. Chem. Phys., 15, 882-892, doi:10.1039/C2CP42500A, 2013.

Lee, L., Teng, A. P., Wennberg, P. O., Crounse, J. D., and Cohen, R. C.: On Rates and Mechanisms of $\mathrm{OH}$ and $\mathrm{O}_{3}$ Reactions with Isoprene-Derived Hydroxy Nitrates, J. Phys. Chem. A, 118, 1622-1637, 2014b.

Lee, L., Wooldridge, P. J., deGouw, J., Brown, S. S., Bates, T. S., Quinn, P. K., and Cohen, R. C.: Particulate organic nitrates observed in an oil and natural gas production region during wintertime, Atmos. Chem. Phys., 15, 9313-9325, doi:10.5194/acp-159313-2015, 2015.

Li, Y. P., Elbern, H., Lu, K. D., Friese, E., Kiendler-Scharr, A., Mentel, T. F., Wang, X. S., Wahner, A., and Zhang, Y. H.: Updated aerosol module and its application to simulate secondary organic aerosols during IMPACT campaign May 2008, Atmos. Chem. Phys., 13, 6289-6304, doi:10.5194/acp-13-6289-2013, 2013.
Liggio, J. and Mclaren, R.: An optimized method for the determination of volatile and semi-volatile aldehydes and ketones in ambient particulate matter, Int. J. Environ. An. Ch., 83, 819-835, 2003.

Lin, P., Liu, J., Shilling, J. E., Kathmann, S. M., Laskin, J., and Laskin, A.: Molecular characterization of brown carbon (BrC) chromophores in secondary organic aerosol generated from photo-oxidation of toluene, Phys. Chem. Chem. Phys., 17, 23312-23325, doi:10.1039/C5CP02563J, 2015.

Liu, S., Ahlm, L., Day, D. A., Russell, L. M., Zhao, Y., Gentner, D. R., Weber, R. J., Goldstein, A. H., Jaoui, M., Offenberg, J. H., Kleindienst, T. E., Rubitschun, C., Surratt, J. D., Sheesley, R. J., and Scheller, S.: Secondary organic aerosol formation from fossil fuel sources contribute majority of summertime organic mass at Bakersfield, J. Geophys. Res.-Atmos., 117, D00V26, doi:10.1029/2012jd018170, 2012a.

Liu, S., Shilling, J. E., Song, C., Hiranuma, N., Zaveri, R. A., and Russell, L. M.: Hydrolysis of Organonitrate Functional Groups in Aerosol Particles, Aerosol Sci. Tech., 46, 1359-1369, doi:10.1080/02786826.2012.716175, 2012b.

Ljungström, E. and Hallquist, M.: Nitrate radical formation rates in Scandinavia, Atmos. Environ., 30, 2925-2932, 1996.

Lockwood, A. L., Shepson, P. B., Fiddler, M. N., and Alaghmand, M.: Isoprene nitrates: preparation, separation, identification, yields, and atmospheric chemistry, Atmos. Chem. Phys., 10, 6169-6178, doi:10.5194/acp-10-6169-2010, 2010.

Lopez-Hilfiker, F. D., Mohr, C., Ehn, M., Rubach, F., Kleist, E., Wildt, J., Mentel, Th. F., Lutz, A., Hallquist, M., Worsnop, D., and Thornton, J. A.: A novel method for online analysis of gas and particle composition: description and evaluation of a Filter Inlet for Gases and AEROsols (FIGAERO), Atmos. Meas. Tech., 7, 983-1001, doi:10.5194/amt-7-983-2014, 2014.

Lopez-Hilfiker, F. D., Iyer, S., Mohr, C., Lee, B. H., D’Ambro, E. L., Kurtén, T., and Thornton, J. A.: Constraining the sensitivity of iodide adduct chemical ionization mass spectrometry to multifunctional organic molecules using the collision limit and thermodynamic stability of iodide ion adducts, Atmos. Meas. Tech., 9, 1505-1512, doi:10.5194/amt-9-1505-2016, 2016.

Loza, C. L., Chan, A. W. H., Galloway, M. M., Keutsch, F. N., Flagan, R. C., and Seinfeld, J. H.: Characterization of Vapor Wall Loss in Laboratory Chambers, Environ. Sci. Technol., 44, 50745078, doi:10.1021/es100727v, 2010.

Lu, J. W., Flores, J. M., Lavi, A., Abo-Riziq, A., and Rudich, Y.: Changes in the optical properties of benzo[a]pyrene-coated aerosols upon heterogeneous reactions with $\mathrm{NO}_{2}$ and $\mathrm{NO}_{3}$, Phys. Chem. Chem. Phys., 13, 6484-6492, doi:10.1039/c0cp02114h, 2011.

Lu, Z., Streets, D. G., de Foy, B., Lamsal, L. N., Duncan, B. N., and Xing, J.: Emissions of nitrogen oxides from US urban areas: estimation from Ozone Monitoring Instrument retrievals for 20052014, Atmos. Chem. Phys., 15, 10367-10383, doi:10.5194/acp15-10367-2015, 2015.

Luecken, D. J., Phillips, S., Sarwar, G., and Jang, C.: Effects of using the CB05 vs. SAPRC99 vs. CB4 chemical mechanism on model predictions: Ozone and gas-phase photochemical precursor concentrations, Atmos. Environ., 42, 5805-5820, doi:10.1016/j.atmosenv.2007.08.056, 2008.

Luecken, D. J., Hutzell, W. T., Strum, M. L., and Pouliot, G. A.: Regional sources of atmospheric formaldehyde and acetaldehyde, 
and implications for atmospheric modeling, Atmos. Environ., 47, 477-490, doi:10.1016/j.atmosenv.2011.10.005, 2012.

Luxenhofer, O., Schneider, M., Dambach, M., and Ballschmiter, K.: Semivolatile long chain $\mathrm{C}_{6}-\mathrm{C}_{17}$ alkyl nitrates as trace compounds in air, Chemosphere, 33, 393-404, doi:10.1016/00456535(96)00205-6, 1996

Ma, X., Yu, F., and Luo, G.: Aerosol direct radiative forcing based on GEOS-Chem-APM and uncertainties, Atmos. Chem. Phys., 12, 5563-5581, doi:10.5194/acp-12-5563-2012, 2012.

Mao, J., Paulot, F., Jacob, D. J., Cohen, R. C., Crounse, J. D., Wennberg, P. O., Keller, C. A., Hudman, R. C., Barkley, M. P., and Horowitz, L. W.: Ozone and organic nitrates over the eastern United States: Sensitivity to isoprene chemistry, J. Geophys. Res.-Atmos., 118, JD020231, doi:10.1002/jgrd.50817, 2013.

Martinez, E., Cabanas, B., Aranda, A., and Martin, P.: Kinetics of the Reactions of $\mathrm{NO}_{3}$ Radical with Selected Monoterpenes: A Temperature Dependence Study, Environ. Sci. Technol., 32, 3730-3734, 1998.

Martínez, E., Cabañas, B., Aranda, A., Martín, P., and Salgado, S.: Absolute Rate Coefficients for the Gas-Phase Reactions of $\mathrm{NO}_{3}$ Radical with a Series of Monoterpenes at $T=298$ to $433 \mathrm{~K}$, J. Atmos. Chem., 33, 265-282, 1999.

Martinez, M., Perner, D., Hackenthal, E.-M., Külzer, S., and Schültz, L.: $\mathrm{NO}_{3}$ at Helgoland during the NORDEX campaign in October 1996, J. Geophys. Res., 105, 22685-22695, 2000.

Matsumoto, J., Imai, H., Kosugi, N., and Kajii, Y.: In situ measurement of $\mathrm{N}_{2} \mathrm{O}_{5}$ in the urban atmosphere by thermal decomposition/laser-induced fluorescence technique, Atmos. Environ., 39, 6802-6811, doi:10.1016/j.atmosenv.2005.07.055, 2005a.

Matsumoto, J., Kosugi, N., Imai, H., and Kajii, Y.: Development of a measurement system for nitrate radical and dinitrogen pentoxide using a thermal conversion/laser-induced fluorescence technique, Rev. Sci. Instrum., 76, 064101, doi:10.1063/1.1927098, $2005 \mathrm{~b}$.

Matsunaga, A. and Ziemann, P. J.: Gas-Wall Partitioning of Organic Compounds in a Teflon Film Chamber and Potential Effects on Reaction Product and Aerosol Yield Measurements, Aerosol Sci. Technol., 44, 881-892, doi:10.1080/02786826.2010.501044, 2010.

McDonald, B. C., Dallmann, T. R., Martin, E. W., and Harley, R. A.: Long-term trends in nitrogen oxide emissions from motor vehicles at national, state, and air basin scales, J. Geophys. Res., 117, D00V18, doi:10.1029/2012jd018304, 2012.

McLaren, R., Salmon, R. A., Liggio, J., Hayden, K. L., Anlauf, K. G., and Leaitch, W. R.: Nighttime chemistry at a rural site in the Lower Fraser Valley, Atmos. Environ., 38, 5837-5848, 2004.

McLaren, R., Wojtal, P., Majonis, D., McCourt, J., Halla, J. D., and Brook, J.: $\mathrm{NO}_{3}$ radical measurements in a polluted marine environment: links to ozone formation, Atmos. Chem. Phys., 10, 4187-4206, doi:10.5194/acp-10-4187-2010, 2010.

McMurry, P. H. and Grosjean, D.: Gas and aerosol wall losses in Teflon film smog chambers, Environ. Sci. Technol., 19, 11761182, doi:10.1021/es00142a006, 1985.

McNeill, V. F., Wolfe, G. M., and Thornton, J. A.: The Oxidation of Oleate in Submicron Aqueous Salt Aerosols?: Evidence of a Surface Process, J. Phys. Chem. A, 111, 1073-1083, doi:10.1021/jp066233f, 2007.

Meinen, J., Thieser, J., Platt, U., and Leisner, T.: Technical Note: Using a high finesse optical resonator to provide a long light path for differential optical absorption spectroscopy: CE-DOAS, Atmos. Chem. Phys., 10, 3901-3914, doi:10.5194/acp-10-39012010, 2010.

Millet, D. B., Baasandorj, M., Hu, L., Mitroo, D., Turner, J., and Williams, B. J.: Nighttime Chemistry and Morning Isoprene Can Drive Urban Ozone Downwind of a Major Deciduous Forest, Environ. Sci. Technol., 50, 4335-4342, 2016.

Mishra, A. K., Klingmueller, K., Fredj, E., Lelieveld, J., Rudich, Y., and Koren, I.: Radiative signature of absorbing aerosol over the eastern Mediterranean basin, Atmos. Chem. Phys., 14, 72137231, doi:10.5194/acp-14-7213-2014, 2014.

Misztal, P. K., Hewitt, C. N., Wildt, J., Blande, J. D., Eller, A. S. D., Fares, S., Gentner, D. R., Gilman, J. B., Graus, M., Greenberg, J., Guenther, A. B., Hansel, A., Harley, P., Huang, M., Jardine, K., Karl, T., Kaser, L., Keutsch, F. N., Kiendler-Scharr, A., Kleist, E., Lerner, B. M., Li, T., Mak, J., Nölscher, A. C., Schnitzhofer, R., Sinha, V., Thornton, B., Warneke, C., Wegener, F., Werner, C., Williams, J., Worton, D. R., Yassaa, N., and Goldstein, A. H.: Atmospheric benzenoid emissions from plants rival those from fossil fuels, Sci. Rep., 5, 12064, doi:10.1038/srep12064, 2015.

Moise, T., Talukdar, R. K., Frost, G. J., Fox, R. W., and Rudich, Y.: Reactive uptake of $\mathrm{NO}_{3}$ by liquid and frozen organics, J. Geophys. Res., 107, D24014, doi:10.21029/22001JD000334, 2002.

Moise, T., Flores, J. M., and Rudich, Y.: Optical Properties of Secondary Organic Aerosols and Their Changes by Chemical Processes, Chem. Rev., 115, 4400-4439, doi:10.1021/cr5005259, 2015.

Moldanova, J. and Ljungstrom, E.: Modelling of particle formation from $\mathrm{NO}_{3}$ oxidation of selected monoterpenes, J. Aerosol. Sci., 31, 1317-1333, 2000.

Müller, J. F., Peeters, J., and Stavrakou, T.: Fast photolysis of carbonyl nitrates from isoprene, Atmos. Chem. Phys., 14, 2497 2508, doi:10.5194/acp-14-2497-2014, 2014.

Muthuramu, K., Shepson, P. B., and Obrien, J. M.: Preparation, Analysis, and Atmospheric Production of Multifunctional Organic Nitrates, Environ. Sci. Technol., 27, 1117-1124, 1993.

Mylonas, D. T., Allen, D. T., Ehrman, S. H., and Pratsinis, S. E.: The sources and size distributions of organonitrates in Los Angeles aerosol, Atmos. Environ., Part A, General Topics, 25, 28552861, doi:10.1016/0960-1686(91)90211-O, 1991.

Nah, T., McVay, R. C., Zhang, X., Boyd, C. M., Seinfeld, J. H., and $\mathrm{Ng}, \mathrm{N}$. L.: Influence of seed aerosol surface area and oxidation rate on vapor wall deposition and SOA mass yields: a case study with $\alpha$-pinene ozonolysis, Atmos. Chem. Phys., 16, 9361-9379, doi:10.5194/acp-16-9361-2016, 2016a. .

Nah, T., Sanchez, J., Boyd, C. M., and Ng, N. L.: Photochemical Aging of $\alpha$-pinene and $\beta$-pinene Secondary Organic Aerosol formed from Nitrate Radical Oxidation, Environ. Sci. Technol., 50, 222-231, doi:10.1021/acs.est.5b04594, 2016 b.

Nakayama, T., Ide, T., Taketani, F., Kawai, M., Takahashi, K., and Matsumi, Y.: Nighttime measurements of ambient $\mathrm{N}_{2} \mathrm{O}_{5}, \mathrm{NO}_{2}$, $\mathrm{NO}$ and $\mathrm{O}_{3}$ in a sub-urban area, Toyokawa, Japan, Atmos. Environ., 42, 1995-2006, doi:10.1016/j.atmosenv.2007.12.001, 2008.

Nakayama, T., Matsumi, Y., Sato, K., Imamura, T., Yamazaki, A., and Uchiyama, A.: Laboratory studies on optical properties of secondary organic aerosols generated during the photooxidation of toluene and the ozonolysis of $\alpha$-pinene, J. Geophys. Res.Atmos., 115, D24204, doi:10.1029/2010jd014387, 2010. 
Naudet, J. P., Huguenin, D., Rigaud, P., and Cariolle, D.: Stratospheric observations of $\mathrm{NO}_{3}$ and its experimental and theoretical distribution between 20 and $40 \mathrm{~km}$, Planet. Space Sci., 29, 707$712,1981$.

Neta, P., Huie, R. E., and Ross, A. B.: Rate Constants for Reactions of Inorganic Radicals in Aqueous Solution, J. Phys. Chem. Ref. Data, 17, 1027-1284, doi:10.1063/1.555808, 1988.

Ng, N. L., Kwan, A. J., Surratt, J. D., Chan, A. W. H., Chhabra, P. S., Sorooshian, A., Pye, H. O. T., Crounse, J. D., Wennberg, P. O., Flagan, R. C., and Seinfeld, J. H.: Secondary organic aerosol (SOA) formation from reaction of isoprene with nitrate radicals $\left(\mathrm{NO}_{3}\right)$, Atmos. Chem. Phys., 8, 4117-4140, doi:10.5194/acp-84117-2008, 2008.

Ng, N. L., Canagaratna, M. R., Zhang, Q., Jimenez, J. L., Tian, J., Ulbrich, I. M., Kroll, J. H., Docherty, K. S., Chhabra, P. S., Bahreini, R., Murphy, S. M., Seinfeld, J. H., Hildebrandt, L., Donahue, N. M., DeCarlo, P. F., Lanz, V. A., Prévôt, A. S. H., Dinar, E., Rudich, Y., and Worsnop, D. R.: Organic aerosol components observed in Northern Hemispheric datasets from Aerosol Mass Spectrometry, Atmos. Chem. Phys., 10, 46254641, doi:10.5194/acp-10-4625-2010, 2010.

Ng, N. L., Herndon, S. C., Trimborn, A., Canagaratna, M. R., Croteau, P. L., Onasch, T. B., Sueper, D., Worsnop, D. R., Zhang, Q., Sun, Y. L., and Jayne, J. T.: An Aerosol Chemical Speciation Monitor (ACSM) for Routine Monitoring of the Composition and Mass Concentrations of Ambient Aerosol, Aerosol Sci. Technol., 45, 780-794, doi:10.1080/02786826.2011.560211, 2011.

Nguyen, T. B., Crounse, J. D., Schwantes, R. H., Teng, A. P., Bates, K. H., Zhang, X., St. Clair, J. M., Brune, W. H., Tyndall, G. S., Keutsch, F. N., Seinfeld, J. H., and Wennberg, P. O.: Overview of the Focused Isoprene eXperiment at the California Institute of Technology (FIXCIT): mechanistic chamber studies on the oxidation of biogenic compounds, Atmos. Chem. Phys., 14, 1353113549, doi:10.5194/acp-14-13531-2014, 2014.

Nguyen, T. B., Crounse, J. D., Teng, A. P., Clair, J. M. S., Paulot, F., Wolfe, G. M., and Wennberg, P. O.: Rapid deposition of oxidized biogenic compounds to a temperate forest, P. Natl. Acad. Sci. USA, 112, E392-E401, 2015.

Nichols, P. L., Magnusson, A. B., and Ingham, J. D.: Synthesis of Nitric Esters by the Addition of Nitric Acid to the Ethylene Oxide Ring, J. Am. Chem. Soc., 75, 4255-4258, 1953.

Niinemets, Ü., Copolovici, L., and Hüve, K.: High within-canopy variation in isoprene emission potentials in temperate trees: Implications for predicting canopy-scale isoprene fluxes, J. Geophys. Res.-Biogeo., 115, G04029, doi:10.1029/2010JG001436, 2010.

Nizich, S. V., Pope, A. A., Driver, L. M., and Group, P.-A.: National Air Pollutant Emission Trends Report, 1900-1998, 2000.

Noda, J., Nyman, G., and Langer, S.: Kinetics of the gas-phase reaction of some unsaturated alcohols with the nitrate radical, J. Phys. Chem. A, 106, 945-951, 2002.

Noxon, J. F., Norton, R. B., and Henderson, W. R.: Observation of Atmospheric $\mathrm{NO}_{3}$, Geophys. Res. Lett., 5, 675-678, 1978.

Noxon, J. F., Norton, R. B., and Marovich, E.: $\mathrm{NO}_{3}$ in the troposphere, Geophys. Res. Lett., 7, 125-128, 1980.

Noxon, J. F.: $\mathrm{NO}_{3}$ and $\mathrm{NO}_{2}$ in the Mid-Pacific Troposphere, J. Geophys. Res., 88, 11017-11021, 1983.
O’Brien, R. E., Laskin, A., Laskin, J., Rubitschun, C. L., Surratt, J. D., and Goldstein, A. H.: Molecular characterization of S- and N-containing organic constituents in ambient aerosols by negative ion mode high-resolution Nanospray Desorption Electrospray Ionization Mass Spectrometry: CalNex 2010 field study, J. Geophys. Res.-Atmos., 119, 12706-712720, doi:10.1002/2014JD021955, 2014.

O'Keefe, A.: Integrated cavity output analysis of ultra-weak absorption, Chem. Phys. Lett., 293, 331-336, doi:10.1016/S00092614(98)00785-4, 1998.

O'Keefe, A. and Deacon, D. A.: Cavity ring-down optical spectrometer for absorption measurements using pulsed laser sources, Rev. Sci. Instrum., 59, 2544-2551, 1988.

O'Keefe, A., Scherer, J. J., and Paul, J. B.: cw Integrated cavity output spectroscopy, Chem. Phys. Lett., 307, 343-349, doi:10.1016/S0009-2614(99)00547-3, 1999.

Odame-Ankrah, C. A., and Osthoff, H. D.: A compact diode laser cavity ring-down spectrometer for atmospheric measurements of $\mathrm{NO}_{3}$ and $\mathrm{N}_{2} \mathrm{O}_{5}$ with automated zeroing and calibration, Appl. Spectrosc., 65, 1260-1268, doi:10.1366/11-06384, 2011.

Odum, J. R., Hoffman, T., Bowman, F., Collins, D., Flagan, R. C., and Seinfeld, J. H.: Gas/Particle Partitioning and Secondary Organic Aerosol Yields, Environ. Sci. Technol., 30, 2580-2585, 1996.

Olariu, R. I., Barnes, I., Bejan, I., Arsene, C., Vione, D., Klotz, B., and Becker, K. H.: FT-IR Product Study of the Reactions of $\mathrm{NO}_{3}$ Radicals With ortho-, meta-, and para-Cresol, Environ. Sci. Technol., 47, 7729-7738, doi:10.1021/es401096w, 2013.

Osthoff, H. D., Pilling, M. J., Ravishankara, A. R., and Brown, S. S.: Temperature dependence of the $\mathrm{NO}_{3}$ absorption cross section above $298 \mathrm{~K}$ and determination of the equilibrium constant for $\mathrm{NO}_{3}+\mathrm{NO}_{2}-\mathrm{N}_{2} \mathrm{O}_{5}$ at atmospherically relevant conditions, Phys. Chem. Chem. Phys., 9, 5785-5793, doi:10.1039/b709193a, 2007.

Osthoff, H. D., Bates, T. S., Johnson, J. E., Kuster, W. C., Goldan, P. D., Sommariva, R., Williams, E. J., Lerner, B. M., Warneke, C., de Gouw, J. A., Pettersson, A., Baynard, T., Meagher, J. F., Fehsenfeld, F. C., Ravishankara, A. R., and Brown, S. S.: Regional variation of dimethyl sulfide oxidation mechanism in the summertime marine boundary layer in the Gulf of Maine, J. Geophys. Res., 114, D07301, doi:10.1029/2008JD010990, 2009.

Pandis, S. N., Paulson, S. E., Seinfeld, J. H., and Flagan, R. C.: Aerosol formation in the photooxidation of isoprene and $\beta$ pinene, Atmos. Environ. Pt. A, 25, 997-1008, doi:10.1016/09601686(91)90141-S, 1991.

Paoli, R., Cariolle, D., and Sausen, R.: Review of effective emissions modeling and computation, Geosci. Model Dev., 4, 643667, doi:10.5194/gmd-4-643-2011, 2011.

Parrish, D. D., Buhr, M. P., Trainer, M., Norton, R. B., Shimshock, J. P., Fehsenfeld, F. C., Anlauf, K. G., Bottenheim, J. W., Tang, Y. Z., Wiebe, H. A., Roberts, J. M., Tanner, R. L., Newman, L., Bowersox, V. C., Olszyna, K. J., Bailey, E. M., Rodgers, M. O., Wang, T., Berresheim, H., Roychowdhury, U. K., and Demerjian, K. L.: The Total Reactive Oxidized Nitrogen Levels and the Partitioning between the Individual-Species at 6 Rural Sites in Eastern North-America, J. Geophys. Res.-Atmos., 98, 29272939, 1993.

Paul, D., Furgeson, A., and Osthoff, H. D.: Measurements of total peroxy and alkyl nitrate abundances in laboratory-generated gas 
samples by thermal dissociation cavity ring-down spectroscopy, Rev. Sci. Instr., 80, 114101, doi:10.1063/1.3258204, 2009.

Paulot, F., Henze, D. K., and Wennberg, P. O.: Impact of the isoprene photochemical cascade on tropical ozone, Atmos. Chem. Phys., 12, 1307-1325, doi:10.5194/acp-12-1307-2012, 2012.

Paulson, S. E. and Seinfeld, J. H.: Development and Evaluation of a Photooxidation Mechnaism for Isoprene, J. Geophys. Res., 97, 20703-20715, 1992.

Peeters, J., Nguyen, T. L., and Vereecken, L.: HOx radical regeneration in the oxidation of isoprene, Phys. Chem. Chem. Phys., 11, 5935-5939, doi:10.1039/B908511D, 2009.

Perraud, V., Bruns, E. A., Ezell, M. J., Johnson, S. N., Greaves, J., and Finlayson-Pitts, B. J.: Identification of organic nitrates in the $\mathrm{NO}_{3}$ radical initiated oxidation of $\alpha$-pinene by atmospheric pressure chemical ionization mass spectrometry, Environ. Sci. Technol., 44, 5887-5893, 2010.

Perring, A. E., Wisthaler, A., Graus, M., Wooldridge, P. J., Lockwood, A. L., Mielke, L. H., Shepson, P. B., Hansel, A., and Cohen, R. C.: A product study of the isoprene $+\mathrm{NO}_{3}$ reaction, Atmos. Chem. Phys., 9, 4945-4956, doi:10.5194/acp-9-4945-2009, 2009.

Perring, A. E., Pusede, S. E., and Cohen, R. C.: An Observational Perspective on the Atmospheric Impacts of Alkyl and Multifunctional Nitrates on Ozone and Secondary Organic Aerosol, Chem. Rev., 113, 5848-5870, doi:10.1021/cr300520x, 2013.

Pfrang, C., Martin, R. S., Canosa-Mas, C. E., and Wayne, R. P.: Gasphase reactions of $\mathrm{NO}_{3}$ and $\mathrm{N}_{2} \mathrm{O}_{5}$ with (Z)-hex-4-en-1-ol, (Z)hex-3-en-1-ol ("leaf alcohol"), (E)-hex-3-en-1-ol, (Z)-hex-2-en1-ol, (E)-hex-2-en-1-ol, Phys. Chem. Chem. Phys., 8, 354-363, 2006.

Pierce, T., Geron, C., Bender, L., Dennis, R., Tonnesen, G., and Guenther, A.: Influence of increased isoprene emissions on regional ozone modeling, J. Geophys. Res.-Atmos., 103, 2561125629, doi:10.1029/98JD01804, 1998.

Pitts, J. N., Jr., Bierman, H. W., Atkinson, R., and Winer, A. M.: Atmospheric implications of simultaneous measurements of $\mathrm{NO}_{3}$ radicals and HONO, Geophys. Res. Lett., 11, 557-560, 1984.

Platt, U., Perner, D., Winer, A. M., Harris, G. W., and Pitts, J. N. J.: Detection of $\mathrm{NO}_{3}$ in the polluted troposphere by differential optical absorption, Geophys. Res. Lett., 7, 89-92, 1980.

Platt, U., Perner, D., Schröder, J., Kessler, C., and Toennissen, A.: The Diurnal Variation of $\mathrm{NO}_{3}$, J. Geophys. Res., 86, 1196511970, 1981.

Platt, U. and Stutz, J.: Differential optical absorption spectroscopy: principles and applications, Springer, Berlin, 2008.

Platt, U., LeBras, G., Poulet, G., Burrows, J. P., and Moortgat, G.: Peroxy radicals from night-time reactions of $\mathrm{NO}_{3}$ with organic compounds, Nature, 348, 147-149, 1990.

Platt, U., Meinen, J., Pöhler, D., and Leisner, T.: Broadband Cavity Enhanced Differential Optical Absorption Spectroscopy (CEDOAS) - applicability and corrections, Atmos. Meas. Tech., 2, 713-723, doi:10.5194/amt-2-713-2009, 2009.

Platt, U. F., Winer, A. M., Bierman, H. W., Atkinson, R., and Pitts, J. N., Jr.: Measurement of Nitrate Radical Concentrations in Continental Air, Environ. Sci. Technol., 18, 365-369, 1984.

Pöschl, U.: Atmospheric Aerosols: Composition, Transformation, Climate and Health Effects, Angewandte Chemie International Edition, 44, 7520-7540, doi:10.1002/anie.200501122, 2005.
Pöschl, U. and Shiraiwa, M.: Multiphase Chemistry at the Atmosphere-Biosphere Interface Influencing Climate and Public Health in the Anthropocene, Chem. Rev., 115, 4440-4475, doi:10.1021/cr500487s, 2015.

Praske, E., Crounse, J. D., Bates, K. H., Kurtén, T., Kjaergaard, H. G., and Wennberg, P. O.: Atmospheric Fate of Methyl Vinyl Ketone: Peroxy Radical Reactions with $\mathrm{NO}$ and $\mathrm{HO}_{2}$, J. Phys. Chem. A, 119, 4562-4572, doi:10.1021/jp5107058, 2015.

Pratt, K. A., Mielke, L. H., Shepson, P. B., Bryan, A. M., Steiner, A. L., Ortega, J., Daly, R., Helmig, D., Vogel, C. S., Griffith, S., Dusanter, S., Stevens, P. S., and Alaghmand, M.: Contributions of individual reactive biogenic volatile organic compounds to organic nitrates above a mixed forest, Atmos. Chem. Phys., 12, 10125-10143, doi:10.5194/acp-12-10125-2012, 2012.

Pye, H. O. T., Chan, A. W. H., Barkley, M. P., and Seinfeld, J. H.: Global modeling of organic aerosol: the importance of reactive nitrogen $\left(\mathrm{NO}_{x}\right.$ and $\left.\mathrm{NO}_{3}\right)$, Atmos. Chem. Phys., 10, 1126111276, doi:10.5194/acp-10-11261-2010, 2010.

Pye, H. O. T., Luecken, D. J., Xu, L., Boyd, C. M., Ng, N. L., Baker, K. R., Ayres, B. R., Bash, J. O., Baumann, K., Carter, W. P. L., Edgerton, E., Fry, J. L., Hutzell, W. T., Schwede, D. B., and Shepson, P. B.: Modeling the Current and Future Roles of Particulate Organic Nitrates in the Southeastern United States, Environ. Sci. Technol., 49, 14195-14203, doi:10.1021/acs.est.5b03738, 2015.

Ramanathan, V., Li, F., Ramana, M., Praveen, P., Kim, D., Corrigan, C., Nguyen, H., Stone, E. A., Schauer, J. J., and Carmichael, G.: Atmospheric brown clouds: Hemispherical and regional variations in long-range transport, absorption, and radiative forcing, J. Geophys. Res.-Atmos., 112, D22S21, doi:10.1029/2006JD008124, 2007a.

Ramanathan, V., Ramana, M. V., Roberts, G., Kim, D., Corrigan, C., Chung, C., and Winker, D.: Warming trends in Asia amplified by brown cloud solar absorption, Nature, 448, 575 pp., $2007 \mathrm{~b}$.

Reemtsma, T., These, A., Venkatachari, P., Xia, X., Hopke, P. K., Springer, A., and Linscheid, M.: Identification of Fulvic Acids and Sulfated and Nitrated Analogues in Atmospheric Aerosol by Electrospray Ionization Fourier Transform Ion Cyclotron Resonance Mass Spectrometry, Anal. Chem., 78, 8299-8304, doi:10.1021/ac061320p, 2006.

Reinmuth-Selzle, K., Ackaert, C., Kampf, C. J., Samonig, M., Shiraiwa, M., Kofler, S., Yang, H., Gadermaier, G., Brandstetter, H., Huber, C. G., Duschl, A., Oostingh, G. J., and Pöschl, U.: Nitration of the birch pollen allergen Bet v 1.0101: Efficiency and site-selectivity of liquid and gaseous nitrating agents, J. Proteome Res., 13, 1570-1577, 2014.

Renbaum-Wolff, L., Grayson, J. W., Bateman, A. P., Kuwata, M., Sellier, M., Murray, B. J., Shilling, J. E., Martin, S. T., and Bertram, A. K.: Viscosity of $\alpha$-pinene secondary organic material and implications for particle growth and reactivity, P. Natl. Acad. Sci. USA, 110, 8014-8019, 2013.

Richter, A., Burrows, J. P., Nusz, H., Granier, C., and Niemeier, U.: Increase in tropospheric nitrogen dioxide over China observed from space, Nature, 437, 129-132, 2005.

Rickard, A.: The Master Chemical Mechanism Version MCM v3.2, available at: http://mcm.leeds.ac.uk/MCMv3.2/, last access: 5 Mai 2015.

Rindelaub, J. D., McAvey, K. M., and Shepson, P. B.: The photochemical production of organic nitrates from $\alpha$-pinene and loss 
via acid-dependent particle phase hydrolysis, Atmos. Environ., 100, 193-201, doi:10.1016/j.atmosenv.2014.11.010, 2015.

Robinson, A. L., Donahue, N. M., and Rogge, W. F.: Photochemical oxidation and changes in molecular composition of organic aerosol in the regional context, J. Geophys. Res.-Atmos., 111, D03302, doi:10.1029/2005JD006265, 2006.

Rollins, A. W., Kiendler-Scharr, A., Fry, J. L., Brauers, T., Brown, S. S., Dorn, H.-P., Dubé, W. P., Fuchs, H., Mensah, A., Mentel, T. F., Rohrer, F., Tilmann, R., Wegener, R., Wooldridge, P. J., and Cohen, R. C.: Isoprene oxidation by nitrate radical: alkyl nitrate and secondary organic aerosol yields, tmos. Chem. Phys., 9, 6685-6703, doi:10.5194/acp-9-6685-2009, 2009.

Rollins, A. W., Smith, J. D., Wilson, K. R., and Cohen, R. C.: Real Time In Situ Detection of Organic Nitrates in Atmospheric Aerosols, Environ. Sci. Technol., 44, 5540-5545, doi:10.1021/es100926x, 2010.

Rollins, A. W., Browne, E. C., Min, K. E., Pusede, S. E., Wooldridge, P. J., Gentner, D. R., Goldstein, A. H., Liu, S., Day, D. A., Russell, L. M., and Cohen, R. C.: Evidence for $\mathrm{NO}_{x}$ Control over Nighttime SOA Formation, Science, 337, 1210-1212, 2012.

Rollins, A. W., Pusede, S., Wooldridge, P., Min, K. E., Gentner, D. R., Goldstein, A. H., Liu, S., Day, D. A., Russell, L. M., Rubitschun, C. L., Surratt, J. D., and Cohen, R. C.: Gas/particle partitioning of total alkyl nitrates observed with TDLIF in Bakersfield, J. Geophys. Res.-Atmos., 118, 6651-6662, doi:10.1002/jgrd.50522, 2013.

Ross, A. B., Bielski, B. H. J., Buxton, G. V., Cabelli, D. E., Helman, W. P., Huie, R. E., Grodkovski, J., Neta, P., Mulazzani, Q. G., and Wilkinson, F.: NIST standard reference database 40: NDRL/NIST solution kinetics database version 3.0, 1998.

Rudich, Y., Talukdar, R. K., Fox, R. W., and Ravinshankara, A. R.: Rate coefficients for reactions of $\mathrm{NO}_{3}$ with a few olefins and oxygenated olefins, J. Phys. Chem. A, 100, 5374-5381, 1996.

Rudich, Y., Talukdar, R. K., and Ravishankara, A. R.: Multiphase chemistry of $\mathrm{NO}_{3}$ in the remote troposphere, J. Geophys. Res.Atmos., 103, 16133-16143, doi:10.1029/98jd01280, 1998.

Rudich, Y.: Laboratory Perspectives on the Chemical Transformations of Organic Matter in Atmospheric Particles, Chem. Rev., 103, 5097-5124, 2003.

Russell, A. R., Valin, L. C., and Cohen, R. C.: Trends in $\mathrm{OMI} \mathrm{NO}_{2}$ observations over the United States: effects of emission control technology and the economic recession, Atmos. Chem. Phys., 12, 12197-12209, doi:10.5194/acp-12-12197-2012, 2012.

Sadanaga, Y., Takaji, R., Ishiyama, A., Nakajima, K., Matsuki, A., and Bandow, H.: Thermal dissociation cavity attenuated phase shift spectroscopy for continuous measurement of total peroxy and organic nitrates in the clean atmosphere, Rev. Sci. Instrum., 87, 074102, doi:10.1063/1.4958167, 2016.

Sanders, R. W., Solomon, S., Mount, G. H., Bates, M. W., and Schmeltekopf, A. L.: Visible Spectroscopy at McMurdo Station, Antarctica 3, Observations of $\mathrm{NO}_{3}$, J. Geophys. Res., 92, 83398342, 1987.

Saunders, S. M., Jenkin, M. E., Derwent, R. G., and Pilling, M. J.: Protocol for the development of the Master Chemical Mechanism, MCM v3 (Part A): tropospheric degradation of nonaromatic volatile organic compounds, Atmos. Chem. Phys., 3, 161-180, doi:10.5194/acp-3-161-2003, 2003.
Schichtel, B., Malm, W. C., Bench, G., Fallon, S., McDade, C. E., Chow, J. C., and Watson, J. G.: Fossil and contemporary fine particulate carbon fractions at 12 rural and urban sites in the United States, J. Geophys. Res., 113, D02311, doi:10.1029/2007JD008605, 2008.

Schlag, P., Kiendler-Scharr, A., Blom, M. J., Canonaco, F., Henzing, J. S., Moerman, M., Prévôt, A. S. H., and Holzinger, R.: Aerosol source apportionment from 1-year measurements at the CESAR tower in Cabauw, the Netherlands, Atmos. Chem. Phys., 16, 8831-8847, doi:10.5194/acp-16-8831-2016, 2016.

Schneider, M. and Ballschmiter, K.: Alkyl nitrates as achiral and chiral solute probes in gas chromatography - Novel properties of a beta-cyclodextrin derivative and characterization of its enantioselective forces, J. Chromatogr. A, 852, 525-534, 1999.

Schuster, G., Labazan, I., and Crowley, J. N.: A cavity ring down/cavity enhanced absorption device for measurement of ambient $\mathrm{NO}_{3}$ and $\mathrm{N}_{2} \mathrm{O}_{5}$, Atmos. Meas. Tech., 2, 1-13, doi:10.5194/amt-2-1-2009, 2009.

Schwantes, R. H., Teng, A. P., Nguyen, T. B., Coggon, M. M., Crounse, J. D., St. Clair, J. M., Zhang, X., Schilling, K. A., Seinfeld, J. H., and Wennberg, P. O.: Isoprene $\mathrm{NO}_{3}$ Oxidation Products from the $\mathrm{RO}_{2}+\mathrm{HO}_{2}$ Pathway, J. Phys. Chem. A, 119, 10158-10171, doi:10.1021/acs.jpca.5b06355, 2015.

Scott, C. E., Rap, A., Spracklen, D. V., Forster, P. M., Carslaw, K. S., Mann, G. W., Pringle, K. J., Kivekäs, N., Kulmala, M., Lihavainen, H., and Tunved, P.: The direct and indirect radiative effects of biogenic secondary organic aerosol, Atmos. Chem. Phys., 14, 447-470, doi:10.5194/acp-14-447-2014, 2014.

Setyan, A., Zhang, Q., Merkel, M., Knighton, W. B., Sun, Y., Song, C., Shilling, J. E., Onasch, T. B., Herndon, S. C., Worsnop, D. R., Fast, J. D., Zaveri, R. A., Berg, L. K., Wiedensohler, A., Flowers, B. A., Dubey, M. K., and Subramanian, R.: Characterization of submicron particles influenced by mixed biogenic and anthropogenic emissions using high-resolution aerosol mass spectrometry: results from CARES, Atmos. Chem. Phys., 12, 8131-8156, doi:10.5194/acp-12-8131-2012, 2012.

Shiraiwa, M., Garland, R. M., and Pöschl, U.: Kinetic double-layer model of aerosol surface chemistry and gas-particle interactions (K2-SURF): Degradation of polycyclic aromatic hydrocarbons exposed to $\mathrm{O}_{3}, \mathrm{NO}_{2}, \mathrm{H}_{2} \mathrm{O}, \mathrm{OH}$ and $\mathrm{NO}_{3}$, Atmos. Chem. Phys., 9, 9571-9586, doi:10.5194/acp-9-9571-2009, 2009.

Shiraiwa, M., Sosedova, Y., Rouviere, A., Yang, H., Zhang, Y., Abbatt, J. P. D., Ammann, M., and Pöschl, U.: The role of longlived reactive oxygen intermediates in the reaction of ozone with aerosol particles, Nat. Chem., 4, 291-295, 2011.

Shiraiwa, M., Pöschl, U., and Knopf, D. A.: Multiphase Chemical Kinetics of $\mathrm{NO}_{3}$ Radicals Reacting with Organic Aerosol Components from Biomass Burning, Environ. Sci. Technol., 46, 6630-6636, doi:10.1021/es300677a, 2012.

Shorees, B., Atkinson, R., and Arey, J.: Kinetics of the gasphase reactions of beta-phellandrene with $\mathrm{OH}$ and $\mathrm{NO}_{3}$ radicals and $\mathrm{O}_{3}$ at 297-K $\pm 2-\mathrm{K}$, Int. J. Chem. Kinet., 23, 897-906, doi:10.1002/kin.550231005, 1991.

Simpson, W. R.: Continuous wave cavity ring-down spectroscopy applied to in situ detection of dinitrogen pentoxide $\left(\mathrm{N}_{2} \mathrm{O}_{5}\right)$, Rev. Sci. Instrum., 74, 3442-3452, doi:10.1063/1.1578705, 2003.

Slusher, D. L., Huey, L. G., Tanner, D. J., Flocke, F. M., and Roberts, J. M.: A thermal dissociation-chemical ionization mass spectrometry (TD-CIMS) technique for the si- 
multaneous measurement of peroxyacyl nitrates and dinitrogen pentoxide, J. Geophys. Res.-Atmos., 109, D19315, doi:10.1029/2004JD004670, 2004.

Smith, J. P. and Solomon, S.: Atmospheric $\mathrm{NO}_{3}$, 3. Sunrise Disappearance and the Stratospheric Profile, J. Geophys. Res., 95, 13819-13827, 1990.

Smith, J. P., Solomon, S., Sanders, R. W., Miller, H. L., Perliski, L. M., Keys, J. G., and Schmeltekopf, A. L.: Atmospheric $\mathrm{NO}_{3}$, 4. Vertical Profiles at Middle and Polar Latitudes at Sunrise, J. Geophys. Res., 98, 8983-8989, 1993.

Sobanski, N., Tang, M. J., Thieser, J., Schuster, G., Pöhler, D., Fischer, H., Song, W., Sauvage, C., Williams, J., Fachinger, J., Berkes, F., Hoor, P., Platt, U., Lelieveld, J., and Crowley, J. N.: Chemical and meteorological influences on the lifetime of $\mathrm{NO}_{3}$ at a semi-rural mountain site during PARADE, Atmos. Chem. Phys., 16, 4867-4883, doi:10.5194/acp-16-4867-2016, 2016.

Solomon, S., Sanders, R. W., Mount, G. H., Carroll, M. A., Jakoubek, R. O., and Schmeltekopf, A. L.: Atmospheric $\mathrm{NO}_{3}$ 2. Observations in Polar Regions, J. Geophys. Res., 94, 16423-16427, 1989.

Solomon, S., Smith, J. P., Sanders, R. W., Perliski, L., Miller, H. L., Mount, G. H., Keys, J. G., and Schmeltekopf, A. L.: Visible and Near-Ultraviolet Spectroscopy at McMurdo Station, Antarctica, 8. Observations of Nighttime $\mathrm{NO}_{2}$ and $\mathrm{NO}_{3}$ from April to October 1991, J. Geophys. Res., 98, 993-1000, 1993.

Song, C., Gyawali, M., Zaveri, R. A., Shilling, J. E., and Arnott, W. P.: Light absorption by secondary organic aerosol from $\alpha$-pinene: Effects of oxidants, seed aerosol acidity, and relative humidity, J. Geophys. Res.-Atmos., 118, 11741-711749, doi:10.1002/jgrd.50767, 2013.

Spittler, M., Barnes, I., Bejan, I., Brockmann, K. J., Benter, T., and Wirtz, K.: Reactions of $\mathrm{NO}_{3}$ radicals with limonene and alphapinene: Product and SOA formation, Atmos. Environ., 40, S116S127, 2006.

Spracklen, D. V., Jimenez, J. L., Carslaw, K. S., Worsnop, D. R., Evans, M. J., Mann, G. W., Zhang, Q., Canagaratna, M. R., Allan, J., Coe, H., McFiggans, G., Rap, A., and Forster, P.: Aerosol mass spectrometer constraint on the global secondary organic aerosol budget, Atmos. Chem. Phys., 11, 12109-12136, doi:10.5194/acp-11-12109-2011, 2011.

Squire, O. J., Archibald, A. T., Abraham, N. L., Beerling, D. J., Hewitt, C. N., Lathière, J., Pike, R. C., Telford, P. J., and Pyle, J. A.: Influence of future climate and cropland expansion on isoprene emissions and tropospheric ozone, Atmos. Chem. Phys., 14, 1011-1024, doi:10.5194/acp-14-1011-2014, 2014.

Squire, O. J., Archibald, A. T., Griffiths, P. T., Jenkin, M. E., Smith, D., and Pyle, J. A.: Influence of isoprene chemical mechanism on modelled changes in tropospheric ozone due to climate and land use over the 21 st century, Atmos. Chem. Phys., 15, 5123-5143, doi:10.5194/acp-15-5123-2015, 2015.

Stark, H., Brown, S. S., Goldan, P. D., Aldener, M., Kuster, W. C., Jakoubek, R., Fehsenfeld, F. C., Meagher, J., Bates, T. S., and Ravishankara, A. R.: Influence of the nitrate radical on the oxidation of dimethyl sulfide in a polluted marine environment, J. Geophys. Res., 112, D10S10, doi:10.1029/2006JD007669, 2007.

Starn, T., Shepson, P., Bertman, S., Riemer, D., Zika, R., and Olszyna, K.: Nighttime isoprene chemistry at an urban-impacted forest site, J. Geophys. Res.-Atmos., 103, 22437-22447, 1998.
Stavrakou, T., Müller, J.-F., Boersma, K. F., De Smedt, I., and van $\operatorname{der}$ A, R. J.: Assessing the distribution and growth rates of $\mathrm{NO}_{x}$ emission sources by inverting a 10-year record of $\mathrm{NO}_{2}$ satellite columns, Geophys. Res. Lett., 35, L10801, doi:10.1029/2008GL033521, 2008.

Steinbacher, M., Dommen, J., Ordonez, C., Reimann, S., Grüebler, F. C., Staehelin, J., Andreani-Aksoyoglu, S., and Prevot, A. S. H.: Volatile Organic Compounds in the Po Basin, Part B: Biogenic VOCs, J. Atmos. Chem., 51, 293-315, doi:10.1007/s10874-0053577-0, 2005.

Stewart, D. J., Almabrok, S. H., Lockhart, J. P., Mohamed, O. M., Nutt, D. R., Pfrang, C., and Marston, G.: The kinetics of the gas-phase reactions of selected monoterpenes and cyclo-alkenes with ozone and the $\mathrm{NO}_{3}$ radical, Atmos. Environ., 70, 227-235, doi:10.1016/j.atmosenv.2013.01.036, 2013.

Stier, P., Seinfeld, J. H., Kinne, S., and Boucher, O.: Aerosol absorption and radiative forcing, Atmos. Chem. Phys., 7, 5237-5261, doi:10.5194/acp-7-5237-2007, 2007.

Strader, R., Lurmann, F., and Pandis, S. N.: Evaluation of secondary organic aerosol formation in winter, Atmos. Environ., 33, 48494863, doi:10.1016/S1352-2310(99)00310-6, 1999.

Streets, D. G., Yu, C., Wu, Y., Chin, M., Zhao, Z., Hayasaka, T., and Shi, G.: Aerosol trends over China, 1980-2000, Atmos. Res., 88, 174-182, doi:10.1016/j.atmosres.2007.10.016, 2008.

Stroud, C., Roberts, J., Williams, E., Hereid, D., Angevine, W., Fehsenfeld, F., Wisthaler, A., Hansel, A., Martinez-Harder, M., and Harder, H.: Nighttime isoprene trends at an urban forested site during the 1999 Southern Oxidant Study, J. Geophys. Res.Atmos., 107, 4291, doi:10.1029/2001JD000959, 2002.

Stutz, J., Alicke, B., and Neftel, A.: Nitrous acid formation in the urban atmosphere: Gradient measurements of $\mathrm{NO}_{2}$ and $\mathrm{HONO}$ over grass in Milan, Italy, J. Geophys. Res.-Atmos., 107, 8192, doi:10.1029/2001JD000390, 2002.

Stutz, J., Alicke, B., Ackermann, R., Geyer, A., White, A. B., and Williams, E.: Vertical profiles of $\mathrm{NO}_{3}, \mathrm{~N}_{2} \mathrm{O}_{5}, \mathrm{O}_{3}$, and $\mathrm{NO}_{x}$ in the nocturnal boundary layer: 1 . Observations during the Texas Air Quality Study 2000, J. Geophys. Res., 109, D12306, doi:10.1029/2003JD004209, 2004.

Stutz, J., Wong, K. W., Lawrence, L., Ziemba, L., Flynn, J. H., Rappenglück, B., and Lefer, B.: Nocturnal $\mathrm{NO}_{3}$ radical chemistry in Houston, TX, Atmos. Environ., 44, 4099-4106, 2010.

Suarez-Bertoa, R., Picquet-Varrault, B., Tamas, W., Pangui, E., and Doussin, J. F.: Atmospheric Fate of a Series of Carbonyl Nitrates: Photolysis Frequencies and OH-Oxidation Rate Constants, Environ. Sci. Technol., 46, 12502-12509, doi:10.1021/es302613x, 2012.

Suda, S. R., Petters, M. D., Yeh, G. K., Strollo, C., Matsunaga, A., Faulhaber, A., Ziemann, P. J., Prenni, A. J., Carrico, C. M., Sullivan, R. C., and Kreidenweis, S. M.: Influence of Functional Groups on Organic Aerosol Cloud Condensation Nucleus Activity, Environ. Sci. Technol., 48, 10182-10190, doi:10.1021/es502147y, 2014.

Suh, I., Lei, W. F., and Zhang, R. Y.: Experimental and theoretical studies of isoprene reaction with $\mathrm{NO}_{3}$, J. Phys. Chem. A, 105, 6471-6478, doi:10.1021/jp0105950, 2001.

Sun, Y. L., Zhang, Q., Schwab, J. J., Yang, T., Ng, N. L., and Demerjian, K. L.: Factor analysis of combined organic and inorganic aerosol mass spectra from high resolution aerosol mass spec- 
trometer measurements, Atmos. Chem. Phys., 12, 8537-8551, doi:10.5194/acp-12-8537-2012, 2012

Surratt, J. D., Kroll, J. H., Kleindienst, T. E., Edney, E. O., Claeys, M., Sorooshian, A., Ng, N. L., Offenberg, J. H., Lewandowski, M., Jaoui, M., Flagan, R. C., and Seinfeld, J. H.: Evidence for Organosulfates in Secondary Organic Aerosol, Environ. Sci. Technol., 41, 517-527, doi:10.1021/es062081q, 2007.

Surratt, J. D., Gómez-González, Y., Chan, A. W. H., Vermeylen, R., Shahgholi, M., Kleindienst, T. E., Edney, E. O., Offenberg, J. H., Lewandowski, M., Jaoui, M., Maenhaut, W., Claeys, M., Flagan, R. C., and Seinfeld, J. H.: Organosulfate Formation in Biogenic Secondary Organic Aerosol, J. Phys. Chem. A, 112, 8345-8378, doi:10.1021/jp802310p, 2008.

Szmigielski, R., Vermeylen, R., Dommen, J., Metzger, A., Maenhaut, W., Baltensperger, U., and Claeys, M.: The acid effect in the formation of 2-methyltetrols from the photooxidation of isoprene in the presence of $\mathrm{NO}_{x}$, Atmos. Res., 98, 183-189, doi:10.1016/j.atmosres.2010.02.012, 2010.

Takagi, H., Washida, N., Akimoto, H., and Okuda, M.: Analysis of Nitrate and Nitrite Esters by Gas-Chromatography Photoionization Mass-Spectrometry, Anal. Chem., 53, 175-179, doi:10.1021/ac00225a011, 1981.

Teng, A. P., Crounse, J. D., Lee, L., St. Clair, J. M., Cohen, R. C., and Wennberg, P. O.: Hydroxy nitrate production in the $\mathrm{OH}-$ initiated oxidation of alkenes, Atmos. Chem. Phys., 15, 42974316, doi:10.5194/acp-15-4297-2015, 2015.

Thieser, J., Schuster, G., Schuladen, J., Phillips, G. J., Reiffs, A., Parchatka, U., Pöhler, D., Lelieveld, J., and Crowley, J. N.: A two-channel thermal dissociation cavity ring-down spectrometer for the detection of ambient $\mathrm{NO}_{2}, \mathrm{RO}_{2} \mathrm{NO}_{2}$ and $\mathrm{RONO}_{2}$, Atmos. Meas. Tech., 9, 553-576, doi:10.5194/amt-9-553-2016, 2016.

Tilgner, A., Bräuer, P., Wolke, R., and Herrmann, H.: Modelling multiphase chemistry in deliquescent aerosols and clouds using CAPRAM3.0i, J. Atmos. Chem., 70, 221-256, doi:10.1007/s10874-013-9267-4, 2013.

Tolocka, M. P., Jang, M., Ginter, J. M., Cox, F. J., Kamens, R. M., and Johnston, M. V.: Formation of Oligomers in Secondary Organic Aerosol, Environ. Sci. Technol., 38, 1428-1434, doi:10.1021/es035030r, 2004.

Tong, D. Q., Lamsal, L., Pan, L., Ding, C., Kim, H., Lee, P., Chai, T., Pickering, K. E., and Stajner, I.: Long-term NOx trends over large cities in the United States during the great recession: Comparison of satellite retrievals, ground observations, and emission inventories, Atmos. Environ., 107, 70-84, doi:10.1016/j.atmosenv.2015.01.035, 2015.

Travis, K. R., Jacob, D. J., Fisher, J. A., Kim, P. S., Marais, E. A., Zhu, L., Yu, K., Miller, C. C., Yantosca, R. M., Sulprizio, M. P., Thompson, A. M., Wennberg, P. O., Crounse, J. D., St. Clair, J. M., Cohen, R. C., Laughner, J. L., Dibb, J. E., Hall, S. R., Ullmann, K., Wolfe, G. M., Pollack, I. B., Peischl, J., Neuman, J. A., and Zhou, X.: Why do models overestimate surface ozone in the Southeast United States?, Atmos. Chem. Phys., 16, 1356113577, doi:10.5194/acp-16-13561-2016, 2016.

Treves, K., Shragina, L., and Rudich, Y.: Henry's law constants of some beta-, gamma-, and delta-hydroxy alkyl nitrates of atmospheric interest, Environ. Sci. Technol., 34, 1197-1203, 2000.

Tröstl, J., Chuang, W. K., Gordon, H., Heinritzi, M., Yan, C., Molteni, U., Ahlm, L., Frege, C., Bianchi, F., Wagner, R., Simon, M., Lehtipalo, K., Williamson, C., Craven, J. S., Duplissy,
J., Adamov, A., Almeida, J., Bernhammer, A.-K., Breitenlechner, M., Brilke, S., Dias, A., Ehrhart, S., Flagan, R. C., Franchin, A., Fuchs, C., Guida, R., Gysel, M., Hansel, A., Hoyle, C. R., Jokinen, T., Junninen, H., Kangasluoma, J., Keskinen, H., Kim, J., Krapf, M., Kürten, A., Laaksonen, A., Lawler, M., Leiminger, M., Mathot, S., Möhler, O., Nieminen, T., Onnela, A., Petäjä, T., Piel, F. M., Miettinen, P., Rissanen, M. P., Rondo, L., Sarnela, N., Schobesberger, S., Sengupta, K., Sipilä, M., Smith, J. N., Steiner, G., Tomè, A., Virtanen, A., Wagner, A. C., Weingartner, E., Wimmer, D., Winkler, P. M., Ye, P., Carslaw, K. S., Curtius, J., Dommen, J., Kirkby, J., Kulmala, M., Riipinen, I., Worsnop, D. R., Donahue, N. M., and Baltensperger, U.: The role of low-volatility organic compounds in initial particle growth in the atmosphere, Nature, 533, 527-531, doi:10.1038/nature18271, 2016.

Utembe, S. R., Cooke, M. C., Archibald, A. T., Shallcross, D. E., Derwent, R. G., and Jenkin, M. E.: Simulating secondary organic aerosol in a 3-D Lagrangian chemistry transport model using the reduced Common Representative Intermediates mechanism (CRI v2-R5), Atmos. Environ., 45, 1604-1614, doi:10.1016/j.atmosenv.2010.11.046, 2011.

Vaattovaara, P., Petaja, T., Joutsensaari, J., Miettinen, P., Zaprudin, B., Kortelainen, A., Heijari, J., Yli-Pirila, P., Aalto, P., Worsnop, D. R., and Laaksonen, A.: The evolution of nucleation- and Aitken-mode particle compsitions in a boreal forest environment during clean and pollution-affected new-particle formation events, Boreal Environ. Res., 14, 662-682, 2009.

Varma, R. M., Ball, S. M., Brauers, T., Dorn, H. P., Heitmann, U., Jones, R. L., Platt, U., Pöhler, D., Ruth, A. A., Shillings, A. J. L., Thieser, J., Wahner, A., and Venables, D. S.: Light extinction by secondary organic aerosol: an intercomparison of three broadband cavity spectrometers, Atmos. Meas. Tech., 6, 3115-3130, doi:10.5194/amt-6-3115-2013, 2013.

Venables, D. S., Gherman, T., Orphal, J., Wenger, J. C., and Ruth, A. A.: High Sensitivity in Situ Monitoring of $\mathrm{NO}_{3}$ in an Atmospheric Simulation Chamber Using Incoherent Broadband Cavity-Enhanced Absorption Spectroscopy, Environ. Sci. Technol., 40, 6758-6763, doi:10.1021/es061076j, 2006.

Verstraeten, W. W., Neu, J. L., Williams, J. E., Bowman, K. W., Worden, J. R., and Boersma, K. F.: Rapid increases in tropospheric ozone production and export from China, Nat. Geosci., 8, 690-695, doi:10.1038/ngeo2493, 2015.

Vijayaraghavan, K., Karamchandani, P., and Seigneur, C.: Plume-in-grid modeling of summer air pollution in Central California, Atmos. Environ., 40, 5097-5109, doi:10.1016/j.atmosenv.2005.12.050, 2006.

Virtanen, A., Joutsensaari, J., Koop, T., Kannosto, J., Yli-Pirila, P., Leskinen, J., Makela, J. M., Holopainen, J. K., Pöschl, U., Kulmala, M., Worsnop, D. R., and Laaksonen, A.: An amorphous solid state of biogenic secondary organic aerosol particles, Nature, 467, 824-827, 2010.

von Friedeburg, C., Wagner, T., Geyer, A., Kaiser, N., Vogel, B., Vogel, H., and Platt, U.: Derivation of tropospheric $\mathrm{NO}_{3}$ profiles using off-axis differential optical absorption spectroscopy measurements during sunrise and comparison with simulations, J. Geophys. Res.-Atmos., 107, 4168, doi:10.1029/2001JD000481, 2002.

von Kuhlmann, R., Lawrence, M. G., Pöschl, U., and Crutzen, P. J.: Sensitivities in global scale modeling of isoprene, Atmos. Chem. Phys., 4, 1-17, doi:10.5194/acp-4-1-2004, 2004. 
Vrekoussis, M., Kanakidou, M., Mihalopoulos, N., Crutzen, P. J., Lelieveld, J., Perner, D., Berresheim, H., and Baboukas, E.: Role of the $\mathrm{NO}_{3}$ radicals in oxidation processes in the eastern Mediterranean troposphere during the MINOS campaign, Atmos. Chem. Phys., 4, 169-182, doi:10.5194/acp-4-169-2004, 2004.

Wagner, N. L., Dubé, W. P., Washenfelder, R. A., Young, C. J., Pollack, I. B., Ryerson, T. B., and Brown, S. S.: Diode laser-based cavity ring-down instrument for $\mathrm{NO}_{3}, \mathrm{~N}_{2} \mathrm{O}_{5}, \mathrm{NO}$, $\mathrm{NO}_{2}$ and $\mathrm{O}_{3}$ from aircraft, Atmos. Meas. Tech., 4, 1227-1240, doi:10.5194/amt-4-1227-2011, 2011.

Wagner, T., Otten, C., Pfeilsticker, K., Pundt, I., and Platt, U.: DOAS moonlight observation of atmospheric $\mathrm{NO}_{3}$ in the Arctic winter, Geophys. Res. Lett., 27, 3441-3444, doi:10.1029/1999g1011153, 2000.

Wang, X., Wang, T., Yan, C., Tham, Y. J., Xue, L., Xu, Z., and Zha, Q.: Large daytime signals of $\mathrm{N}_{2} \mathrm{O}_{5}$ and $\mathrm{NO}_{3}$ inferred at 62 amu in a TD-CIMS: chemical interference or a real atmospheric phenomenon?, Atmos. Meas. Tech., 7, 1-12, doi:10.5194/amt-71-2014, 2014.

Wangberg, I., Barnes, I., and Becker, K. H.: Product and mechanistic study of the reaction of $\mathrm{NO}_{3}$ radicals with alpha-pinene, Environ. Sci. Technol., 31, 2130-2135, 1997.

Warneke, C., de Gouw, J. A., Goldan, P. D., Kuster, W. C., Williams, E. J., Lerner, B. M., Brown, S. S., Stark, H., Aldener, M., Ravishankara, A. R., Roberts, J. M., Marchewka, M., Bertman, S., Sueper, D. T., McKeen, S. A., Meagher, J. F., and Fehsenfeld, F. C.: Comparison of day and nighttime oxidation of biogenic and anthropogenic VOCs along the New England coast in summer during New Enlgand Air Quality Study 2002, J. Geophys. Res., 109, D10309, doi:10.1029/2003JD004424, 2004.

Washenfelder, R., Attwood, A., Brock, C., Guo, H., Xu, L., Weber, R., Ng, N., Allen, H., Ayres, B., and Baumann, K.: Biomass burning dominates brown carbon absorption in the rural southeastern United States, Geophys. Res. Lett., 42, 653-664, 2015.

Wayne, R. P., Barnes, I., Biggs, P., Burrows, J. P., Canosa-Mas, C. E., Hjorth, J., LeBras, G., Moortgat, G. K., Perner, D., Poulet, G., Restelli, G., and Sidebottom, H.: The Nitrate Radical: Physics, Chemistry, and the Atmosphere, Atmos. Environ. Pt. A, 25, 1203, 1991.

Weaver, A., Solomon, S., Sanders, R. W., Arpag, K., and Miller, H. L. J.: Atmospheric $\mathrm{NO}_{3}$ 5, Off-axis measurements at sunrise: Estimates of tropospheric $\mathrm{NO}_{3}$ at $40^{\circ} \mathrm{N}, \mathrm{J}$. Geophys. Res., 101, 18605-18612, 1996.

Weber, R. J., Sullivan, A. P., Peltier, R., Russell, A., Yan, B., Zheng, M., de Gouw, J. A., Warneke, C., Brock, C. A., Holloway, J. S., Atlas, E. L., and Edgerton, E.: A study of secondary organic aerosol formation in the anthropogenicinfluenced southeastern United States, J. Geophys. Res., 112, D13302, doi:10.1029/2007JD008408, 2007.

Werner, G., Kastler, J., Looser, R., and Ballschmiter, K.: Organic nitrates of isoprene as atmospheric trace compounds, Angew. Chem. Int. Edit., 38, 1634-1637, 1999.

Wille, U., Becker, E., Schindler, R. N., Lancar, I. T., Poulet, G., and Lebras, G.: A Discharge flow mass-spectrometric study of the reaction between the $\mathrm{NO}_{3}$ radical and isoprene, J. Atmos. Chem., 13, 183-193, doi:10.1007/bf00115972, 1991.

Winer, A. M., Atkinson, R., and Pitts, J. N. J.: Gaseous Nitrate Radical: Possible Nighttime Atmospheric Sink for Biogenic Organic Compounds, Science, 224, 156-158, 1984
Woidich, S., Froescheis, O., Luxenhofer, O., and Ballschmiter, K.: El- and NCl-mass spectrometry of arylalkyl nitrates and their occurrence in urban air, Fresen. J. Anal. Chem., 364, 91-99, 1999.

Wolke, R., Sehili, A. M., Simmel, M., Knoth, O., Tilgner, A., and Herrmann, H.: SPACCIM: A parcel model with detailed microphysics and complex multiphase chemistry, Atmos. Environ., 39, 4375-4388, doi:10.1016/J.Atmosenv.2005.02.038, 2005.

Wong, K. W. and Stutz, J.: Influence of nocturnal vertical stability on daytime chemistry: A one-dimensional model study, Atmos. Environ., 44, 3753-3760, 2010.

Wood, E., Bertram, T., Wooldridge, P., and Cohen, R.: Measurements of $\mathrm{N}_{2} \mathrm{O}_{5}, \mathrm{NO}_{2}$, and $\mathrm{O}_{3}$ east of the San Francisco Bay, Atmos. Chem. Phys., 5, 483-491, doi:10.5194/acp-5-483-2005, 2005.

Wood, E. C., Wooldridge, P. J., Freese, J. H., Albrecht, T., and Cohen, R. C.: Prototype for In Situ Detection of Atmospheric $\mathrm{NO}_{3}$ and $\mathrm{N}_{2} \mathrm{O}_{5}$ via Laser-Induced Fluorescence, Environ. Sci. Technol., 37, 5732-5738, doi:10.1021/es034507w, 2003.

Worton, D. R., Mills, G. P., Oram, D. E., and Sturges, W. T.: Gas chromatography negative ion chemical ionization mass spectrometry: Application to the detection of alkyl nitrates and halocarbons in the atmosphere, J. Chromatogr. A, 1201, 112-119, doi:10.1016/j.chroma.2008.06.019, 2008.

Wu, C., Pullinen, I., Andres, S., Carriero, G., Fares, S., Goldbach, H., Hacker, L., Kasal, T., Kiendler-Scharr, A., Kleist, E., Paoletti, E., Wahner, A., Wildt, J., and Mentel, T. F.: Impacts of soil moisture on de novo monoterpene emissions from European beech, Holm oak, Scots pine, and Norway spruce, Biogeosciences, 12, 177-191, doi:10.5194/bg-12-177-2015, 2015.

Wu, T., Coeur-Tourneur, C., Dhont, G., Cassez, A., Fertein, E., He, X., and Chen, W.: Simultaneous monitoring of temporal profiles of $\mathrm{NO}_{3}, \mathrm{NO}_{2}$ and $\mathrm{O}_{3}$ by incoherent broadband cavity enhanced absorption spectroscopy for atmospheric applications, J. Quant. Spectrosc. R., 133, 199-205, 2014.

Xiao, S. and Bertram, A. K.: Reactive uptake kinetics of $\mathrm{NO}_{3}$ on multicomponent and multiphase organic mixtures containing unsaturated and saturated organics, Phys. Chem. Chem. Phys., 13, 6628-6636, 2011.

Xie, Y., Paulot, F., Carter, W. P. L., Nolte, C. G., Luecken, D. J., Hutzell, W. T., Wennberg, P. O., Cohen, R. C., and Pinder, R. W.: Understanding the impact of recent advances in isoprene photooxidation on simulations of regional air quality, Atmos. Chem. Phys., 13, 8439-8455, doi:10.5194/acp-13-8439-2013, 2013.

Xing, J., Pleim, J., Mathur, R., Pouliot, G., Hogrefe, C., Gan, C. M., and Wei, C.: Historical gaseous and primary aerosol emissions in the United States from 1990 to 2010, Atmos. Chem. Phys., 13, 7531-7549, doi:10.5194/acp-13-7531-2013, 2013.

Xing, J., Mathur, R., Pleim, J., Hogrefe, C., Gan, C. M., Wong, D. C., Wei, C., Gilliam, R., and Pouliot, G.: Observations and modeling of air quality trends over 1990-2010 across the Northern Hemisphere: China, the United States and Europe, Atmos. Chem. Phys., 15, 2723-2747, doi:10.5194/acp-15-2723-2015, 2015.

Xiong, F., McAvey, K. M., Pratt, K. A., Groff, C. J., Hostetler, M. A., Lipton, M. A., Starn, T. K., Seeley, J. V., Bertman, S. B., Teng, A. P., Crounse, J. D., Nguyen, T. B., Wennberg, P. O., Misztal, P. K., Goldstein, A. H., Guenther, A. B., Koss, A. R., Olson, K. F., de Gouw, J. A., Baumann, K., Edgerton, E. S., Feiner, P. A., Zhang, L., Miller, D. O., Brune, W. H., and Shepson, P. B.: Observation of isoprene hydroxynitrates in the southeastern United 
States and implications for the fate of $\mathrm{NO}_{x}$, Atmos. Chem. Phys., 15, 11257-11272, doi:10.5194/acp-15-11257-2015, 2015.

Xiong, F., Borca, C. H., Slipchenko, L. V., and Shepson, P. B.: Photochemical degradation of isoprene-derived 4, 1-nitrooxy enal, Atmos. Chem. Phys., 16, 5595-5610, doi:10.5194/acp-16-55952016, 2016.

Xu, L., Guo, H., Boyd, C. M., Klein, M., Bougiatioti, A., Cerully, K. M., Hite, J. R., Isaacman-VanWertz, G., Kreisberg, N. M., Knote, C., Olson, K., Koss, A., Goldstein, A. H., Hering, S. V., de Gouw, J., Baumann, K., Lee, S.-H., Nenes, A., Weber, R. J., and Ng, N. L.: Effects of anthropogenic emissions on aerosol formation from isoprene and monoterpenes in the southeastern United States, P. Natl. Acad. Sci. USA, 112, 37-42, 2015 a.

Xu, L., Suresh, S., Guo, H., Weber, R. J., and Ng, N. L.: Aerosol characterization over the southeastern United States using highresolution aerosol mass spectrometry: spatial and seasonal variation of aerosol composition and sources with a focus on organic nitrates, Atmos. Chem. Phys., 15, 7307-7336, doi:10.5194/acp15-7307-2015, 2015 b.

Yarwood, G., Rao, S., Yocke, M., and Whitten, G. Z.: Updates to the Carbon Bond chemical mechanism: CB05 Final Report prepared for US EPA, 2005.

Ye, P., Ding, X., Hakala, J., Hofbauer, V., Robinson, E. S., and Donahue, N. M.: Vapor wall loss of semi-volatile organic compounds in a Teflon chamber, Aerosol Sci. Technol., 50, 822-834, doi:10.1080/02786826.2016.1195905, 2016.

Yeh, G. K. and Ziemann, P. J.: Alkyl Nitrate Formation from the Reactions of $\mathrm{C}_{8}-\mathrm{C}_{14}$ n-Alkanes with $\mathrm{OH}$ Radicals in the Presence of NOx: Measured Yields with Essential Corrections for Gas-Wall Partitioning, J. Phys. Chem. A, 118, 8147-8157, doi:10.1021/jp500631v, 2014.

Yokelson, R. J., Burkholder, J. B., Fox, R. W., Talukdar, R. K., and Ravishankara, A. R.: Temperature Dependence of the $\mathrm{NO}_{3}$ Absorption Cross Section, J. Phys. Chem., 98, 13144-13150, 1994.

Yvon, S. A., Plane, J. M. C., Nien, C.-F., Cooper, D. J., and Saltzman, E. S.: Interaction between nitrogen and sulfur cycles in the polluted marine boundary layer, J. Geophys. Res., 101, 13791386, 1996.

Zaveri, R. A., Berkowitz, C. M., Brechtel, F. J., Gilles, M. K., Hubbe, J. M., Jayne, J. T., Kleinman, L. I., Laskin, A., Madronich, S., Onasch, T. B., Pekour, M. S., Springston, S. R., Thornton, J. A., Tivanski, A. V., and Worsnop, D. R.: Nighttime chemical evolution of aerosol and trace gases in a power plant plume: Implications for secondary organic nitrate and organosulfate aerosol formation, $\mathrm{NO}_{3}$ radical chemistry, and $\mathrm{N}_{2} \mathrm{O}_{5}$ heterogeneous hydrolysis, J. Geophys. Res., 115, D12304, doi:10.1029/2009jd013250, 2010.

Zhang, Q., Jimenez, J. L., Canagaratna, M. R., Allan, J. D., Coe, H., Ulbrich, I., Alfarra, M. R., Takami, A., Middlebrook, A. M., Sun, Y. L., Dzepina, K., Dunlea, E., Docherty, K. S., DeCarlo, P. F., Salcedo, D., Onasch, T. B., Jayne, J. T., Miyoshi, T., Shimono, A., Hatakeyama, S., Takegawa, N., Kondo, Y., Scheider, J., Drewnick, F., Borrman, S., Weimer, S., Demerjian, K. L., Williams, P. I., Bower, K., Bahreini, R., Cottrell, L., Griffin, R. J., Rautiainen, J., Sun, J. Y., Zhang, Y. M., and Worsnop, D. R.: Ubiquity and dominance of oxygenated species in organic aerosols in anthropogenically-influenced Northern Hemisphere midlatitudes, Geophys. Res. Lett., 34, L13801, doi:10.1029/2007GL029979, 2007.
Zhang, X., Cappa, C. D., Jathar, S. H., McVay, R. C., Ensberg, J. J., Kleeman, M. J., and Seinfeld, J. H.: Influence of vapor wall loss in laboratory chambers on yields of secondary organic aerosol, $\mathrm{P}$. Natl. Acad. Sci. USA, 111, 5802-5807, 2014a.

Zhang, X., Schwantes, R. H., McVay, R. C., Lignell, H., Coggon, M. M., Flagan, R. C., and Seinfeld, J. H.: Vapor wall deposition in Teflon chambers, Atmos. Chem. Phys., 15, 4197-4214, doi:10.5194/acp-15-4197-2015, 2015.

Zhang, Y., Chapleski, R. C., Lu, J. W., Rockhold, T. H., Troya, D., and Morris, J. R.: Gas-surface reactions of nitrate radicals with vinyl-terminated self-assembled monolayers, Phys. Chem. Chem. Phys., 16, 16659-16670, doi:10.1039/C4CP01982B, 2014b.

Zhang, Y. and Morris, J. R.: Hydrogen Abstraction Probability in Reactions of Gas-Phase $\mathrm{NO}_{3}$ with an $\mathrm{OH}$-Functionalized Organic Surface, J. Phys. Chem. C, 119, 14742-14747, doi:10.1021/acs.jpcc.5b00562, 2015.

Zhao, Z., Husainy, S., Stoudemayer, C. T., and Smith, G. D.: Reactive uptake of $\mathrm{NO}_{3}$ radicals by unsaturated fatty acid particles, Phys. Chem. Chem. Phys., 13, 17809-17817, 2011a.

Zhao, Z. J., Husainy, S., and Smith, G. D.: Kinetics Studies of the Gas-Phase Reactions of $\mathrm{NO}_{3}$ Radicals with Series of 1-Alkenes, Dienes, Cycloalkenes, Alkenols, and Alkenals, J. Phys. Chem. A, 115, 12161-12172, doi:10.1021/jp206899w, 2011 b.

Zheng, J., Zhang, R., Fortner, E. C., Volkamer, R. M., Molina, L., Aiken, A. C., Jimenez, J. L., Gaeggeler, K., Dommen, J., Dusanter, S., Stevens, P. S., and Tie, X.: Measurements of $\mathrm{HNO}_{3}$ and $\mathrm{N}_{2} \mathrm{O}_{5}$ using ion drift-chemical ionization mass spectrometry during the MILAGRO/MCMA-2006 campaign, Atmos. Chem. Phys., 8, 6823-6838, doi:10.5194/acp-8-6823-2008, 2008.

Zheng, Y., Unger, N., Hodzic, A., Emmons, L., Knote, C., Tilmes, S., Lamarque, J. F., and Yu, P.: Limited effect of anthropogenic nitrogen oxides on secondary organic aerosol formation, Atmos. Chem. Phys., 15, 13487-13506, doi:10.5194/acp15-13487-2015, 2015.

Zhou, S. and Wenger, J. C.: Kinetics and products of the gas-phase reactions of acenaphthene with hydroxyl radicals, nitrate radicals and ozone, Atmos. Environ., 72, 97-104, doi:10.1016/j.atmosenv.2013.02.044, 2013. 